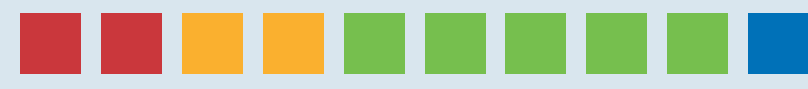 THE ECONOMICS OF ECOSYSTEMS AND BIODIVERSITY \\ TEEB $\quad$ FOR BUSINESS
}

\section{Chapter 1 Business, biodiversity and ecosystem services}

Chapter 2 Business impacts and dependence on biodiversity and ecosystem services

Chapter 3 Measuring and reporting biodiversity and ecosystem impacts and dependence

Chapter 4 Scaling down biodiversity and ecosystem risks to business

Chapter 5 Increasing biodiversity business opportunities

Chapter 6 Business, biodiversity and sustainable development

Chapter 7 A recipe for biodiversity and business growth 


\section{Chapter 1: Business, biodiversity and ecosystem services}

TEEB for Business Co-ordinator: Joshua Bishop (International Union for Conservation of Nature)

Editors: Joshua Bishop (IUCN), William Evison (PricewaterhouseCoopers)

Contributing author: Olivia White (PricewaterhouseCoopers)

Acknowledgements: Annika Andersson (Vattenfall), Celine Tilly (Eiffage), Christoph Schröter-Schlaack (UFZ), Daniel Skambracks (KfW Bankengruppe), Deric Quaile (Shell), Dorothea Seebode (Philips), Elaine Dorward-King (Rio Tinto), Gemma Holmes (PricewaterhouseCoopers), Gérard Bos (Holcim), Jennifer McLin (IUCN), Juan Gonzalez-Valero (Syngenta), Juan Marco Alvarez (IUCN), Jun Hangai (Nippon Keidanren), Kerstin Sobania (TUI), Kii Hiyashi (Nagoya University), Lloyd Timberlake (WBCSD), Margaret Adey (Cambridge U.), Monica Barcellos (UNEP-WCMC), Naoki Adachi (Responsibility), Nina Springer (Exxon/IPIECA), Oliver Schelske (SwissRe), Olivier Vilaca (WBCSD), Paul Hohnen, Per Sandberg (WBCSD), Polly Courtice (Cambridge U.), Ravi Sharma (CBD Sec.), Roberto Bossi (ENI), Ruth Romer (IPIECA), Ryo Kohsaka (Nagoya City U.), Sachin Kapila (Shell), Sagarika Chatterjee (F\&C Investment), Simon Anthony, Toby Croucher (Repsol/IPIECA), Valerie David (Eiffage), Virpi Stucki (IUCN)

Disclaimer: The views expressed in this report are purely those of the authors and may not in any circumstances be regarded as stating an official position of the organisations involved.

The final edition of the TEEB for Business report will be published by Earthscan. If you have any additional information or comments you feel should be considered for inclusion in the final report then please email them by 6 th September, 2010 to: teeb4biz@ufz.de

TEEB is hosted by the United Nations Environment Programme and supported by the European Commission; the German Federal Environment Ministry; the UK Government's Department for Environment, Food and Rural Affairs; the UK Department for International Development; Norway's Ministry for Foreign Affairs; The Netherlands' Interministerial Program Biodiversity; and the Swedish International Development Cooperation Agency. 


\section{THE ECONOMICS OF ECOSYSTEMS AND BIODIVERSITY Chapter 1}

Business, biodiversity and ecosystem services

\section{Contents}

Key messages 3

$\begin{array}{lll}1.1 & \text { Background to this report } & 4\end{array}$

1.2 Approach, structure and contents $\quad 5$

1.2.1 Definitions $\quad 5$

1.2.2 Assumptions $\quad 5$

$\begin{array}{ll}1.2 .3 \text { Methodology } & 7\end{array}$

$\begin{array}{ll}1.2 .4 \text { Objectives and key questions } & 7\end{array}$

$\begin{array}{ll}1.2 .5 \text { Audience } & 8\end{array}$

$\begin{array}{lll}1.3 & \text { Biodiversity and ecosystems in a changing world } & 10\end{array}$

1.3.1 Perceptions of business leaders on biodiversity and ecosystems $\quad 10$

1.3.2 The emerging business environment: What trends matter? $\quad 12$

1.3.3 Linkages between trends and their relation to business and biodiversity 14

1.3.4 Changing consumer preferences: Implications for business and biodiversity 20

1.4 From major trends to business values $\quad 22$

$\begin{array}{ll}\text { References } & 24\end{array}$

\section{Figures}

1.1 Views of global CEOs on the threat to business growth from biodiversity loss

1.2 Views of global CEOs on government protection of biodiversity and ecosystems

1.3 Links between biodiversity and ecosystem loss and other major trends

\section{Tables}

1.1 Major trends and their implications for biodiversity and business 


\section{Key messages}

The world is changing in ways that affect the value of biodiversity and ecosystem services (BES) to business: The value of biodiversity and ecosystem services is a function of population growth and urbanization, economic growth and ecosystem decline, changing politics and environmental policy, and developments in information and technology.

Biodiversity loss and ecosystem decline cannot be considered in isolation from other trends: The continuing loss of biodiversity and associated decline in ecosystem services is driven by growing and shifting markets, resource exploitation and climate change, among other factors. Equally, the loss of BES contributes to many of these other trends, implying the need for an integrated business response.

Business risks and opportunities associated with biodiversity and ecosystem services are growing: Given the on-going decline of BES and the interaction between biodiversity loss, decline in ecosystem services and other major trends, business can expect both the associated risks and opportunities to increase over time.

There will be increasing pressure on and more restricted access to natural resources: Growing market demand for natural resources combined with increasing public concerns about environmental quality point towards increasing competition and more restricted access to natural resources on both land and sea.

Consumers increasingly consider biodiversity and ecosystems in their purchasing decisions: Consumer understanding and expectations of how products and companies relate to BES are becoming more sophisticated. Consumer facing businesses, in particular, but also their suppliers, may need to reexamine how they manage BES and how their actions are communicated to customers.

Business is beginning to notice the threat posed by biodiversity loss: $27 \%$ of global CEOs surveyed by PwC in 2009 expressed concern about the impacts of biodiversity loss on their business growth prospects. Interestingly, $53 \%$ of CEOs in Latin America and $45 \%$ in Africa expressed concern about biodiversity loss, compared to just $11 \%$ in Central and Eastern Europe. 
We live in a world transformed by business. Business has prospered by providing products and services to people everywhere, and plays a key role in economic development. For nature, however, the price of development and business success has been very high.

Most people in business know about climate change and accept the need to reduce greenhouse gas emissions to levels that are consistent with a stable climate. Business leaders are also becoming more aware of the risks of biodiversity loss and the need to respect ecological limits generally (Millennium Ecosystem Assessment 2005).

The economic value of nature is changing, reflecting changes in people's preferences, demography, markets, technology and the environment itself. Companies are responding but much more work is required to develop and scale up competitive business models that can conserve biodiversity and deliver ecosystem services while also meeting people's needs for better products and services.

The loss of biodiversity and the related decline in ecosystem services (BES) are increasingly well-documented (see chapter 2) and increasingly recognized as creating risks to business (Athanas et al. 2006). Business risk may be related to the direct impacts of a company's operations on biodiversity, or to the dependence of a business on ecosystem services as inputs to production. In other cases, the business risks associated with biodiversity loss may be indirect, operating through supply chains or through market decisions on investment, production, distribution and marketing (see chapter 3). Companies around the world are finding ways to identify, avoid and mitigate their BES risks, using a range of new tools developed by, with and for business (see chapter 4).

At the same time, biodiversity and ecosystem services are also the basis of new business opportunities (see chapter 5). This is most obvious in the case of companies selling goods and services that are directly associated with biodiversity and ecosystems, such as nature-based tourism. But as with BES risk, there are less direct links between commerce and conservation that offer further opportunities. As a result, more and more investors and entrepreneurs are setting up funds and firms dedicated to building biodiversity business (Bishop et al. 2008). At the same time, some companies are discovering that integrating biodiversity and ecosystem services in their management systems can also help achieve wider corporate social responsibility goals (see chapter 6).

This report is part of a study of The Economics of Ecosystems and Biodiversity (TEEB), launched by the Government of Germany and the European Commission in response to a proposal by the environment ministers of the G8 and five emerging economies (Potsdam Initiative 2007). TEEB is an independent study, led by Mr Pavan Sukhdev, hosted by the United Nations Environment Programme, with financial support from the European Commission, Germany, the Netherlands, Norway, Sweden and UK governments, as well as in-kind contributions from many public and private organizations. The aim of TEEB is to assess the economic impacts of biodiversity loss and to offer practical responses to ecosystem decline ${ }^{1}$.

The starting point for this analysis is the well-known fact that markets will not ensure efficient use of resources for which prices are lacking (TEEB Ecological and Economic Foundations 2010). Because many of the benefits of BES are not reflected in the market prices of goods and services, often due to missing or poorly enforced property rights, these benefits tend to be neglected or undervalued in both public and private decision-making. This leads to actions that result in biodiversity and ecosystem loss, which in turn may affect human well-being adversely. This report reviews the state-of-the-art in measuring and managing biodiversity and ecosystem risks in business, capitalizing on new biodiversity business opportunities, and integrating business, biodiversity and sustainable development. 


\section{APPROACH, STRUCTURE AND CONTENTS}

This section offers a preview of the remainder of this report. First however we define some key terms, identify our major assumptions, describe the methods used to compile this report, and list the main objectives and questions that this report seeks to address. We also identify the potential audience for this report and suggest where different readers will find material of interest to them. In the following section, the chapter turns to recent evidence of how business leaders and consumers think about biodiversity and ecosystems, and how this relates to other major trends affecting business.

\subsubsection{DEFINITIONS}

Throughout this report we use the terms biodiversity, ecosystems and ecosystem services, frequently abbreviated as 'BES'. These terms are defined as follows:

'Biodiversity' is short-hand for 'biological diversity'. We follow the UN Convention on Biological Diversity (CBD), which defines biodiversity as:

"The variability among living organisms from all sources including, inter alia, terrestrial, marine and other aquatic ecosystems and the ecological complexes of which they are part; this includes diversity within species, between species and of ecosystems" (Article 2).

According to the CBD, ecosystems are thus one component of biological diversity. This is consistent with definitions subsequently adopted by the Millennium Ecosystem Assessment (MA 2005), which identifies an ecosystem as "a dynamic complex of plant, animal, and microorganism communities and the non-living environment interacting as a functional unit". The main contribution of the MA is the elaboration of the concept of 'ecosystem services', defined simply as the benefits people receive from ecosystems (for further discussion see Chapter 2).

An important feature of ecosystem services is that they are culturally determined and therefore dynamic. As noted by TEEB, ecosystem services are "conceptualizations ... of the 'useful things' ecosystems 'do' for people, directly and indirectly, whereby it should be realized that properties of ecological systems that people regard as 'useful' may change over time even if the ecological system itself remains in a relatively constant state" (TEEB 2010, Chapter 1, pp. 12 and 15).

\subsubsection{ASSUMPTIONS}

Turning from definitions to assumptions and from ecology to economics, this report adopts an explicitly economic perspective on the links between business, biodiversity, ecosystems and ecosystem services. This implies a focus on the value of natural resources to people, rather than on any 'intrinsic' value that may be ascribed to natural resources in their own right (e.g. a 'right to exist'). Of course, we recognize that many of the values people derive from BES are intangible, including recreational, cultural and 'existence' values, and that these intangible values may be significant. They are also measurable.

An economic approach further implies the acceptance of marginal trade-offs between BES benefits and other things that people value. While trade-offs may be constrained by lack of adequate substitutes for certain natural 
resources or ecosystem services, the fact remains that people do weigh the benefits of nature conservation against other things they value in life. In principle, if all values to people are fully reflected in these trade-offs, and subject to some other standard economic assumptions, we can be confident that the resulting use of resources will be economically efficient.

In practice, of course, the economic ideal of perfectly competitive markets, complete and instantaneous information, zero transaction costs, perfect substitution, complete property rights, etc is never fulfilled. Nevertheless, we argue that more explicit consideration of BES costs and benefits in economic decision-making generally results in better if not optimal outcomes. Economic valuation may never be perfectly accurate, especially where non-market values are at stake, but it is hard to think of decisions that are not improved by information about economic values, alongside other considerations.

Some other important assumptions behind this report should also be acknowledged:

- We assume continued economic growth and further integration of market-based democracies worldwide, alongside increased public awareness and concern about environmental change, and increased government regulatory capacity and constraints on the use of natural resources. While we acknowledge the existence of non-market models of economic organization, as well as non-democratic forms of government, we see no reason to doubt the continued growth of private enterprise, within increasingly subtle frameworks of economic policy, overseen by democratic governments and guided by increasingly well-informed citizens.

- We also recognize the growing economic and political power of several 'emerging' economies (e.g., the so-called BRICS), and of companies headquartered in these countries. One notable feature of these emerging economies and companies is their apparent lack of explicit attention to environmental issues generally, and BES specifically, relative to more 'established' industrial economies and companies. While we have sought out developing country examples to illustrate our arguments throughout this report, we must acknowledge that the weight of documented experience (or claims) is concentrated in the developed world.

- Adopting an economic approach implies that incentives matter. In other words, property rights and prices influence human behaviour and the use of natural resources. The current failure of market incentives and public policy in most countries to reflect the full value of biodiversity and ecosystem services is one of the main reasons for continued loss of biodiversity and under-investment in natural capital. By the same token, effective action to conserve biodiversity and secure ecosystem services often requires creating or strengthening economic incentives for the conservation and sustainable use of biological resources.

- One corollary of this assumption is that purely charitable approaches to nature conservation, based on appeals to moral, ethical or religious values, are unlikely to mobilize significant private investment in biodiversity conservation, in market-dominated economies. Although charity can make a real difference and should always be encouraged, any attempt to promote widespread, sustained and substantial private investment in nature conservation requires more forceful arguments, based on commercial logic and shareholder value.

- While charity may not be sufficient, the principles of free choice and voluntary action should be cherished and are essential features of an economic approach to nature conservation. Wherever possible, private firms and consumers should be allowed and encouraged to make mutually satisfactory environmental 'deals' on a voluntary basis, supported by legally-binding contracts. Where such voluntary arrangements are not efficient, due to the presence of 'externalities' or other market distortions, governments can sometimes 
help by creating an enabling framework of incentives to encourage producers and consumers to 'internalize' environmental values in their transactions. What governments must avoid, however, are simplistic rules and regulations that ignore real differences in private costs and preferences, 'lock in' outmoded technologies or production practices, or otherwise undermine the constructive potential of business innovation.

- The last point relates to yet another key assumption, namely continued technological progress, stimulated in part by the increasing scarcity of natural resources and ecosystem services. Having said that, we do not believe that technological innovation can compensate entirely and in every case for the loss of biodiversity and ecosystem decline. This implies that there are situations in which some type or level of environmental damage may be deemed unacceptable, irrespective of opportunity costs or the extent and quality of compensation provided. In short, marginal economic analysis does not apply to non-marginal events.

- Finally, we argue here that conservation and commerce can and, indeed, must work hand-in-hand if biodiversity loss and ecosystem decline are to be slowed and ultimately halted. While business is often responsible for environmental damage, efforts to make business part of the solution to biodiversity loss are likely to involve more not less business involvement in nature conservation and environmental management. This last point, of course, is not easily proved. It is hoped that this report will go some way to showing, through multiple examples and practical inspiration, how increased environmental rights for business can be combined with increased responsibilities, such that commercial success is more closely aligned with conserving nature.

\subsubsection{METHODOLOGY}

The assumptions outlined above have guided our approach to compiling arguments and evidence for this report. In general, we have sought out examples that show how integrating BES in decision-making can deliver real and tangible value to business, as well as positive environmental outcomes. Wherever possible, we have favoured case studies that provide financial and/or economic data on BES values.

Unfortunately, business records and reporting on BES are sketchy, anecdotal and inconsistent, making it difficult to paint a complete picture of biodiversity in business today. We rely heavily on case studies from those few companies that are willing and able to provide information about their policies and actions in relation to BES, along with a handful of independent assessments. Almost by definition, the case studies highlighted here are not from typical companies.

While our findings are therefore preliminary and incomplete, it is hoped that this report will stimulate more systematic and comprehensive study of business awareness, strategy and action in relation to BES. Such research is urgently needed to identify the most efficient means of stimulating business investment in biodiversity conservation, ecosystem restoration and sustainable use of natural resources.

\subsubsection{OBJECTIVES AND KEY QUESTIONS}

Given the limitations outlined above, what objectives did we set out to achieve and what questions do we seek to answer? In general terms, this report aims to present the best available evidence of the case for incorporating BES in business, including both risks and opportunities. In order to make this case and provide practical guidance to readers, the report compiles and summarizes multiple examples of how real businesses are using specific tools, techniques and initiatives to manage their relationship with BES and prepare for the future. More specifically, the report addresses the following questions: 
How is the business and biodiversity context changing? How do business leaders perceive the risks of biodiversity loss? Will new technologies and emerging markets, as well as changing public policies and consumer preferences, alter the way that business values biological resources? (See section 1.3)

What is happening to biological diversity, what are the direct and underlying drivers of environmental change, and how does this affect business? What are the impacts and dependencies of different industry sectors on biodiversity and ecosystems? How do these impacts and dependencies create risks and opportunities for business? (Chapter 2)

How can business measure and report its impacts and dependence on biodiversity and ecosystems? Where does BES fit into corporate governance and management information? How can environmental information systems at site, product and group level be expanded to accommodate BES information? What is the experience of BES reporting in business and how can it be strengthened? (Chapter 3)

What are the risks of biodiversity and ecosystem loss to business and how can they best be managed? What tools are available to identify, assess and mitigate BES risks, and what value do they offer to business? What other methods and approaches can help companies reduce BES risk? (Chapter 4)

What are the main business opportunities related to biodiversity and ecosystems and how can they best be realized? How can BES be a value proposition today for existing industries? How can business make the best of emerging markets for biodiversity and ecosystem services? What tools and policies are available to support markets for biodiversity and ecosystem services? (Chapter 5)

How can business integrate action on BES with wider commitments to sustainable development? What are the trade-offs and potential synergies between BES, socio-economic development and poverty reduction? What are the main barriers to integrating BES and poverty reduction, and what role can business play in helping to minimize trade-offs and maximize positive synergies? (Chapter 6) and

Who needs to act and how in order to improve business-biodiversity relations? What guidance is available to business on biodiversity and ecosystems? What is the experience of voluntary action by business on BES and what lessons may be learned from other corporate responsibility initiatives? What are the main information gaps and other constraints on business action in favour of BES? (Chapter 7)

\subsubsection{AUDIENCE}

This report argues that biodiversity and ecosystems are valuable to all business, in every sector and country. Hence the target audience for this report includes publicly-traded companies and industry associations, stateowned enterprises and financial services, small-and-medium sized enterprises, emerging companies from developing economies, business schools and others working at the interface between business and nature. The report considers a range of industry sectors, including agriculture, food and beverages, extractive industries, manufacturing, infrastructure and services.

Although detailed analysis of individual business sectors is beyond the scope of this study, preliminary assessments of BES impacts and dependencies, risks and opportunities are provided for a range of sectors (see especially Chapters 2 and 5). Moreover, in all chapters we try to include a selection of different sectors in the choice of case studies. 
General readers interested in obtaining an overview of the status and trends in biodiversity, ecosystems and ecosystem services, focusing on links with business, should look at Chapter 2.

Those responsible for business environmental information systems and seeking to integrate BES data in corporate planning, accounting and reporting will find detailed discussion of current trends and tools in Chapter 3 .

Project and product managers concerned about identifying and reducing BES risks should turn to Chapter 4 for practical guidance and examples.

Business planners, investors and entrepreneurs, as well as government regulators and development bankers, may find inspiration in Chapter 5 , with its focus on BES as the basis of cost-savings, potential new products and the promise of new markets for biodiversity and ecosystem services.

Chapter 6 will interest those researching or responsible for corporate social responsibility in general, who may wonder how to integrate BES in business commitments to sustainable development.

Finally, Chapter 7 should be most relevant to those seeking an overview and comparative assessment of corporate social and environmental responsibility initiatives. 


\section{BIODIVERSITY AND ECOSYSTEMS IN A CHANGING WORLD}

This report focuses on the links between business, biodiversity and ecosystem services. Of course, businesses are influenced by a range of social and economic factors, many of which also have implications for biodiversity and ecosystem services. Any attempt to improve the relationship between business, biodiversity and ecosystems must therefore take account of these wider factors and the linkages between them. This section examines several major trends that affect business, focusing on the linkages between these trends, BES risk and BES opportunity. First, however, we look at evidence of the current awareness and response of business leaders to biodiversity loss.

\subsubsection{PERCEPTIONS OF BUSINESS LEADERS ON BIODIVERSITY AND ECOSYSTEMS}

A survey of 1,200 CEOs from around the world provides insight into current perceptions of the risk of biodiversity loss to business (PricewaterhouseCoopers 2010). When asked to rate their levels of concern about a range of threats to business growth prospects, $27 \%$ of CEOs were either 'extremely' or 'somewhat' concerned about 'biodiversity loss'. Given the current economic context, it is striking that biodiversity loss is such a concern for some businesses. There is some interesting regional variation, with $53 \%$ of CEOs in Latin America and $45 \%$ in Africa expressing concern that biodiversity loss will adversely affect business growth prospects, compared to just $11 \%$ in Central and Eastern Europe (Figure 1.1).

\section{Figure 1.1 Views of global CEOs on the threat to business growth from biodiversity loss}

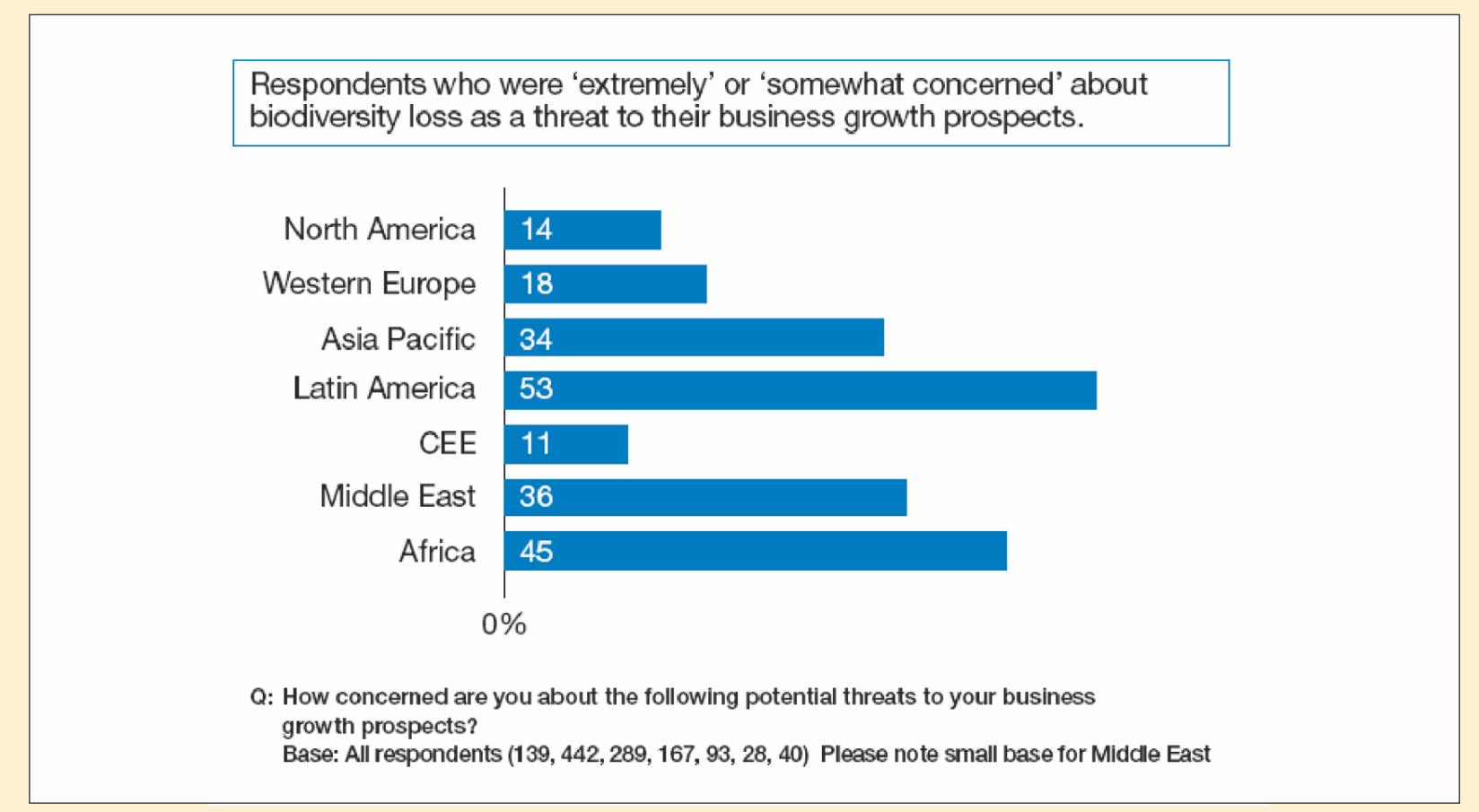

Source: PricewaterhouseCoopers 13th Annual Global CEO Survey 2010 
Nevertheless, at a global level CEO concern about biodiversity loss does not appear to be high as for some other risks. For example, in the same survey, $65 \%$ of CEOs expressed concern about a protracted global recession, $60 \%$ about over-regulation, $54 \%$ about energy costs, while $35 \%$ had concerns about climate change.

The apparent lack of focus on biodiversity loss by business leaders may be partly due to lack of understanding of the potential implications for business. It may also reflect the fact that the effects of biodiversity loss and declining ecosystem services are not, in most cases, dramatic one-off events but rather a gradual trend and so less visible to business leaders. In addition, as outlined below, the loss of BES may be overlain by other, more immediate trends and risks that are more visible to business leaders.

The same CEO survey found more scepticism than optimism about the effectiveness of government action to protect biodiversity and ecosystems (Figure 1.2). What is less clear is the extent to which business leaders would like to see more government action, including regulatory reforms, to address biodiversity loss.

\section{Figure 1.2 Views of global CEOs on government protection of biodiversity and ecosystems}

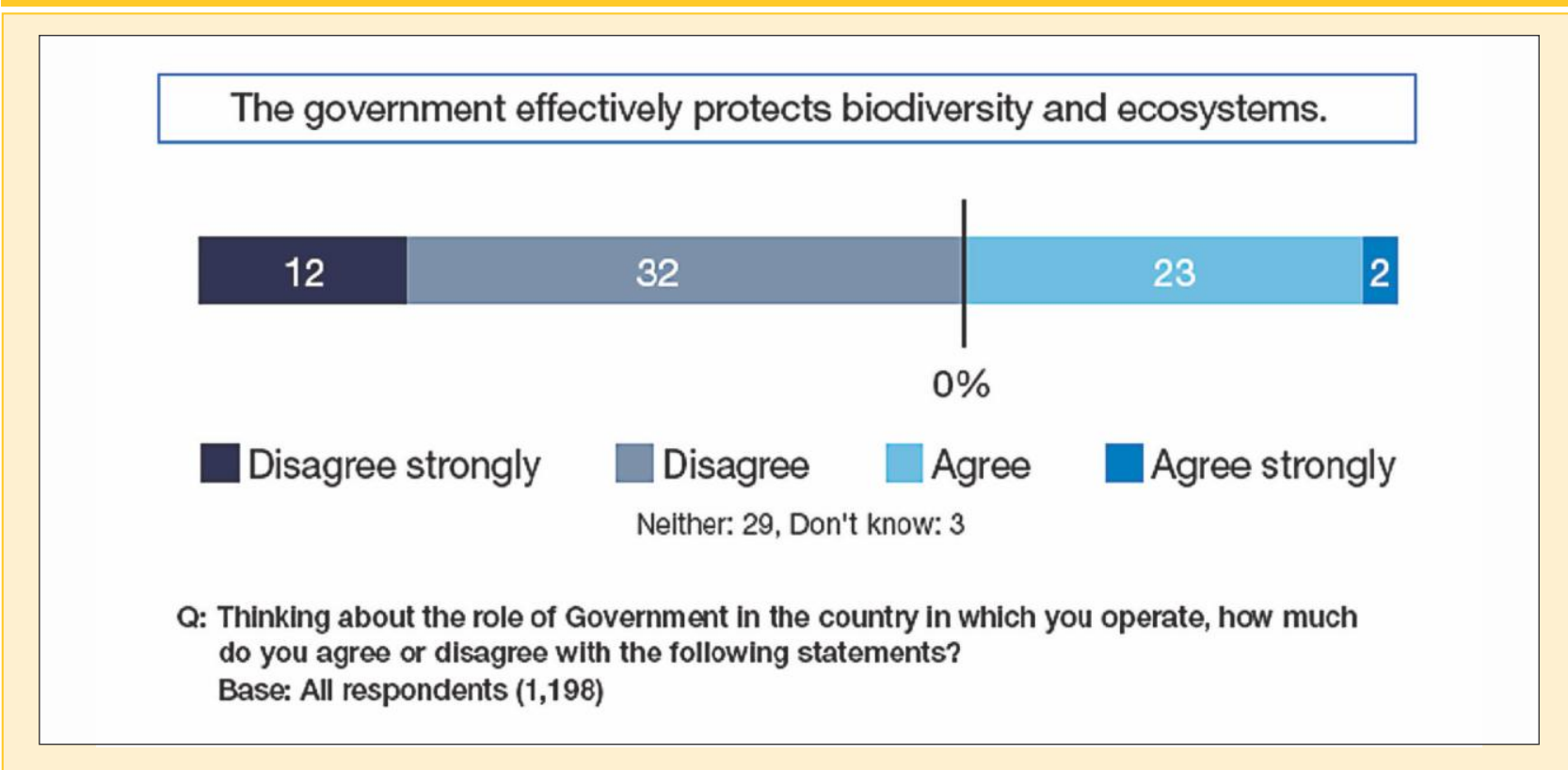

Source: PricewaterhouseCoopers 13th Annual Global CEO Survey 2010

A separate and more focused survey of Japanese companies, carried out in early 2010, provides further insight on the level of business awareness and action about biodiversity in a major industrialized economy. This survey targeted 493 companies, of which 147 responded. The survey was designed as a follow-up to the 2009 'Declaration of Biodiversity' by a major Japanese business association and thus could be expected to reveal relatively high levels of awareness (Nippon Keidanren 2010). It is therefore perhaps not surprising that $50 \%$ of respondents reported that they had already integrated 'biodiversity' into their company environmental policy, with a further $57 \%$ of those who had not done so suggesting that they would in the future.

Amongst the same group of Japanese companies, $15 \%$ confirmed that they have developed internal guidelines on biodiversity, with a further $42 \%$ indicating that guidelines were either under development or planned. This survey demonstrates the impact that a business-led initiative, such as Nippon Keidanren's 'Declaration of Biodiversity', can have on corporate perceptions. Of course, recognition in company policy is only the first step towards effective management of biodiversity and ecosystem service. Because the initiative by Nippon Keidanren and its members is relatively new, clear evidence of improved BES outcomes is not yet available. 


\subsubsection{THE EMERGING BUSINESS ENVIRONMENT: WHAT TRENDS MATTER?}

Surveys of business leaders suggest limited awareness of the potential risks posed by biodiversity loss, although some companies in some countries are more concerned and have begun to respond. This section and the following one explore some of the external factors - and the linkages between them - that may lead to more business awareness and action on biodiversity and ecosystem services in the coming years.

Visions of the future are inevitably uncertain. Nevertheless, several organizations have developed projections or scenarios, across a range of themes and time periods, from climate change (International Panel on Climate Change - IPCC) to energy (International Energy Agency - IEA), demographics (United Nations - UN), the environment and human well-being (United Nations Environment Programme - UNEP), food and water security (Food and Agriculture Organisation - FAO), ecosystem health (Millennium Ecosystem Assessment - MA) and many other issues. All of these efforts to explore the future have an element of truth to them. At the same time, past experience suggests that such forecasts are almost always inaccurate, due to our inability to anticipate significant changes, be they social, political, technological or environmental.

Such forecasts may be most useful as reminders of the major risks and opportunities that can affect business in the future, to which the appropriate response is not hard planning and irreversible commitments but rather investments in organizational resilience and adaptability.

One of the most comprehensive recent explorations of the future was a collaborative study led by the World Business Council for Sustainable Development, under the banner 'Vision 2050' (WBCSD 2010). Vision 2050 framed its analysis around the key factors or conditions that any plan for a more sustainable future needs to address, including:

- Population growth and urbanization

- Economic growth and ecosystem decline

- Politics and environmental policy

- Information and technology

These are briefly examined below, focusing on their relevance to biodiversity and ecosystems.

\section{Population growth}

According to the UN, the world population is expected to grow from 6.7 billion today to 9.2 billion by 2050 . $98 \%$ of this increase will occur in the developing world. The populations of developed countries are stabilizing and aging, a pattern that will eventually apply worldwide (the proportion of people aged over 60 has been rising steadily, passing from $8 \%$ in 1950 to $11 \%$ in 2007 , and is expected to reach $22 \%$ in 2050).

Population growth is expected to lead to increased demand for goods and services and more pressure on natural resources. It is less clear what impact the aging of society will have on nature. However, the shifting balance of population implies that public perceptions of nature and the value of ecosystems may increasingly reflect the historical traditions and norms of developing rather than currently developed countries. These cannot be generalized but will likely reflect social attitudes to and human experience of nature in each region.

\section{Urbanization}

The world's urban population is expected to double by 2050, when about two-thirds of humanity will reside in cities. Urbanization suggest a more distant or indirect relation between people and nature, and thus perhaps greater emphasis on recreational, amenity and existence values of ecosystems and species, compared to more productive or utilitarian concerns. Urbanization also implies increased spatial concentration of some environmental impacts (e.g. residential and industrial land use, waste disposal, water pollution), as well as greater scope (and need) to 
establish payments for ecosystem services and other transfer mechanisms to capture and convey the willingness to pay of urban residents for resource stewardship by the remaining rural population.

\section{Economic growth and ecosystem decline}

Average income and consumption levels are generally increasing, mainly in the developing world. Continued reliance on carbon-based energy and accelerating use of natural resources will increase pressure on ecosystem services, threatening future supplies of food, freshwater, fibre and fish. According to Vision 2050, more than half the world's population is projected to live under conditions of severe water stress by 2025 , while a larger proportion of the world's water use will be for irrigation. Simply meeting the demand for food for 9 billion people will require an in- crease in average crop yields of $2 \%$ a year or more above recent levels.

WBCSD argues that economic growth must be "decoupled from ecosystem destruction and material consumption, and re-coupled to sustainable economic development and meeting changing needs" (WBCSD 2010: 6). The challenge is to ensure that such 'de-coupling' does not simply imply the de-localization of adverse environmental impacts to distant production sites, but rather real improvements in the efficiency of energy and materials use. For instance, how can rising demand for animal protein be met without turning the world's remaining forests into pasture and feed crops? How can demand for mobility be satisfied without turning landscapes into motorways and car parks?

\section{Politics}

Current demographic and economic trends suggest that the developing economies will increasingly be on the front lines of efforts to achieve a sustainable future. According to WBCSD, the key challenge in the transition to sustainability is improving the quality of governance. As described in Vision 2050, governance systems should respect the principle of subsidiarity (i.e. decentralizing and making decisions at the most appropriate local level) but they must also "pool sovereignty" where necessary to address international challenges such as trade, infectious disease, climate change, water resource management, high seas fisheries and other trans-boundary issues (WBCSD 2010: 6).

According to WBCSD, future governance systems also need to be better at guiding markets to internalize environmental externalities, ensure transparency and inclusiveness, create a "level playing field" and enable business to develop and deploy sustainable solutions. An outstanding question is whether the expected shift in economic and political power towards the larger emerging economies (i.e. the so-called BRICS) will result in new attitudes and approaches to environmental management and ultimately help or hinder efforts to reach international cooperative agreements on managing the global commons.

\section{Valuing ecosystem services}

Reducing the environmental impacts of economic activity will entail changes in regulations, markets, consumer preferences, the pricing of inputs, and the measurement of profit and loss - all of which affect business. In the more "sustainable future' envisaged by WBCSD, "prices reflect all externalities: costs and benefits" (WBCSD 2010: 18). This is seen as necessary to ensure that energy and resources are used efficiently and harmful emissions are reduced. For example, Vision 2050 proposes a 50\% reduction in greenhouse gas emissions by 2050, relative to 2005 levels (IEA, ETP 2008, Blue Map Scenario), stimulated in part by public policy reforms that put a price on carbon (WBCSD 2010: 35).

Such market-based approaches are increasingly being applied to other ecosystem services (besides climate regulation), implying that business can expect to pay more in future for its access to and impacts on a wide range of natural resources. At the same time, the adoption of market-based approaches to environmental management may imply greater business opportunities, based on the conservation of biodiversity and the provision or restoration of ecosystem services. Estimates developed by PricewaterhouseCoopers for Vision 2050 of "sustainability related global business opportunities in natural resources (including energy, forestry, agriculture and food, water 
and metals)" suggest a potential market in the range of US\$ 2-6 trillion by 2050 (at constant 2008 prices), about half of which is comprised of "additional investments in the energy sector related to reducing carbon emissions" (WBCSD 2010: 34). While these estimates may be questioned, it seems likely that business will play an increasingly important role in the sustainable management of natural resources and the environment.

\section{Information and technology}

One of the biggest unknowns in attempts to predict the future is the pace and impact of technological change. To cite just one example, over 4 billion cell phone handsets are now in use worldwide, three-quarters of them in the developing world. According to the World Bank, an extra 10 phones per 100 people in a typical developing country boosts GDP growth by almost one full percentage point, making a significant contribution to human well-being.

As noted by WBCSD, the challenge is to foster technological change that allows cultures to remain diverse and heterogeneous, while at the same time improving access to education and internet connectivity to ensure that people are "more aware of the realities of their planet and everyone on it" (WBCSD 2010: 6). The Vision 2050 project envisages changes in the concept of work, to include more part-time, flexi-time, tele-working, co-working and years off. Increased access to information should facilitate environmental monitoring and management. The impacts of other new technologies on biodiversity are less clear.

\subsubsection{LINKAGES BETWEEN TRENDS AND THEIR RELATION TO BUSINESS AND BIODIVERSITY}

The projections summarized above outline some of the many factors that business must consider in order to prepare for and contribute to a more sustainable future. What are less obvious are the connections between these trends and biodiversity, and the implications of these linkages for business. This section considers a range of major trends that affect business today, assesses the linkages with biodiversity and ecosystem services, and identifies the business risks, implications and opportunities that may result.

We suggest that biodiversity loss and ecosystem decline are linked to various major trends affecting business, including social, economic and environmental changes (Figure 1.3). In most cases, the causality runs both ways: various factors influence the pace and scale of biodiversity loss; equally, the loss of biodiversity and ecosystems contributes to other major trends (Millennium Assessment 2005; World Economic Forum 2009; UNEP 2007). In short, the business response to biodiversity loss cannot be defined in isolation from the business response to a range of major trends.

For example, the disturbance or conversion of coastal ecosystems - particularly mangrove forests and vegetated dunes - typically results in greenhouse gas emissions that contribute to climate change. Such removals may also exacerbate the severity of climate change impacts such as coastal flooding (Dahdouh-Guebas et al. 2005). Conversely, rising and increasingly stormy seas - which are among the expected impacts of climate change - can accelerate the loss of some coastal ecosystems, particularly inter-tidal mudflats and mangroves (Sharp 2000).

The linkages between biodiversity and other trends are explored further in Table 1.1, which examines a selection of major global trends in terms of how they affect potential biodiversity and ecosystem related risks and opportunities, and the implications for business. The table provides:

- A description of the trend and how it relates to biodiversity and ecosystem services;

- Examples of the biodiversity-related risks this may present to business, along with potential business responses (see also chapter 4); and

- Examples of potential biodiversity-related business opportunities (see also chapter 5). 


\section{Figure 1.3 Links between biodiversity and ecosystem loss and other major trends}

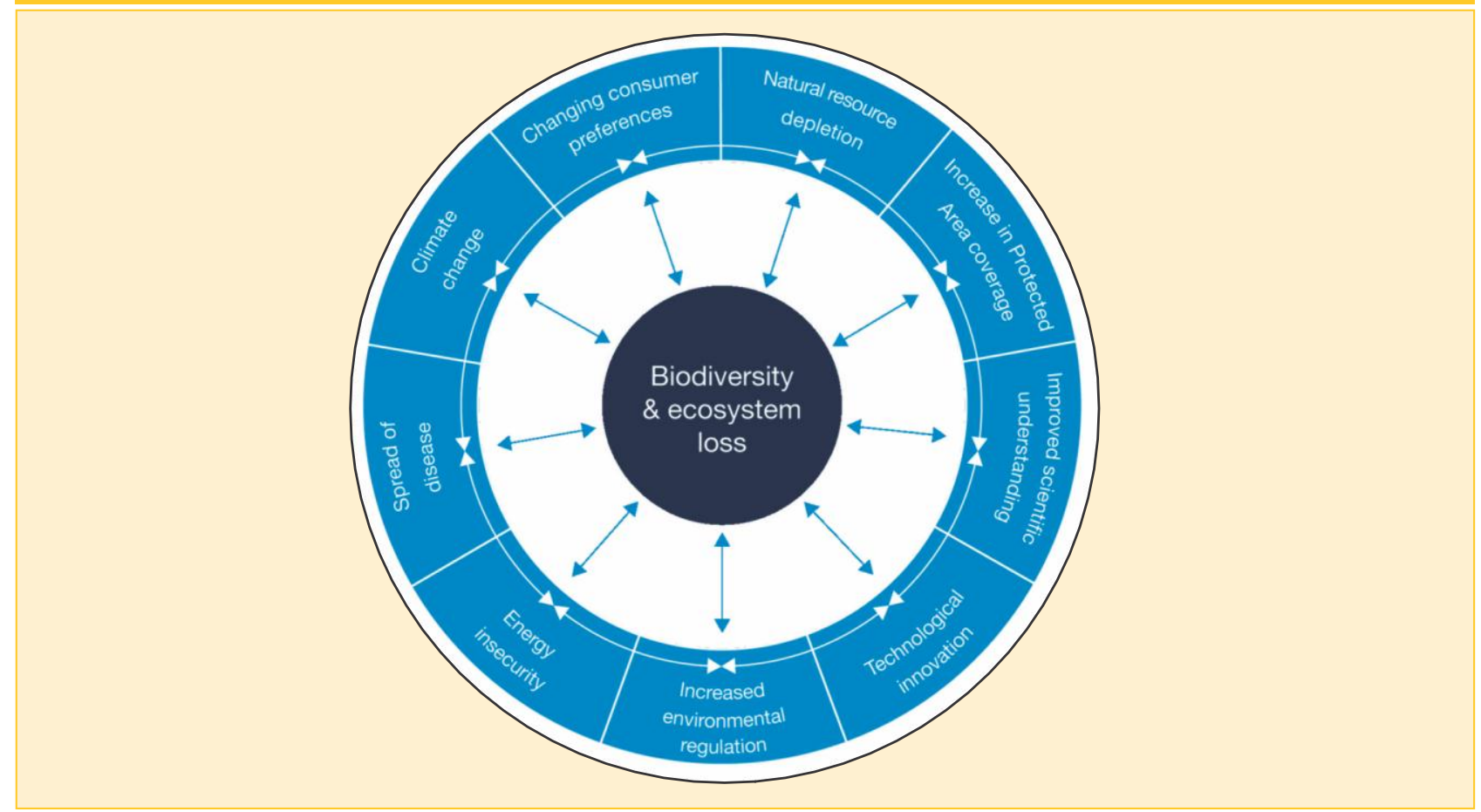

Source: PricewaterhouseCoopers for TEEB

The trends included in Table 1.1 are not exhaustive and the analysis is necessarily general, but this may provide a starting point for more detailed analysis along company or industry lines. The list of trends has not been prioritised and in fact the relevance of each trend will vary depending on a company's geographic exposure and business activities. Further detail is given in the following section on trends in consumer preference, pointing the way to deeper analysis of the links between major global trends, biodiversity and business.

Some of the trends outlined in Table 1.1 lie outside the traditional sphere and mandate of business sustainability, environmental or biodiversity management systems. However, as biodiversity and ecosystems are linked to many other trends, they should not be considered in isolation. Business risk management systems can help make the connections and provide a structure to analyse and track such trends, allocate resources and determine responses. We suggest that if biodiversity and ecosystem risks are identified, assessed and managed early, they can provide a basis for business competitive advantage. 


\section{Table 1.1 Major trends and their potential implications for biodiversity and business}

What is the trend?

\section{Biodiversity-related business risk and implications}

\section{Natural resource depletion}

Diminishing supplies of raw materials and biological resources, such as fresh water, fertile soils, timber, fish, etc. This trend is exacerbated by pollution, climate change (see below), the spread of alien invasive species, and rising levels of consumption in many emerging economies. For example, in 2006 it was projected that the world's commercial fisheries will collapse in less than 50 years if current rates of fishing continue (Worm 2006).

\section{Increased protected area coverage \\ Over the last three decades there has been a threefold increase in the total coverage of Protect Areas (UNEP 2007) and this expansion is expected to continue, particularly for under- represented marine and coastal areas.}

\section{Risk:}

- Increasing scarcity of natural resources implies reduced or more costly access. Secondary risks related to declining availability of natural resources (e.g. interstate conflict, resource nationalism, terrorism or mass migration) could further reduce business access.

\section{Implication:}

- Business needs tools to monitor stocks of natural resources on which they rely, and to account for potential resource scarcity in long-term planning.

- Business may need to find creative ways to secure access to their resource requirements, particularly fertile and well-watered agricultural land, that consider the needs of other stakeholders.

\section{Risk:}

- Continued expansion of protected areas vill restrict some business operations or increase operating costs for businesses that rely on access to, or conversion of, land / marine areas. This will especially influence sectors such as tourism, agriculture, forestry, fishing, shipping and extractives.

\section{Implication:}

- Businesses will need to work at a regional or landscape level with peers, regulators and NGOs to secure their license to operate. This may include direct business contributions to PA objectives.

- Some businesses may need to tighten and devote more resources to their internal controls for environmental management in order to secure and maintain operating consent in PAs.
Biodiversity-related business opportunity and implications

\section{Opportunity}

- Resource efficiency will become more important to business competitiveness. Early adapters may gain competitive advantage.

\section{Opportunities}

- Businesses able to generate the same output from a smaller land/sea 'footprint' will outperform their peers where PAs constrain access.

- A track record of good environmental stewardship and support for PAs may be viewed favourably by regulators when considering business requests for access to resources. 


\begin{tabular}{|c|c|c|}
\hline What is the trend? & $\begin{array}{l}\text { Biodiversity-related business risk and } \\
\text { implications }\end{array}$ & $\begin{array}{l}\text { Biodiversity-related } \\
\text { business opportunity } \\
\text { and implications }\end{array}$ \\
\hline $\begin{array}{l}\text { Improved scientific } \\
\text { understanding } \\
\text { A combination of research } \\
\text { and improvements in infor- } \\
\text { mation technology mean } \\
\text { that ecological data is in- } \\
\text { creasingly reliable, more } \\
\text { easily accessible, and } \\
\text { spatial data is of higher } \\
\text { resolution. For example, } \\
2007 \text { - } 2009 \text { saw major } \\
\text { quality and accuracy } \\
\text { improvements in the } \\
\text { ecological information } \\
\text { on the World Database on } \\
\text { Protected Areas, including } \\
\text { the integration of marine } \\
\text { protected areas, now avai- } \\
\text { lable online (WDPA 2009). }\end{array}$ & $\begin{array}{l}\text { Risk: } \\
\text { - Advancements in measurement of natural } \\
\text { resource use will enable increased scrutiny } \\
\text { by external stakeholders of business use } \\
\text { and impacts on biodiversity and ecosystems. } \\
\text { Implication: } \\
\text { - Better evidence of how companies depend } \\
\text { upon biodiversity and ecosystem services } \\
\text { will push BES higher up the agenda of } \\
\text { business priorities. }\end{array}$ & $\begin{array}{l}\text { Opportunities } \\
\text { - Companies that use } \\
\text { improved ecological } \\
\text { information may gain } \\
\text { advantage through earlier } \\
\text { acquisitions of high value } \\
\text { resources, ecosystem } \\
\text { service agreements and/ } \\
\text { or operating licences. }\end{array}$ \\
\hline $\begin{array}{l}\text { Technological } \\
\text { innovation } \\
\text { Continued development of } \\
\text { bio-mimicry engineering, } \\
\text { biotechnology, etc. For } \\
\text { example, in 2008, } 2^{\text {nd }} \\
\text { generation bio-fuels (bio- } \\
\text { chemical and thermo- } \\
\text { chemical) reached the } \\
\text { demonstration stage, } \\
\text { while } 3^{\text {rd }} \text { generation algal } \\
\text { bio-fuels promise further } \\
\text { increases in productivity } \\
\text { (IEA 2008). }\end{array}$ & $\begin{array}{l}\text { Risk: } \\
\text { - Some technologies and resource manage- } \\
\text { ment systems mə!! reduce genetic diversity } \\
\text { (e.g. high-yield hybrid or monoclonal crop } \\
\text { varieties) or impair ecosystems in other ways, } \\
\text { generating both operational and reputational } \\
\text { risks for business. } \\
\text { Implication: } \\
\text { - More stringent safeguards to protect endange- } \\
\text { red species and ecosystems from the risks } \\
\text { posed by new technology may be imposed } \\
\text { e.g. extended R\&D procedures, increased } \\
\text { quality control, bans on trials of new products } \\
\text { close to sensitive habitats. }\end{array}$ & $\begin{array}{l}\text { Opportunities } \\
\text { - Business can use } \\
\text { education and communi- } \\
\text { cation, in collaboration } \\
\text { with peers and NGOs, to } \\
\text { allay public concerns } \\
\text { about new technology. } \\
\text { - Potential commercial } \\
\text { opportunities for busines- } \\
\text { ses that invest in or } \\
\text { develop new technologies } \\
\text { and production practices } \\
\text { that are sympathetic to } \\
\text { biodiversity and ecosys- } \\
\text { tem services }\end{array}$ \\
\hline
\end{tabular}


What is the trend?

\section{Biodiversity-related business risk and}

\section{implications}

\section{Increasingly stringent \\ tions \\ Increasing pace of change, stringency and enforcement of public policies to protect and ensure business pays for damage to biodiversity e.g. EU Environmental Liability Directive, EU Habitats Directive, US Clean Water Act, Me- xico's Sustainable Forestry Code (Ecosys- tem Marketplace 2010), Brazil's Compensação Ambiental Law². Volun- tary approaches are in- creasingly influencing public policy, e.g. biodi- versity offsets, certifica- tion and labelling.}

\section{Energy insecurity}

Diminishing and increasingly inaccessible fossil fuel reserves, combined with political risks to energy supply, are forcing countries and businesses to reassess and diversify their energy supplies.
- Unforeseen regulatory change and increasing regulatory burden on business to reduce adverse impacts on biodiversity, with governments applying the 'polluter pays principle' more widely and stringently.

- Compliance costs and 'green' taxes on carbon, water, land and other resources imply higher business costs.

\section{Implication:}

- Business should familiarize itself with emerging environmental policy regimes and ensure they have appropriate procedures in place to identify, control, monitor and report their environmental performance.

- More time and effort may be required for business expansion (e.g. permitting and planning consents, credit conditions) as impacts on biodiversity are subjected to greater scrutiny.

\section{Risk:}

- Increasing reliance on land intensive energy sources (bio-energy, concentrated solar thermal power, onshore wind, oil sands etc.) further increases competition for and pressure on the land base.

- Energy businesses increasingly look to technically challenging operating environments (e.g. deep water and arctic) to secure access to hydrocarbons.

\section{Implication:}

- Businesses operating in areas where policy supports land-intensive energy generation will need to plan to ensure future access. For example, agri-business in India may find it more difficult to secure fertile land, due to national policy support for the development of bio-fuels (policy requires that $20 \%$ of diesel fuel demand is met by bio-fuels by 2017 , which may require 14 million hectares of land (NCAER 2009).
Biodiversity-related

business opportunity

and implications

\section{Opportunities}

- Some companies go 'beyond compliance' to prepare for impending regulatory change. Business may benefit by helping to shape future regulations and improve stakeholder relations.

- Increased reliance of policymakers on market-based environmental policy, such as payments for ecosystem services, may offer new revenue opportunities for some businesses and/or make the mitigation of impacts more flexible and less costly.

\section{Opportunities}

- Business may develop bio-crops or bio-fuel technologies that do not compete with food crops for land and water.

- Opportunity to gain competitive advantage by planning ahead to secure energy needs. 
What is the trend?

\section{Spread of disease \\ Changing patterns \\ of disease and pandemics such as Avian flu, Swine flu and West Nile virus, exacerbated by poor water quality and other features of degraded ecosys- tems. Other trends such as climate change, urbanisation and globalisation may accelerate the spread of disease.}

\section{Climate change \\ Complex phenomena attributed to green- house gas emissions are changing the functioning of ecosys- tems at regional and global levels.}

Under various scenarios, the IPCC suggests a global temperature increase of between 1 and $6^{\circ} \mathrm{C}$ by the end of this century (IEA 2009). Even with a global average temperature increase of just $1.5-2.5^{\circ} \mathrm{C}$, it is expected that $20-30 \%$ of all species are likely to be at increased risk of extinction (IPCC 2007).

\section{Biodiversity-related business risk and} implications

\section{Risk:}

- Society (hence business) relies on healthy ecosystems including clean air and water to control the spread of diseases. Degraded ecosystems can jeopardise the health of consumers and employees, and affect business value chains.

- Biodiversity loss could affect businesses that seek to exploit medicinal and other properties of wild plants and animals (e.g. in the health sector).

\section{Implications:}

- Business may wish to assess how their operations would be affected by the increasing incidence of disease, and take actions to reduce the spread of disease amongst employees.

- Businesses that rely on wild genetic resources (e.g. bio-technology, pharmaceutical sector) should plan for a world of declining biodiversity and increased raw material costs.

\section{Risk:}

- Changing temperatures, increased extreme weather events, sea-level rise, increased water stress and drought will dramatically alter the availability of ecosystem services upon which all businesses rely. For example, loss of natural tourism assets such as coral reefs due to changes in sea temperature and acidity, or reduction of agricultural yields due to increased water scarcity.

\section{Implications:}

- Businesses can integrate climate change impacts into long-term planning and assess where this trend may jeopardise access to ecosystem services.
Biodiversity-related

business opportunity

and implications

\section{Opportunities}

- Spread of infectious diseases (exacerbated by poor water quality and degraded ecosystems) may lead to increased health spending and could provide increasing opportunities for the healthcare sector.

- Business can develop tailored treatments or technologies to mitigate and/or adapt to the health consequences of ecosystem decline.

\section{Opportunities}

- Development of business services and tools to evaluate risks associated with climate change (e.g. climate risk mapping) or provide climate adaptation services (e.g. drought resistant crops).

- Potential advantage for businesses that can anticipate climate change impacts and 'climate proof' their business models.

- Participation in emerging markets for bio-carbon offsets (including REDD+). 


\subsubsection{CHANGING CONSUMER PREFERENCES: IMPLICATIONS FOR BUSINESS AND BIODIVERSITY}

Business, biodiversity and the linkages between them are heavily influenced by consumer preferences, which are constantly evolving. A recent survey of over 13,000 people suggests that consumers are more concerned about the environment today than just a few years ago: $82 \%$ of Latin American consumers were more concerned; $56 \%$ in Asia; $49 \%$ in USA and $48 \%$ in Europe (TNS 2008). Some examples of changing consumer preferences include reduced demand for traditional Chinese medicine, due to perceived impacts on endangered species (e.g. tigers, bears, sea horses), or the changing acceptance of fur clothing in Europe and North America, with knock-on effects on both wild hunting and farming of animals for their fur.

Public awareness of biodiversity is also growing: a 2010 survey by IPSOS revealed that $60 \%$ of consumers in Europe and the United States (and 94\% in Brazil) had heard of biodiversity, representing an increase on the previous year (UEBT 2010). Increasing awareness is likely to influence purchasing behaviour, with $81 \%$ of consumers interviewed in the same survey declaring that they would cease buying products from companies that disregard ethical sourcing practices. In another survey of UK consumers, conducted in May 2010, around half of all respondents indicated that they would be willing to pay between $10 \%$ and $25 \%$ more for purchases up to GB£100, in order to account for their impacts on biodiversity and ecosystems ${ }^{3}$.

The proliferation of ecologically certified products is another indication of changing consumer preferences: the IPSOS survey referred to above also revealed that $82 \%$ of consumers would have more faith in companies that subject themselves to independent verification of their sourcing practices (UEBT 2010). Many labelling schemes arose in response to NGO campaigns, public concerns and changing preferences related to biodiversity loss, including the Forest Stewardship Council (FSC), Marine Stewardship Council (MSC) and Rainforest Alliance certified coffee, cocoa and tea, while membership of the International Social and Environmental Accreditation and Labelling Alliance has more than doubled over the last two years (ISEAL 2010).

In addition to the increased number of eco-labelling schemes, total sales and the market share of certified products are also growing, albeit from a small base. Between 2005 and 2007, for instance, sales of FSC labelled goods quadrupled (FSC 2008) while spending on ethical food and drink in general has increased more than threefold over the last decade, growing from GB£1.9 billion in 1999 to over GB£6 billion in 2008 (The Co- operative Bank 2008). In another example, between April 2008 and March 2009, the global market for MSC-labelled seafood products grew by over $50 \%$ to reach a retail value of US\$1.5 billion (MSC 2009).

The behaviour of some FMCG (Fast Moving Consumer Goods) brand owners suggests that eco-labelling is moving from niche markets into the mainstream. In recent years, several brand owners and retailers have added ecologically-friendly product attributes to their major brands, often through certification. Examples include Domtar (FSC certified paper), Mars (Rainforest Alliance cocoa), Cadbury (Fairtrade cocoa), Kraft (Rainforest Alliance Kenco coffee) and Unilever (Rainforest Alliance PG Tips). Importantly, all of these brands offer biodiversity attributes through certification schemes but do not ask consumers to pay a premium or to compromise on quality, taste or availability. Retailers are also taking action on biodiversity and communicating that action to consumers. In the UK, for example, the Waitrose supermarket chain links their Palm Oil Policy to customer labelling:

"Waitrose already has in place a technical policy to name oils, rather than use the term 'blended vegetable oils'. As a result we can confirm that palm oil is used as an ingredient in only a small number of our own branded products, which are identifiable to our customers" (Waitrose 2009). 
Business action is not only responding to consumer preferences but is itself a key driver in influencing and educating consumers. Governments can also influence consumer choice and producer behaviour by market regulation and incentives, e.g. taxes and subsidies, but also through their own purchasing strategies. For example, sixteen EU Member States have adopted Green Public Procurement National Action Plans, which include environmental criteria for the purchase of products and services (EC 2009).

As consumer demand for biodiversity-friendly products and services increases, business should attempt to ensure that the implications for their operations are identified, assessed and managed. Increasingly, the supply chains of consumer goods companies are under scrutiny in terms of their biodiversity impacts and management. For example, Wal-Mart has begun scoring its suppliers based on their sustainability performance, with biodiversity and use of natural resources featuring heavily in the process. Wal-Mart aims to establish eco-labels for all of its products within five years. Pressure on suppliers to embed biodiversity considerations within their internal management processes is thus likely to increase.

For consumer-facing businesses, in particular, companies may wish to ensure that biodiversity is fully embedded in risk management systems. This may include:

- Ensuring that biodiversity-related consumer concerns are included on the corporate risk register (e.g. how well does the business know its customers' attitudes?);

- Assessing significance of the risk (e.g. how will it impact brand value? Are biodiversity-related shifts in customer preferences likely to influence demand for key products? How does this relate to other risks such as climate change, water scarcity, business cycles?);

- Designing appropriate responses (e.g. modify internal procurement or production procedures and influence key players in the value chain to ensure that biodiversity impacts are minimised, establish collaborative processes to combine expertise across an industry on biodiversity-related consumer issues, devise specific biodiversity policy and communications strategy to address customer concerns and educate consumers).

In order to capitalise on growing markets for environmentally responsible goods and services, businesses may wish to consider whether they have relevant processes and expertise. For example, adherence to eco-certification schemes requires a thorough understanding of the biodiversity impacts of business products and processes, as well as the development of capacity to support monitoring, system controls, evaluation and reporting systems. 


\section{FROM MAJOR TRENDS TO BUSINESS VALUES}

The preceding section reviewed some major trends that affect business and showed how these trends may influence business responses to biodiversity loss and ecosystem decline. Whilst many of these trends lie outside the traditional sphere of biodiversity and ecosystem management, we argue here that they cannot be considered in isolation.

In order to develop effective responses to these trends and their interactions, business needs reliable information to assess its impacts and dependence on biodiversity and ecosystems. Risk management frameworks can provide a structure and process for analysing and tracking such trends, allocating resources and determining adequate responses. If significant risks are identified, assessed and managed early, they can be transformed into competitive advantage.

The next chapter of this report provides an overview of the status and trends in biodiversity and ecosystems, the drivers of biodiversity loss, and describes the economic values at stake. The impact and dependencies of a range of sectors on BES are also explored, together with an overview of how these create both risks and opportunities for business. 


\section{Endnotes}

More information about this and other TEEB reports can be found at: www.teebweb.org

2 The "Compensação Ambiental" is described within Article 36 of Brazilian law (Law nr. 9985) and is designed to offset the negative impacts on the natural environment from project development, requiring developers to pay a licensing fee.

3 Survey carried out on behalf of PricewaterhouseCoopers by Opinium, in May 2010, with over 2,000 respondents across the UK. Respondents were asked a mix of single and multiple choice questions. 


\section{References}

Athanas, A., Bishop, J., Cassara, A., Donaubauer, P., Perceval, C. Rafiq, M., Ranganathan, J., and Risgaard, P. (2006) Ecosystem Challenges and Business Implications. Business and Ecosystems Issue Brief, Earthwatch Institute, World Resources Institute, WBCSD and IUCN (November).

Bishop, J., Kapila, S., Hicks, F., Mitchell, P. and Vorhies, F. (2008) Building Biodiversity Business. Shell International Limited and the International Union for Conservation of Nature: London, UK, and Gland, Switzerland. 164 pp. (March).

Dahdouh-Guebas, F. et al. (2005) How effective were mangroves as a defence against the recent tsunami? Current Biology Vol 15 No 12. URL: http://www.vub.ac.be/APNA/staff/FDG/pub/Dahdouh-Guebasetal_2005b_CurrBiol.pdf (last access 17 June 2010)

European Commission (2009), National GPP policies and guidelines. URL: http://ec.europa.eu/environment/gpp/national_gpp_ strategies_en.htm (last access 9 October 2009)

Forest Stewardship Council (2008), Facts and Figures on FSC growth and markets. URL: http://www.fsc.org/fileadmin/ web-data/public/document_center/powerpoints_graphs/facts_ figures/2008-01-01_FSC_market_info_pack_-_FINAL.pdf (last access 9 January 2009)

Global Environment Outlook: Environment for Development. GEO4. UNEP/ Earthprint. URL: http://www.unep. org/geo/geo4/media/ (last access 21 August 2009).

Global Risks 2009: A Global Risk Network Report, Figure 2. URL: http://www.weforum.org/pdf/globalrisk/2009.pdf (last access 21 August 2009); UNEP - United Nations Environment Programme (2007)

G8 Environment Ministers Meeting (2007) Potsdam Initiative - Biological Diversity 2010. Potsdam, 15-17 March 2007. URL: http://www.bmu.de/files/pdfs/allgemein/application/pdf/potsdam_ initiative_en.pdf (last access 8 July 2010)

http://www.g-8.de/Content/EN/_Anlagen/2007-03-18potsdamer-erklaerung-en, property=publicationFile.pdf

International Energy Agency (2009) World Energy Outlook. Organi- zation for Economic Cooperation \& Development, Paris.

International Energy Association (2008), From 1st - 2nd Biofuel Generation Technologies. URL: http://www.iea.org/papers/ 2008/2nd_Biofuel_Gen_Exec_Sum.pdf (last access 9 January 2010)

IPCC - Intergovernmental Panel on Climate Change (2007), Fourth Assessment Report Climate Change, Synthesis Report. URL: http://www.ipcc.ch/ (last access: 9 January 2010)

ISEAL Alliance (2009), pers. comm.

Marine Stewardship Council (2009), Annual Report 2008/2009.

URL: http://www.msc.org/ (last access 9 October 2009)
Millennium Assessment (2005) Ecosystems and human wellbeing: Opportunities and challenges for business and industry, Figure 2. Island Press, Washington D.C.; World Economic Forum (2009) Millennium Ecosystem Assessment (2005) Ecosystems and human well-being: Opportunities and challenges for business and industry. Island Press, Washington, D.C.

National Council of Applied Economic Research (2009), Biodiesel from jatropha: Can India meet the $20 \%$ blending target? Elsevier. URL: http://linkinghub.elsevier.com/retrieve/pii/ S0301421509008593 (last access 9 January 2010)

Nippon Keidanren (2010), Declaration of Biodiversity by Nippon Keidanren, URL: http://www.keidanren.or.jp/english/policy/2009/ 026.html (last access 15 June 2010)

PricewaterhouseCoopers (2010), 13th Annual Global CEO Survey 2010. Available at: http://www.pwc.com/gx/en/ceo-survey/index. jhtml (last access: 15 June 2010)

Sharp, J. (2000) Coast in Crisis, Protecting wildlife from sea level rise and climate change, Royal Society for the Protection of Birds, UK. URL: http://www.rspb.org.uk/Images/CRISIS72_tcm9133013.pdf (last access 17 June 2010)

Taylor Nelson Sofres (TNS) (2008). 'Global Shades of Green - TNS Green Life Study' presented at TNS Green Life Conference in New York City October 2008.

TEEB - The Economics of Ecosystems and Biodiversity: The Ecological and Economic Foundations (2010), Chapter 2, European Commission, Brussels. URL: http://teebweb.org

The Co-operative Bank and the Ethical Consumer Research Association (2008), Ten Years of Ethical Consumerism: 1999-2008. URL: http://www.ethicalconsumer.org/Portals/0/Downloads/ETH CAL\%20CONSUMER\%20REPORT.pdf (last access 9 October 2009)

The Ecosystem Marketplace, (2010) State of Biodiversity Markets: Offset and Compensation Programs Worldwide. Forest Trends, Washington, DC.

UNEP - United Nations Environment Programme (2007) Global Environment Outlook: Environment for Development. GEO4. UNEP/ Earthprint. URL: http://www.unep.org/geo/geo4/media/ (last access 19 May 2010)

Union for Ethical BioTrade (2010) Biodiversity Barometer 2010 URL: http://www.countdown2010.net/2010/wpcontent/uploads/ UEBT_BIODIVERSITY_BAROMETER_web-1.pdf (last access 25 May 2010)

United Nations (1993) Convention on biological diversity (with annexes). Concluded at Rio de Janeiro on 5 June 1992. Treaty series No. 30619. URL: http://www.cbd.int/convention/convention.shtml 
Waitrose (2009), Palm Oil Policy. URL: http://www.waitrose.com/ food/foodissuesandpolicies/palmoil.aspx (last access 9 October 2009)

WBCSD (2010) Vision 2050: The New Agenda for Business. World Business Council for Sustainable Development: Geneva (February). Available at: http://www.wbcsd.org/web/vision 2050.htm

World Database on Protected Areas (2009), Annual Release. URL: http://www.wdpa.org/AnnualRelease.aspx (last access 9 January 2010)

Worm, B. et al. (2006) Impacts of Biodiversity Loss on Ocean Ecosystem Services, Science Vol. 314. no. 5800, pp. 787 - 790 URL: http://www.sciencemag.org/cgi/content/abstract/314/5800/ 787 (last access 21 Aug 2009) 


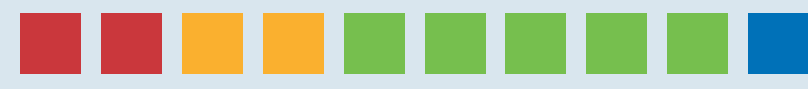 THE ECONOMICS OF ECOSYSTEMS AND BIODIVERSITY \\ TEEB FOR BUSINESS}

Chapter 1 Business, biodiversity and ecosystem services

Chapter 2 Business impacts and dependence on biodiversity and ecosystem services

Chapter 3 Measuring and reporting biodiversity and ecosystem impacts and dependence

Chapter 4 Scaling down biodiversity and ecosystem risks to business

Chapter 5 Increasing biodiversity business opportunities

Chapter 6 Business, biodiversity and sustainable development

Chapter 7 A recipe for biodiversity and business growth 


\section{Chapter 2: Business impacts and dependence on biodiversity and ecosystem services}

TEEB for Business Co-ordinator: Joshua Bishop (International Union for Conservation of Nature)

Editors: Mikkel Kallesoe (WBCSD), Nicolas Bertrand (UNEP)

Contributing authors: Scott Harrison (BC Hydro), Kathleen Gardiner (Suncor Energy Inc.), Peter Sutherland (GHD), Bambi Semroc (Cl), Julie Gorte (Pax World), Eduardo Escobedo (UNCTAD), Mark Trevitt (Trucost plc), Nathalie Olsen (IUCN), James Spurgeon (ERM), John Finisdore (WRI), Jeff Peters (Syngenta), Ivo Mulder (UNEP FI), Christoph Schröter-Schlaack (UFZ), Emma Dunkin, Cornelia Iliescu (UNEP)

Acknowledgements: Adachi Naoki (Responsibility), Alistair McVittie (SAC), Delia Shannon (Aggregate Industries), Gerard Bos (Holcim), Luke Brander (IVM), Richard Mattison (Trucost plc), Alison Reinert (Syngenta), Donn Waage (NFWF), Gigi Arino (Syngenta), Jeffrey Wielgus (WRI), Jennifer Shaw (Syngenta), JiSu Bang (Syngenta), Juan Valero-Gonzalez (Syngenta), Rufus Isaacs (Michigan State University), Steve Bartell (E2 Consulting)

Disclaimer: The views expressed in this report are purely those of the authors and may not in any circumstances be regarded as stating an official position of the organisations involved.

The final edition of the TEEB for Business report will be published by Earthscan. If you have any additional information or comments you feel should be considered for inclusion in the final report then please email them by 6 th September, 2010 to: teeb4biz@ufz.de

TEEB is hosted by the United Nations Environment Programme and supported by the European Commission; the German Federal Environment Ministry; the UK Government's Department for Environment, Food and Rural Affairs; the UK Department for International Development; Norway's Ministry for Foreign Affairs; The Netherlands' Interministerial Program Biodiversity; and the Swedish International Development Cooperation Agency. 


\section{THE ECONOMICS OF ECOSYSTEMS AND BIODIVERSITY Chapter 2}

\section{Business impacts and dependence on biodiversity and ecosystem services}

\section{Contents}

Key messages

2.1 Introduction 5

2.2 Biodiversity, ecosystems and ecosystem services 6

2.2.1 Biodiversity, ecosystems and ecosystem services status and trends $\quad 7$

2.2.2 Modelling the future of biodiversity and ecosystem services 8

2.2.3 Drivers of biodiversity loss and ecosystem degradation 9

2.2.4 Implications for business 11

2.2.5 Externalities and the values at stake 13

2.3 Impacts and dependence on biodiversity and ecosystem services across sectors 16

2.3.1 Agriculture 16

2.3.2 Forestry 19

$\begin{array}{lll}\text { 2.3.3 } & \text { Mining and quarrying } & 19\end{array}$

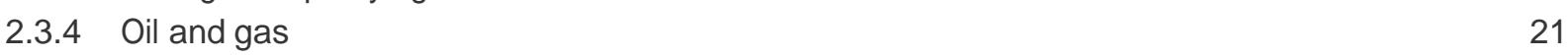

2.3.5 Cosmetics and personal care 21

2.3.6 Water supply and sanitation 22

$\begin{array}{lll}2.3 .7 & \text { Fisheries } & 23\end{array}$

2.3.8 Tourism 23

2.3.9 Transport 23

2.3.10 Manufacturing 24

2.3.11 Finance $\quad 25$

2.4 Biodiversity and ecosystem risks and opportunities for business 26

$\begin{array}{lll}2.4 .1 & \text { Operational } & 26\end{array}$

$\begin{array}{lll}2.4 .2 & \text { Regulatory and legal } & 27\end{array}$

$\begin{array}{lll}2.4 .3 & \text { Reputational } & 27\end{array}$

$\begin{array}{lll}\text { 2.4.4 Market and product } & 27\end{array}$

2.4.5 Financing 28

2.5 Conclusion $\quad 29$

$\begin{array}{ll}\text { References } & 30\end{array}$

\section{Boxes}

2.1 Operation Pollinator: Investing in natural capital for agriculture

2.2 Cotton production and the Aral Sea

2.3 Construction and deforestation in China

2.4 Holcim and the value of wetland restoration

2.5 How water utilities depend on watershed services 
Figures

2.1 The ecosystem services balance sheet

2.2 Effects of the main direct drivers of biodiversity loss

2.3 Feedbacks and interaction between drivers

2.4 Estimated environmental damages for five major industry sectors

2.5 Ricoh's map of corporate activities and biodiversity

\section{Tables}

2.1 Four categories of ecosystem services

2.2 Relationship between biodiversity, ecosystems and ecosystem services 


\section{Key messages}

All companies, regardless of sector, both impact on biodiversity and ecosystems and depend on ecosystem services: It is hard to think of any economic activity that does not benefit from BES or in some way modify the ecosystems around it. For example the bio-tech industry benefits from access to wild genetic resources but may also create risks through the introduction of genetically-modified organisms; agribusiness and the food sector depend on ecosystem services like pollination but also, through impacts on land and water resources, reduce other ecosystem services; forest industries, construction and publishing rely on sustained supplies of timber and wood fiber but can alter forest structure at the expense of wildlife and recreational values; and tourism derives profit from the cultural services and aesthetic values of natural landscapes but may bring so many tourists into an area that nature values are diminished.

BES decline continues at unprecedented rates: Most indicators of the state of BES show declines, indicators of pressures on biodiversity show increases, and despite some local successes and responses, the rate of biodiversity and ecosystem loss does not appear to be slowing. This poses real and tangible risks for business and for society in general, as BES generate value for businesses and the wider economy and the loss of BES imposes both private and public costs.

Key direct drivers of BES decline are habitat change, climate change, invasive species, overexploitation and pollution: Business can help reduce these pressures by managing and mitigating their impacts on biodiversity and ecosystem services. They should systematically review their operations in relation to BES and assess how direct and indirect drivers of change in ecosystem services may affect their business.

Operational, regulatory, reputational, market and product and financial risks associated with BES decline are often overlooked and underestimated by business, particularly when they are indirect: Companies need to examine their entire value chain in order to determine how and where BES impacts and dependence may affect their business. Although historically BES has been given little attention in financial analyses of company performance, this is changing partly as a consequence of increased attention to climate change risks and opportunities in business.

There are untapped business opportunities to address BES decline while contributing to other societal goals: Far-sighted businesses can create opportunities from the greening of investor, client and consumer preferences. However, businesses that fail to assess their impacts and dependence on BES may neglect some of these profitable opportunities.

The values of BES are often external to business decision-making: While acknowledging the importance of BES decline and measuring ecosystem impacts and dependencies, many companies still find it difficult to integrate such information into their core operational and corporate decisions. 
Most companies have a two-way relationship with nature. On the one hand they may have direct impacts on biodiversity and ecosystems through their core operations or indirectly through their supply chain, or through their lending and investment choices. On the other hand, many companies depend on biodiversity and the services provided by ecosystems as key inputs to products and production processes.

It is hard to think of any economic activity that does not benefit from ecosystem services in some way (WRI et al. 2008). Freshwater, for instance, is a critical input to almost every industrial process - from fresh-cut lettuce processing to large-scale mining. Pharmaceutical companies rely on wild genetic resources to identify new active compounds. Agribusiness depends on natural pollination, pest control and soil biological processes. Many tourism destinations owe their attractiveness to surrounding natural environments. The protection offered by ecosystems, such as wetlands and mangroves, can reduce damages from storms and flooding and is monitored by insurance and reinsurance companies.

How a business conducts its operations can affect the value of biodiversity generally or a specific ecosystem service - for the company itself, as well as for other sectors and society as a whole. Today, however, most company managers pay little or no attention to the links between biodiversity, ecosystems and their business. Whilst some companies recognize the importance of their impacts and dependence on biodiversity and ecosystem services, many others struggle to understand how to integrate such information into day-to-day business.

The Millennium Ecosystem Assessment (MA) offers a sobering account of biodiversity loss and ecosystem degradation (MA 2005a). Although this loss of natural capital is still not adequately reflected in national economic statistics or company accounts, the impacts are real and increasingly seen as material by businesses.

New public policies and regulations are being developed in response to biodiversity loss and ecosystem degradation - at global, regional and local levels. Business impacts on BES are under increasing scrutiny from customers, investors, employees and regulators. More and more business managers are taking action to improve their understanding and manage their biodiversity and ecosystem impacts and dependence, while also developing new business solutions to meet these challenges.

This chapter summarizes the status, trends and forecasts for biodiversity, ecosystems and ecosystem services. We present the main drivers of biodiversity loss and ecosystem degradation, introduce the concept of externalities and describe the economic values at stake. We highlight typical impacts and dependencies on biodiversity and ecosystems for a range of business sectors, and outline how these create both risks and opportunities. 
Biodiversity is defined by the UN Convention on Biological Diversity (CBD) as the variability among living organisms within species (genetic variation), between species, and between ecosystems. Species richness is probably the best documented of these three components. Today approximately 1.75 million species are known to science, although plausible estimates suggest that the total number of species on earth ranges from 5-30 million.

Ecosystems are a major component of biodiversity and are defined by the MA as a dynamic complex of plant, animal and micro-organism communities and the non-living environment interacting as a functional unit (MA 2005a). Examples include deserts, coral reefs, wetlands, rain forests, boreal forests, grasslands, urban parks and cultivated farmland.

The MA defined "ecosystem services" as the benefits that people obtain from ecosystems. These are sometimes grouped into four categories (Table 2.1).

\section{Table 2.1 Four categories of ecosystem services}

\begin{tabular}{|l|l|}
\hline $\begin{array}{l}\text { Provisioning } \\
\text { Regulating }\end{array}$ & $\begin{array}{l}\text { Goods or products obtained from ecosystems such as food, freshwater, timber and fibre } \\
\text { Benefits obtained from natural processes such as climate, disease, erosion, water flows and } \\
\text { pollination, as well as protection from natural hazards. Note that "regulating" in this context is } \\
\text { a natural phenomenon and is not to be confused with government policies or regulations }\end{array}$ \\
\hline Cultural & $\begin{array}{l}\text { Non-material benefits obtained from ecosystems, such as recreation, spiritual values and } \\
\text { aesthetic enjoyment }\end{array}$ \\
\hline Supporting & $\begin{array}{l}\text { Natural processes, such as nutrient cycling and primary production, that } \\
\text { maintain all other ecosystem services }\end{array}$ \\
\hline
\end{tabular}

Source: adapted from Millennium Ecosystem Assessment (2005)

The value of ecosystem services is intimately linked to biodiversity. Table 2.2 illustrates how the ecosystem services enjoyed by people depend on both the diversity (quality) as well as the sheer amount (quantity) of genes, species and ecosystems found in nature.

Table 2.2 Relationship between biodiversity, ecosystems and ecosystem services

\begin{tabular}{|c|c|c|c|}
\hline Biodiversity & Quality & Quantity & Services (examples) \\
\hline Ecosystems & Variety & Extent & $\begin{array}{ll}\text { - } & \text { Recreation } \\
\text { - } & \text { Water regulation } \\
\text { - } & \text { Carbon storage }\end{array}$ \\
\hline Species & Diversity & Abundance & $\begin{array}{ll}\text { - } & \text { Food, fibre, fuel } \\
\text { - } & \text { Design inspiration } \\
\text { - } & \text { Pollination }\end{array}$ \\
\hline Genes & Variability & Population & $\begin{array}{l}\text { - Medicinal discovery } \\
\text { - } \quad \text { Disease resistance } \\
\text { - Adaptive capacity }\end{array}$ \\
\hline
\end{tabular}




\subsubsection{BIODIVERSITY, ECOSYSTEMS AND ECOSYSTEM SERVICES STATUS AND TRENDS}

Over the past 50 years, humans have altered ecosystems more than in any comparable period in our history, largely in order to meet growing demand for food, freshwater, timber, fibre, energy and other materials.

Whilst the use of natural resources has helped to satisfy human needs, an unintended consequence has been widespread fragmentation, degradation or outright conversion of ecosystems, leading to the loss of biodiversity and reductions in the quality and quantity of important ecosystem services. A key indicator of ecological deterioration is the increasing vulnerability of species to extinction, as well as the genetic impoverishment of remaining populations.

Species extinction is a natural part of the evolutionary process. However, the rate of species loss in recent decades is estimated by the MA to be 100-1,000 times faster than the "natural" rate. The largest declines have occurred in temperate and tropical grasslands and forests, areas where human civilizations first developed and disturbance is most pronounced.

More recently, the Global Biodiversity Outlook 3 (GBO-3) found that amphibians face the greatest risk of extinction and that coral species are deteriorating most rapidly (CBD 2010). Furthermore, the abundance of vertebrate species (based on assessed populations) fell by nearly one-third on average between 1970 and 2006 and continues to fall globally, with especially severe declines in the tropics and among freshwater species (CBD 2010). Other assessments show similar deterioration across a range of indicators (Butchart et al. 2010).

The loss of a single species can have wider effects on other species and entire ecosystems. In general, species extinction appears to reduce the resilience of ecosystems, leaving them at greater risk of further deterioration. Recent projections of the impacts of climate change indicate continuing and accelerating rates of species extinction, continued loss of natural habitats, and changes in the distribution and abundance of species, species groups and biomes (CBD 2010).

At the level of ecosystems, primary forests have completely disappeared in a number of countries, and every year millions of hectares are lost to deforestation, mainly in Latin America, South-East Asia and Africa (FAO 2000). The world has lost roughly half of its wetlands since 1900 (UNWWAP 2003), and about $20 \%$ of its mangrove forests between 1980-2005 (FAO 2007). In addition, 20\% of the world's coral reefs have been destroyed (MA 2005a) and a further $30 \%$ have been seriously damaged by destructive fishing practices, pollution, disease, coral bleaching, invasive alien species and unsustainable tourism (Wilkinson 2008).

Such rapid alterations are compromising the ability of ecosystems to recover from extreme events and external shocks. Evidence is growing that many species and ecosystems are nearing their "tipping points", where further disturbance may result in abrupt and possibly irreversible decline in the benefits they provide. GBO-3 identified the following tipping-points:

- The dieback of large areas of the Amazon forest, due to interactions between climate change, deforestation and fires, with adverse impacts on the global climate, regional rainfall patterns and species survival;

- Changes in the chemistry of many freshwater lakes and other inland water bodies due to runoff from agriculture, industry and urban areas, leading to the buildup of nutrients, algae blooms, fish die-off and reduced recreational value; and

- Collapsing coral reef ecosystems due to a combination of climate change (which results in ocean acidification, warmer water and coral bleaching), as well as over-fishing, destructive fishing practices and nutrient pollution. 
The impacts of changes in ecosystem extent and quality, species diversity and abundance, and genetic variety can be expressed in terms of the loss or decline of ecosystem services. According to the MA, almost two-thirds of the 24 ecosystem services they examined have been significantly reduced over the past 50 years, including almost all non-commodity benefits (Figure 2.1).

\section{Figure 2.1 The ecosystems services balance sheet}

Balance sheet: Ecosystem services

\begin{tabular}{|c|c|c|}
\hline \multicolumn{3}{|c|}{ Provisioning services } \\
\hline Food & crops & $\uparrow$ \\
\hline & livestock & $\uparrow$ \\
\hline & capture fisheries & $\downarrow$ \\
\hline & aquaculture & $\uparrow$ \\
\hline & wild foods & $\downarrow$ \\
\hline Fiber & timber & $+1-$ \\
\hline & cotton, silk & $+1-$ \\
\hline & wood fuel & $\downarrow$ \\
\hline Genet & & $\downarrow$ \\
\hline Bioche & edicines & $\downarrow$ \\
\hline Water & freshwater & $\downarrow$ \\
\hline
\end{tabular}

$\uparrow$ globally enhanced $\downarrow$ globally degraded

\begin{tabular}{|l|c|}
\hline Regulating services & $\downarrow$ \\
\hline Air quality regulation & $\uparrow$ \\
\hline Climate regulation - global & $\downarrow$ \\
\hline Climate regulation - regional and local & $+/-$ \\
\hline Water regulation & $\downarrow$ \\
\hline Erosion regulation & $\downarrow$ \\
\hline Water purification and waste treatment & $+/-$ \\
\hline Disease regulation & $\downarrow$ \\
\hline Pest regulation & $\downarrow$ \\
\hline Pollination & $\downarrow$ \\
\hline Natural hazard regulation & \\
\hline Cultural services & $\downarrow$ \\
\hline Spiritual and religious values & $\downarrow$ \\
\hline Aesthetic values & $+/-$ \\
\hline Recreation and ecotourism &
\end{tabular}

Recreation and ecotourism

The MA evaluated the global status of provisioning, regulating and cultural services. An upwards arrow indicates that the condition of the service globally has been enhanced and a downwards arrow that it has been degraded in the recent past.

Source: Millennium Ecosystem Assessment (2005c)

\subsubsection{MODELLING THE FUTURE OF BIODIVERSITY AND ECOSYSTEM SERVICES}

If we continue on our current development path and maintain today's patterns of resource exploitation, the world is likely to continue to lose biodiversity and many ecosystem services will be further reduced. However, it is difficult to predict the exact rates at which biodiversity and ecosystem change will occur.

The MA analysed four scenarios for the period 2000-2050. All four scenarios indicate a general increase in provisioning services, achieved primarily through land-use change, but at the cost of further degradation in supporting, regulating and cultural services. Additional common results across the four scenarios include:

- Increased demand for provisioning services

- Low levels of food security and child nutrition

- Fundamental modifications of freshwater resources

- Growing demand for fish and fish products leading to increased risk of decline in regional marine fisheries, with aquaculture unable to alleviate pressures due to its dependence on marine fish as feed

- Provision of ecosystem services is driven to a large extent by land-use change

- Provision of clean water is further impaired by wetland drainage and conversion

- Uncertainty over the role of terrestrial ecosystems as a net $\mathrm{CO} 2$ sink

- Difficult trade-offs between food and water supply

Predictions by the OECD suggest that agriculture will continue to be a major source of pressure on biodiversity; they highlight the risk of a business-as-usual scenario that would result in the loss of additional mature forests around the world by 2030: 68\% in South Asia, 26\% in China, 24\% in Africa and about 20\% in Eastern Europe, Australia and New Zealand (OECD 2008). 
Figure 2.2 Effects of the main direct drivers of biodiversity loss

\begin{tabular}{|c|c|c|c|c|c|c|}
\hline & & $\begin{array}{l}\text { Habitat } \\
\text { change }\end{array}$ & $\begin{array}{l}\text { Climate } \\
\text { change }\end{array}$ & $\begin{array}{l}\text { Invasive } \\
\text { species }\end{array}$ & $\begin{array}{l}\text { Over- } \\
\text { explotitation }\end{array}$ & $\begin{array}{l}\begin{array}{c}\text { Pollution } \\
\text { (nitrogen, } \\
\text { phosphorus) }\end{array}\end{array}$ \\
\hline \multirow{3}{*}{ Forest } & Boreal & $\nearrow$ & $\uparrow$ & $\nearrow$ & $\rightarrow$ & $\uparrow$ \\
\hline & Temperate & 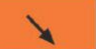 & $\uparrow$ & $\uparrow$ & $\rightarrow$ & $\uparrow$ \\
\hline & Tropical & $\uparrow$ & $\uparrow$ & $\uparrow$ & $\nearrow$ & $\uparrow$ \\
\hline \multirow{4}{*}{ Dryland } & Temperate grassland & $\nearrow$ & $\uparrow$ & $\rightarrow$ & $\rightarrow$ & $\uparrow$ \\
\hline & Medterranean & $\pi$ & $\uparrow$ & $\uparrow$ & $\rightarrow$ & $\uparrow$ \\
\hline & $\begin{array}{l}\text { Tropical grassland } \\
\text { and savanna }\end{array}$ & $\nearrow$ & $\uparrow$ & $\uparrow$ & $\rightarrow$ & $\uparrow$ \\
\hline & Desert & $\rightarrow$ & $\uparrow$ & $\rightarrow$ & $\rightarrow$ & $\uparrow$ \\
\hline \multicolumn{2}{|c|}{ Inland water } & $\uparrow$ & $\uparrow$ & $\uparrow$ & $\rightarrow$ & $\uparrow$ \\
\hline \multicolumn{2}{|l|}{ Coastal } & $\nearrow$ & $\uparrow$ & $\nearrow$ & $\nearrow$ & $\uparrow$ \\
\hline \multicolumn{2}{|l|}{ Marine } & $\uparrow$ & $\uparrow$ & $\rightarrow$ & $\nearrow$ & $\uparrow$ \\
\hline \multicolumn{2}{|l|}{ Island } & $\rightarrow$ & $\uparrow$ & $\rightarrow$ & $\rightarrow$ & $\uparrow$ \\
\hline \multicolumn{2}{|l|}{ Mountain } & $\rightarrow$ & $\uparrow$ & $\rightarrow$ & $\rightarrow$ & $\uparrow$ \\
\hline \multirow[t]{6}{*}{ Polar } & & $\pi$ & $\uparrow$ & $\rightarrow$ & $\nearrow$ & $\uparrow$ \\
\hline & \multicolumn{3}{|c|}{$\begin{array}{l}\text { Driver's impact on biodiversity } \\
\text { over the last century }\end{array}$} & Driver's current trends & & \\
\hline & & Low & Decrea & npact & & \\
\hline & & Moderate & Conin & napat $\rightarrow$ & & \\
\hline & & High & & npact & & \\
\hline & & Very high & Vey raf & eased & urce: Millennium E & stem Assessment \\
\hline
\end{tabular}

Source: Millennium Ecosystem Assessment 2005a

The MA scenarios analysis implies both risks and opportunities for business (MA 2005b). New markets may emerge for companies that are able to meet increased future demand for food, fibre and fresh water in a sustainable way. On the other hand, businesses involved in fish products and related activities will face increasing challenges, unless new technologies or fisheries management practices are adopted that can sustain productivity. Wetland conservation is expected to become a major public concern that businesses will need to factor into planning and decision-making. Finally, carbon capture and storage technologies and ecosystem conservation and restoration may become significant business opportunities, as part of climate change mitigation and adaptation strategies.

\subsubsection{DRIVERS OF BIODIVERSITY LOSS AND ECOSYSTEM DEGRADATION}

Effective responses to biodiversity loss and ecosystem decline begin with understanding the causes of environmental change. The various factors that directly or indirectly result in the loss of biodiversity are known as drivers. So-called direct drivers unequivocally influence biodiversity and ecosystems, but often vary in their importance depending on the context. Major direct drivers include climate change, nutrient deposition, land conversion, diseases and invasive species. These affect different ecosystems in different ways (Figure 2.2). 
Indirect drivers operate more diffusely, by accelerating one or more direct drivers. The MA identifies several indirect drivers, namely demographic, economic, socio-political, scientific and technological change, as well as cultural and religious trends (MA 2005c). Changes in biodiversity and ecosystems are almost always the result of the interaction of multiple drivers acting across different spatial, temporal and organizational scales (Figure 2.3).

\section{Figure 2.3 Feedbacks and interaction between drivers}

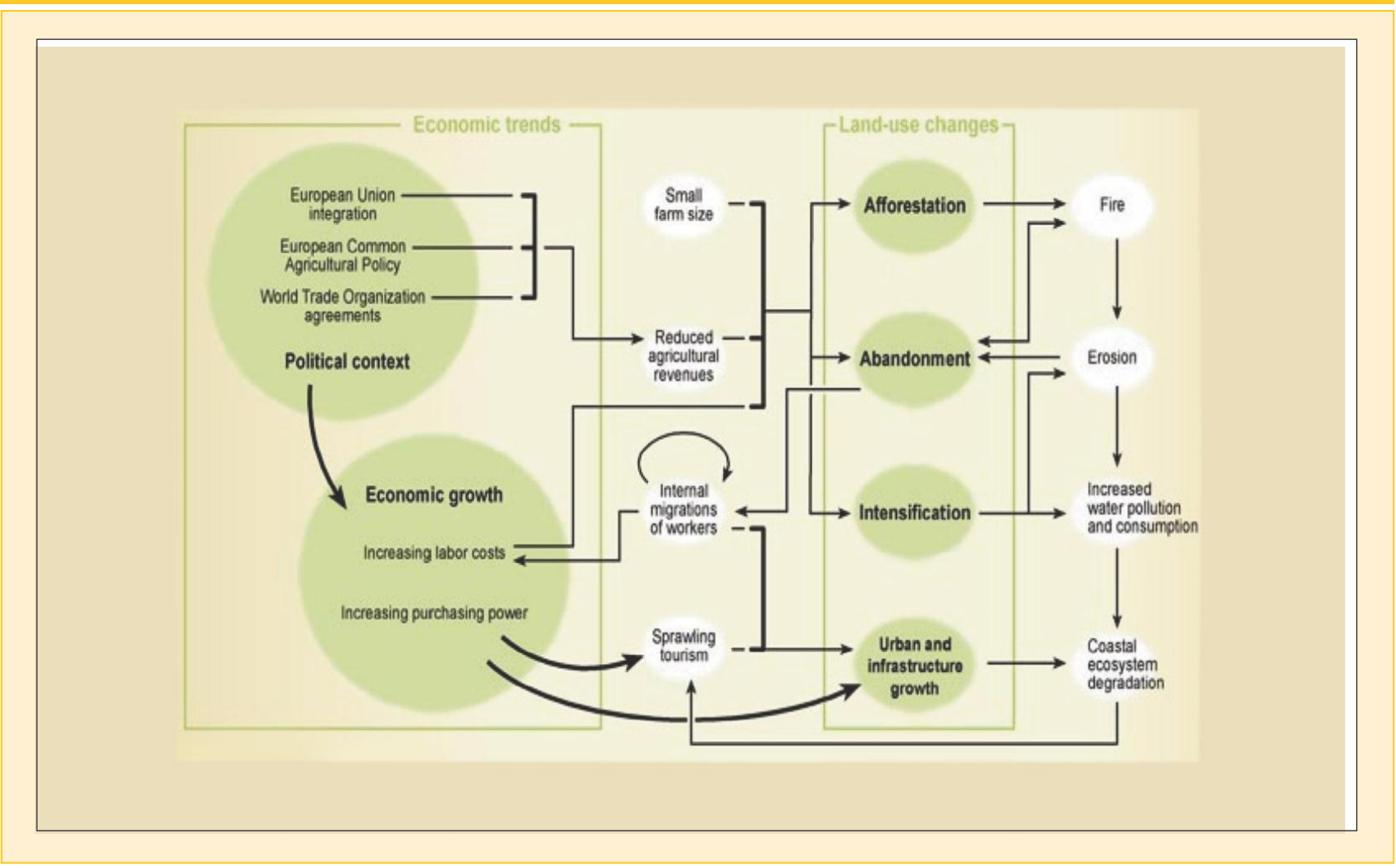

Source: Millennium Ecosystem Assessment (2005a)

Over the past 50 years, the most significant direct driver for terrestrial ecosystems (forests and drylands) has been land-use change, mostly due to agricultural expansion and urbanization. The latter includes both direct expansion of urban areas and indirect impacts due to the development of transport and infrastructure networks.

In marine ecosystems, the most important direct driver of change over the same period has been industrial fishing. Technical advances in the fishing industry, including more and larger boats and more efficient fishing equipment, have depleted fish stocks to such a degree that it has affected the overall biodiversity, structure and functioning of the oceans. Pressure from fishing on some marine ecosystems is now so intense that commercial fish stocks have been reduced by up to $90 \%$, compared to levels that existed prior to the onset of industrial fishing. A classic example is the collapse of the Atlantic cod stocks off the East Coast of Newfoundland in 1992 (MA 2005a).

For freshwater ecosystems, the most important direct drivers of change over the past 50 years vary across regions but include the modification of hydrological regimes, invasive alien species and pollution. As mentioned above, about $50 \%$ of the world's wetlands have been lost since 1900 and invasive species are now a major cause of species extinction in freshwater systems. Discharge of nutrients from agriculture, industry and built areas has caused widespread eutrophication and increased levels of nitrates in drinking water, while pollution from point sources such as mining has had significant adverse impacts on the biodiversity of some inland waters (MA 2005c). 
In many cases, actions taken to enhance one ecosystem service will exacerbate pressures on other services. For example, increased food production has typically resulted in the loss of other ecosystem services, through impacts on land cover, increased fresh water withdrawals for irrigation and release of agro-chemical nutrients into surface water.

A more recent assessment indicates that the main direct drivers of biodiversity loss and ecosystem degradation (i.e. habitat change, over-exploitation, pollution, invasive alien species and climate change) are either constant or increasing in intensity (CBD 2010). Moreover, today many drivers converge in the same place and at a greater intensity than ever before. Because exposure to one threat can make a species or an ecosystem more susceptible to a second, and so on, multiple threats can accumulate with dramatic impacts on biodiversity and ecosystems.

\subsubsection{IMPLICATIONS FOR BUSINESS}

The MA identified six ecosystem challenges of particular concern for business:

\section{Freshwater scarcity}

Forest and mountain ecosystems are the source of fresh water for two-thirds of the world's population. The availability of freshwater per person varies globally, but only about $15 \%$ of the world's population enjoys abundant supplies of freshwater. Currently between 1 and 2 billion people lack access to sufficient clean water to meet their needs, affecting food production, human health and economic development.

Most businesses depend on reliable sources of water for their operations. Many businesses also influence water quality through their wastewater discharge. Overuse of fertilizer, poor sanitation facilities and storm water runoff are other causes of declining freshwater quality.

Freshwater scarcity creates both business risks and opportunities. Risks include: increased water costs, unpredictable water supply, government imposed water restrictions or rationing, and reputational damage as a result of poor water treatment or inefficient use. Opportunities for business include: improving the efficiency of water use through market mechanisms (e.g., water trading) or new technologies (e.g., wastewater treatment, desalinization, closed-loop systems), developing new products and processes that are less water-intensive, improving reputation through participation in water management initiatives such as partnerships with government, local communities and civil society.

\section{Climate change}

Over the past 200 years, land clearing and the use of fossil fuels to meet growing energy demand has contributed to an increase in greenhouse gasses (GHGs) in the Earth's atmosphere. It is generally believed that this increase is leading to climate change, with multiple adverse effects on the environment. Scenarios developed by the Intergovernmental Panel on Climate Change (IPCC) predict an increase in global mean surface temperatures of between 2.0 and 6.40 Celsius above pre-industrial levels, by 2100 . The IPCC also forecasts increased frequency and intensity of storms, floods and droughts, as well as a rise in sea levels of between 8-88 centimetres between 1990 and 2100 (IPCC 2007).

Biodiversity, ecosystems and climate are closely linked. Local and global climate cycles are influenced by the way that ecosystems sequester and emit GHGs, such as carbon dioxide (CO2), methane $(\mathrm{CH} 4)$ and nitrous oxide (N2O). Furthermore, changes in land cover can alter water cycles and rainfall patterns over time and space, contributing to droughts and floods. Deforestation reduces the ability of ecosystems to sequester $\mathrm{CO} 2$, while natural processes in wetlands and in agriculture (ruminant animals and rice paddies) release $\mathrm{CH} 4$. N2O emissions come from farming systems, primarily driven by manure and fertilizer use. Increased temperatures due to climate change 
are expected to exacerbate biodiversity loss, modify entire ecosystems and vegetation zones, and may heighten the prevalence of pests and diseases such as malaria, dengue fever and cholera.

The challenge of climate change is increasingly understood by business. Leading companies have audited and reported their greenhouse gas (GHG) emissions for years. Others have begun incorporating carbon prices in their project and investment appraisals. A growing number of investors and entrepreneurs are developing new climaterelated businesses, including carbon accounting and trading, climate mitigation and adaptation.

\section{Habitat change}

Habitat change results from both natural disturbances (such as fires) and human activities, especially agriculture. While modern agriculture has delivered massive increases in food production, contributing to food security and poverty reduction, it has also contributed to considerable damage to biodiversity and ecosystems, primarily through land conversion. Habitat fragmentation is most severe in Europe and least severe in South America. Many countries in sub-Saharan Africa are characterized by low soil productivity and thus rely on the continuous expansion of cultivated area to meet demand for food (WBCSD et al. 2006).

Habitat change can take the form of ecosystem alteration, as in the case of deforestation and urban development, as well as fragmentation. The latter may seem less harmful but can greatly reduce ecosystem resilience and capacity to support viable populations of wildlife. Habitat change is a particular challenge for businesses that depend heavily on ecosystem services, as these may be reduced or modified as a consequence of habitat change.

\section{Invasive species}

The introduction of certain alien species into ecosystems unaccustomed to them has been a major cause of biodiversity loss, especially on islands and in freshwater habitats. Increasing travel and trade associated with globalization and human population growth have facilitated the intentional or unintentional movement of species beyond their natural habitat. Some of these alien species have become invasive, due to lack of natural pests and predators. The result is the total domination of ecosystems by a few alien species, often at the expense of native plants and animals.

The economic impacts of invasive alien species and the costs of preventing or controlling them are not well documented. Recent estimates suggest that total costs are in the range of millions to billions of dollars per year (Lovell et al. 2005). For businesses that rely on native plants and animals, the spread of invasive alien species can be a major challenge. Other companies may be affected by reductions in water availability or by fouling of equipment and infrastructure, also due to the spread of alien plants and animals.

\section{Overexploitation of oceans}

The oceans play a key role in climate regulation, the freshwater cycle, food supply and recreation. Coastal zones cover only $8 \%$ of the Earth's surface, but the benefits they provide account for more than two-fifths of the total value of all ecosystem services. Coastal zones yield about $90 \%$ of the marine fisheries catch, while nearly $40 \%$ of the human population lives within $100 \mathrm{~km}$ of a coast (WBCSD et al. 2006). Pressures on coastal zones around the world are increasing for shipping, oil and gas exploration, military and security needs, recreation and aquaculture.

Over-exploitation is the most significant immediate threat to marine biodiversity and thus also to commercial fisheries. Projections based on current rates of exploitation imply that there will be no economically viable stocks of fish or invertebrate species left by 2050. 


\section{Nutrient overloading}

Chemical nutrients are essential ingredients for the supply of farmed and wild products. This includes Nitrogen, Phosphorus, Sulphur, Carbon and Potassium, among others. However, human activities, particularly agriculture, have significantly changed nutrient balances and natural nutrient cycles in some regions. Over the last few decades, the flow of reactive Nitrogen has doubled. Over half of the nitrogen-based fertilizer ever used has been applied since 1985. Phosphorus is also accumulating in many ecosystems, due to the use of mined Phosphorus in agriculture and in industrial products. While Sulphur emissions have been reduced in Europe and North America, they are still rising in countries like China, India and South Africa and in southern regions of South America.

Nutrient loading (pollution) has emerged as one of the most significant drivers of change in terrestrial, freshwater and coastal ecosystems. The introduction of nutrients can have both beneficial and adverse effects, but the beneficial effects will eventually reach a plateau (for example, beyond a certain point, additional inputs do not lead to further increases in crop yield), while harmful effects will continue to increase (MA 2005d). The impacts of nutrient loading on business are not well-documented but are likely to include increased water treatment costs, reduced access to key resources (e.g. freshwater fish), and reduced value of freshwater bodies for recreation and tourism.

\subsubsection{EXTERNALITIES AND THE VALUES AT STAKE}

Underlying all of the drivers described above is the fact that many biodiversity and ecosystem values remain largely invisible to economic decision-makers, including government policy-makers as well as business and consumers.

The lack of property rights and prices for biodiversity and many ecosystem services can suggest that their use, whether sustainable or not, incurs low or even no cost. In fact, the costs of biodiversity loss and ecosystem degradation are all too real, but are usually incurred by other people than the user, with no basis for claiming compensation or redress. The lack of property rights and prices for biodiversity and ecosystem services also weakens the motivation for individuals or businesses to adopt environmentally responsible behaviour - even when the result would be a net improvement in overall economic welfare.

This gives rise to what economists call "externalities": the negative or positive consequences of an economic activity experienced by third parties. These occur when costs are imposed by one party upon another without agreement or compensation or, alternatively, when third parties enjoy benefits from an economic activity without offering any reward or recompense. The result is that market prices and private production costs fail to reflect the full value of biodiversity and ecosystem services - economic incentives to provide biodiversity benefits are weak as are the incentives to avoid harm.

In addition, the public good character of biodiversity and many ecosystem services (i.e. their inherent 'non-excludability' and 'non-rivalry') often leads businesses to see them as purely a government responsibility. Recently, however, the sheer magnitude of business risks and opportunities associated with biodiversity loss, ecosystem impacts and ecosystem service dependencies is opening new spaces for corporate leadership.

Well-known environmental externalities include impacts on ecosystems, but also to other receptors such as humans, buildings and structures (including cultural assets) and economic activities. The impacts typically relate to adverse implications associated with air emissions, discharges, spills, land-take, noise, sedimentation and waste disposal, etc. At the same time, positive externalities may arise deliberately or inadvertently (e.g., providing wildlife habitat on non-operational 'buffer' land around a major mining operation), for which companies often do not derive a direct financial return. 
Monetary estimates of the economic value of environmental externalities, both positive and negative, can help inform and motivate increased conservation efforts and more sustainable use of biodiversity and ecosystem services by business and others. As the TEEB study makes clear, this kind of economic evaluation is increasingly feasible but not always easy:

- There are still many unanswered questions about the role and economic value of genetic variability, species diversity and ecosystem variety. Interactions among species and the importance of complementarities or redundancy in communities of species are largely unknown. The same is true at a genetic level. TEEB summarizes current understanding of the intricacies of ecological dynamics and lays out priorities for research (TEEB Ecological and Economic Foundations, Chapter 2).

- Most indicators of biodiversity and ecosystems were not developed for economic analysis or the needs of business. TEEB aims to identify indicators that show the relationship between biodiversity and the benefits provided to people, as well as the impacts and dependence of business on biodiversity (Chapter 3 in this report).

- Ecosystems are subject to various pressures but vary in their resilience. If pushed beyond critical thresholds, ecosystems may be transformed into less desirable states. As with economic evaluations of climate change, conventional analysis breaks down in the face of non-marginal changes. In such cases, economic analysis gives way to ethics (see TEEB Climate Issues Update, 2009).

- Cost-benefit analysis may be unreliable when key parameters are uncertain (e.g. prices, the discount rate, critical thresholds). TEEB seeks to identify aspects of biodiversity loss that are 'non-marginal' and the implications for decision-making. Extinction for example is a non-marginal event, but not all extinctions have the same implications. What matters for business is the loss of species or ecosystem services essential for production, or the collapse of entire ecosystems (e.g. due to invasive alien species), or the loss of consumer confidence in a product, brand or industry due to perceived adverse impacts. Some ecosystem values may not become known until far into the future, hence there is a positive 'option value' to conserving biodiversity even when current valuations appear small.

- Many ecosystem values are context specific, not only due to the diversity of nature but also the fact that economic values reflect the number of beneficiaries and local socio-economic contexts and culture. Hence the value of a service measured in one location cannot simply be extrapolated or transferred to other sites, unless certain adjustments are made. Cultural context also influences the response to economic arguments, as societies, communities and stakeholder groups differ in their degree of acceptance of monetary valuations.

Notwithstanding such challenges, there has been considerable progress in the valuation of environmental externalities and, in particular, ecosystem services and biodiversity. TEEB has collected valuation studies for a range of ecosystem services in several biomes and ecosystems around the globe (TEEB Ecological and Economic Foundations, supplementary on-line database). It is hoped that this database will give new impetus to public policy making and also be of value for business decisions.

Making the economic value of ecosystems and biodiversity explicit can help generate support for new instruments and approaches that change the decision equation facing landowners, investors and other users of biodiversity and ecosystem services. Appropriate policy responses can take many forms; including payments for ecosystem services, reform of environmentally harmful subsidies or the introduction of resource user charges, pollution taxes and offset requirements (see TEEB for Policy Makers, 2009, Chapters 5-7). These and other potential policy reforms have significant implications for business. 
Business can also use economic valuation to inform its own decisions. As described in this report, ecosystem valuation methods are being used by some pioneer companies to identify risk, improve operational efficiency or develop new business ventures (see Chapters 3, 4, 5). Ecosystem valuation is also essential for understanding the true value of environmental assets and business impacts.

For example, in a report soon to be published by UNPRI (United Nations Principles for Responsible Investment), the top 3,000 listed companies in the world are estimated to be responsible for environmental externalities worth at least US\$2.2 trillion per year (for details see www.trucost.com). Of this, the major contributing costs are greenhouse gas emissions, overuse and pollution of water and particulate air emissions. Only a proportion of these costs relate to ecosystem services (e.g., water-related impacts, as water is a provisioning service).

The Trucost analysis for UNPRI includes a breakdown of estimated environmental externalities for major industrial sectors, revealing that some sectors are more exposed to potential environmental liabilities than others (Figure 2.4). This analysis also shows the relative significance of climate change in estimates of environmental impacts, mainly reflecting the lack of reliable monetary estimates of industrial impacts on biodiversity and ecosystems services.

Being able to assess and measure the value of ecosystems from an economic perspective provides information that can be directly integrated with conventional financial measures and unequivocally linked to business' financial bottom line, as discussed further in Chapter 3.

\section{Figure 2.4 Estimated environmental damages for five major industry sectors}

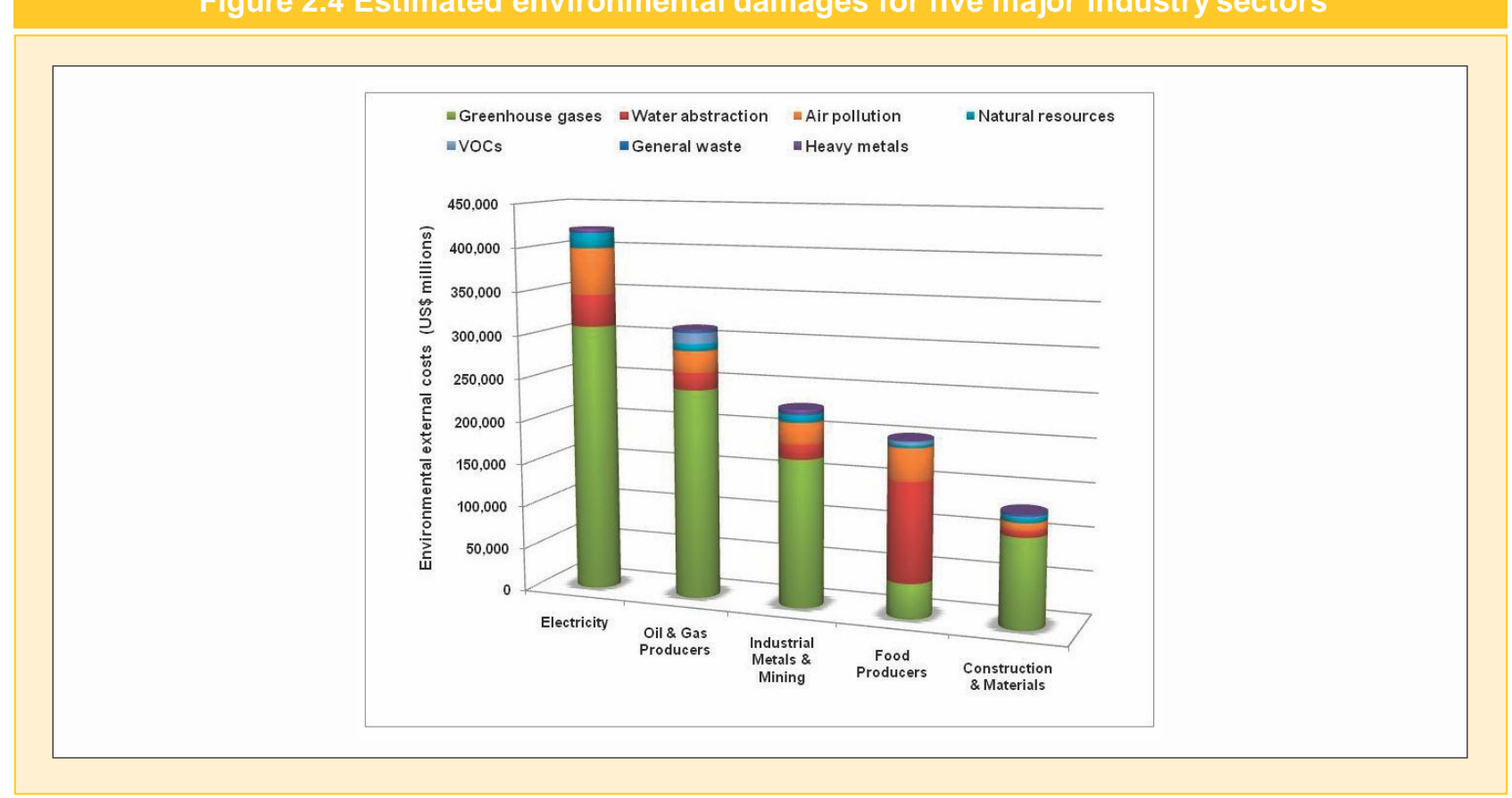


The links between business, biodiversity and ecosystem services vary across sectors and even within sectors. These links depend on the location of the business, the source of its raw materials, in some cases the location of its customers, and/or the production technology employed.

Broadly, these links can be grouped into business impacts on biodiversity, on the one hand, and business dependence on ecosystem services on the other. In each case it is important to look beyond direct impacts and dependence, to consider the indirect links arising through business value chains.

This section provides an overview and some concrete examples of business impacts and dependence on biodiversity and ecosystem services, across a range of sectors.

\subsubsection{AGRICULTURE}

The agriculture sector faces a growing dilemma: it needs to feed a rapidly growing and increasingly affluent global population while also conserving biodiversity and sustainably managing natural resources on an increasingly depleted planet. The need for increased food production is meanwhile constrained by poor land management and lack of means (financial and technological) to maintain let alone enhance productivity.

Agriculture as a sector is the biggest land manager in the world and provides important habitats for many wild plant and animal species. At the same time, extensive land clearing for farming, and especially for large-scale intensive crop production and livestock, is one of the main drivers of biodiversity loss. Examples include the conversion of large areas of the Amazon rainforest and Brazilian savannah to soybean and cattle production, and conversion of lowland rainforest in Southeast Asia to palm oil plantations. Not all recent land conversion is attributable to food production; some is also due to expanding demand for biofuels.

Crop and livestock genetic diversity are also declining, due to the narrowing of varieties and land races in agricultural systems. For example, more than sixty breeds of livestock are reported to have become extinct since 2000 (CBD 2010).

Agricultural productivity is heavily dependent on numerous species and ecosystem services, including soil micro-organisms, natural and domesticated pollinators and pest predators, the genetic diversity of crops and livestock, as well as freshwater supplies, climate regulation and nutrient cycling.

Insect pollinators, for example, are estimated to provide services worth US\$189 billion per year to global agriculture (Gallai et al. 2009) through increased yields and other benefits. Loss of native bees and other pollinators is linked to loss of suitable habitat, agricultural intensification and urbanization, among other factors. Even managed honey bees that are imported to provide these services are experiencing steep declines (Pettis and Deplane 2010). Grower economics, food security, and biodiversity may be at risk without sustainable solutions to pollinator declines (Box 2.1).

Agriculture is a major contributor to climate change, responsible for around $14 \%$ of global greenhouse gas (GHG) emissions in 2000, from sources including fertilizers, livestock, wetland rice cultivation, manure management, burning of savannah and agricultural residues, and ploughing (IPCC 2007). Conversion of forests to agriculture, primarily in developing countries and particularly in tropical Asia, accounts for a comparable share of greenhouse gas emissions (WBCSD et al. 2008 and Werf et al. 2009). 
Other agricultural impacts arise from the introduction of invasive alien species, soil and water pollution due to inefficient use of pesticides and fertilizers, erosion and/or sedimentation of downstream ecosystems including wetlands and even offshore coral reefs (Box 2.2). Overall, about $85 \%$ of agricultural land is considered to be degraded due to erosion, salinisation, soil compression, nutrient depletion, biological degradation, or pollution, while each year 12 million hectares are lost to desertification (WBCSD et al. 2008).

\section{Box 2.1 Operation pollinator: Investing in natural capital for agriculture}

Syngenta, a leading company in the agriculture sector, is developing a conservation program that may enhance farm productivity by reversing the decline of an ecosystem service critical to agriculture - pollination. From field vegetables in Italy, to melons in France, to blueberries in the United States, the importance of insect pollination is unequivocal.

In 2009, Syngenta launched Operation Pollinator, an initiative which currently involves $13 \mathrm{EU}$ countries and the USA that aims to restore native pollinators in agricultural landscapes by creating suitable habitats on or near farm- land. Establishing and managing floral plant margins around crops increases plant diversity and native pollinator populations, delivering significant environmental benefits with the potential to increase farm profits.
Blueberry Production in Michigan

- In 2006 there were 575 blueberry

farms across the state, with

18,500 acres under production

- The average yield of blueberries in 2009 was 5,350 pounds/acre

- In 2007-2008 fresh blueberries retailed above $\$ 2.00$ /pound (USD) although prices have since dropped to below $\$ 1.30 /$ pound (USD)

- Managed bees cost Michigan blueberry growers about $\$ 80 /$ acre/year (based on 2 hives/acre)

The potential benefits of Operation Pollinator are clearly apparent in the State of Michigan, home to the USA's largest blueberry industry. The economic value of pollinators in Michigan is substantial: the fruit and vegetable sector is worth approximately US $\$ 800$ million annually and includes crops that are highly dependent on pollination to sustain marketable yields. In Michigan, blueberry production has $90 \%$ reliance on bees for pollination, to help ensure high yields in this crop worth an estimated US\$ 124 million annually (USDA NASS 2008). With recent declines in honey bee populations, other crop pollination strategies are needed to protect grower productivity.

Operation Pollinator advises and trains growers interested in converting marginal agricultural land to native pollinator habitat. In coordination with federal conservation programs, growers are assisted to make simple changes in farm operations that are compatible with current practices and existing goals for soil and water conservation. Enhanced native pollinator populations are part of a diversified strategy for maintaining crop yields and improving fruit quality for insect pollination-dependent crops. When managed bees are in short supply or if bee hive rental costs increase, abundant native bee populations can provide supplementary pollination services to farmers.

Syngenta understands that the future of agriculture ultimately depends on protecting the environment and enhancing the livelihoods of growers, through the development of more sustainable agricultural systems. Modern agriculture increasingly recognizes the commercial benefits of farm management that increases the biodiversity of beneficial insect species, while also conserving other natural resources (e.g., soil and water). If this can be done in a way that enhances long-term agricultural productivity, not only Syngenta but also the growers it serves and society as a whole will reap the rewards.

For more information see: www.operationpollinator.com 


\section{Box 2.2 Cotton production and the Aral Sea}

A striking example of how the over-use of water can destroy an entire ecosystem is provided by the desiccation of the Aral Sea, located between Kazakhstan and Uzbekistan in Central Asia (formerly part of the Soviet Union). In 1960 the Aral Sea was the world's fourth largest inland sea, providing a wealth of ecosystem services. Over the period 196090, development of irrigated agriculture around the Aral Sea increased from some 4.5 million ha to just over 7 million ha, while the surface area of the Aral Sea declined from almost $70 \mathrm{~km} 2$ to under $40 \mathrm{~km} 2$. By 2007 the Aral Sea had shrunk to 10 percent of its original size, mainly due to water abstraction from two major tributaries, the Amu Darya and Syr Darya rivers, for irrigated cotton production (Scientific American 2010).

The growth of cotton production led to increased use and runoff of pesticides and fertilizer, resulting in pollution of surface and groundwater. Water abstraction for irrigation reduced the flow of water downstream, drying out lakes and wetlands, while also increasing salinity. As a result, the ecosystems of both the Amu Darya delta in Uzbekistan and the Syr Darya delta in Kazakhstan have suffered substantial damages. From 1960 to 1990, 95\% of the wetlands surrounding the Amu Darya delta disappeared; more than 50 delta lakes, covering 60,000 ha, dried up (FAO 1998). 100,000 ha of Tugai forests, which covered the Amu Darya delta in 1950, were reduced to less than 30,000 ha by 1999 (Severskiy 2005). The Syr Darya delta was also severely affected; its lakes shrank from about $500 \mathrm{~km} 2$ to $40 \mathrm{~km} 2$ from 1960-80 (Micklin 1992).

A 1990 study suggested that the minimum environmental damage due to unsustainable agricultural and irrigation practices in the Aral Sea was at least US\$1.4 billion, based on estimates of the cost of measures to address at least some impacts (Glazovsky 1991). A follow-up study estimated the cost to improve sanitary, hygienic and medical ser- vices in the region, create alternative jobs, and shift the economy onto a more sustainable path, raising the level of re- sponse required to over US\$3.5 billion (Glazovsky 1995). Yet another study focused on the costs of redirecting water from the Volga, Ob and Irtysh Rivers to restore the Aral Sea to its former size, estimated at more than US $\$ 30$ billion (Temirov et al. 2003).

These cost-based studies do not explicitly consider the loss of ecosystem services within the Aral Sea basin. For TEEB, a meta-analytic value function was used to estimate the decline in ecosystem services resulting from the disappearance of 522,500 ha of wetlands over the period 1960-90, suggesting annual losses of about US $\$ 100$ million (Brander 2010). This may be seen as a conservative estimate, as it includes only a portion of the value of ecosystem loss and may not accurately reflect the specific characteristics of the Aral Sea basin. In any case, it should be clear that the ecosystem externalities due to cotton production in the Aral Sea basin are significant. Unsustainable irrigation practices led to water-logging, increased soil salinity and reduced crop yield, with lost crop production alone valued at US $\$ 1.4$ billion per year or about 32\% of the value of potential crop production (Kijne 2005).

The case study illustrates that the manufacture of apparel by the retail clothing industry is connected to a chain of environmental impacts on water resources in the countries where cotton is grown and processed. Almost two-thirds of all cotton produced worldwide is used by the textiles industry for clothing manufacture (Chapagain et al. 2006). Global demand for cotton has increased steadily; in 2008 annual world cotton production reached 26 million tonnes (United States Department of Agriculture 2008). Cotton production and processing is estimated to be responsible for $2.6 \%$ of global water use, accounting for over 250 billion m3 of water per year (Chapagain et al. 2006). In the case of Uzbekistan, over $70 \%$ of cotton production - around 800,000 tonnes per year - is exported, making it the world's second largest exporter (Environmental Justice Foundation 2005). The single largest consumer of Uzbek cotton is the Europe Union, accounting for $29 \%$ of Uzbek cotton exports or about US $\$ 350$ million per year (Environmental Justice Foundation

2005). What is not clear is how this trade would be affected if the environmental impacts of cotton production were included in the price of Uzbek cotton. 


\subsubsection{FORESTRY}

Forest ecosystems are important habitats for many wild plant and animal species, and the forestry industry depends on numerous ecosystem services, including freshwater supply, climate regulation and nutrient cycling.

Sustainable forest management has a large role to play in biodiversity conservation and mitigating climate change. On the latter point, not only do forests and wood products act as carbon sinks, but the main industrial outputs of the forest products industry - timber and pulp — are renewable if managed sustainably. In addition, compared to other common building materials like cement, steel and aluminium, wood-based building materials require less energy for production, have higher thermal efficiency, and can be reused, recycled, or used as biomass for energy.

While forest loss is primarily driven by expanding agriculture, unsustainable commercial logging activities are nevertheless a significant contributor to forest and biodiversity loss around the world (Box 2.3). In South and Southeast Asia and the Pacific, for example, unsustainable commercial wood extraction is thought to account for about $25 \%$ of deforestation (Mardas et al. 2009).

Such activities are often driven by illegal logging, which particularly occurs in parts of Asia, Russia, Central and Eastern Europe and Central Africa. Illegal logging includes various activities; those of particular concern to biodiversity include harvesting without authority in protected areas, harvesting without or in excess of concession permit limits, failing to report harvesting activity, and violating international trade agreements such as the Convention on International Trade of Endangered Species (CITES). Such activities have been estimated to represent $5-10 \%$ of global industrial roundwood production (Seneca Creek Associates 2004).

Both legal and illegal logging activities can also indirectly affect biodiversity through the construction of logging roads (habitat fragmentation), which can facilitate small-scale mining, hunting, illegal logging, fishing and settlement within previously untouched forests.

The forestry industry, especially the pulp and paper sector, is relatively energy intensive. However, wood-based biomass is often used as a fuel that, if sourced from a sustainably managed forest, is carbon neutral or near carbon neutral. Overall, production processes in the forest products industry make a relatively small contribution to climate change, being responsible for about $1.6 \%$ of global CO2 emissions (WBCSD 2007).

\subsubsection{MINING AND QUARRYING}

With the exception of supplies of freshwater for mineral processing, the mining industry is not directly dependent on biodiversity or ecosystem services. However, it has a number of significant direct and indirect impacts on BES which if ignored can create major risks to mining operations.

One of the main direct impacts comes from surface mining, whereby overlying habitats and geological features are removed during the extraction of minerals. Other disturbances to plants and animals during the quarrying process include noise, dust, pollution and removal and storage of waste (tailings).

While the process of quarrying itself is mainly associated with negative impacts, a growing number of companies are beginning to use biodiversity offsets to compensate for residual impacts that cannot be mitigated onsite, while also investing in ecological restoration and rehabilitation on former mine sites. In some cases, such activities can deliver significant biodiversity value (Box 2.4). 


\section{Box 2.3 Construction and deforestation in China}

Forests provide valuable goods and services on which many businesses depend (Salim et al. 1999). However, over the period 1949-1981, China significantly depleted its natural forests in order to meet increasing demand for timber for construction and other uses. A cumulative area of 75 million hectares was harvested, of which 92\% were natural forests (Song et al. 2009). This rapid deforestation resulted in: (1) reduced per-hectare timber stocks, (2) an age structure tilted towards younger forest stands, (3) changed species composition, (4) low rates of regeneration, and (5) low growth and yields of forest plantations (Yin 1998). Furthermore, key ecosystem services such as watershed protection and soil conservation were severely comprised. The prolonged deforestation and degradation of natural forests reached a tipping point and, in 1997, severe droughts caused the lower reaches of the Yellow River to dry up for 267 days, threatening industrial, agricultural and residential water users in the northern plains (Xu et al. 2002). Then, in 1998, major flash flooding occurred in China in almost all major river basins, devastating large areas, causing 248 billion Yuan (approximately $\$ 30$ billion USD in 1998) in damage, a loss of 4150 human lives and the displacement of millions of people (Sun et al. 2002).

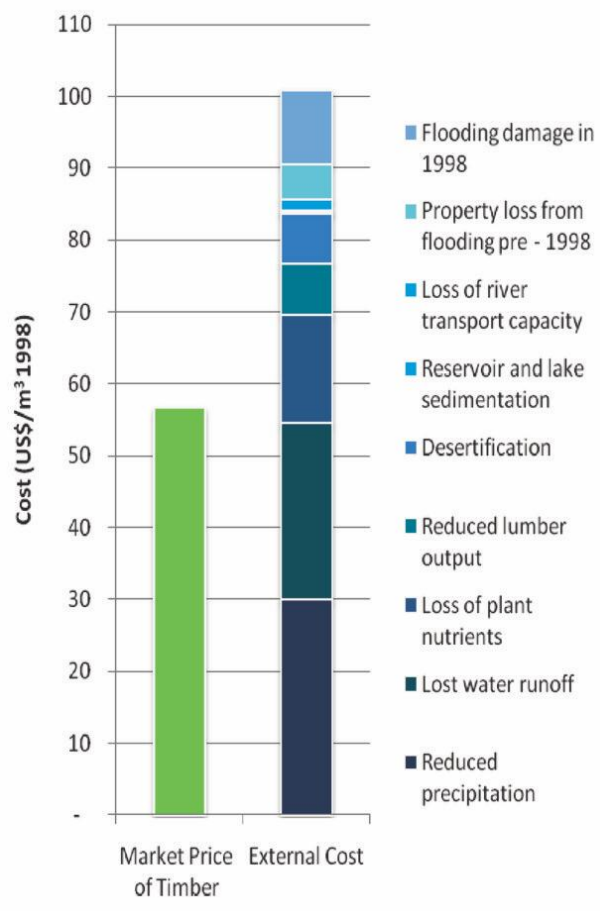

The Chinese government determined that deforestation, which had removed $85 \%$ of the upper river basin's original tree cover, together with farming on steep slopes, were the primary causes of both the drought that affected the Yellow River in 1997 and the flooding in the Yangtze River Basin in 1998 (Earth Policy 2010). Excessive logging in areas around the major river systems had resulted in increased runoff, soil erosion and siltation of water ways (Lang et al. 2002). As a consequence, the Chinese government, in 1998, banned domestic logging in 17 provinces of the country, under the Natural Forest Conservation Program (NFCP). The NFCP was designed to run from 1998 to 2010 and timber harvests from natural forests in China were reduced from 32 million $\mathrm{m}^{3}$ in 1997 to 12 million $\mathrm{m} 3$ by 2003 . The logging restrictions resulted in a significant drop in roundwood production between 1998 and 2003, reflected in 20-30\% higher prices for timber at the Beijing wood market.

In a study by Wang Hongchang (1997), the cost of deforestation in China was estimated by separately examining the various ecosystem services lost, such as climate regulation, provision of timber, food provisioning, water regulation, erosion prevention, flood prevention and nutrient cycling (Wang Hongchang 1997). Based on this study, the value of lost ecosystem services due to logging for the Chinese construction and materials sector was roughly estimated at US $\$ 12.2$ billion annually (McVittie 2010). If we compare the value of these ecosystem service losses to the value of timber for the construction and materials sectors, it seems clear that the impacts of forest degradation are not adequately reflected in market prices (see figure). According to full cost recovery principles, if the external costs of ecosystem degradation due to unsustainable logging and deforestation were incorporated in the price of timber, we would expect to see a significant increase in prices. 
The indirect impacts of mining on biodiversity and ecosystems include pollution and water used during refining and smelting processes. Mining operations can also have significant indirect impacts on biodiversity sensitive areas by developing roads that provide access to areas that were previously underdeveloped and inaccessible, leading to immigration and accelerated conversion of habitat.

\section{Box 2.4 Holcim and the value of wetland restoration}

Aggregate Industries UK, a subsidiary of Holcim, restores ecosystems as part of its quarrying operations. In support of a request to extend an existing quarry in North Yorkshire, the company proposed to create a mix of wetlands for wildlife habitat as well as an artificial lake for recreation, following the extraction of sand and gravel from land currently used for agriculture. Stakeholders were consulted to determine their preferences. Ecosystem valuation was undertaken, using the benefits transfer approach, to assess the types and scale of economic benefits associated with wetland restoration. The study showed that the value of biodiversity benefits that would be generated by the proposed wetlands (GBP£ 1.4 million), the recreational benefits of the lake (GBP£ 350,000) and increased flood storage capacity (GBP£ 224,000) would, after deducting restoration and opportunity costs, deliver net benefits to the local community of about GBP£ 1.1 million, in present value terms. The value of carbon sequestration in these wetlands was found to be relatively small, while the marginal benefits associated with wetland restoration far exceeded the current benefits derived from agricultural production. The study further shows that the costs of ecosystem restoration and aftercare are low, compared to both the economic benefits of wetland restoration and the financial returns from sand and gravel extraction. This example illustrates that compensation for adverse environmental impacts is not only an important means for companies to maintain their license to operate, but can deliver overall improvements in ecosystem services with substantial economic benefits at modest expense.

Source: Olsen and Shannon (2010)

\subsubsection{OIL AND GAS}

The oil and gas sector delivers a range of products to end-users, including fuel, electricity and derivatives of oil-like plastics and lubricants. Like the mining sector, most parts of the oil and gas sector are not directly dependent on biodiversity and ecosystems services except for supplies of freshwater.

In terms of direct biodiversity impacts, the industry can be split between upstream (exploration and production) and downstream (marketing and distribution) activities. The most obvious impacts on biodiversity are from upstream activities (seismic studies, drilling, construction, production, maintenance and transportation). Although significant progress has been made to reduce these impacts, environmental gains have been overwhelmed by increased consumption and demand for energy, and increasing exploration and production in sensitive environments, such as deep water drilling, oil sands and the arctic. The industry also has significant indirect impacts on biodiversity due to the emission of greenhouse gases from upstream and downstream activities, and from the consumption of oil and gas products.

\subsubsection{COSMETICS AND PERSONAL CARE}

The cosmetics sector relies on biodiversity for many natural ingredients. As the variety of species and habitats continue to decline, both the quality and quantity of these natural ingredients may be jeopardized. In its activity report for 2008, Colipa, the European Cosmetics Association, identified respecting the scarcity of natural resources, reducing biodiversity damage and developing resource efficient product life cycles as among the primary challenges for the sector (Colipa 2008). 
According to the Union for Ethical BioTrade, the top 20 cosmetics and personal care companies communicate the most about biodiversity (Union for Ethical BioTrade 2010). This number is likely to increase as a growing number of companies in this sector take steps to integrate the principles and practices of sustainable use in their supply chains.

Brazilian cosmetics company Natura, for example, adopted the sustainable use of biodiversity as the main driver of innovation. Natura developed vegetable renewable alternatives to petrochemical raw materials, reducing the company's carbon footprint, and created an entire product line (Ekos) based on the sustainable use of biodiversity. Ekos has since grown to account for a substantial share of company sales (Natura 2008). Another company, L'Oréal, has developed approaches aimed at ensuring sustainable sourcing practices for plantbased ingredients (L'Oréal 2008).

A renewed focus on natural ingredients is apparent throughout the food and cosmetics sectors. Consumer concerns about health and adoption of more 'wholesome' lifestyles are important market drivers, as affluent consumers are keen to buy products that enhance (or are perceived to enhance) their well-being.

\subsubsection{WATER SUPPLY AND SANITATION}

The water sector is highly dependent on ecosystems for sustainable and cost-effective operations. The quantity and quality of water depends on functioning aquatic ecosystems, including lakes, rivers, streams and wetlands, as well as local bio-physical processes and land-use practices (Box 2.5). Ecosystem services important to water utilities include:

- Protection of water quality and quantity through the water cycle and hydrological processes throughout a catchment area

- Riparian vegetation filtering water, removing impurities and reducing erosion

- Catchment rehabilitation processes following natural events such as flood and fire

- Flood protection

- Assimilative capacity of large waterways and the ocean for waste water discharge and treatment

- Microbiological purification of wastewater

- Other ecosystem services associated with intact watershed catchments (e.g., carbon sequestration, pollination, bio-banking and biodiversity offset value, recreational and cultural values) 


\section{Box 2.5 How water utilities depend on watershed services}

\section{Murray Darling River Basin, Australia}

The Murray Darling River Basin in Australia comprises just $6 \%$ of the total surface water runoff in Australia but the basin supports $75 \%$ of the nation's irrigated agriculture, valued at almost US\$ 9 billion per year. Prior to a cap on water diversions introduced in 1995, the growth in irrigation development had led to severe over-allocation of the water resource, resulting in degradation of river and wetland ecosystems and reduced security of supply for rural and urban water users. The over-use of water has been exacerbated by shortages due to droughts and climate change. In response, the Commonwealth government invested over US\$11 billion in programmes designed to improve the efficiency of irrigation systems and to purchase water entitlements from irrigators. In New South Wales, for example, the State and Commonwealth governments provided US $\$ 95$ million in structural adjustment payments to irrigators, as part of a programme to reduce water allocations in ground water systems to more sustainable levels (Sutherland 2007).

\section{Melbourne, Australia}

The City of Melbourne draws a significant proportion of its water supply from watersheds where the forests are protected. These provide natural filtration of water flowing through the catchments. If these watersheds were logged or if the land was converted to agricultural or urban development, Melbourne would need to build a new water treatment plant at a cost of about US\$ 1 billion, with additional operating costs running into hundreds of millions of dollars each year (Young 2003).

\section{British Columbia, Canada}

For BC Hydro, one of the largest electricity companies in Canada, water-use planning provided a means to balance competing uses of water, such as domestic supply, fish and wildlife, recreation, heritage and electrical power needs (BC hydro 2010).

\subsubsection{FISHERIES}

Coral reefs in the Caribbean have shrunk by about $80 \%$ over the past three decades. As a direct result, revenues from dive tourism (which account for almost $20 \%$ of total tourism receipts) have declined and are predicted to fall by up to US $\$ 300$ million per year, or more than twice as much as losses in the fisheries sector (TEEB 2008).

Unilever, an international manufacturer of food, home care and personal care products, confronted a problem as the user of a wild biological resource vulnerable to over-harvesting - namely fish. Cod was the main fish species used in the company's premium frozen food products. In the 1990s, cod stocks declined precipitously and collapsed altogether in the western North Atlantic, due to mismanagement and overexploitation. As a result, cod prices have increased substantially since the early 1990s and by over 50\% between 1996 and 2000. These dramatic price increases reduced the profit margins on Unilever's cod-related products by about $30 \%$ (ISIS 2004).

\subsubsection{TOURISM}

The global tourism industry generated about US $\$ 5.7$ trillion of value added in 2010 (over $9 \%$ of global GDP) and employs around 235 million people directly or indirectly (WTTC 2010). Many tourism businesses are fully or partially dependent on biodiversity and ecosystem services, whether relating to eco-tourism, beach holidays, 
skiing, visiting national parks etc. Whale watching alone was estimated to generate US $\$ 2.1$ billion per year in 2008, with over 13 million people undertaking the activity in 119 countries (IFAW 2009).

On the other hand, tourism developments and associated activities can also result in considerable damage to biodiversity and ecosystems through land conversion, water use, sewage and solid waste. In addition, tourism businesses that depend on ecosystem services are susceptible to external impacts on biodiversity. The situation is particularly acute for tourism businesses that depend on coral reefs, due to the threat posed by climate change (Wilkinson 2008).

One pioneering eco-resort company, Chumbe Island Coral Park Ltd, has identified both the opportunities and risks associated with dependence on fragile coral reefs. The company has invested over US $\$ 1.2$ million to establish a marine park in order to protect the coral reefs surrounding Chumbe Island, just off Zanzibar in Tan- zania. The company manages the park with 11 park staff and restricts guest numbers to a maximum of 16 at a time. The business currently generates over US $\$ 500,000$ per year in revenues and employs 43 staff, all but two of whom are locals (Sibylle Riedmiller, pers com, 2010). In a similar vein, public-private partnerships are in creasingly being developed between tourism companies, governments and NGOs to protect ecosystems in order to support businesses and livelihoods.

\subsubsection{TRANSPORT}

Transport within business comprises specialist transport and logistics companies as well as distribution, logistics and transport departments within larger companies. Covering air, road, rail and sea transport, this sector is characterized more by its impacts on biodiversity than by its dependence on ecosystem services. Typical risks to biodiversity relate to transport infrastructure (e.g. land take and pollution associated with developing and operating roads, ports and depots), incidents such as ship groundings on corals and oil spills, and operational externalities such as emissions of carbon, NOx, SOx and particulates.

Recent work by ERM and EcoConsult, relating to relocating and expanding port, ferry and container terminals in Jordan, identified potential compensation activities for impacts on coral reefs, amounting potentially to millions of US\$, depending on the size of impact. Proposals were also developed to transplant coral and create artificial reefs to offset part of the damages.

Oil spills and ship groundings on reefs can lead to multi-million dollar compensation and remediation claims (IOPC Fund 2009 and Spurgeon 2006). With regard to day-to-day operational impacts, the impacts of road transport on air pollution are under increasing scrutiny, as reflected for instance in the proposed EU Eurovignette Directive targeting Heavy Goods Vehicle emissions (Grangeon et al. 2009).

\subsubsection{MANUFACTURING}

The impacts of manufacturing industry on biodiversity are both direct and indirect, reflecting the footprint of facilities and the pollution arising from production processes, as well as the impacts of suppliers of raw materials or semifinished goods. These linkages are often complex and sector specific, as illustrated by the 'biodiversity map' developed by Ricoh, a Japanese office equipment manufacturer (Figure 2.5).

Figure 2.5 also highlights some of the difficulties of attempting to measure the links between manufacturing, biodiversity and ecosystem services. In the case of Ricoh the main impacts on BES arise through the procurement of raw materials (e.g., paper pulp and metals) as well as in the manufacturing process itself (particularly with regard to water resources). 


\section{Figure 2.5 Ricoh's map of corporate activities and biodiversity}

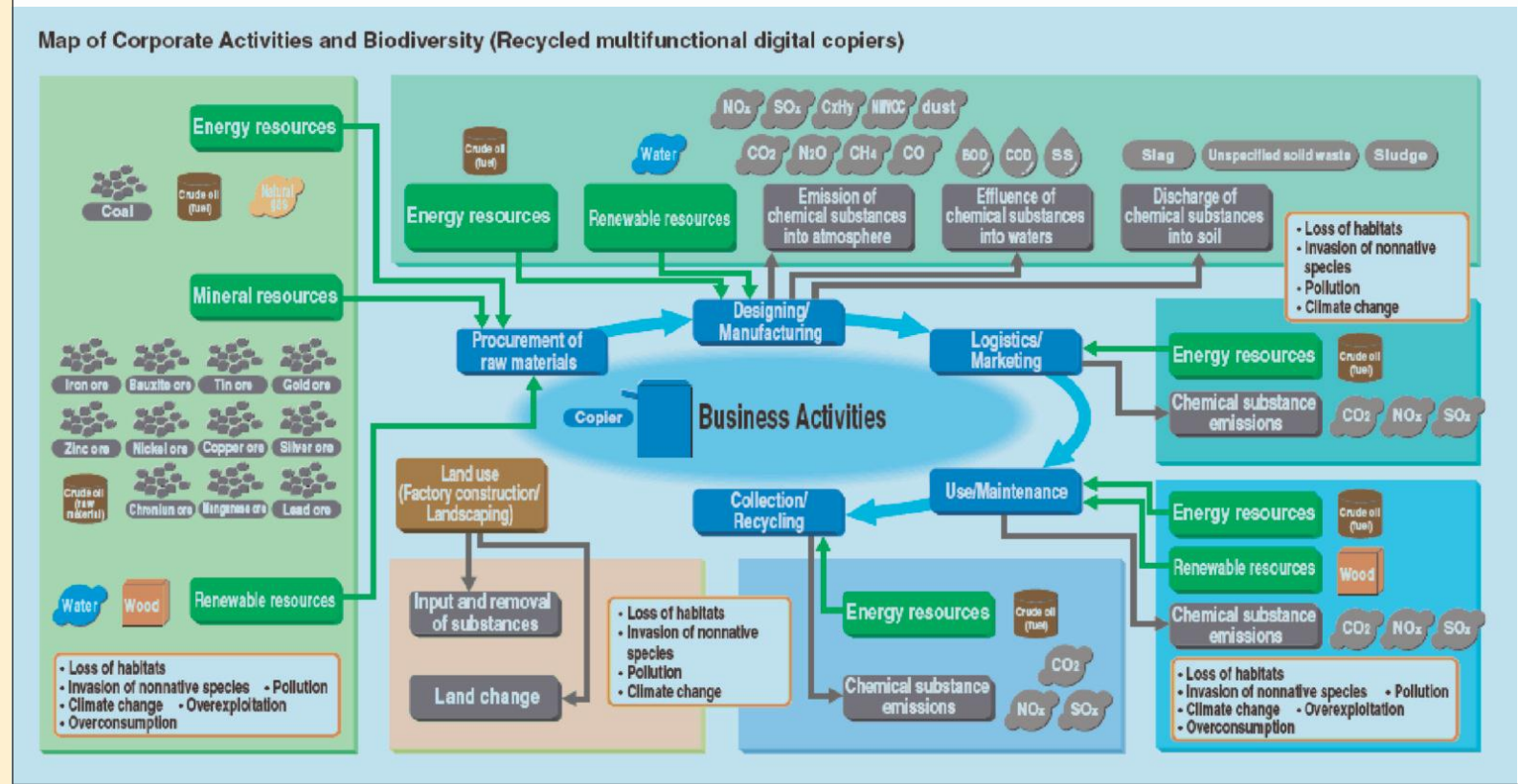

Source: Ricoh 2009

\subsubsection{FINANCE}

The impacts of the financial services industry on biodiversity are indirect but nevertheless can be very significant. While financial institutions are not directly dependent on ecosystem services, they are exposed to BES risks through the loans, investments and insurance cover they provide to companies and projects.

The banking sector uses at least four strategies to manage biodiversity risks: 1) 'red-lining' investments in areas of high biodiversity; 2) developing sector guidelines for environmentally sensitive sectors; 3) refraining from financing sectors in which a bank lacks specialist knowledge; and 4) working together with borrowers to improve their environmental performance and mitigate harm through an engagement policy (Coulson 2009).

A recent review of 50 large banks revealed that $32 \%$ of them have developed sector specific guidelines for clients and projects in the forestry sector (Mulder et al. forthcoming). For example, JPMorgan Chase sets deadlines for verifying the legal origin of wood sourced by clients from countries with a reputation for illegal logging (FSC 2005). Similarly, HSBC has developed guidelines for its project finance activities in the freshwater infrastructure sector (HSBC 2005). These limit HSBC investments in projects located in, or impacting on, critical natural habitats, sites inscribed on the Ramsar list of internationally important wetlands, UNESCO World Heritage Sites, and dam projects that do not conform to the framework of the World Commission on Dams. 


\section{BIODIVERSITY AND ECOSYSTEM RISKS AND OPPORTUNITIES FOR BUSINESS}

As outlined above, companies face several risks related to biodiversity and ecosystem services (WRI et al. 2008). These may be summarized as:

- Operational

- Regulatory

- Reputational

- Market or product

- Financial

At the same time, it is clear that biodiversity and ecosystem services present new business opportunities, such as:

- New technologies and products - that will serve as substitutes, reduce degradation, restore ecosystems or increase the efficiency of ecosystem service use

- New markets - such as water-quality trading, certified sustainable products, wetland banking and threatened species banking

- New businesses - such as ecosystem restoration and environmental asset finance or brokerage

- New revenue streams - for assets currently unrealised, such as wetlands and forests, but for which new markets or payments for ecosystem services could emerge.

These are discussed in general terms below, with examples from several companies. Further detail on the tools and approaches available for business to reduce their BES risks and seize BES opportunities is provided in chapters 4 and 5 , respectively.

\subsubsection{OPERATIONAL}

- Risks - Increased scarcity and cost of raw materials such as freshwater, disruptions to business operations caused by natural hazards and higher insurance costs for disasters such as flooding

- Opportunities - Benefits from increasing water-use efficiency or building an on-site wetland to eliminate the need for new water treatment infrastructure

In 2001, Anheuser-Busch, the world's largest brewer of beer, experienced unexpected water shortages that affected its supply chain. A temporary drought in the US Pacific Northwest increased the price and reduced the availability of key inputs to Anheuser-Busch's brewery operations: namely barley and aluminium. This example highlights the need for business to take a comprehensive view of its dependence on ecosystem services (Global Environmental Management Initiative 2002a).

Wetlands are known for their ability to clean water, absorb waste and breakdown some pollutants. DuPont built a wetland to treat waste water from a plant in Victoria, Texas, after local residents started expressing concerns about the deep well injection process the company had previously been using. After recovering over 250,000 pounds of material formerly lost to wastewater streams each day, the wastewater is treated in an on-site biological facility before being released to the constructed wetlands for further natural 'polishing' prior to its eventual return to the Guadalupe River. Over 2.4 million gallons of recovered water are returned to the Guadalupe River each day (Global Environmental Management Initiative 2002b). 


\subsubsection{REGULATORY AND LEGAL}

- Risk - emergence of new fines, new user fees, government regulations, or lawsuits by communities or groups that challenge business activities

- Opportunity - engaging governments to develop policies and incentives to protect or restore ecosystems that provide services a company needs

In 2004, the UK government denied Associated British Ports planning permission for a port expansion at Dibden, due to its potential encroachment on nearby coastal ecosystems that were valued for their biodiversity and associated cultural services. As a result, Associated British Ports had to write off GB£ 45 million that it had already spent on the proposal and the company's share price dropped by $12 \%$ in the week immediately following the permit denial (ISIS 2004).

The International Maritime Organization issued regulations that took effect in 2009 in order to prevent the transport of invasive alien species via ship ballast water. Aquatic species transported from one ecosystem to another by ship can have devastating effects on marine life and on local economies. To help ship owners meet the new requirements, Alfa Laval developed and launched PureBallast, a first-to-market ballast water treatment system that removes unwanted marine organisms without additives or chemicals (Alfa Laval 2010).

\subsubsection{REPUTATIONAL}

- Risk - damage to corporate reputation from media and non-governmental organization (NGO) campaigns, hareholder resolutions and changing customer preferences

- Opportunity - Benefits from implementing and communicating sustainable purchasing, operating, or investment practices in order to differentiate corporate brands

In 1995, the Canadian aluminium manufacturer Alcan sought to divert a river to generate hydropower for one of its smelters. However, local indigenous communities objected since the river was a source of freshwater, fish and cultural services for them. In the end Alcan was unable to receive consent and ultimately abandoned the project, losing US\$500 million in upfront investment (Esty et al. 2006).

GDF Suez aims to improve relations with stakeholders by partnering with France's National Museum of Natural History to create hundreds of kilometres of grassland corridors above and around their natural gas pipelines. These corridors in the lle-de-France region increase the ascetic value of lands through which the pipelines pass, and decrease operational disruption to surrounding ecosystems (WBCSD et al. 2002).

According to Steve Hounsell, Environmental Advisor of Ontario Power Generation, an electric utility, biodiversity programmes are typically very low cost relative to the benefits gained in corporate image: "Groups that would be normally critical of OPG (and our fossil emissions) are very much 'on-side" and supportive of this programme. They have become our allies. This helps to earn a 'community license to operate' and although it is difficult to monetise, the loss of community support can, conversely, spell the demise of operations" (WBCSD 2008).

\subsubsection{MARKET AND PRODUCT}

- Risk - customers switching to other suppliers that offer products with lower ecosystem impacts or governments implementing new sustainable procurement policies 
- Opportunity - launching new products and services that reduce customer impacts on ecosystems, participating in emerging markets for carbon sequestration and watershed protection, capturing new revenue streams from company-owned natural assets, and offering eco-labelled wood, seafood, produce and other products

Wal-Mart, the world's largest retailer, is working with the Global Aquaculture Alliance (GAA) and the Aquaculture Certification Council (ACC) to certify, by 2011, that all its foreign shrimp suppliers adhere to US standards of Best Aquaculture Practices (Wal-Mart 2010). In addition, Wal-Mart has set itself the goal that by 2011 the company will purchase only wild-caught fresh and frozen fish for the U.S. from Marine Stewardship Council (MSC)-certified fisheries.

\subsubsection{FINANCING}

- Risk - Higher costs of capital or difficulties acquiring debt or equity as banks and investors adopt more rigorous lending and investment policies.

- Opportunity - more favourable financing terms or improved access to capital for companies supplying products and services that improve resource efficiency or restore degraded ecosystems.

Rabobank has developed a policy that will enable the bank to exclude certain undesired operational practices in the palm oil supply chain. The policy includes binding conditions on the bank and its clients that should help promote more sustainable operations (Rabobank).

Goldman Sachs has established and funded a Center for Environmental Markets to undertake independent research with partners in the academic community and non-governmental organizations (NGOs) to explore and develop public policy options for establishing effective markets around climate change, biodiversity conservation and ecosystem services (Goldman Sachs 2008). 


\section{CONCLUSION}

There is mounting evidence of global biodiversity decline and pressures on biodiversity are increasing. Most regulating ecosystem services are under pleasure and many ecosystems have experienced severe degradation over the past 50 years.

Projections of the status of biodiversity and ecosystems by 2050 suggest that the world is likely to continue to lose biodiversity and many ecosystem services if we maintain our current development path, consumption patterns and levels of resource use.

Because all businesses depend on biodiversity and ecosystem services, either directly or indirectly, their continued decline creates real business risks. As a consequence, business should systematically review their BES dependence, covering direct operations and those of suppliers and customers. Business should also assess their impacts on nature, direct and indirect, positive or negative.

Business can make use of integrated environmental management and assessment tools to better understand their dependence and impacts on biodiversity and ecosystems, and to design appropriate mitigation and management responses. Biodiversity and ecosystem values can and should be integrated more fully into corporate decision making at all levels.

BES impacts and dependence can affect the competitive position and performance of a company. In addition, public perception of business impacts on nature may influence consumer trends, corporate reputation and/or the ability to maintain the legal or social license to operate.

Many of the drivers of biodiversity loss and ecosystem decline pose challenges for business. For example, fresh water scarcity, habitat loss and degradation, climate change, pollution, over-exploitation and the spread of invasive alien species can all compromise business operations and investments. Measures to reduce the direct drivers of BES decline should continue and may be supported by business. This includes developing appropriate corporate strategy, policy and operational responses, guided by the hierarchy of avoiding, minimizing, mitigating and (where feasible) offsetting negative impacts.

It is also clear that BES loss cannot be tackled by business alone, but requires partnerships involving governments, business and civil society. Impacts on BES need to be understood on both a local and global scale. While the legal frameworks in which companies do business are primarily local, the world is increasingly global in its economics and in the spread of information. Meeting growing demand for commodities like food and water while also maintaining and restoring BES is likely to involve changes in public policies and regulations, as well as business practices. There is a need for better technology and business can play a key role as a solutions provider.

Halting biodiversity loss and ecosystem degradation, however, also presents new business opportunities. For example, by developing technologies and products that will serve as substitutes, reduce degradation, restore ecosystems or increase the efficiency of natural resource use. Other opportunities include new markets such as water quality trading, certified sustainable products, wetland and species banking or other new revenue streams for assets that are currently unrealized. 


\section{References}

Alfa Laval (2010) URL: http://www.pureballast.alfalaval.com/PureBallast.aspx (last access 28 May 2010)

BC hydro (2010) URL: http://www.bchydro.com/planning_regulatory/water_use_planning.html (last access 28 May 2010

Brander, L. (2010) Personal Communication, Institute for Environmental Studies, VU University Amsterdam.

Butchart, S.H., Walpole, M., Collen, B., van Strien, A., Scharlemann, J.P., Almond, R.E., Baillie, J.E., Bomhard, B., Brown, C., Bruno, J., Carpenter, K.E., Carr, G.M., Chanson, J., Chenery, A.M., Csirke, J., Davidson, N.C., Dentener, F., Foster, M., Galli, A., Galloway, J.N., Genovesi, P., Gregory, R.D., Hockings, M., Kapos, V., Lamarque, J.F., Leverington, F., Loh, J., McGeoch, M.A., McRae, L., Minasyan, A., Hernández Morcillo, M., Oldfield, T.E., Pauly, D., Quader, S., Revenga, C., Sauer, J.R., Skolnik, B., Spear, D., Stanwell-Smith, D., Stuart, S.N., Symes, A., Tierney, M., Tyrrell, T.D., Vié, J.C., Watson, R. (2010) Global Biodiversity: Indicators of Recent Declines, Science 328 (5982), 1164-8, Epub 2010 Apr 29.

CBD - Secretariat of the Convention on Biological Diversity (2010) Global Biodiversity Outlook 3, Montréal. URL: http://www.cbd.int/ doc/publications/gbo/gbo3-final-en.pdf

Chapagain, A.K., Hoekstra, A.Y., Savenje, H.H.G. and Gautam, R. (2006) The water footprint of cotton consumption: An assessment of the impact of worldwide consumption of cotton products on the water resources in cotton producing countries. Ecological economics, 60 (1). pp. 186-203.

Colipa (2008) Value \& Values: In Today's Cosmetics Industry, Annual Report 2008, the European Cosmetics Association, Brussels. URL: http://www.colipa.eu/downloads/16.html

Coulson, A.B. (2007) How should banks govern the environment? Challenging the construction of action versus veto. Business Strategy and the Environment (March 2009) 18 (3). pp. 149-161

Earth Policy Institute (2002) Illegal Logging Threatens Ecological and Economic Stability. URL: http://www.earth-policy.org/

index.php?/plan_b_updates/2002/update11 (last access May 28, 2010)

Environmental Justice Foundation (2005) White Gold: the true cost of cotton. Environmental Justice Foundation, London, UK.

Esty, D. and Winston, A. (2006) Green to Gold: How smart companies use environmental strategy to innovate, create value, and build competitive advantage. New Haven and London, Yale University Press

FAO - Food and Agriculture Organization (1998) Time to save the Aral Sea? Agriculture and Consumer Protection Department, Paris
FAO - Food and Agriculture Organization (2001) Global forest resources assessment 2000. FAO, Rome. URL: ftp://ftp.fao.org/ docrep/fao/003/y1997E/frA\%202000\%20Main\%20report.pdf

FAO - Food and Agriculture Organization (2007) The world's mangroves 1980-2005. FAO Forestry Paper, Rome. URL: ftp://ftp.fao.org/docrep/fao/010/a1427e/a1427e00.pdf

FSC - Forest Stewardship Council (2005) Leading our world towards responsible forest stewardship: A progress report, Bonn. URL: http://www.fsc.org/fileadmin/web-data/public/document_ center/publications/annual_reports/FSC_GA2005_Brochure_Lo wRes.pdf

Gallai, N., Salles, J.M., Settele, J. and Vaissière, B.E. (2009) Economic valuation of the vulnerability of world agriculture confronted with pollinator decline, Ecological Economics, 68 (3). pp. 810821

Glazovskiy, N.F. (1991) Ideas on an escape from the 'Aral Crisis', Soviet Geography, 22 (2). pp. 73-89 (February 1991)

Global Environmental Management Initiative (2002a) Connecting the drops toward creative water strategies: A water sustainability tool, "Anheuser-Busch Inc.-Exploring water connections along the supply chain", Washington, D.C. URL: http://www.gemi.org/water/anheuser.htm

Global Environmental Management Initiative (2002b) Connecting the drops toward creative water strategies: A water sustainability tool, "DuPont: Managing strategic risk through innovative wastewater treatment", Washington, D.C. URL: http://www.gemi.org/ water/dupont.htm

Goldman Sachs (2008) Environmental Report. URL: http://www2.goldmansachs.com/services/advising/environmental-markets/documents-links/env-report-2008.pdf

Goldman Sachs, Environmental Policy Framework. URL http://www2.goldmansachs.com/services/advising/environmental-markets/documents-links/environmental-policyframework.pdf

Grangeon, D. and Cousin, P. (2009) Toward a greener road pricing system in Europe. European Transport Conference, Netherlands, October 2009

Grigg, A., Cullen, Z., Foxall, J., Crosbie, L., Jamison, L. and Brito, R. (2009) The ecosystem services benchmark, Fauna \& Flora International, United Nations Environment Programme Finance Initiative and Fundação Getulio Vargas FGV. URL: http://www.naturalvalueinitiative.org/content/005/501.php

HSBC (2005) Freshwater infrastructure sector guideline. URL: http://www.hsbc.com/1/PA_1_1_S5/content/assets/csr/freshwat er_infrastructure_guideline.pdf (last access June 15, 2010) 
IFAW (2009) Whale watching report. International Fund for Animal Welfare

IOPC Fund (2009) Annual Report 2008, International oil pollution compensation funds, London

IPCC - Intergovernmental Panel on Climate Change (2007) Fourth assessment report climate change, Synthesis Report, Geneva. URL: http://www.ipcc.ch/publications_and_data/publications ipcc_fourth_assessment_report_synthesis_report.htm

F\&C Asset Management (2004) Is biodiversity a material risk for companies? An assessment of the exposure of FTSE sectors to biodiversity risk, F\&C Asset Management plc, London. URL:

http://www.businessandbiodiversity.org/pdf/FC\%20Biodiversity\%20Report\%20FINAL.pdf.

Kijne, J.W. (2005) Aral sea basin initiative: Towards a strategy for sustainable irrigated agriculture with feasible investment in drainage. Synthesis report. FAO, Rome

L’Oréal (2009) 2008 Sustainable Development Report

Lang, G. (2002) Deforestation, floods, and state reactions in China and Thailand, Working Paper Series, 21, City University of Hong Kong, SEARC

Lovell, S.J. and Stone, S.F. (2005) The economic impacts of aquatic invasive species: A review of the literature, National Center for Environmental Economics, Working Paper Series, no 0502, U.S. EPA, Washington, D.C.

Millennium Ecosystem Assessment (2005a) Ecosystems and human well-being: Biodiversity synthesis. World Resources Insti- tute. Island Press, Washington, D.C. URL: http://www.millenniu-

massessment.org/documents/document.354.aspx.pdf (last access 23 June, 2010)

Millennium Ecosystem Assessment (2005b) Ecosystems and human well-being: Opportunities and challenges for business and industry. Island Press, Washington, D.C. URL: http://www.millen-

niumassessment.org/documents/document.353.aspx.pdf

Millennium Ecosystem Assessment (2005c) Ecosystems and human well-being: Current state and trends - findings of the con- dition and trends working group. (eds) Hassan, R., Scholes, R. and Ash, N. URL: http://www.millenniumassessment.org/ en/Condition.aspx

Millennium Ecosystem Assessment (2005d) Ecosystems and human well-being: Scenarios - findings of the scenarios working group.

URL:

http://www.millenniumassessment.org/en/Scena- rios.aspx

Mardas, N., Mitchell, A., Crosbie, L., Ripley, S., Howard, R., Elia, C. and Trivedi, M. (2009) Global forest footprints, Forest footprint disclosure project, Global Canopy Programme, Oxford. URL: http://forestdisclosure.com/docs/FFD-Global-Fo rest- Footprints-Report.pdf
McVittie, A. (2010) Personal Communication, Land Economy \& Environment Research Group, Scottish Agricultural College

Micklin, P.P. (1992) The Aral crisis: Introduction to the special issue, Post-Sov. Geogr., 33 (5). pp. 269-82

MSC - Marine Stewardship Council (2007) Annual Report 200607, London. URL: http://www.msc.org/documents/msc-brochures/annual-report-archive/MSC_Annual_report_2006-07_EN.pdf Mulder, I. and Koellner, T. (forthcoming) Banks on biodiversity: Assessing how the banking sector accounts for biodiversity risks and opportunities in its business operations.

Natura (2008) Annual Report 2008. URL: http://www2. natura.net/Web/Br/relatorios_anuais/_PDF/AnnualReport2008.pdf

OECD - Organisation for Economic Co-operation and Development (2008) Environmental outlook to 2030. OECD, Paris. URL: http://www.oecd.org/document/20/0,3343,en_2649_34305_39 676628 1_1_137465,00.html

Olsen, N. and Shannon, D. (2010) Valuing the net benefits of ecosystem restoration: the Ripon City Quarry in Yorkshire, Ecosystem Valuation Initiative, Case Study No. 1, WBCSD and IUCN: Geneva and Gland

Peters, J. , Shaw, J., Valero-Gonzalez, J., Arino, G., Bang, J., Reinert, A., Finisdore, J., Wielgus, J., Waage, D., Isaacs, R., Bartell, S., (2010) Operation Pollinator: Investing in natural capital for agriculture, for TEEB

Pettis, J.S. and Delaplane, K.S. (2010) Coordinated responses to honey bee decline in the USA, Apidologie, 41 (3). pp. 256-263 Pimentel, D., Lach, L., Zuniga, R. and Morrison, D. (2000) Environmental and economic costs of non-indigenous species in the United States, Bioscience, 50 (1). pp. 53-56

Rabobank, "Rabobank's position on Palm oil" URL http://www.rabobank.com/content/images/positionpaper_palmoi I_tcm43-107432.pdf (last access June 15, 2010)

Ricoh (2009) Group Sustainability Report (Environment), pg. 70. URL: http://www.ricoh.com/environment/report/pdf2009/all.pdf (last access 4 July 2010)

Salim, E. and Ullsten, O. (1999) Our Forests: Our future - Report of the world commission on forests and sustainable development. Cambridge University Press, Cambridge, UK

Scientific American (2010) URL: http://www.scientificamerican. com/article.cfm?id=reclaiming-the-aral-sea Last accessed May 28, 2010-07-06

Micklin, P. and Aladin, N.V. (2008) Reclaiming the Aral Sea, Scientific American, April 2008. URL: http://www.scientificamerican. com/article.cfm?id=reclaiming-the-aral-sea (last access May 28, 2010) 
Seneca Creek Associates (2004) "Illegal" logging and global wood markets: The competitive impacts on the U.S. wood products industry. URL: http://www.illegal-logging.info/uploads/afandpa.pdf Severskiy, I., Chervanyov, I., Ponamorenko, Y., Novikova, N.M., Miagkov, S.V., et al. (2005) Global International Waters Assessment (GIWA) 24, Aral Sea. Univ. Kalmar, Swed., United Nations Environment Programme

Song, C. and Zhang, Y. (2009) Reforestation and afforestation efforts in China from 1949 to 2006

Spurgeon, J.P.G. (2006) Reefs in an economics context: Time for a "Third Generation" economics based approach to coral management, in Cote, I.M. and Reynolds, J.D. (eds) Coral Reef Conservation, Cambridge University Press

Sun, J., Zhao, C. and Wang, L. (2002) The long march of green: The chronicle of returning agricultural land to forests in China, China Modern Economics Press, Beijing, P. R. China

Sutherland, P.D. (2007) Major water resource challenges - A view across two Southeast States, Proceedings of Ozwater Conference, March 2007, Sydney, Australia

TEEB -The Economics of Ecosystems and Biodiversity (2008) An interim report. European Communities. URL: http://www.teebweb.org/LinkClick.aspx?fileticket=5y_qRGJPOao\%3d\&tabid=10 18\&language $=$ en-US

Temirov, R. (2003) Lobbying grows in Moscow for Siberia-Uzbekistan water scheme, Eurasianet.org

Trevitt, M. (2010) Cotton Production and the Aral Sea, Trucost, for TEEB

Trevitt, M. (2010) Construction and Deforestation in China, Trucost, for TEEB

Union for Ethical BioTrade (2010) Biodiversity Barometer 2010. URL: http://www.countdown2010.net/2010/wp-content/uploads/UEBT_BIODIVERSITY_BAROMETER_web-1.pdf

United States Department of Agriculture (2008) Cotton: Production, supply and distribution, Foreign Agricultural Service

UNPRI, UNEPFI and Trucost (forthcoming) Universal Ownership and Environmental Externalities.

UNWWAP - United Nations World Water Assessment Programme (2003) Water for people, Water for life. URL: http://www.unesco.org/water/wwap/wwdr/wwdr1/

van der Werf, G.R., Morton, D.C., DeFries, R.S., Olivier, J.G.J., Kasibhatla, P.S., Jackson, R.B., Collatz, G.J. and Randerson, J.T. (2009) CO2 emissions from forest loss, Nature Geoscience , 2. pp. $737-738$
Wal-Mart (2010) Global Sustainability Report: 2010 progress update, We save people money so they can live better.

URL:

http://cdn.walmartstores.com/sites/sustainabilityreport/2010/W MT2010GlobalSustainabilityReport.pdf

Wang Hongchang (1997) Deforestation and Desiccation in China: A Preliminary Study, in Mao Yu-shi, Ning Datong, Xia Guang, Wang Hongchang, Vaclav Smil (1997) An assessment of the Economic Losses Resulting from Various Forms of Environmental Degradation in China, Occasional Paper of the Project on Environmental Scarcities, State Capacity, and Civil Violence. Ame- rican Academy of Arts and Sciences, Cambridge, and University of Toronto, URL: http://www.library.utoronto.ca/pcs/state/chi- naeco/forest.htm $<$ http://www.library.utoronto.ca/pcs/state/chi-

naeco/forest.htm> (last access 6 July 2010). Also published in: Smil, Vaclav and Mao Yushi (1998) The Economic Costs of China's Environmental Degradation. American Academy of Arts and Sciences: Cambridge. URL: http://www.amacad.org/publi- cations/china2.aspx\#toc <http://www.amacad.org/publicati- ons/china2.aspx\#toc> (last access 6 July 2010)

WBCSD, IUCN and EarthWatch (2002) Business and biodiversity: Handbook for corporate action, World Business Council for Sustainable Development, Geneva. URL: http://www.wbcsd.org/web /publications/business_biodiversity2002.pdf

WBCSD and IUCN (2008) Agricultural Ecosystems - Facts and trends, World Business Council for Sustainable Development, Geneva. URL: http://cmsdata.iucn.org/downloads/agriculturalecosystems_2.pdf

WBCSD (2007) The sustainable forest products industry, Carbon and climate change: Key messages for policy-makers, World Business Council for Sustainable Development, Geneva. URL: http://www.wbcsd.org/DocRoot/oNvUNPZMuugn75jrL8KS/sfpicarbon-climate.pdf

WBCSD (2008) Gaz de France: Partnering for conservation, World Business Council for Sustainable Development, Geneva URL: http://www.wbcsd.org/DocRoot//1nBxnCYgi4PKwa5j8Tk/ GazdeFrancefullcasefinal.pdf

WBCSD (2009a) Corporate ecosystem valuation: A scoping report, World Business Council for Sustainable Development, Geneva. URL: http://www.wbcsd.org/DocRoot/pdK9r5TpPijC1X Xpx7QR/EcosystemsServices-ScopingReport_280509.pdf

WBCSD (2009b) Corporate ecosystem valuation: Building the business case, World Business Council for Sustainable Development, Geneva. URL: http://www.wbcsd.org/DocRoot/ sTRJLXdoq8SPdrVilYHq/CorporateEcosytemsValuation-BuildingTheBizCase.pdf

WBCSD, WRI, IUCN and EarthWatch (2006) Business and Ecosystems, Issue Brief: Ecosystem challenges and business implications, Geneva. URL: http://www.wbcsd.org/DocRoot/ Ejk5KCJOlkVkRngCksWD/Business\%20and\%20Ecosystems_211106_final.pdf 
Wilkinson, C. (2008) Status of coral reefs of the World: 2008. Global Coral Reef Monitoring Network and Reef and Rainforest Research Centre, Townsville, Australia

WRI, WBCSD and Meridian Institute (2008) The corporate ecosystem services review: Guidelines for identifying business risks and opportunities arising from ecosystem change, World Resources Institute, Washington, D.C. URL: http://pdf.wri.org/corporate_ecosystem_services_review.pdf

WTTC (2010) Travel and tourism economic impact 2010. World Travel and Tourism Council

Xu, J.T. and Cao, Y.Y. (2002) Converting steep cropland to forest and grassland: Efficiency and prospects of sustainability, International Economic Review (Chinese), 2. pp. 56-60.

Yin, R.S. (1998) Forestry and the environment in China: The current situation and strategic choice, World Development, 26 (12). pp. 2153-2167

Young, L. (2003) Putting an economic value on environmental or natural benefits that create commercial wealth is a concept that is gaining momentum. Article in The Source, A Magazine by Melbourne Water, Issue 26, June 2003 


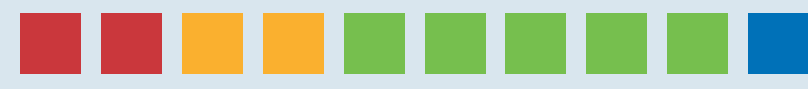 THE ECONOMICS OF ECOSYSTEMS AND BIODIVERSITY \\ TEEB FOR B USINES S}

Chapter 1 Business, biodiversity and ecosystem services

Chapter 2 Business impacts and dependence on biodiversity and ecosystem services

Chapter 3 Measuring and reporting biodiversity and ecosystem impacts and dependence

Chapter 4 Scaling down biodiversity and ecosystem risks to business

Chapter 5 Increasing biodiversity business opportunities

Chapter 6 Business, biodiversity and sustainable development

Chapter 7 A recipe for biodiversity and business growth 


\section{Chapter 3: Measuring and reporting biodiversity and ecosystem impacts and dependence}

TEEB for Business Co-ordinator: Joshua Bishop (International Union for Conservation of Nature)

Editors: Cornis van der Lugt (UNEP), Sean Gilbert (GRI), William Evison (PricewaterhouseCoopers).

Contributing authors: Roger Adams (ACCA), Wim Bartels (KPMG), Michael Curran (ETH Zurich), Jas Ellis (PricewaterhouseCoopers), John Finisdore (WRI), Sean Gilbert (GRI), Stefanie Hellweg (ETH Zurich), Joël Houdet (Oree), Thomas Koellner (Bayreuth University), Tim Ogier (PricewaterhouseCoopers), Jerome Payet (SETEMIP-Environnement), Fulai Sheng (UNEP), James Spurgeon (ERM).

Acknowledgements: Wim Bartels (KPMG), Gerard Bos (Holcim), Sagarika Chatterjee (F\&C Investment), Derek de la Harpe (African Conservation Projects Ltd), Frauke Fischer (Wurzburg University), Juan Gonzalez-Valero (Syngenta), Stefanie Hellweg (ETH Zurich), Kiyoshi Matsuda (Mitsubishi Chemicals), Narina Mnatsakanian (UNPRI), Herman Mulder (GRI), Kurt Ramin (IUCN), Virpi Stucki (Shell).

Disclaimer: The views expressed in this report are purely those of the authors and may not in any circumstances be regarded as stating an official position of the organisations involved.

The final edition of the TEEB for Business report will be published by Earthscan. If you have any additional information or comments you feel should be considered for inclusion in the final report then please email them by 6 th September, 2010 to: teeb4biz@ufz.de

TEEB is hosted by the United Nations Environment Programme and supported by the European Commission; the German Federal Environment Ministry; the UK Government's Department for Environment, Food and Rural Affairs; the UK Department for International Development; Norway's Ministry for Foreign Affairs; The Netherlands' Interministerial Program Biodiversity; and the Swedish International Development Cooperation Agency. 


\section{THE ECONOMICS OF ECOSYSTEMS AND BIODIVERSITY}

Chapter 3

\section{Measuring and reporting biodiversity and ecosystem impacts and dependence}

\section{Contents}

Key messages $\quad 4$

3.1 Introduction $\quad 5$

3.2 Designing BES information management and accounting systems $\quad 6$

3.2.1 Corporate governance and accountability: the point of departure 6

3.2.2 Planning boundaries, scope and materiality 7

3.2.3 Principles to consider in setting objectives and targets 11

3.2.4 Measuring and monitoring performance $\quad 12$

3.2.5 Linking with mainstream environmental accounting systems $\quad 14$

3.3 Incorporating BES in capital investment decisions 16

3.3.1 Barriers to proper valuation of BES in capital investment 18

3.4. Collecting and using information at the product level 23

3.4.1 A brief overview of Life Cycle Assessment 23

3.4.2 Integrating BES in LCA $\quad 25$

3.5. Collecting and using information at the group level 26

$\begin{array}{ll}\text { 3.5.1 Financial accounting standards and BES } & 27\end{array}$

3.5.2 Public reporting 29

3.5.3 Guidance on BES reporting 32

3.5.4 Integrated reporting 33

3.5.5 Barriers to better BES accounting and reporting 33

3.6. Conclusions and recommendations

3.6.1 Technical improvements $\quad 35$

3.6.2 Market improvements $\quad 36$

$\begin{array}{ll}\text { 3.6.3 Disclosure improvements } & 37\end{array}$

$\begin{array}{ll}\text { References } & 40\end{array}$

\section{Boxes}

3.1 Water reporting by SAB Miller

3.2 Discount rates in UK government planning decisions

3.3 Contingent valuation in the Kakadu Conservation Zone

3.4 Carbon reporting by Typico Group

3.5 UK National Forest Company: 2008/09 Annual Report and accounts

3.6 Selected initiatives offering guidance on BES measurement, management and reporting

3.7 Biodiversity reporting by Rio Tinto

3.8 Biodiversity in Scottish Power plc 2004 environmental report

3.9 Biodiversity in Baxter Healthcare 2008 sustainability report

3.10 The Ecosystem Services Benchmark 
Figures

3.1 Visual tool to define a reporting boundary

3.2 Selecting the scope of BES measurement and reporting

3.3 Four phases of LCA according to ISO standards 14040 and 14044

3.4 Assignment of interventions, impact categories and damage categories

3.5 Reporting on biodiversity by the 100 largest companies in 2008

3.6 Reporting by high impact or dependency sectors on biodiversity in 2008

Tables

3.1 Commonly used business valuation techniques and implications for BES 


\section{Key messages}

A commitment to pro-active management of biodiversity and ecosystem services in business starts with corporate governance and more informed decision-making. This implies the integration of BES into business risk and opportunity management, information management and accounting systems. These systems need to support analysis and decision-making at multiple levels, including site/project level, group level, and product level. BES information is needed for both internal and external reporting. It is important to measure and report on internal processes, but these alone are not sufficient to inform decisions by internal managers or other stakeholders regarding actions and likely consequences.

Businesses can frame BES targets based on principles that define limits such as 'no-go' areas, use a precautionary approach, and work towards Net Positive Impact. Business efforts around BES have typically started by identifying what to avoid (e.g., certain activities, technologies or locations). Recently, this has been complemented by emerging concepts and supporting methodologies that define positive aspirations in terms of net impact. Both approaches are valid, given that focusing on 'net' impacts alone may fail to recognize the unique significance of certain natural assets.

There are major barriers to BES measurement and gaps in reporting by business. The economic costs of BES loss are an externality for most companies, which means that they are often not perceived as financially material. For those companies that do report on BES, most treat it in a superficial manner. This is the case even in high impact industries and is partly due to limits in guidance available to business on BES reporting, including techniques to translate physical metrics into monetary ones, and partly a consequence of the low priority assigned to BES by reporting organizations.

Measurement of BES in business must expand with support by technical advances. More baseline information on BES is required to support companies in measuring and comparing their own performance. Life cycle assessment (LCA) techniques need to be expanded and refined to enable companies to assess BES along product life cycles and value chains. Environmental management and accounting systems need to capture BES service dependencies and impacts more consistently. Methodological challenges also exist in how information on BES values are incorporated into business planning and decision-making systems, rooting it in existing systems rather than adding new parallel systems.

Increased capacity to value BES, together with increased use and continued evolution of existing guidance, will help to improve business accounting and reporting. Improving the ability of companies to value $B E S$ through the adaptation of economic valuation tools and changes in the regulatory environment will help establish BES as a more material issue for business accounting and reporting. Existing guidance can be better applied through voluntary efforts and by ensuring that existing management standards provide better support and clarification on BES. A key step is for securities and exchange regulators to provide formal interpretations that can serve as the basis for assessing the materiality of BES with respect to company filings. Further innovation by BES experts in collaboration with the accounting field can help drive standardization, particularly in the area of ecosystem service valuations. 
As discussed in the preceding chapter, businesses of all types impact or depend to some degree on biodiversity and ecosystems (BES) and consequently face a range of risks but also opportunities. Good business planning requires adequate internal systems to monitor and measure BES to support decision-making.

The challenge is to establish reliable information management and accounting systems that can provide relevant information on BES to support operational decisions (e.g., the choice of production technology), to inform financial valuations or project assessments (e.g., capital investment), and for internal and external reporting. The information needs within a company can be diverse and wide-ranging since BES data must be used for activities and decisions at multiple levels: site- or project-level decisions, product decisions, and group- or corporate decisions. Among the reasons that businesses may use BES indicators include:

- understanding the impacts and dependencies of different business models on BES;

- tracking key performance indicators that relate to strategic business goals and enable effective risk and opportunity management; and

- communicating BES related performance and challenges to internal and external stakeholders.

The practice of environmental performance measurement in business is well-established, but does not address BES as systematically as more 'traditional' areas of environmental management. Within the environmental information and performance tracking systems adopted by many companies, BES represents a special challenge. Business impacts and dependence on BES are typically more difficult to measure than standard environmental performance indicators, which focus on direct business inputs (e.g., water, energy or materials) and outputs (e.g., pollutant emissions and solid waste).

Effective management of BES requires measurement of business impacts on various components of biodiversity (i.e., genes, species, ecosystems), as well as business dependence on intangible biological processes (e.g., natural pest and disease control, nutrient cycles, decomposition, etc). In addition, BES assessment requires attention to wider ecological linkages and thresholds, which may lie beyond the boundaries of corporate control. However, existing approaches and tools for environmental measurement and reporting can provide a basis for BES measurement, management and reporting, as well as a foundation for further development of the field.

This chapter looks at the measurement of and reporting on BES impacts and dependencies in business. The chapter first explores the core parameters and goals of BES information systems and then discusses the use of such information in business. The chapter concludes with recommendations to improve measurement, valuation and reporting of BES in business. 


\section{DESIGNING BES INFORMATION MANAGEMENT AND ACCOUNTING SYSTEMS}

This section sets BES accounting in the context of corporate governance and business information systems. It also examines potential BES goals and metrics, in general terms.

Designs for stand-alone BES information management and accounting systems, or the integration of BES into existing business information systems, can follow a Plan-Do-Check-Act (PDCA) approach that involves an initial assessment stage to define boundaries and materiality, followed by setting objectives and targets, measuring progress on the basis of clear indicators, and backing this up with environmental management and communications systems. The following sections go through these steps, considering what guidance and examples are available at each stage. While much of this involves non-financial data, section 3.3 will address the role of financial valuation of BES in capital investment decisions.

\subsubsection{CORPORATE GOVERNANCE AND ACCOUNTABILITY: THE POINT OF DEPARTURE}

The commitment to address BES systematically starts at the level of corporate governance, the system by which any organisation's decisions are made and implemented. Corporate governance is considered here as something that encompasses corporate sustainability and responsibility, going beyond a narrow focus on shareholder value and voting. This implies the consideration of BES impacts and dependencies in relation to overall corporate strategy, together with procedures for their measurement, management and reporting. Biodiversity and ecosystem information systems thus need to be linked to overall business information management, as well as fitting into wider environmental management (see section 3.2.4).

Much the effort involved in measuring BES relates to tracking non-financial information that may be important for the company and its stakeholders. This can also provide a basis for integrating BES into financial valuations. While there are few examples of companies that have published a financial valuation of BES risks and opportunities, many companies have identified ecological systems that merit attention as part of their corporate strategy.

Of course, for some companies, the impacts of BES will be visible, measurable in financial terms and thus considered material. For example, litigation arising from an oil spill and the associated compensation claims for ecological damage may become a significant concern for investors. BES concerns may also influence private investment decisions. For example, Associated British Ports (ABP), Britain's largest port operator, suffered a decline of $10 \%$ in its stock market value after the UK government blocked the company's plans for a container terminal at a site in southern England, in April 2004. The plans were rejected in major part due to opposition from environmental campaigners, who claimed that the terminal would threaten important wildlife populations (UK Environment Agency, 2004).

Even when there is no measurable short-term financial impact, good corporate governance encourages a longterm perspective and consideration of stakeholder relations. For example, The King III Code of Conduct, issued in the Republic of South Africa, states that:

"Governance, strategy and sustainability have become inseparable... It is expected that the company will be directed to be and be seen to be a decent citizen. This involves social, environmental and economic issues - the triple bottom line" (King, 2009). 
In its guidance on Social Responsibility, the new ISO 26000 standard recognises the basic principle "that an organization should respect and consider the interests of its stakeholders". The four core environmental issues addressed in the new standard include "protection of the environment and restoration of natural habitats", with further guidance highlighting the importance of valuing and protecting BES (ISO/TMB WG SR IDTF_N101, draft July 2009).

Business measurement of its impacts and dependence on biodiversity and ecosystems can serve both private and public interests. For example, efforts by business to collect BES data can serve purposes beyond the boundaries of the firm, such as complementing national inventories and state of the environment reports.

\subsubsection{PLANNING BOUNDARIES, SCOPE AND MATERIALITY}

In order to track performance in relation to BES, a company must first define whose performance will be measured (the analytical boundary) and what aspects to include (scope and materiality). Company managers may need to consult and agree with experts from other disciplines, such conservation agencies, on what to measure and over what time period.

A company must also determine from which entities to gather data on BES (e.g., should they consider the impacts of actions by suppliers, subsidiaries, employees or customers?). In the early years of environmental reporting, most organisations measured their impacts by gathering data only from entities over which they had legal ownership and direct control, as required in financial reporting. However, as noted elsewhere in this report, significant aspects of an organisation's BES impacts and dependencies may fall outside legal or financial boundaries.

\section{Figure 3.1 Visual tool to define a reporting boundary}

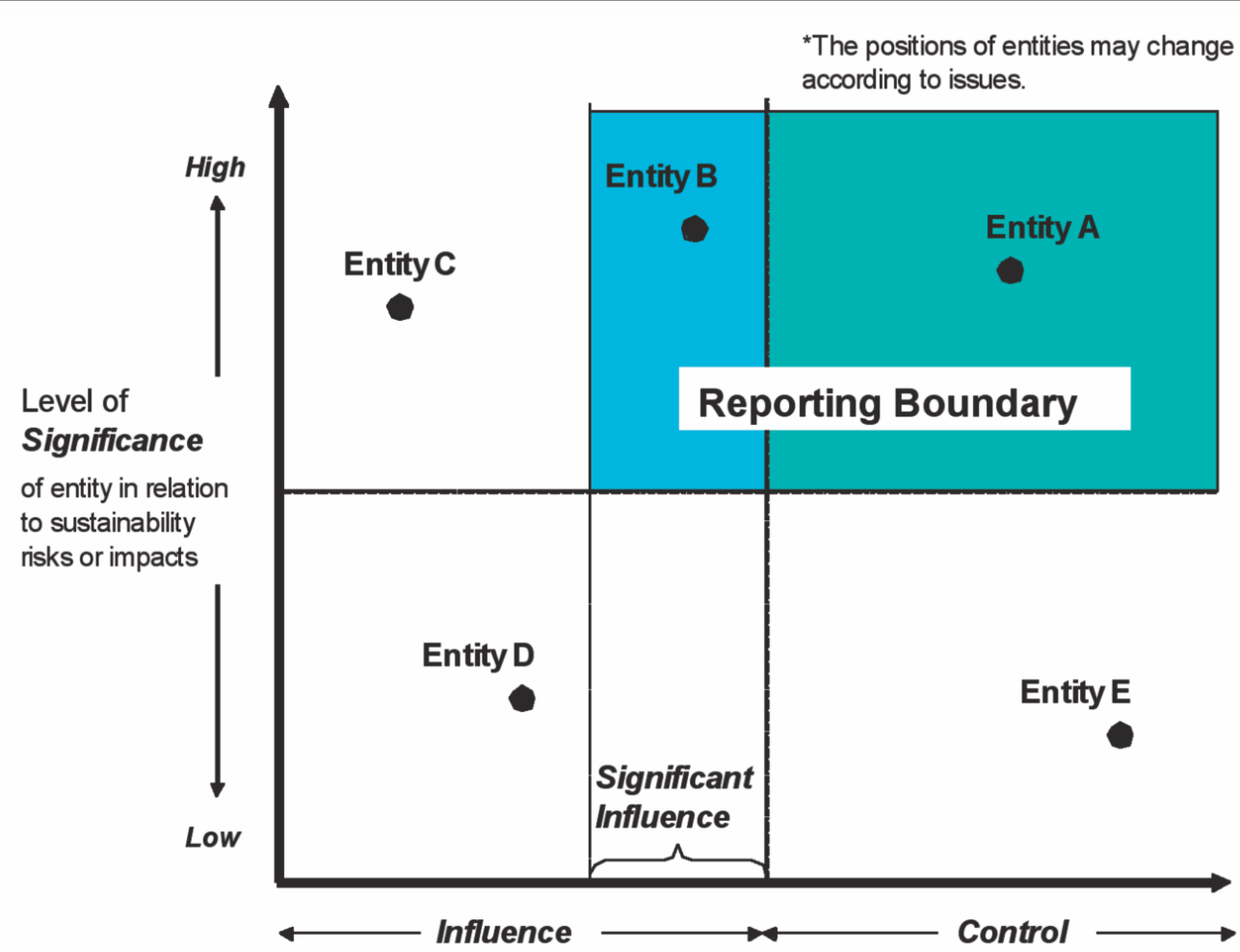

Degree of Control or Influence by the reporting organisation over an entity in its value chain 
The boundary for BES measurement and reporting can be defined in terms of the intersection of 'significance' and 'control' or 'influence'. In short, BES measurement should focus on the performance of entities that generate significant risks or impacts and over which the reporting organisation has control and/or significant influence. Figure 3.1 illustrates these two dimensions in terms of reporting boundaries and the priority entities for monitoring. Business entities in the top right quadrant (i.e. high risk/impact and high level of control) are priorities for BES measurement. Typical examples of significant control or influence include a business subsidiary, where the reporting organisation has operational responsibility for a joint venture (regardless of the actual equity ownership), or a buying relationship where the company accounts for a substantial portion of total sales by the supplier.

While the definition of 'control and influence' may be clear, in terms of legal and financial accounting rules, the determination of 'significant impact' may involve more qualitative considerations such as stakeholder perceptions of impacts, alongside scientific analysis of cause and effect relations. Assessment of the significance of impacts on $\mathrm{BES}$ requires close collaboration with experts in land, water, biological and physical resources.

Considerable research has been conducted on the direct and indirect drivers and pressures on BES, as well as the status and trends in BES. The challenge addressed in this report is to define cause and effect relations in terms of business operations. Scientists and managers working in the field of life cycle assessment, using the products of a business as the point of reference (see below), as well as site-level managers looking at their direct and indirect operational impacts, are at the core of this link. Other points of reference include industrial processes, the production site, business unit, corporate group, supply chain and external value chain. Each of these points of reference has different implications for measurement, the selection of indicators, scope and aggregation of information.

Many companies today set narrow measurement and reporting boundaries that do not reflect key BES issues and entities. Reviews of extractive industry and the food, beverage and tobacco sectors have identified weaknesses in biodiversity targets set by many companies (ISIS Asset Management, 2004; Grigg et al. 2009, Foxall et al. 2005). In the food, beverage and tobacco sectors, for example, corporate biodiversity targets generally focused on direct operational impacts rather than indirect impacts within the supply chain.

Companies that manage large areas of land or sea, such as forestry, mining or oil and gas, often find that their own operations represent the most significant portion of their impacts on biodiversity. On the other hand, companies that do not manage land may find that good BES measurement and management requires more extended boundaries. For example, food processors are dependent on the health and productivity of the land of farmers upstream in their supply chains. This highlights again the balance between direct control and influence on the one hand, and level of significance of an issue or entity on the other. Determining the latter can be aided through expert assessment and systematic stakeholder engagement, as set out by the AA1000 standard. Advice on setting reporting boundaries can also be found in the Boundaries Protocol of the Global reporting initiative (GRI) Guidelines.

\section{Defining operational stages, entities and timing}

The concepts of influence, impact and stakeholder interest are reasonable starting points for BES measurement and reporting in business. However, applying these concepts across a large organization can be complex. Such organizations may have multiple points of contact with a range of different ecosystems. For a business with just one major product, service, or market, the scope of analysis of their dependence and impacts on BES could be the entire company. For a business with multiple products and services, or active in several markets, the relevant scope may be a particular part of the company. A business may begin with a high-level assessment to identify those parts of the company that have the most significant impacts and/or dependence on BES, followed by a narrower focus for detailed analysis. 


\section{Figure 3.2 Selecting the scope of BES measurement and reporting}

1. Which stage of the value chain?

2. Who and where specifically?

3. Is it strategic, timely, and supported?

\begin{tabular}{|lll|}
\hline Suppliers & Company & Customers \\
\hline -Which suppliers? & $\begin{array}{l}\text { What aspect of the } \\
\text { company? }\end{array}$ & - Which customers? \\
- In which geographic & - Business unit & - In which geographic \\
market(s)? & market(s)? \\
& - Product line & \\
& - Projity & \\
& - Landholdings
\end{tabular}

Building on methods developed by WBCSD and WRI (2008) for the Ecosystem Service Review (ESR), three basic questions can help managers select an appropriate scope of analysis for biodiversity and ecosystems (Figure 3.2):

1) Which stage of the value chain? The starting point for most companies is to examine their own operations, in terms of how impacts on or trends in biodiversity and ecosystem services may affect their business. A useful extension is to look 'upstream' in the value chain, to shed light on how BES impacts and dependence may affect key suppliers, and the business risks and opportunities that these, in turn, may pose to the company. Another approach is to look 'downstream,' to gain insight into the implications of BES for the company's major customers.

2) Who and where specifically? When conducting a review of the company itself, certain aspects of the business may be prioritized. Options include-but are not limited to-a particular business unit, product line, facility, project (such as a mine, pipeline, other infrastructure development), or natural asset owned by the company (such as forest or other landholdings). If the focus is on key suppliers, a specific supplier or category of suppliers may be targeted and the scope further narrowed by selecting a particular geographic market in which these suppliers operate. Similarly, if an assessment focuses on major customers, a particular customer or customer segment may be chosen and the scope later refined by selecting a particular market in which these customers are located.

3) Is the proposed scope strategic, timely, and supported? The scope of analysis should be of strategic importance. Examples include a company's fastest growing market, an upcoming major product line, or the business unit with the greatest market share and/or profitability. The chosen scope should ideally provide an opportunity to influence impending business decisions. There should be internal support for conducting a review within the selected scope, which of course implies management buy-in.

Experience to-date with the ESR shows that it is often most effective to schedule such analysis during regularly planned audits, environmental reviews, or strategy sessions (WRI 2008). 


\section{Deciding on the materiality of the issues}

In addition to defining the boundaries of measurement, a company must also decide which issues should be prioritized. The materiality of an issue may be assessed in purely financial terms, but this can create blind spots for companies where significant BES externalities exist that are borne by other entities. More nuanced assessments of materiality or relevance should consider how actions that may not have an easily measureable financial impact will affect other drivers of business success such as reputation, license to operate, employee morale, and productivity.

Rather than following the traditional accounting definition of materiality - i.e. an item is material if it could influence decisions taken on the basis of financial statements - some argue that more inclusive stakeholder definitions should prevail, such as those put forward by AccountAblity (Zadek and Merme 2003) or the Global Reporting Initiative (2006). This perspective is based on the idea that factors significant enough to substantially concern external stakeholders will ultimately affect the business, particularly if a company looks beyond the very short-term. Proponents argue that a strict focus on quantifiable, financial assessments of BES will not properly inform business decision-making, because not all relevant risks and opportunities can be translated reliably into impacts on a company's cash flow or financial position.

For those BES issues that are considered material, it is important for a company to articulate, both internally and externally, their relevance from two perspectives:

1) Whether BES is a material issue for the company as a whole or only for specific operations/regions/ products; and

2) Which aspects of impacts and dependence on BES should be prioritised for action, considering scale and time frame.

Some work has been undertaken to examine the materiality of BES at sector level. Recent examples include work by Oekom and Eurosif (2009), which examine both impacts and dependence on BES. One of the most comprehensive publications to date is the materiality analysis produced by F\&C Investments in $2004{ }^{1}$. However, little work has been undertaken to quantify the financial consequences of BES impacts and dependence. Nor has the second layer of detail been explored very much - namely what aspects of BES are most material and should be prioritized?

In terms of the ecosystem service categories defined by the Millennium Assessment, the provisioning services of ecosystems represent the most common dependencies and risks for companies. All companies require a flow of raw materials either for direct purchase or for acquisition from suppliers as semi-processed goods.

Less obvious but often important are risks associated with impairment of regulating services. These may affect the ability of ecosystems to provide key business inputs (e.g., climate change may affect the availability of timber, cotton, or other agricultural products) or result in negative impacts on other stakeholders that become a reputational risk or otherwise affect the business license to operate. Materiality assessments should consider ecosystems in terms of both business dependence on ecological processes and the potential benefits or services produced by these natural processes. 


\subsubsection{PRINCIPLES TO CONSIDER IN SETTING OBJECTIVES AND TARGETS}

With boundaries and priorities for BES monitoring and reporting identified, companies must also set goals for BES. The dilemma for many sectors is that almost all business operations will inevitably lead to some degree of adverse impact on ecosystems and biodiversity - it is virtually impossible to achieve zero ecological impact. Furthermore, as noted above, changes in BES do not necessarily follow linear paths, so that it is often unclear whether the actions of one company, however small, will have negligible impact on biodiversity and ecosystems or if a threshold may be crossed which results in sudden ecological collapse.

Several principles have emerged over time that can be used by companies to help define objectives and targets related to BES. The principles around 'no-go' and the precautionary principle were designed to express minimum standards and underline some limitations faced. The concept of 'Net Positive Impact' has emerged more recently as an aspiration that allows for trade-offs and in-kind compensation for ecological damage.

\section{- No-Go Areas}

In recent years, several companies within the extractive sectors have made voluntary commitments to forgo the exploitation of natural resources within certain highly important ecological areas (see for example ICMM 2003, JPMorgan Chase undated).. Such voluntary commitments by business can complement mandatory land use planning to protect sensitive sites. These are typically expressed in terms of avoiding areas that have been designated to meet a certain classification by international bodies (e.g., commit not to exploit resources near World Heritage Sites). To be effective, such voluntary commitments require universal adherence (i.e. lack of 'free riding').

\section{- Precaution}

The consequences of biodiversity loss and ecosystem degradation are often associated with high degrees of uncertainty, and precaution is frequently advocated around actions which may result in irreversible environmental harm. It is not always possible to obtain clear evidence of a threat to the environment before damage occurs. Precaution - the 'Precautionary Principle' or 'Precautionary Approach' - is a response to this uncertainty and has been embedded in both international and national law.

The principle of precaution, as recognised in the 1992 Rio Declaration, states that if an action or policy is suspected of causing harm to the public or the environment, in the absence of scientific consensus that such harm would not ensue, the burden of proof falls on those who would advocate taking the action. Part of the justification for the principle is that biological systems are complex and it is often difficult to predict when thresholds or tipping points will be reached. As a consequence, organizations are advised to proceed with caution in the face of uncertainty. Application of the precautionary principle in the realm of biodiversity is perhaps most obvious with respect to the release of genetically modified organisms. The approach is similar to 'no-go' pledges, but typically focuses on the prohibition of technologies rather than avoiding certain geographies.

As with the 'no-go' approach, the precautionary principle takes little account of economic opportunity costs. Moreover, the effectiveness of the principle depends on its universal application, which may not be realized through purely voluntary action. It also implies that actions will be taken to reduce the scientific uncertainty which prompts its use. Without this commitment, the principle could become a tactic for blocking actions. When the principle is invoked, plans should be defined to generate the evidence needed to revisit the decision (see Emerton et al. 2005). 
- No Net Loss or Net Positive Impact

The concepts of No Net Loss (NNL), ecological neutrality or Net Positive Impact (NPI) are based on recognition that certain economic activities (e.g., resource extraction or agriculture) will inevitably result in some residual impairment of BES on a given area of land or sea, even with the best environmental mitigation and restoration efforts. While such residual impacts cannot be avoided entirely, a company can aim to achieve a net zero or positive impact by taking actions to conserve or restore BES in other areas, with a view to maintaining overall ecological integrity. There are examples of companies that have committed themselves to being net positive or neutral with respect to carbon, water, wetlands, or other ecosystems and services. Along with cities such as Daejeon and Sydney, companies such as Deutsche Post DHL, Microsoft and Japan Airlines have committed themselves to climate neutrality².

While NNL or NPI can be a powerful aspiration and principle to motivate business action on BES, there are many challenges to achieving such a goal in practice. Some dispute whether NNL or NPI is technically or politically feasible (cf Walker et al. 2009). Nevertheless, the implementation of biodiversity offsets has progressed beyond mere concept and is currently practiced extensively across the globe (Madsen et al. 2010). See chapter 5 for further discussion.

\subsubsection{MEASURING AND MONITORING PROGRESS}

Most large companies have environmental data collections systems that gather information from sites and facilities to support local decisions as well as group-level management. At a corporate or group-level, aggregate information on BES may be used by internal and external stakeholders to assess the breadth and depth of the management processes in place and their performance.

In general, two broad categories of quantitative indicators are used:

- Process based: these measure the extent to which companies have in place processes and management systems which, if operating effectively, can drive performance improvements. An example is the number of sites that have a biodiversity action plan in place, or the extent to which environmental impact assessments incorporate biodiversity and ecosystem services impacts and dependence. Such process-based indicators have been criticized because they do not provide a clear picture of outcomes. If based on 'tick the box' completion of procedures, they may suggest progress even when implementation and actual improvements on the ground are minimal.

- Results based: such indicators provide a picture of performance over time and are essential for the valuation of BES impacts and dependence. They tend to be quantitative, e.g., the volume of water abstracted per hectare of crop, or the number of organic product lines in a range. Performance-based indicators are infrequently used and tend to be customized to individual companies, which can create barriers to benchmarking and interpretation by other stakeholders. There is currently no consensus on which corporate indicators for BES-related performance may be applied across different sectors and regions, due to the variety of circumstances in which companies operate.

Environmental performance measures that assess the use of resources (e.g. energy, water, materials) and the non-product outputs of business (e.g. wastewater, air emissions, solid waste, etc.) are relatively welldefined within both national legislation and voluntary initiatives, such as the Global Reporting Initiative, ISO14000 series, Carbon Disclosure Project, etc. Developing indicators to assess BES performance is more complex, as it typically involves measuring impacts on or changes to systems that may extend far outside the company's operational boundaries or direct control. 
Companies can however use conventional environmental indicators of resource flows, emissions and pollution as proxies for BES impacts, dependencies and/or responses. For example, the volume and toxicity of wastewater discharges may be used as a rough indicator of potential impacts on biodiversity in receiving water bodies, in the absence of more precise impact data. Conventional environmental indicators may also be relevant when considering how investments in ecosystem conservation or restoration can help improve

\section{Box 3.1 Water reporting by SAB Miller}

\section{Water to beer ratio $\mathrm{hl}$ water/hl beer}

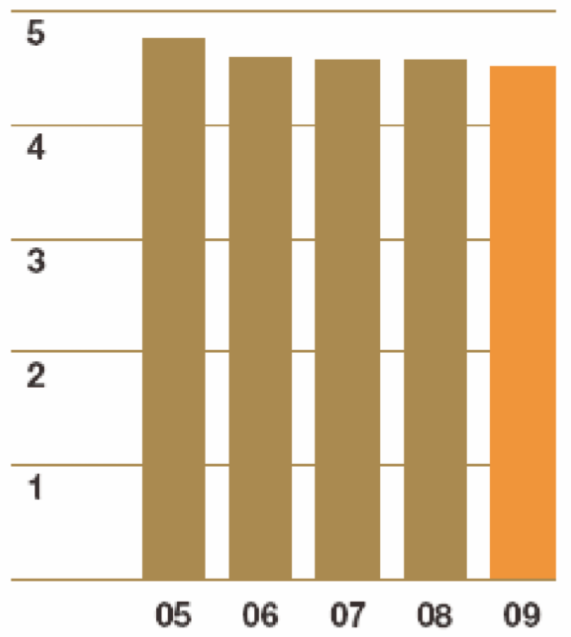

Water sources

percentage breakdown by volume

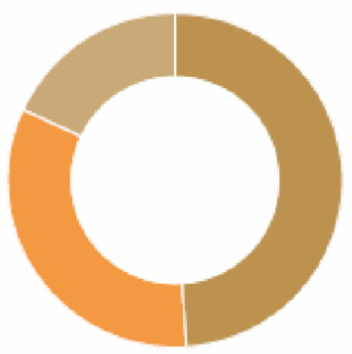

$49 \%$ Municipal sources

$33 \%$ Surface water

$18 \%$ Ground water

\section{Regional water to beer ratio $\mathrm{hl}$ water/hl beer}

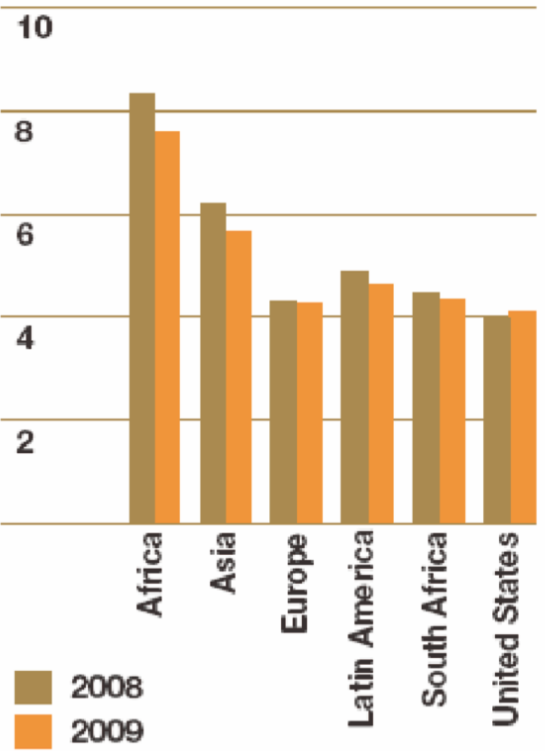

$A B$ Miller is one of the world's largest brewers with operations in more than 32 countries. In 2008 SAB Miller announced a commit- ment to reduce water consumption across its global operations by setting a target of cutting the amount of water it uses per hectolitre (hl) of beer produced to an average of $3.5 \mathrm{hl}$ by 2015 - a $25 \%$ reduction from 2008 . This initiative is designed to save around 20 billion litres of water every year by 2015. The 2015 target is part of a new water strategy which takes a comprehensive risk-based approach to the value chain. $S A B$ Miller chooses to report on average water use per hl of beer, water to beer ratio ( $h l$ water / hl beer), regional water to beer ratio and the different sources of water as a percentage breakdown. This information is reported in their sustainability report and links back to their water strategy and target to reduce water use per $\mathrm{hl}$ by $25 \%$. 
environmental performance. For example, a company may ask which is cheaper - investing in the natural filtration and cleaning capacity of a wetland or purchasing end-of-pipe pollution control equipment.

BES concerns often arise in relation to changes at a given time and place, which are easiest to measure and monitor in the context of a specific site or location. The information gathered from individual sites forms the basis for aggregation and decision-making across a company. For industries with significant direct impacts on terrestrial or marine ecosystems, measuring BES performance at the site or project level forms the basis for BES decisions throughout the organization. At the site level, BES performance data can be used for managing impacts and developing biodiversity management plans. Different indicators may be needed to address the particular challenges and opportunities for a given area and the information requirements of group-level strategies and reporting. For example, a refinery's emissions might have substantial impacts on local wetlands, which implies certain monitoring needs. In addition, the organization might have a group-level goal defined in terms of nutrient loading, which would require additional information.

At the site-level, it is often important to set corporate performance in the context of external conditions. Tools such as water footprinting, the WBCSD Global Water Tool as well as the Integrated Biodiversity Assessment Tool (IBAT) can help companies understand the relevance of their impacts on the wider landscape and on other stakeholders Using the IBAT for project planning and site selection processes enables consideration of alternative projects or locations at a point in the decision-making process when changes are still economically feasible.

Emerging water accounting or footprinting methodologies enable a company to quantify its operational and supply-chain water footprint, considering: (i) use of blue water (volume of freshwater taken from surface water and ground water), (ii) use of green water (volume of freshwater taken from rainwater stored in the soil as soil moisture), and (iii) cause of grey water (volume of polluted water, expressed as the volume of water required to dilute pollutants to such an extent that the quality of the receiving water body remains above agreed water quality standards). Box 3.1 shows reporting of water footprint data by SAB Miller, based on the collection of data at site level and the aggregation of results at group level, for a particular product line (liter of beer) and a particular region.

\subsubsection{LINKING BES WITH MAINSTREAM ENVIRONMENTAL ACCOUNTING SYSTEMS}

Mainstreaming BES considerations into business planning involves linking general business management accounting with the data systems for environmental management. This does not mean inventing completely new systems and layers of management. Some aspects of BES, for example water use, may already be captured in a company's existing environmental management system. Evidence from public reporting, however, suggests that other aspects of BES are not well-integrated into existing EMS, particularly at the group level.

Environmental management systems focus on those environmental interactions that are considered 'significant'. The International Standards Organization (ISO) has developed a concept of 'significance' that is similar to the concept of materiality put forward by AccountAbility (AccountAbility 2008) and the GRI (Global Reporting Initiative 2006). In the terminology of ISO 14001, environmental management tackles a range of environmental 'aspects' (input and outputs of an activity) and their associated environmental 'impacts'. An aspect is seen as 'significant' if, among other things, it has the potential to cause a demonstrable impact on the environment, and has major financial implications (positive or negative). Definitions of materiality tend to focus on assessing whether the impacts associated with an issue are significant and whether the company's performance in this regard may affect stakeholder decisions. Impacts are often grouped into categories for example air pollution, water pollution and land contamination. 
Management accounting systems provide information for internal planning, budgeting, control and decisionmaking and should include relevant BES information. This may include decisions about old or new products, in-house production versus outsourcing, process improvements and pricing. Decisions about products critically include the question of which materials are required for their production, which has clear implications for BES. Management accounting can incorporate BES metrics and link non-monetary data with financial information. For example, when looking at product manufacturing costs and raw material supply, a company with large impacts on BES may need to consider potential natural resource scarcities.

Furthermore, management accounting can provide key inputs in the development of balanced scorecard performance measures, considering for example how operational processes may be changed to improve resource efficiency and productivity. Related eco-efficiency targets with implications for BES may include reducing the material intensity of products and increasing the use of renewable resources.

Environmental Management Accounting (EMA) has been developed in response to the difficulties of capturing environmental costs within traditional accounting systems. EMA is defined as the identification, collection, analysis and use of information for internal decision making (UNDSD 2001; Savage and Jasch, 2005), covering: (a) financial information on environment-related costs, earnings and savings, and (b) physical information on the use, flows and destinies of energy, water and materials (including waste). EMA techniques allow firms to develop and use environmental performance indicators, which may be based solely on physical data or combine monetary and physical data to create eco-efficiency indicators. Physical data may include quantities of ecosystem services used or damages caused to BES, which may or may not be readily translated into monetary values. EMA systems can be aligned with major standards such as ISO14031 or with the indicators specified in reporting initiatives such as the GRI, CDP and Forest Footprint Disclosure Initiative.

In current practice, EMA primarily addresses the direct costs of environmental flows by:

- Putting a 'price' on non-product output (i.e., pollution and waste), thus highlighting the costs of materials converted into non-marketable waste and emissions.

- Quantifying the monetary impacts of external environmental pressures (e.g. taxes, norms, quotas) in relation to other factors that influence financial results, in order to distinguish transactions of an 'environmental' nature (e.g. compliance costs) from other business transactions.

To provide a more complete picture, companies may supplement EMA by analysing the potential consequences of decisions with respect to intangible assets. While BES involves tangible assets from a public perspective, it remains more difficult for business to define and measure their indirect impacts and dependencies on these assets. This raises the challenge of expanding the scope of BES assessment, going beyond first tier suppliers and clients in the business value chain (this issue is discussed in more detail below, under 'life cycle management'). 
Capital investment is based on identifying viable business opportunities that will generate attractive cash flows within a given time frame. The investment may relate - for example - to entering a new market, expansion, diversification, or replacing / upgrading technology. Such decisions are typically informed by systematic evaluation of alternative options, using 'net present value', 'payback period' or some other financial criterion to help managers decide whether to approve or reject a proposed investment.

The most basic rationale for business investment is to enhance the value of the firm, i.e. creating value for owners. An investor will normally consider a range of value drivers, such as potential growth in sales or taxation, which may be directly or indirectly influenced by 'green' issues. The analytical tools relevant here focus on the financial return for the company rather than the wider socio-economic consequences of an investment.

Biodiversity and ecosystem services may feature in various stages of the investment appraisal process. It could be a decision about entering a market for BES related goods and services, for example organic food. It could be about diversification into products that use more or use natural resource inputs. It may involve deciding on expansion into a new country, or acquiring a new company, in an environmentally sensitive area. It could be about investing in new technology that reduces pollution. It could also be an investment decision with no direct link to BES, but which results in impacts on BES further up or down the value chain. In considering such options, a business is likely to focus on direct costs and benefits. Making the business case for BES use in this context requires the identification of win-win opportunities, based on convincing metrics. While all investment decisions have some BES consequences, these may not translate easily into quantifiable impacts on cash flow and may therefore have little influence on investment decisions.

In order to decide what investments to make, businesses need to evaluate the alternatives available to them. Table 3.1 provides an overview of commonly used valuation techniques for business investment, with their implications for BES. Normally the main criterion for approving an investment proposal will be its potential to increase shareholder value and profitability. Other criteria, such as protecting the environment, are often secondary as long as legal requirements are met.

There are several barriers to changing 'business as usual' and mainstreaming BES into investment appraisal. These include the fact that:

- Environmental externalities do not form part of formal business valuations;

- Business discount rates often differ from so-called 'social' discount rates;

- Businesses may ignore some of the intangible values of BES; and

- There is often limited information and uncertainty about BES values.

These barriers can result in the approval of projects and investments that are less profitable from the perspective of society as a whole than for the owners of the business. 


\section{Table 3.1 Commonly used business valuation techniques and implications for BES}

\section{Methodology}

Net present value of discounted cash flows

\section{Key features}

Discounted cash flow (DCF) analysis is the most commonly used investment appraisal methodology in both the public and private sectors. It involves assessing the cash flows that a project, investment or business will generate over a time horizon which encompasses its full life. In order to compare costs and revenues arising at different points in time, future expenses or earnings are normally 'discounted' at a fixed rate, typically based on the investor's weighted average cost of capital. The sum of discounted revenues less discounted costs is known as the "net present value' (NPV) of the investment, or the value today of the project over its whole life.

Internal rate of return (IRR

Payback period
IRR is defined as the level of returns which, if used as the discount rate for a particular investment, would result in the discounted costs of the project being equal to discounted revenues (i.e. the IRR is defined as the discount rate which yields an NPV of zero). A higher IRR indicates that the project offers a higher level of return on the initial investmert.

Payback period is a streamlined investment appraisal technique, employed particularly by SMEs. It is defined as the length of time needed to pay back the initial investment. While the method involves simple calculations, it is necessarily short-sighted both from a business and a BES perspective. A project that is beneficial over the long run is likely to be overlooked if it does not repay the initial investment quickly.

\section{Implications for valuing B\&E}

Provided all relevant BES impacts and dependencies are accurately valued and included within the scope of business decision-making, DCF/NPV offers a plausible framework for investment appraisal. The risk is that certain BES values may be unknown, mis-priced or fall outside the scope of analysis because they do not result in costs or benefits to the investor. The choice of a discount rate can also be problematic, due to uncertainties about the future availability and value of BES.

IRR can give ambiguous results for projects characterized by negative cash flows at the end their lives. IRR may therefore be unsuitable for projects that involve delayed environmental costs, including remediation expenses incurred at the end of the main operational phase.

BES impacts that take a long time to manifest would rarely be considered in a payback period calculation. Similarly, other costs incurred at the end of a project's life, such as repairing environmental damage, are also ignored in this evaluation technique, though they are relevant costs to the business. 


\section{Table 3.1 Commonly used business valuation techniques and implications for BES}

\section{Methodology}

Indirect valuation

Informal valuation techniques

\section{Key features}

Investors often have to perform an external valuation of companies or other assets. A number of methods may be used to do so, including comparisons of earnings, price to earnings ratios or comparisons to other market benchmarks, such as the value of previous transactions.

\section{Implications for valuing B\&E}

Indirect valuation approaches will only reflect $B E S$ values to the extent that the target asset or company is properly valued in terms of its impacts and dependence on BES. Use of market benchmarks can be misleading due to the fact that they generally do not reflect $B E S$ values.

Informal decision-making has both benefits and drawbacks for BES valuation. The approach relies on the investors' personal perspective and values, which may give more or less weight to BES issues depending on the individuals involved.

\subsubsection{BARRIERS TO PROPER VALUATION OF BES IN CAPITAL INVESTMENT}

\section{Barrier 1: Externalities are missed from business valuation}

When applying standard investment appraisal methods, such as those outlined in Table 3.1, and assuming that management seeks to maximise profits and value to owners, a firm will only include the values for costs and revenues that are relevant or material from its own point of view. Therefore, a firm will only consider damage to an ecosystem in its investment appraisal if it expects to bear the cost of the damage itself. Where a firm does not believe that it will bear at least some of the cost of environmental damage, this will not normally form part of a formal valuation appraisal. In this case, the cost is an externality, i.e. an impact that is external to the company and its decision making. This also applies to external benefits, such as those arising from ecological restoration activities that do not generate revenue for the investor.

When a business has a detrimental impact on the functioning of an ecosystem, costs may result from reductions in both marketed and non-marketed services. For example, inefficient harvesting by a forest management company imposes a cost on the company since future yields may be reduced. This cost is internal. However, it may also impose non-market costs by reducing the recreational value of the forest. If the company is able to extract some of the value of these services, for example by charging access fees to recreational users, this cost will be partially internalised and may be valued by the business. However, often the costs of the damage will be external. Because many intangible ecosystem services are not valued in the market, they often remain external to investor decision-making, particularly if there is no legal basis for external stakeholders to claim for damages, as is commonly the case. 
What would change this? Setting aside the personal views of business owners, managers or employees, the fundamental logic for a business is to maximise profitability. A business may be concerned about the impact of its operations on ecosystem services if these are likely to damage services itself relies on, or result in reputational damage, delay, litigation or other costs of doing business, leading to reduced sales or recruitment problems. Even when there is not a quantifiable short-term financial impact, changes in BES resulting from investment decisions may still affect the long-term ability of the business to achieve its strategy.

Alternatively, regulation, taxation, subsidies and markets for BES may oblige a business to consider BES impacts and ensure that ecosystem damage and opportunities form part of its decision-making. Environmental regulations could mean that certain industrial processes need to be revised, while taxes and subsidies could alter the payoffs to investments, and markets would put prices on BES which business would need to buy or sell.

\section{Barrier 2: Business discount rates often differ from social discount rates}

An individual will discount future costs and benefits at rates determined by his/her pure time preference and the expected growth in his/her future consumption. In other words, people tend to give less weight to costs and benefits that occur in the future than those arising today, first because they are mortal, and therefore impatient, and second because they expect their income to rise over time. The latter point is subtle but reflects the fact that each additional unit of income delivers slightly less additional utility than the last, due to diminishing returns. If on average people are expected to be wealthier in the future, due to general economic growth, we can expect that an additional increment of income received in the future will generate less utility than the same increment delivered today.

The same logic with respect to future costs and benefits may be applied in business. Because individuals invest in businesses both directly and indirectly (e.g. via pension funds), the discount rates used in business decisions will ultimately reflect the underlying individual discount rates. In addition, businesses expose investors to risk there is no guaranteed return on an investment in a firm. So on top of the sources of individual discounting outlined above, business discount rates will also include a risk element to compensate investors for the possibility that they may not get their money back.

The standard discount rate used in business investment decisions is the weighted average cost of capital (WACC). The WACC faced by a given company is established in the debt and equities markets and depends on the preferences and discount rates of the potential pool of investors as well as the perceived risk of the company or investment project for which capital is solicited. The WACC represents the opportunity cost of investing in the business - forgoing cash that could be spent today for an uncertain return later. For most core activities of a business, it is the appropriate rate by which to discount future returns, though for non-core projects the WACC may be different. Normally, a business should only invest in those projects that are expected to enhance value when discounted at the appropriate WACC.

Typical discount rates seen in the market and generally applied by businesses reflect the savings and investment decisions of institutions and individuals around the world. The longest instruments commonly available are 30-year government bonds, often used by pension funds to match their liabilities to provide long-term retirement pensions. While people may and do care about even more distant futures, it is currently impossible to derive an appropriate long-term discount rate simply by looking at financial markets. Indeed, for decisions that affect society over the very long-term, market discount rates are probably not appropriate. Nevertheless, policy makers need a basis to compare present and future costs and benefits. In practice, governments often use a 'social' discount rate for such purposes (Box 3.2). Social discount rates are almost always lower than market rates, reflecting the fact that society as a whole is not mortal (we hope) and is less risk averse than most individuals. 


\section{Box 3.2 Discount rates in UK government planning decisions}

The discount rate used to assess UK government policy decisions is the Social Time Preference Rate (STPR). The STPR discounts future consumption, not future utility. The SPTR is the sum of two elements:

- A pure rate of time preference reflecting the fact that individuals discount future consumption, irrespective of changes in per capita consumption; and

- A component reflecting the fact that, if consumption is growing over time, an additional unit of Consumption in the future will bring less additional utility than an additional unit of consumption today (reflecting diminishing returns to consumption).

As an example, the UK government uses an annual STPR of 3.5\% for its planning decisions [HMT Green Book], based on a discount rate of $1.5 \%$ (accounting for risk of death and pure time preference) plus an estimate of the long-run per capita income growth of $2 \%$ annually. The STPR further reflects the assumption that each increment of future consumption would be worth half as much to people who are twice as wealthy as current the generation (i.e. the marginal utility of consumption is assumed to have elasticity of one). The STPR is used to evaluate public investment decisions up to 30 years' duration. Lower discount rates are used for longer time horizons, due to uncertainty about the distant future.

Business decisions that affect biodiversity and ecosystems are often made using relatively high, market discount rates. The danger is that, by doing so, business may be under-valuing potential adverse impacts on future generations. In addition, even the social discount rates commonly used by governments may be too high. As set out in Box 3.2, it is assumed that consumption growth will be positive in the future. However, biodiversity loss and ecosystem degradation is likely to lead to lower levels of at least some ecosystem services in the future. Some of this damage may not be reversible at any cost, and there is a limit to which other resources or technologies can substitute for the loss of ecosystem services. This implies that future generations may be worse off than our own, in which case a very low or even negative consumption discount rate could be justified.

Further discussion of discounting and its application to BES, as well as related ethical issues, can be found in Chapter 6 of the TEEB D0 report. This concludes that a variety of discount rates, including zero and negative rates, may be used depending on the time period involved, the degree of uncertainty and risk, ethical considerations around intra and intergenerational equity, as well as the scope of the project or policy under consideration.

\section{Barrier 3: Businesses may not account for intangible values}

It is well known that biodiversity and ecosystems generate both tangible and intangible values. The latter include so-called 'non-use' values, defined as the value that people place on an ecosystem or resource that is not related to any direct or indirect use, including the value of species and habitats for religious aesthetic, heritage or bequest reasons. Some argue further that ecosystems or component species have an 'intrinsic' or moral value, independent of human preferences (see chapter 4 of TEEB D0). In addition, ecosystems provide regulating, provisioning and supporting services which can be important even when they are intangible or difficult to value.

These and other intangible benefits of BES are not generally traded in markets and their value is not widely understood or agreed. Such values may be reflected in public policy, for example through environmental restrictions on certain activities in certain locations, but there remains wide disagreement about the importance of intangible 
benefits, which makes it difficult to include loss or gains in such services in business investment decisions. As noted above, firms may not bear the costs of damaging, or reap the rewards of providing, intrinsic or intangible values, except where:

- Regulation limits damage to ecosystems or requires remediation or compensation (e.g. restrictions on pollution, production capacity or total output, offset requirements);

- Environmental damage affects the firm's own revenues, now or in the future (e.g. changes in real estate value due to loss of environmental amenity);

- Payments or other incentives are provided by other firms, NGOs or public agencies; or

- Adverse publicity damages the firm's reputation or brand.

For these reasons, businesses may have an interest in properly valuing their impacts on biodiversity and ecosystems, including intangible values. This is increasingly possible using tools developed by economists to measure the non-use values of environmental assets, including so-called 'existence' values. The contingent valuation method, for example, asks individuals about their own valuations of intangible environmental benefits and is the main method used to assess non-use values (Box 3.3). Contingent valuation has gained wider acceptance since its use in 1992 by Richard Carson and others (Carson et al. 1992) to value damages resulting from the Exxon-Valdez oil spill. After an 18 year legal battle, the US Supreme Court finalised Exxon's compensatory payments at over $\$ 500$ million, including damage to so-called existence and other non-use values of biodiversity.

\section{Barrier 4: Limited information and uncertainty}

Businesses may find it difficult to value BES risks and opportunities accurately, due to lack of scientific and economic data or regulatory uncertainty. Although DCF modelling and other valuation techniques can account for uncertainty, they require that a defined probability is placed on every eventuality. The difficulty in assigning probabilities to potential BES outcomes is a barrier to including them in business valuations. This is exacerbated by the absence of standard metrics with which to monitor BES impacts and dependence.

Another characteristic of BES decline is that it can be hard to predict or subject to sudden, unexpected change. A small amount of degradation may have little effect on the value that people obtain from ecosystems. However, as the level of negative environmental impacts increases, the loss of ecosystem services may occur at an accelerating rate. Thresholds or 'tipping points' may also arise, beyond which an ecosystem enters a new state and the supply of certain ecosystem services is significantly reduced. Moreover, in some cases, ecosystem damage or modifications may be irreversible on a human time-scale.

Finally, companies are taking actions today that will be affected by legislation in the future. Costs that may materialise over the life of a project or investment due to new regulation will only be considered if business decision makers think they will occur or are likely to occur. As with other risks, regulatory impacts can be included with a probability if this is known, but, as in the case of carbon liabilities, uncertainty may simply lead firms to ignore the future costs of their actions. Importantly, this is likely to be more common for opportunities than risks - an investment in ecosystem assets such as biodiversity credits may be viewed as 'speculative', while acknowledging that a firm undertaking a damaging activity may need to pay could be considered 'prudent'. 


\section{Box 3.3 Case study - Contingent valuation in kakadu conservation zone}

In the early 1990s, the Reserve Assessment Commission (RAC) in Australia investigated options for the use of resources within the Kakadu Conservation Zone (KCZ). Alternatives included opening the $\mathrm{KCZ}$ for mining, or combining the KCZ with the adjoining Kakadu National Park (KNP).

The KCZ is believed to contain significant reserves of gold, platinum and palladium. Environmental groups argued that potential damage from mining was likely to extend beyond the $\mathrm{KCZ}$ to the KNP, and that this was significantly detrimental to the public use and non-use values of the park. Conversely, the mining company sponsoring the proposals argued that damage would be minimal and that the public did not place a high value on the KCZ.

The RAC's investigation involved two major components. First, a study was undertaken to estimate the likely risk of damage from mining. Second, the RAC used a contingent valuation survey to estimate the economic value of potential damages. Because the extent of damage was unknown when the survey was undertaken, major- and minor- damage scenarios were considered. Based on a description of the $\mathrm{KCZ}$ and the potential environmental damage scenarios, respondents across Australia were asked if they would pay a pre-determined price to avoid the damage. By randomising the prices proposed to each respondent, an average willingness to pay (WTP) could be estimated while controlling for differences in the characteristics of the sample population. The results of the CV study implied that public WTP to avoid damage to the $\mathrm{KCZ}$, at $\mathrm{A} \$ 435$ million, far exceeded the net present value of the proposed mine, estimated at $A \$ 102$ million. The total value of avoiding mining da- mage was obtained by multiplying the median WTP to avoid the minor impact scenario ( $\mathrm{A} \$ 80$ per household surveyed) by the total number of households in Australia.

Following the RAC's report, in 1990, the Australian government decided not to issue a permit to mine the KCZ site. Interestingly, the results of the CV study were not included in the final RAC report, perhaps due to uncertainty (at that time) about the validity of non-market valuation methods. Nevertheless, this example demonstrates the potential of economic valuation techniques for assessing the value of ecosystem services in a project appraisal setting, and highlights the fact that intangible values can be measured to some degree. Such an approach can help firms to establish the potential costs of damages associated with their investments. Project planners can also use such techniques to identify configurations and methods that would have the least impact on intangible ecosystem values. 


\section{COLLECTING AND USING INFORMATION AT THE PRODUCT LEVEL}

Life Cycle Management provides a practical approach for product-based decision-making in business, which may incorporate BES aspects. Life Cycle Management typically combines product-level assessment tools, such as Life Cycle Assessment (LCA), with environmental management (such as ISO 14001) and reporting systems. Life Cycle Management looks beyond a particular industrial site or stage of the value chain to assess the full impact - including socio-economic impacts - associated with a product or service throughout its life cycle. This section reviews recent efforts to integrate BES information in LCA methods.

\subsubsection{A BRIEF OVERVIEW OF LIFE CYCLE ASSESSMENT (LCA)}

LCA is used to study the environmental interventions and potential impacts throughout a product's life from raw material acquisition through production, to use and final disposal (i.e. from cradle to grave). For instance, the life cycle of a tomato would include the production of fertilizer, pesticides, water, peat for seedling production, energy for heating of greenhouses, transport processes, packaging, processing energy (e.g. cooking) and waste treatment.

The aim of LCA is to provide information to enable business to reduce resource consumption and emissions and thus environmental impacts at all stages of a product's life. LCA serves to compare different products (e.g. biofuels with fossil fuels) or to identify key environmental issues and thus potential improvements along the life cycle.

\section{Figure 3.3 The four phases of LCA according to ISO standards 14040 and 14044}

\begin{tabular}{|c|c|}
\hline $\begin{array}{l}\text { 1. Definition of goal and scope } \\
\text { - What is the purpose of the LCA? } \\
\text { - Who is the intended audience? } \\
\text { - What is / are the systems under study and what are their functions? } \\
\text { - What are the underlying assumptions / limitations? } \\
\text { - What are the data quality requirements? }\end{array}$ & \multirow{5}{*}{$\begin{array}{l}\text { 4. Interpretation } \\
\text { - What are the } \\
\text { conclusions? } \\
\text { - What are the } \\
\text { limitations? } \\
\text { - How reliable and } \\
\text { sensitive are the } \\
\text { results? } \\
\text { - What are the re- } \\
\text { commendations? }\end{array}$} \\
\hline$\downarrow \mid$ & \\
\hline $\begin{array}{l}\text { 2. Inventory analysis } \\
\text { What are the relevant emissions and resources the systems } \\
\text { produce or consume? } \\
\text { - How are these inputs and outputs allocated to the functions of the } \\
\text { system? } \\
\text { What is the quality of data (uncertainties)? }\end{array}$ & \\
\hline \begin{tabular}{l|l}
$\uparrow$ & $\uparrow$
\end{tabular} & \\
\hline $\begin{array}{l}\text { 3. Impact assessment } \\
\text { - Which impact categories are considered and which models are used? } \\
\text { - What environmental impacts are caused by the emissions and the } \\
\text { - How is the aggregation within the impact categories performed? } \\
\text { - Are impact categories weighted and, if so, how? }\end{array}$ & \\
\hline
\end{tabular}


Standard phases with related questions in the LCA are set out in Figure 3.3. The Life Cycle Inventory (LCI) involves data collection and calculation procedures to quantify relevant inputs (resources) and outputs (emissions). The Life-Cycle Impact Assessment ( $\mathrm{LCIA}$ ) aims to understand and evaluate the magnitude and significance of the potential environmental impacts of a product system. LCIA is needed because in the inventory analysis several hundred emissions and resource uses may be quantified, and a comparison of two products or scenarios based on so many environmental interventions is virtually impossible. In the LCIA, an aggregation of these environmental interventions according to the type of impact or damage is performed. This reduces the number of environmental indicators to between 1 (for fully aggregating methods) and approximately 10, which is far easier than comparing hundreds of emissions and resource use flows.

The overall framework for Life Cycle Assessment is described by Udo de Haes (1999) and redefined in the Life Cycle Data System Handbook (2009). This framework defines the relationship between environmental interventions -i.e. the modification of the environment resulting directly from a business activity - and the resulting impacts. Due to the complexity of the causal chain, several steps are considered between alterations of the environment and final impact (also called endpoint). Each intermediate point of measurement along the causal chain is called a midpoint (such as ecotoxicity, eutrophication, land use, etc). Beyond this, the endpoint refers to an Area of Protection which refers to entities of ultimate interest to society, such as human health or the quality of the natural environment.

Over the last 20 years, several LCIA methods have been developed. These differ by their definition of impact categories, consideration of environmental compartments, number of emissions and resources considered, and level of aggregation. There are methods that stay at the level of impact categories, and those that aggregate further to the level of damages to the three areas of protection: natural environment (ecosystem health), human health and resources (see Figure 3.4). Different weighting techniques can also be used, e.g. based on targets set by government or by experts.

\section{Figure 3.4 Assignment of environmental interventions (left) to impact categories (middle) and damage categories (right)}

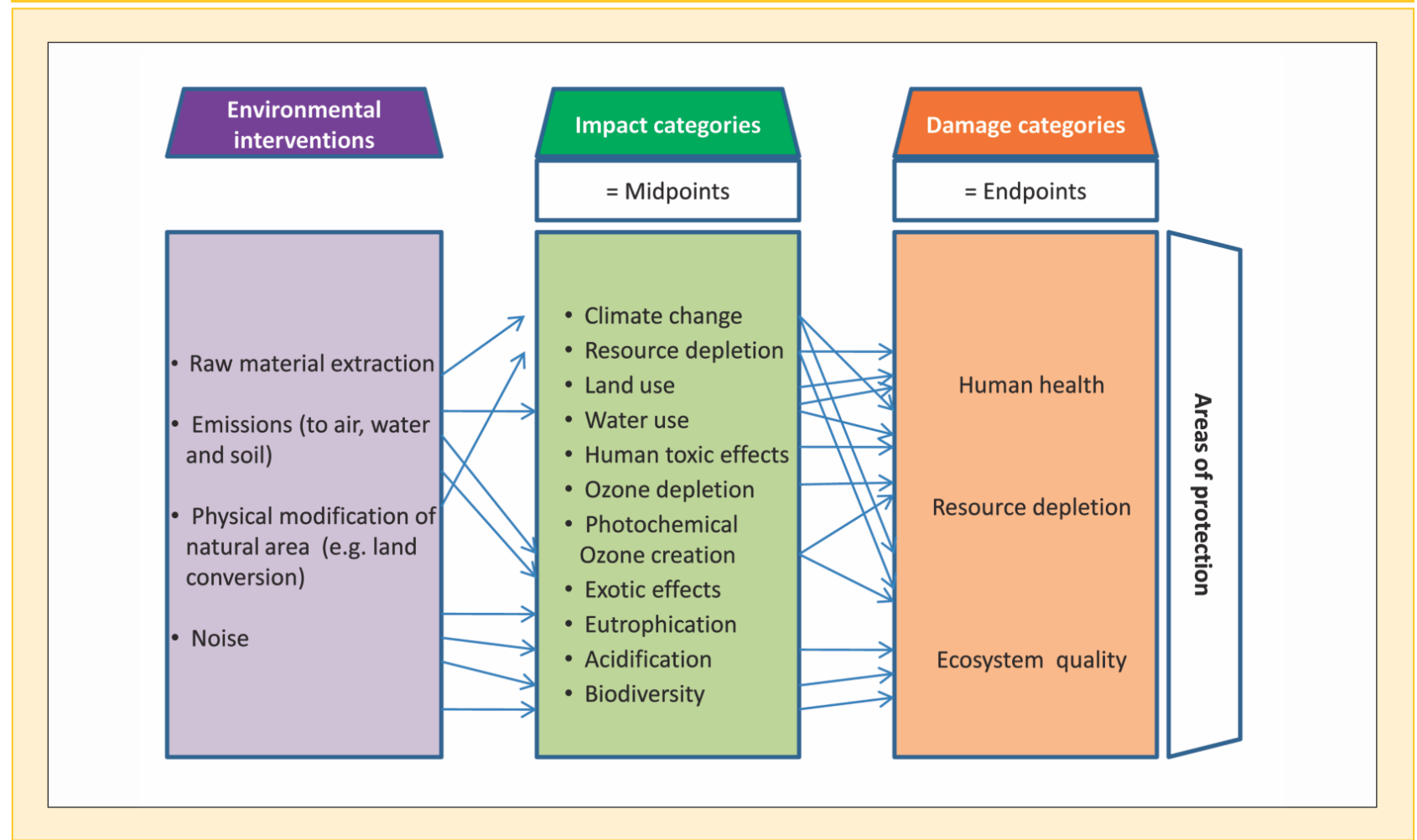

Source: Jolliet et al. 2003 


\subsubsection{INTEGRATING BIODIVERSITY AND ECOSYSTEM SERVICES IN LCA}

Biodiversity-related endpoints are not currently well integrated in LCA methods and guidelines. Various approaches are being examined under the UNEP/SETAC Life Cycle Initiative (http://linitiative.unep.fr). Some approaches estimate a potential percentage change in ecosystem diversity, independent of the location and time of the impact. Other emerging methodologies express damage in terms of the fraction of species eliminated over an area and time period.

LCA incorporating BES needs to account for a wide range of impacts, such as ecotoxicity or land use change, for example. These impacts result from different types of environmental interventions. In the case of ecotoxicity, for example, the impact is due to emissions of substances to the environment. Thus impact is related to the quantity of a particular substance released into the environment and is proportional to the hazard or toxicity of the substance. Ecotoxicity is assessed by modelling exposure concentrations and looking at species level indicators of abundance and reproductive decline, extrapolating from a number of indicator species to entire ecosystems (related to the volume of emissions of any toxic substance and depending also on substance-specific properties).

For land use, impacts are proportional to the surface of land transformed and the ecological sensitivity of the area. Both the type of land use and its coverage in terms of area and time should be considered. Quantification of land transformation takes account of the type of land before transformation, the type after transformation, the geographic extent and a relaxation period. The life cycle inventory of a product system thus shows different land use types and gives information about their quantities in space and time. In the LCIA, these are weighted with respect to their potential ecological value or impact.

Land use in particular influences biodiversity through habitat change, fragmentation, and pollution linked to intensive agriculture, forestry and the expansion of urban areas and infrastructure. The measurement of land use impacts on biodiversity, however, is a complex task. The UNEP/SETAC Land Use Working Group distinguishes between Biodiversity Damage Potential (BDP) and Ecosystem Services Damage Potential (ESDP).

BDP addresses the 'intrinsic' or conservation value of biodiversity. It is based on factors for different land use types and intensity classes (see Koellner and Scholz 2008). It takes into account the diversity of plants and explicitly considers threatened species. This diversity is then related to regional mean species numbers as a reference or benchmark. Until now, most of the quantification has been carried out for European land use. However, Schmidt (2008) compared the occupation impacts related to 1 hectare-year in Denmark, Malaysia and Indonesia. Such a globally applicable method needs further development in order to assess global resource flows and associated land use change.

While LCA is increasingly applied to decisions about product choices and optimizations, it has some limitations. For many impacts, in particular those on BES, the magnitude of impact depends heavily on spatial conditions. For instance, cutting down tropical rain forest to produce biofuels has a different impact on biodiversity than expanding production on a plot that was previously used as farmland. Additionally, the lion's share of impact often occurs in locations far removed from the place of final consumption. This is especially the case for agricultural products, which cause a variety of ecosystem impacts at the place of cultivation and are then often exported. Such products carry a 'virtual' burden which is important to account for - including its spatial dimension.

With increasing globalization, supply chains have become more complex and difficult to track. Nevertheless, the growing interest and perceived responsibility of consumers and companies in importing countries as well as the increasing destruction of $\mathrm{BES}$ in producing countries call for more spatial information along the value chain of products. One of the major strengths of LCA is that it considers the whole life cycle. LCA is slowly catching up and practitioners are developing tools that allow for greater spatial differentiation. However, it may be difficult, even impossible, to track the complete value chain of all products with a high level of spatial resolution. LCA will thus never provide a complete substitute for site level assessments. At the same time, it should be recognised that many companies have influence on the whole life-cycle in one way or the other, and LCA enables them to take responsibility for this. 


\section{COLLECTING AND USING INFORMATION AT THE GROUP LEVEL}

The combination of dependencies, impacts, risk and opportunities associated with BES at the site level and the product level together constitute the overall BES profile for a company. Box 3.4 provides an example from the field of carbon measurement and reporting, based on typical company data but 'anonymized' in order to respect confidentiality. This box shows how environmental indicators collected at product and activity level can be aggregated at the group level.

\section{Box 3.4 Carbon reporting by Typico Group}

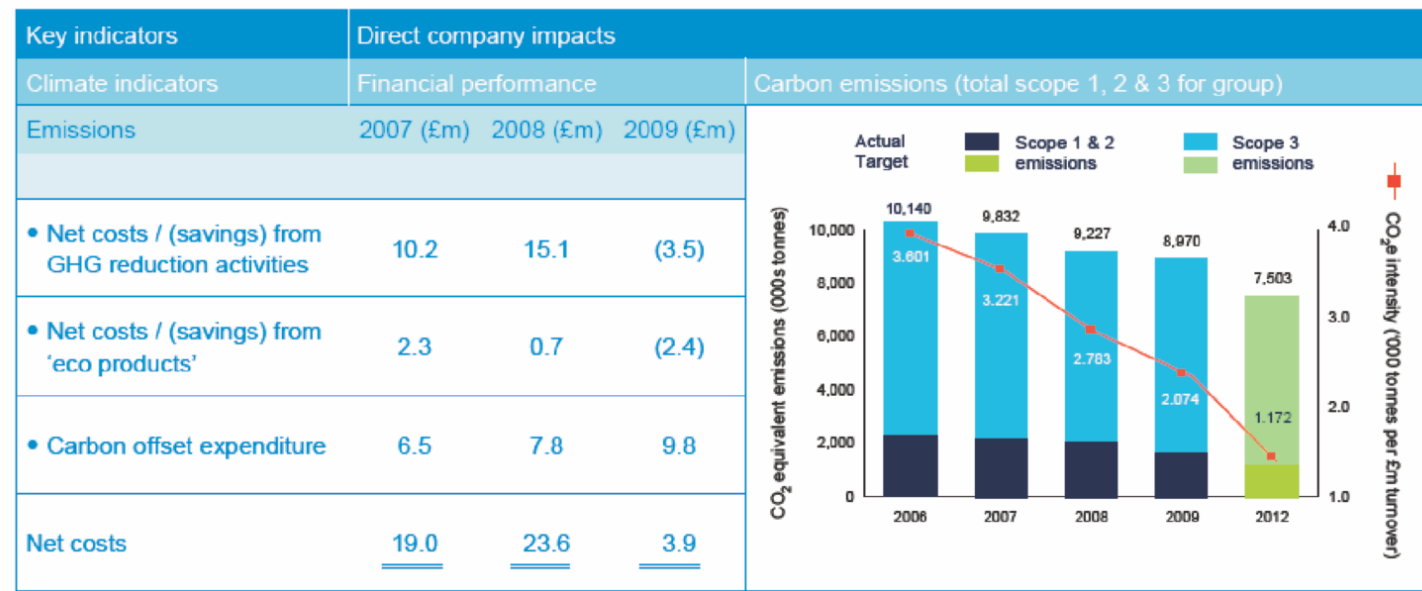

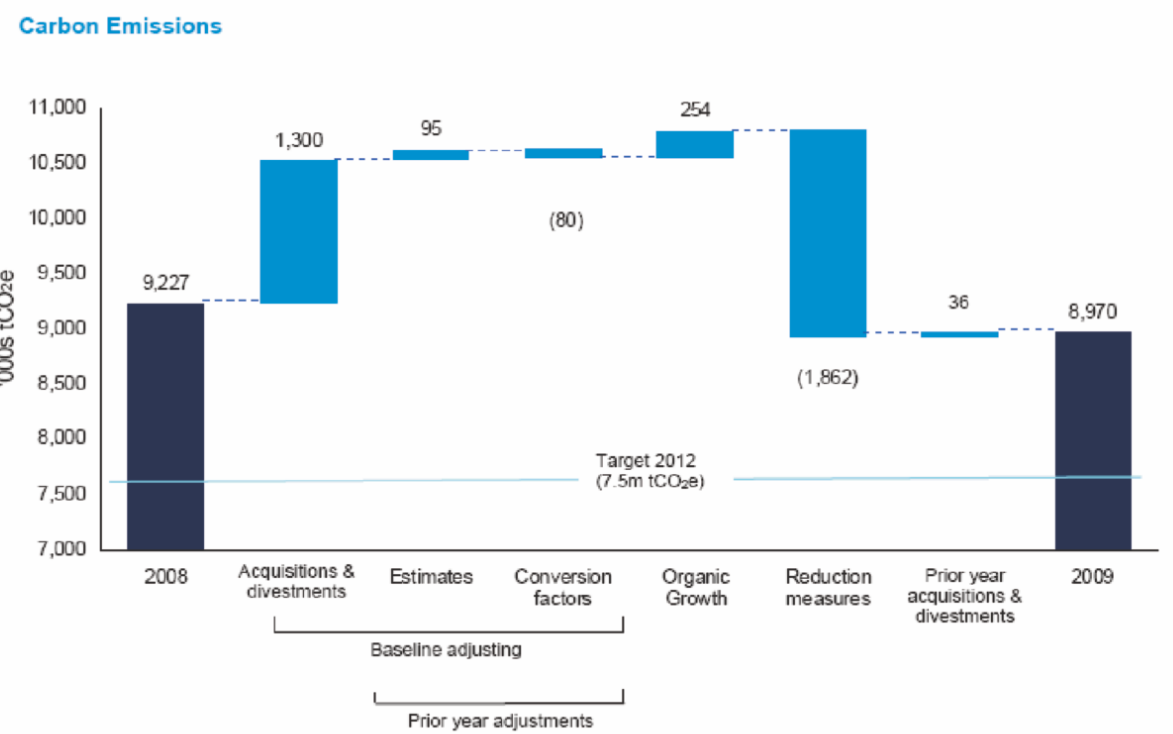

Carbon reporting - adding it up at group level: Developments in carbon reporting provide a benchmark for the progress we might expect in reporting on biodiversity and ecosystem services in the coming years. In 2009, the above ideal example of carbon and climate change reporting for a fictional technology company 'Typico plc' was prepared by PricewaterhouseCoopers andincluded in the exposure draft of the climate disclosure standards board's (CDSB) reporting framework. 
The tools used to evaluate a company at the group-level are generally different from those used at the site or product level. Overall, at a group level, a company could be expected to:

- have relevant BES policies and procedures in place;

- monitor performance relative to those policies;

- consider BES in financial analysis and decisions; and

- publicly report on their relationship to BES.

Tools are available to assist companies in these practices, but working at the group level bring its own challenges. For instance, it is generally not possible to generate aggregate BES numbers at group-level, simply by adding up site-level or product-level impacts, due to the heterogeneous nature of biodiversity and ecosystem services. Moreover, existing methodologies and tools, particularly those related to valuation, provide limited guidance or emphasis on BES. Hence this section examines the integration of BES in group-level financial accounting and public (financial and sustainability) reporting.

\subsubsection{FINANCIAL ACCOUNTING STANDARDS AND BES}

Financial accounting and reporting differs from life cycle accounting, environmental performance measurement, and other types of management accounting in that it is primarily intended to serve external audiences rather than internal users. Over the last decade, and especially in the past two years, there has been widespread debate over the purpose of financial reporting. According to the International Accounting Standards Board (IASB, 2001), the objective of financial statements is "to provide information about the financial position, performance and changes in financial position of an entity that is useful to a wide range of users in making economic decisions". The IASB go on to say that:

"Financial statements prepared for this purpose meet the common needs of most users. However, financial statements do not provide all the information that users may need to make economic decisions since they largely portray the financial effects of past events and do not necessarily provide non-financial information." (IASB, 2001: 12-14)

Defining the purpose of financial reporting in terms of the needs of a narrow class of stakeholders -i.e. investors and lenders - influences the extent to which such reporting can address issues such as BES. This is because the criteria developed to ensure relevant and reliable financial reporting for the purposes highlighted above are almost inevitably framed in such a way as to exclude so-called 'intangible' issues, such as BES impacts or dependencies.

At the heart of this disconnect is the accounting concept of 'recognition'. This suggests that for an item to be recognised as an asset or a liability by an entity, it must be considered probable that any future economic benefit associated with the item will flow to or from the entity and that the item has a cost or value that can be measured reliably. For accounting purposes, an asset is a resource controlled by an entity as a result of past events from which future economic benefits are expected to flow to the entity, and a liability is a present obligation of an entity arising from past events, the settlement of which is expected to result in an outflow from the entity of resources embodying economic benefits.

The vast majority of ecosystem services and the vast bulk of biodiversity fall outside these recognition criteria and are thus neither accounted for internally by organisations (in the public or private sectors) nor are they (or management's stewardship of them) reported externally in conventional financial statements. The main exceptions to this rule occur where: 


\section{Box 3.5 UK National Forest Company - extract from 2008/09 Annual Report and accounts}

\section{Objectives:}

- To secure further forest creation, contributing to the delivery of targets contained within the Forest Strategy $2004-2014$ and the National Forest Biodiversity Action Plan.

- To achieve a high quality, sustainable National Forest.

- To demonstrate a leadership role in responding to climate change, both in forest creation practice and in work with other forestry organisations to develop a national approach to domestic forestry and climate.

- To realise the economic potential of the Forest, building on its environmental foundations, and to consolidate the sustainable development achieved to date.

- To make further improvements to access and participation in the Forest, broadening the range of people using and enjoying it.

\section{Headline achievements - significant activity in the year included:}

- The National Forest recognised as one of the first three UK examples of the European Landscape Convention.

- The Woodland Owners' Club re-established, as a driver for good woodland management, including dealing with pests and diseases.

- A comprehensive bird survey completed, applying national surveying methods.

- Further high quality visitor signage and furniture installed in the East and West Midlands. (The tourism economy was confirmed as being worth more than $£ 260 \mathrm{~m}$ a year).

Source: http://www.nationalforest.org/about_us/

(a) A recognisable market exists which gives rise to 'reliable' valuations. Examples include agricultural land and produce, forestry, fish-farming, or carbon trading in areas with regulated emission trading schemes. For companies operating in related sectors, recognised accounting valuation rules are applied to stocks of land, timber, crop, herd or other 'inventory' items in order to price transactions or to value assets and liabilities.

(b) An enterprise operates in a sector where stewardship of BES is fundamental to its license to operate. An example is the UK National Forest Company (Box 3.5) whose annual reports and accounts contains a wealth of information dealing with management's stewardship of the natural resources in the charge of the enterprise.

(c) The organisation is located in the public or not-for profit sectors and is subject to (or volunteers for) detailed accounting of BES assets and liabilities. This is similar to the National Forest company example mentioned above, but the general purpose of the organisation is to provide services that support the public good (e.g. local authorities or government departments). It should be noted however that most public agencies and NGOs nevertheless do not account for BES assets and liabilities.

While BES typically falls outside of traditional business accounts and reporting, the World Business Council for Sustainable Development (WBCSD) has begun work to assess how corporate accounting practices could incorporate BES values. Developed by the WBCSD (2009) in partnership with IUCN, WRI and several companies, the Ecosystem Valuation Initiative has identified 10 reasons why business may wish to value ecosystem services, namely:

1. Improved business decisions: Companies can use ecosystem valuation to strengthen internal management planning and decision-making around environmental impacts or the use of natural resources. 
2. Capture new income streams from product diversification and market creation: Valuation can help to assess the benefits to companies of participating in ecosystem markets by determining whether the returns are sufficiently high to warrant investing in market or product diversification.

3. Identify opportunities to reduce taxes or secure positive incentives: Companies may be eligible for tax relief or other financial incentives if they own assets that generate ecosystem benefits valued by the public, or if they carry out their operations in a recognized 'nature-friendly' manner.

4. Highlight opportunities to reduce costs: Valuation may be used to identify ecosystem management options that reduce business costs or risks, such as the role of wetlands in water filtration and purification, or the role of vegetation in protecting against floods, storm surges and other natural hazards.

5. Assess how business revenues can be sustained: Companies can use valuation to estimate the returns from investing in BES as inputs to production.

6. Value company assets: Companies that own significant ecosystem assets can use valuation to assess their worth and identify opportunities to generate or increase returns to management.

7. Assess liability or compensation: Valuation can be used to estimate damage to ecosystems and inform liability claims or determine compensation payments.

8. Measure company and share value: Investors may obtain a more accurate picture of the value of their portfolio by including ecosystem assets and liabilities.

9. Improve reporting and disclosure of corporate performance: Companies can assess the monetary value of their environmental actions and performance and thereby achieve more comprehensive reporting, while also facilitating the integration of environmental impacts with conventional financial measures.

10. Explore new goods and services: Valuation may be used to determine the magnitude of BES costs or benefits associated with new technologies and business activities.

In reality, the idea that biodiversity or ecosystem services have economic value is scarcely reflected in the conventional measures used to assess and report on company performance, and to weigh alternative business opportunities and risks. As a result, business decisions are made based on a partial understanding of environmental costs and benefits. However, the ability to factor BES values into corporate decision-making is becoming more important, as new markets for ecosystem services are developed and as new regulations increasingly require companies to measure, manage and report their BES impacts.

The extent to which economic value (let alone market prices) can or should be the basis for decision-making about BES is open to debate. TEEB recognizes the limitations of economic valuation but also argues that information about ecosystem values is generally helpful and rarely harmful (see chapter 4 of TEEB D0). Given the current limitations of markets and accounting, BES values rarely appear as a material component of financial accounts. More generally, as noted above, very few companies have applied economic valuation to their BES impacts and dependencies.

\subsubsection{PUBLIC REPORTING}

While biodiversity and ecosystem values can be important to companies, as illustrated in this report, the issue is generally not well-represented in public reporting by business. Analysis by PWC shows that of the 100 largest 


\section{Figure 3.5 Reporting on biodiversity by the 100 largest companies in 2008}

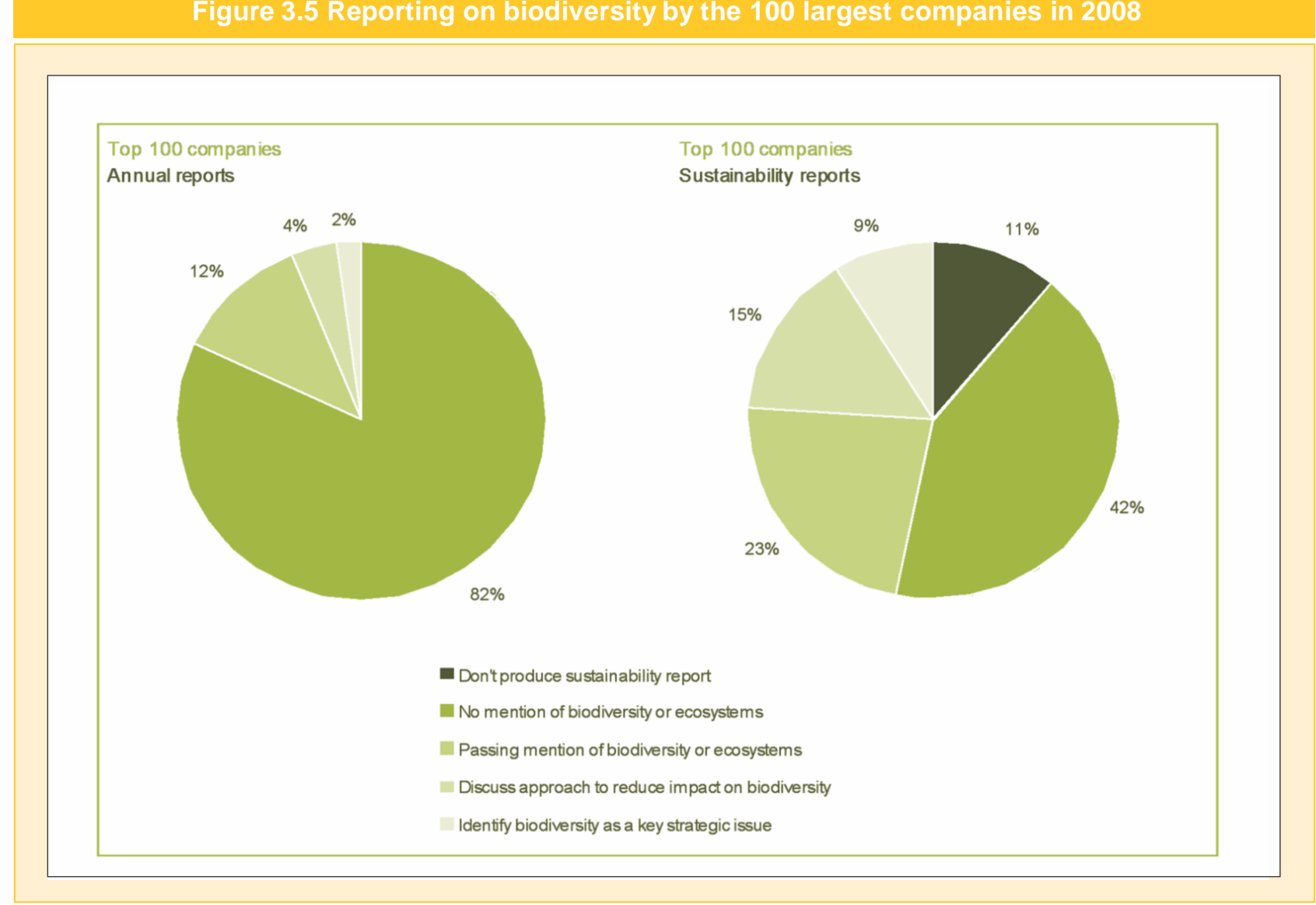

Source: PricewaterhouseCoopers for TEEB

companies in the world in 2008, by revenue, only 18 made any mention of biodiversity or ecosystems in their annual reports. Of these 18, just six companies reported measures to reduce their impacts and only two companies identified biodiversity as a key strategic issue.

Of the same 100 companies, 89 publish a sustainability report. Of these, 24 disclose some measures taken to reduce impacts on BES, while nine companies identified impacts on biodiversity as a key sustainability issue (Figure 3.5).

Further analysis focused on a subset of the 100 largest companies, including only those that fall into either high biodiversity impact or high biodiversity dependent sectors. Looking first at these companies' annual reports, we observe a similar pattern as was found for the top 100 companies, with the proportion of biodiversity reporters in each category almost the same (Figure 3.6). Looking at these companies' sustainability reports, however, there is a notable difference, with a significantly larger proportion of the high dependence or high impact group identifying biodiversity as a key strategic issue (19\% versus $9 \%$ ) and a higher proportion reporting measures to reduce their impacts on biodiversity (36\% versus $24 \%)$.

More detailed examination of corporate reporting on BES shows that the information presented by companies is rarely sufficient to enable external stakeholders to form an accurate picture of companies' efforts to assess, avoid, mitigate or offset their impacts on BES. A survey (Grigg et al. 2009) conducted by Fauna and Flora International in 2008-09 as part of the Natural Value Initiative showed that companies in the food, beverage and tobacco sectors produced limited public disclosures, rarely stated clear targets and used mainly qualitative data (case studies, descriptions of initiatives) to communicate their management of biodiversity and ecosystems, rather than quantitative indicators of performance. Only 15 of the 31 companies evaluated in this survey were able to provide reasonable disclosures in relation to BES, despite the focus on sectors in which both impacts and dependence on biodiversity and ecosystem services are relatively high. 


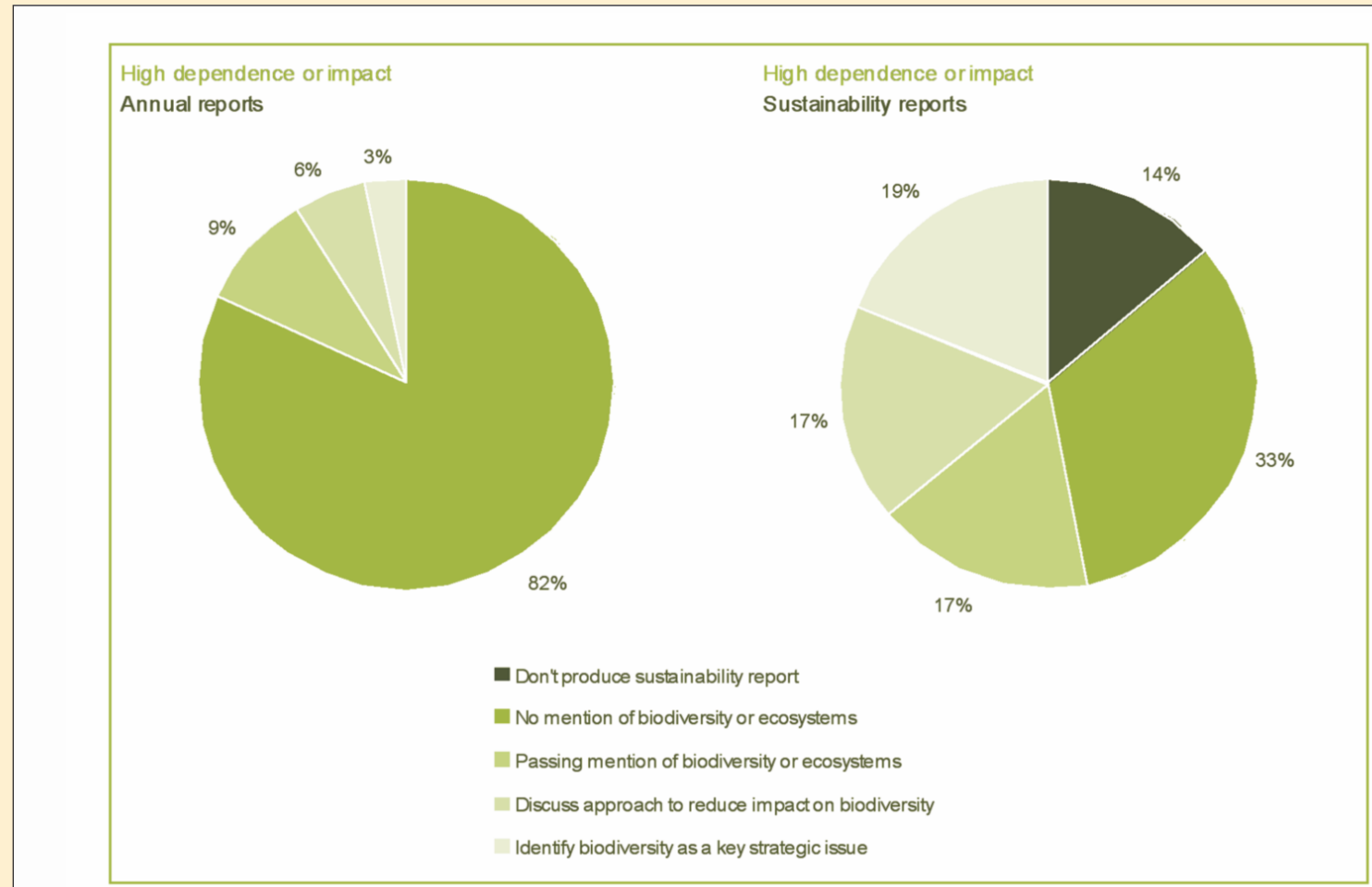

Similar studies conducted by UK based asset manager Insight Investment on the extractive industry, one on 22 companies in 2004 (Grigg et al. 2004) and another on 36 companies in 2005 (Foxall et al. 2005), revealed similar results. Information is often qualitative in nature and frequently scattered throughout a company's website. As a result, it can be challenging for stakeholders, including investors, to assess whether a company has understood its BES risk exposure and is managing these risks effectively.

Both the Natural Value Initiative's review of the food, beverage and tobacco sectors, and Insight Investment's review of the extractive sector, highlighted that even companies that are relatively advanced in considering this

\section{Box 3.6 Selected initiatives offering guidance on BES measurement, management and reporting}

- Integrated Biodiversity Assessment Tool - www.ibatforbusiness.org

- Natural Value Initiative - www.naturalvalueinitiative.org

- Global Reporting Initiative -G3 guidelines and industry sector supplements www.globalreporting.org

- Stewardship Index for Specialty Crops - www.stewardshipindex.org

- The Keystone Centre - Field to Markets Alliance for Sustainable Agriculture www.keystone.org

- Roundtable on Sustainable Palm Oil - www.rspo.org

- Roundtable on Sustainable Biofuels - http://cgse.epfl.ch

- Energy and Biodiversity Initiative - www.theebi.org

- ICMM Good Practice Guidance for Mining and Biodiversity - www.icmm.com

- IPIECA/API Oil and Gas Industry Guidance on Voluntary Sustainability Reporting - www.ipieca.org

- WBCSD Cement Sustainability Initiative - www.wbcsdcement.org

- Forest Footprint Disclosure Project - www.forestdisclosure.com

- Water Footprint Network - www.waterfootprint.org 
issue are struggling with performance indicators for BES management and reporting. A number of companies are working with sectoral initiatives, such as the Global Reporting Initiative sector supplements to develop improved standards of reporting (see Box 3.6). The development of sector specific indicators offers the opportunity for more targeted measurement and reporting within sectors characterized by high BES impact or dependence.

\subsubsection{GUIDANCE ON BES REPORTING}

Whilst few organisations in the public or private sectors report comprehensively (or at all) on biodiversity and/or ecosystems in their annual report and accounts, a few more do so in separate annual sustainability or corporate responsibility reports. Here, unlike in financial reporting, there are no mandated standards that all companies or organisations must follow. Examples of how some companies report on BES are provided in Boxes 3.7, 3.8 and 3.9).

\section{Box 3.7 Biodiversity reporting by Rio Tinto}

Biodiversity values assessment for our sites (2009)

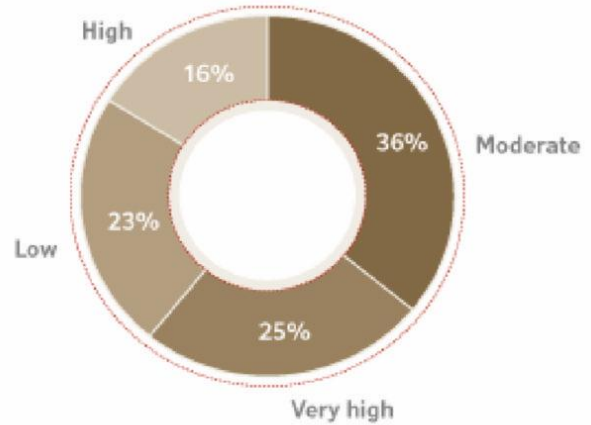

Recorded species of conservation significance with habitats or life cycle dependency on areas within the land holding (a), (b)

\begin{tabular}{|c|c|c|}
\hline & $\begin{array}{l}\text { Number of } \\
\text { operations }\end{array}$ & $\begin{array}{l}\text { Number of } \\
\text { species }\end{array}$ \\
\hline & $59(65)$ & $559(698)$ \\
\hline $\begin{array}{l}\text { High value } \\
\text { - Critically endangered or endangered species } \\
\text { (IUCN or nationally listed); and } \\
\text { - Site/local endemics }\end{array}$ & $38(47)$ & $280(345)$ \\
\hline $\begin{array}{l}\text { Moderate value } \\
\text { - Threatened or vulnerable species (IUCN or } \\
\text { nationally listed), and } \\
\text { - Restricted range species }\end{array}$ & $47(59)$ & $193(248)$ \\
\hline $\begin{array}{l}\text { Low value } \\
\text { - Near threatened or conservation dependent } \\
\text { species (IUCN or nationally listed); and } \\
\text { - National listed serious decline (NZ), gradual } \\
\text { decine (NZ), special concern ( } C a n a d a) \text {, and } \\
\text { rare (South Africa) }\end{array}$ & $28(32)$ & 59 (105) \\
\hline
\end{tabular}

(a) GRI -EN 15 Number of IUCN Red List species and national conservation list

(b) The number inside the brackets is the number of species that could be

present on the land holdings and the number of operations at which these

species occur. The number outside the brackets is the total number of species

of conservation value that have been recorded as having habitats or life cycle

dependency on areas within the land holdings, and the number of operations at

which these species occur.
Rio Tinto is a major international mining company with operations in more than 50 countries, employing approximately 102,000 people. In 2004, Rio Tinto launched its biodiversity strategy which includes the over-arching goal to have a 'net positive impact' (NPI) on biodiversity. The company has developed practical tools and methodologies to assess the biodiversity values of their land holdings and has commenced, in association with its conservation partners, the application of offset methodologies in Madagascar, Australia and North America. In 2009, Rio Tinto completed a methodology for developing Biodiversity Action Plans (BAPs) in collaboration with Fauna and Flora International (FFI). Rio Tinto reports on the biodiversity value of its sites, the amount of land in proximity to biodiversity rich habitats, and the number of plant and animal species of conservation significance within these land holding. This information is reported on their corporate website. 


\section{Box 3.8 Biodiversity in Scottish Power plc 2004 environmental report}

Scottish Power publishes an annual Environmental Performance Report, which includes a section on 'Land and Biodiversity'. The 2004 report lays out the company's policy on biodiversity and summarises their objectives and targets under five priority areas of minimising impact, fisheries, birds, land reclamation and contamination.

Each section of Scottish Power's Environmental Performance Report sets out their potential impacts on biodiversity and their general approach to the issues. A key issue associated with birds, for example is overhead lines: "Overhead lines have the potential to harm birds so we have conducted surveys to identify high-risk areas, often in partnership with other organisations, and then implement bird protection programmes to reduce or prevent injuries and mortalities. In the UK bird diverters have been fitted to many lines crossing rivers and canals to reduce the risk of collision by wildfowl such as swans and geese."

As well as summarising the key biodiversity issues for the company and their achievements over the year, Scottish Power summarise their current targets, progress against these targets and sets revised targets for the following year in concise tables. Progress is illustrated through boxes showing key achievements such as awards received and new habitats created on Scottish Power land.

Source: $h$ ttp://www.scottishpower.com/pdf/esir04/environment/environmental_performance report_03 04.pdf

\subsubsection{INTEGRATED REPORTING}

Increasingly, many stakeholders are exploring how to integrate financial and non-financial information in a single report that provides a balanced and meaningful picture of a company. Early examples from companies such as Natura and Telefonica are based around providing annual reports and CSR/sustainability reports as a single package. Some companies produce these as paired documents and others as a single volume.

Alongside the pioneering efforts of individual companies, other networks and standards bodies are also exploring how to promote more integrated reporting. With respect to BES, the challenge is how to manage and track information within a company and how to ensure that the economic values of BES are properly reflected at a level of detail that can influence corporate financial analysis.

\subsubsection{BARRIERS TO BETTER BES ACCOUNTING AND REPORTING}

Several barriers to comprehensive corporate disclosure on BES remain to be resolved, including:

Lack of consistent 'currency' or metrics: although different initiatives and companies have developed metrics of relevance to BES, there is no single unit of measure or set of performance metrics that are consistently applied by companies within let alone across a range of sectors. In the case of greenhouse gas reporting by business, a key turning point was the publication of the WRI/WBCSD (WRI 2001/2004). Currently no such guidance exists for biodiversity or ecosystem reporting and developing such a standard is arguably more challenging, as BES encompass a wide range of issues and there is no one indicator that can provide a reference point for assessing progress.

Perceived immateriality: the absence of a compelling company-level business case that sets out the financial costs and benefits of (mis)managing BES results in a perceived lack of importance of the issue amongst many company managers and investors. The lack of prices for many intangible ecosystem services is a large part of this problem. 


\section{Box 3.9 Biodiversity in Baxter Healthcare 2008 sustainability report}

Baxter Healthcare has a long-standing commitment to transparency with respect to its environmental costs and savings. Baxter is also unusual in the level of detail provided on biodiversity issues in a recent sustainability report.

While biodiversity is not among Baxter's stated sustainability priorities, it is an element of the company's bioethics policy: "Baxter recognizes that protecting the environment and maintaining the biological diversity of our planet is of vital importance to human life. Baxter believes in the importance of maintaining global biodiversity and sustainable use of global resources."

Baxter owns or leases approximately 910 hectares of land, about one quarter of which is impermeable (paved) surface. Baxter's operations typically are located in light industrial areas in metropolitan regions. However, twenty- one of Baxter's 58 manufacturing and research and development facilities are located in some of the world's bio- diversity 'hot spots' as defined by Conservation International.

Baxter facilities undertake various initiatives to protect biodiversity. For example, since 2006 the company's facility in Round Lake, Illinois, in the United States, has worked with a professional habitat restoration company and the local forest preserve to restore four hectares of the campus to a more natural habitat, including wooded savannah and a stream-bank riparian zone. As part of the project, the site used controlled burning to destroy invasive alien species. After the burn, Baxter employees planted 750 native plant species in an effort to facilitate regeneration of the native vegetation.

Source: See Baxter 2008 sustainability report at http://www.sustainability.baxter.com

Lack of understanding: issues related to biodiversity and ecosystem services are often viewed as complex, in comparison to issues such as climate change, water and human rights. Understanding how BES issues and impacts relate to other sustainability concerns remains challenging and as a result many companies do not know how to being measuring and reporting effectively on BES.

Issues of scope: the sustainable use of biodiversity and ecosystem services frequently goes beyond the measurement boundaries of direct ownership and control, and therefore is both difficult to quantify and difficult to measure. Clarity is required on what constitutes a reasonable reporting scope for a company

Lack of demand: the failure of investors to demand data on BES impacts and dependence may reflect the relatively short-term focus of many people in the investment community.

Challenges in aggregation: BES lends itself best to measurement when confined to a specific site or land area, and is challenging to aggregate into indicators that describe overall corporate performance. Further, it is often difficult to attribute changes in biodiversity or ecosystem services to the actions of an individual company. 
Despite all of the barriers and challenges reviewed above, there are significant opportunities to improve the measurement and disclosure of BES in business. Companies can take action on their own or in collaboration with others to address these barriers. This section outlines the way forward for integrating BES in business valuation, accounting and reporting.

\subsubsection{TECHNICAL IMPROVEMENTS}

Further work is needed on the fundamental science and practical techniques of measuring BES at site, product and organizational levels. Opportunities include the following:

Advance scientific assessment, provision of relevant information and appropriate safeguards: Accessible information and relevant data on BES are essential for making sound business decisions that properly account for impacts on biodiversity and dependence on ecosystem services. Progress is being made in understanding how human actions affect the ecosystem, for example with satellite imaging and remote sensing. In addition, national and international standards are improving, and various frameworks for assessing ecosystem impacts have been developed.

Gaps remain in the scientific data and information required to link the status of biodiversity or the condition of particular ecosystems to the delivery of specific ecosystem services, as well as how these may change if ecosystems are degraded. Some of the risks associated with ecosystem decline and biodiversity loss may be uncertain but potentially catastrophic and irreversible. An options valuation approach might be one way to address these risks - by preserving BES, a firm (and society) retains an option on the availability of these resources in the future. However, in view of the long-term considerations and present uncertainty about where tipping points lie, it may be difficult for firms to address these risks adequately or take decisions that appropriately account for them. Therefore responsibility for ensuring that biodiversity degradation does not exceed a tipping point may fall to governments and regulators, which need to set clear limits on resource use or ecosystem conversion and disturbance. Moreover, governments, international organisations and other public bodies must work together to ensure that the policy direction is communicated effectively at the earliest possible stage, and that regulation is clear, easy to understand and does not introduce perverse incentives.

Current impact assessment methodologies in LCA address a number of drivers for loss in biodiversity and ecosystem services. Their results need to be communicated more widely so that LCA is able to provide an overview of a range of environmental impacts including loss in BES. Advanced use of LCA faces barriers similar to those highlighted with respect to reporting methodologies, including understanding cause-effect chains, defining suitable indicators to quantify changes in BES, and lack of data to calculate such indicators on a global scale. Emerging research and methodological harmonisation on LCA and BES needs to expand the number of drivers of BES loss covered, advance agreement on impact categories and develop illustrative case studies that show how impacts and associated damage can be translated into economic values. Research on land use change can provide practical examples of the complexities involved and the type of methodologies able to link drivers to loss through pressure indicators. Research on downstream risks and opportunities associated with BES, including product use and consumption, is still in its infancy. 
In addition, LCM experts would do well to consider management guidance on boundaries and materiality as they seek to add up impacts along different tiers of the value chain. Avoiding the perception that LCA involves endless, academic analysis of various factors along the full value chain, LCA experts need to provide guidance that helps businesses make practical decisions on what are the most material impacts and dependencies to measure at different stages of the product life cycle and value chain. This requires, among other things, the application of inventory analysis to assess the relevance (direct / indirect) of the different categories of ecosystem services within a particular industry. A tourism business, for example, has more direct links with the cultural services provided by ecosystems, whereas the food and beverage industries have clear dependence on provisioning services such as water.

Integrate BES information with core business planning and decision-making systems: Methodological challenges relate not only to the choice of analytical framework (such as cost benefit analysis), metrics (physical or financial) or the techniques used to value BES, but also to how information on BES values is integrated in business planning and decision-making systems. It is important not to force 'mainstream' economic models into a business perspective, or superimpose a public economic approach onto business calculations. A more productive approach may be to find new ways of valuing BES impacts and dependencies within the context of existing financial and business planning procedures that companies already use. Unless BES values are considered by companies in the same way as other costs, benefits and management decisions, they are likely to remain marginal to corporate decision-making.

\subsubsection{MARKET IMPROVEMENTS}

There are many opportunities to improve valuation techniques and help markets recognize BES more effectively:

Getting externalities into business valuation: When a firm's actions impose a significant externality, and existing legal avenues for redress are not sufficient, governments may wish to 'internalize' BES impacts into relevant business costs or revenues. In the case of damage to ecosystem services (a negative externality), taxes or licences may be used to internalise the cost of depletion. Similarly, tax exemptions or subsidies may be used to encourage business to conserve biodiversity or restore ecosystems. Where relevant, new markets for BES (such as biodiversity credits) can put a market price on biodiversity impacts and dependencies (see Chapter 3.5 in this report).

Align business and social valuations, using regulatory and market mechanisms to reconcile differing discount rates: Assuming that most economies will continue to have a large market sector, the challenge is to encourage commercial entities to make decisions that reflect the values of BES appropriately. Discounted cash flow analysis is likely to remain the dominant valuation and appraisal technique, and investors are likely to continue to expect business managers to apply relatively high discount rates in financial analyses.

As with climate change, decisions taken today may have an impact on BES in the future as well as immediately. The challenge for regulators is to bring potential future losses of BES into today's decision making. Policymakers will need to make judgements about the long-run costs of damage and define appropriate restrictions, licences or taxes that lead businesses to incorporate this cost in their decisions. If such policies are designed correctly, they can help to align business incentives with wider societal values.

Introduce techniques for capturing intangible values: If a business does recognise that its actions may have an impact on intangible BES values, there are several ways to measure this impact, such as contingent valuation. These tools are currently used most often by public policymakers to assess the social values of BES, but in future are likely to be applied more widely by businesses also, to evaluate their own impacts and dependencies. 
More case studies are needed of the value of BES at the corporate level and to private investors (Box 3.10). Further research is required to establish the costs and benefits of managing BES sustainably (or mismanaging them), with a view to establishing more reliable estimates that business (and regulators) can use to internalize biodiversity costs.

\section{Box 3.10 The Ecosystem Services Benchmark}

Several tools have been developed within the asset management community to evaluate the BES risks and opportunities of investments. One example is the Ecosystem Services Benchmarking (ESB) tool, developed by the Natural Value Initiative in collaboration with investors from Europe, Brazil, the USA and Australia (Aviva Investors, F\&C Investments, Insight Investment, Pax World, Grupo Santander Brasil and the Australian pension fund VicSuper). Designed to assess investment risk and opportunity associated with BES impacts and dependence in the food, beverage and tobacco sector, the Ecosystem Services Benchmark is aimed primarily at asset managers, but can also inform the banking and insurance sectors more generally. It has a secondary application for companies within the food, beverage and tobacco sectors, for which it provides a framework within which to consider the issue.

The ESB focuses on impacts and dependencies on biodiversity and ecosystem services associated with the production and harvesting of raw materials in companies with agricultural supply chains (including agricultural commodities, livestock and fish). It evaluates companies against five broad categories of performance; competitive advantage, governance, policy and strategy, management, and implementation and reporting. Each company evaluated receives a summary of their results. By incorporating discussion of the recommendations and outcomes of the analysis into investor dialogues with poorly performing companies, improved performance can be encouraged and ultimately risk is more effectively managed.

Source: $h$ ttp://www.naturalvalueinitaitive.org

Educate investors and set minimum requirements for BES in financial ratings: In a review of 20 rating agencies, investment indices and ranking services was conducted by IUCN (Mulder, 2007), only one made specific reference to biodiversity - the Business in the Community Environment Index, in which companies were invited to complete voluntary questions on biodiversity. A more recent study by the Nyenrode Business School, Amsterdam, showed that whilst there was demand from clients such as pension funds, rating agencies rarely supply their clients with biodiversity related information - in large part because metrics are unavailable but also because they perceived limited demand for such information. Ultimately, the quality of business measurement and reporting on BES will depend on the quality of questions asked by investors, analysts and other stakeholders.

\subsubsection{DISCLOSURE IMPROVEMENTS}

The information on BES presented in most company reports is rarely set out in a way that communicates that: 1) key risks have been identified, 2) policy and position on the issue is clear, 3) a strategy to address those risks has been developed, 4) management tools are in place to address the risks, and 5) monitoring and review of processes is being undertaken to ensure implementation. Without such information, reports on BES are of limited value to an investor or any other stakeholder with an interest in BES. From their benchmarking analysis of corporate disclosure on risks related to water scarcity, CERES et al. (2010) concluded that the vast majority of companies in water-intensive industries have weak management and disclosure of water-related risks and opportunities. CERES' report scored a hundred companies based on five categories of disclosure: water accounting, risk assessment, direct operations, supply chain management and stakeholder engagement. 
Some steps that can be taken to improve the situation include:

Encourage enhanced reporting on existing BES activities: Many companies could significantly improve their reporting by disclosing more fully the actions they undertake to understand and manage biodiversity and ecosystem services. Examples might include the presence of risk management frameworks, policies, strategy and targets, assessment of potential impacts on sensitive sites and actions taken to mitigate them, management plans and other activities undertaken to manage BES issues.

Increase cross sector collaboration to develop and apply performance metrics and reporting guidance for BES: Pilot projects and cross sector collaboration will be required to develop BES metrics that are relevant to both corporate management processes and global conservation priorities. The need for sector specific reporting guidelines within such an approach should continue to be explored. A number of platforms and processes exist at various levels that could advance the issue (e.g., the Convention on Biological Diversity, roundtables on sustainable soy, palm oil, and other commodities, the GRl's ongoing work on reporting guidance for industry sectors supplements, etc.).

Improve mandatory requirements for companies to assess material environmental issues (including BES) in reporting: In many jurisdictions, companies are required to include material information in their annual accounts and are also sometimes subject to other forms of public reporting. With respect to annual accounts, governments should consider how to improve the understanding of materiality to result in more detailed reporting. Where economic instruments have been implemented to drive environmental performance, e.g. carbon trading, it is particularly important to provide such guidance.

In its overview of reporting legislation world-wide, the report 'Carrots and Sticks' by KPMG and UNEP (2006: 57) noted that the viability of most regulatory instruments is dependent on the availability and quality of relevant information. For example, adequate reporting on greenhouse gas emissions is required for carbon markets to function properly. Many stakeholders would add that such disclosures require 3rd party verification and assurance, just as financial accounts require independent validation. The recent decision by the US Securities and Exchange Commission (February 2010) to require disclosure on climate change issues and the environment that affect capital expenditures (infrastructure issues), products and certain financial expenses (insurance) will have significant bearing on future financial reporting of environmental assets and liabilities by business.

In addition to reporting in annual accounts, other reporting requirements can exist such as product-based, issuebased and site-based reporting. This raises the possibility of linking these requirements in a comprehensive reporting framework. The 'Carrots \& Sticks II' report by UNEP, GRI, KPMG et al. (2010) confirmed the growing regulatory interest in integrated reporting. 


\section{Endnotes}

1 See the report originally published by ISIS Asset Management, a UK-based socially responsible investment firm now part of F\&C Asset Management plc, a publication entitled "Is Biodiversity a Material Risk for Companies? An assessment of the exposure of FTSE sectors to biodiversity risk", September 2004, available online at: www.businessandbiodiversity.org/publications

2 See more detail under the UNEP Climate Neutral Initiative at www.unep.org/climateneutral 


\section{References}

AccountAbility (2008) AA1000 AccountAbility Principles Standard. London: AccountAbility. URL: www.accountability21.net

Carson, R., Mitchell, R., Hanemann, W., Kopp, R., Presser, S. and Ruud, P. (1992). "A Contingent Valuation Study of Lost Passive Use Values Resulting from the Exxon Valdez Oil Spill". Report to the Attorney General of the State of Alaska. 10 November 1992.

CERES, UBS and Bloomberg (2010) Murky Waters? Corporate

Reporting on Water Risk. Boston:

CERES

De Haes, U. et al. (1999). Best available practice regarding impact categories and category indicators in Life cycle impact assessment. Background document for the second working group on Life cycle impact assessment of SETAC-Europe (WIA-2). International. Journal of LCA 4 (1999) pages 66 - 74

Emerton, L, Grieg-Gran, M., Kallesoe, M. and MacGregor, J. (2005). "Economics, the precautionary principle and natural resource management:key issues, tools and practices" in Rosie Cooney and Barney Dickson (eds). Biodiversity and the precautionary principle: risk and uncertainty in conservation and sustainable use. Earthscan, London.

Eurosif \& Oekom Research (2009) Biodiversity. Theme report - 2nd in a series. Paris / Munich: European Sustainable Investment Forum and Oekom Research AG.

Foxall, J., Grigg, A. and Ten Kate, K (2005) Protecting shareholder and natural value. 2005 benchmark of biodiversity management practices in the extractive industry. Insight Investment, London, UK

Global Reporting Initiative, (2005) Boundary Protocol. Amsterdam: GRI

Global Reporting Initiative (GRI) (2006) Sustainability Reporting Guidelines. Amsterdam: GRI. URL: www.globalreporting.org

Grigg, A., Cullen, Z., Foxall, J., and Strumpf, R. (2009) Linking shareholder and natural value. Managing biodiversity and ecosystem services risk in companies with an agricultural supply chain. Fauna and Flora International, United Nations Environment Programme Finance Initiative and Fundação Getulio Vargas.

ICMM (2003) Landmark 'no-go' pledge from leading mining companies. URL: http://portal.unesco.org/culture/fr/files/12648/ 10614596949ICMM_Press_Relase.pdf/ICMM_Press_Relase.pdf

International Accounting Standards Board (IASB) (2001), The Objective of Financial Statements. London: IASB.

International Organisation for Standardisation (ISO). Guidance on Social Responsibility. ISO/TMB WG SR IDTF_N101, draft July 2009.

ISIS Asset Management (2004). Are Extractive Companies Compatible with Biodiversity? Extractive Industries and Biodiversity: A Survey . London : ISIS Asset Management, February 2004 Jolliet, O., Margni, M., Charles, R., Humbert, S., Payet, J., Rebitzer,
G. And Rosenbaum, R. (2003) "IMPACT 2002+: A new life cycle impact assessment methodology" in The International Journal of Life Cycle Assessment, Volume 8, Number 6 / November, 2003, pages 324-330

JPMorgan Chase (no date) Public Environmental Policy Statement. URL: http://www.jpmorganchase.com/corporate/CorporateResponsibility/environmental-policy.htm

King Committee, The (2009) King Report on Governance for South Africa. Johannesburg: Institute of Directors

Koellner, T. (2003) Land Use in Product Life Cycles and Ecosystem

Quality, Bern, Frankfurt a. M., New York: Peter Lang.

Koellner, T. and Scholz, R. (2008) 'Assessment of land use impacts on the natural environment. Part 2: Generic characterization factors for local species diversity in Central Europe', International Journal of LCA, 13(1): 32-48

KPMG Sustainability B.V. (2008). International Survey of Corporate Responsibility Reporting 2008. Amsterdam: KPMG International.

Madsen, B., Carroll, N., Moore Brands, K. (2010) State of Biodiversity Markets Report: Offset and Compensation Programs Worldwide. at: http://www.ecosystemmarketplace.com/documents/acrobat/sbdmr.pdf

Mulder, I. (2007). Biodiversity, the Next Challenge for Financial Institutions? Gland, Switzerland: IUCN.

Savage, D. and Jasch, C.M. (2005) International Guidance Document on environmental management accounting (EMA), International Federation of Accountants, IFAC, New York 2005, www.ifac.org

Schmidt, J. (2008) 'Development of LCIA characterisation factors for land use impacts on biodiversity', Journal of Cleaner Pro- duction, 16(18): 1929-1942

UK Environmental Agency, (2004). Corporate Environmental Governance. A study into the influence of Environmental Performance and Financial Performance. Environment Agency, Bristol, UK

United Nations Division for Sustainable Development (UNDSD). (2001) Environmental Management Accounting, Procedures and Principles. New York, Geneva: United Nations Publications.

United Nations Environmental Program (UNEP), and UN Global Compact CEO Water Mandate (2010). Corporate Water Accounting. Oakland: Pacific Institute.

United Nations Environmental Program (UNEP) and KPMG Sustainability Services. (2006) Carrots and Sticks for Starters. Current trends and approaches in Voluntary and Mandatory Standards for Sustainability Reporting. Amsterdam / Paris: KPMG, UNEP DTIE.

United Nations Environmental Program(UNEP), KPMG Sustaina- 
bility Services, University of Stellenbosch Business School (USB) and Global Reporting Initiative (GRI). (2010) Carrots and Sticks Promoting Transparency and Sustainability. Amsterdam: GRI, KPMG, UNEP, USB.

Verfaillie, H., and R. Bidwell (2000), Measuring Eco-efficiency: A Guide to Reporting Company Performance, World Business Council for Sustainable Development, Geneva

Walker, S, Brower, A.L., Stephens, R.T. Theo, L. and William G. (2009) "Why bartering biodiversity fails" in Conservation Letters, Volume 2, Number 4, August 2009 , pp. 149-157(9).

World Business Council for Sustainable Development / WBCSD (2009). Corporate Ecosystem Valuation: Building the Business Case. Geneva: World Business Council for Sustainable Development

World Resources Institute (WRI) and World Business Council for Sustainable Development (WBCSD) (2008) Corporate Ecosystem Service Review. Washington DC, Geneva: WRI, WBCSDURL: www.wri.org/publication/corporate-ecosystemservices-review

World Resources Institute (WRI) and World Business Council for Sustainable Development (WBCSD) (2001 / 2004) The Greenhouse Gas Protocol. Washington DC, Geneva: WRI, WBCSD . URL: www.ghgprotocol.org/standards/corporate-standard

Zadek, S. and Merme, M. (2003) Redefining Materiality. Practice and public policy for effective corporate reporting. London: AccountAbility 


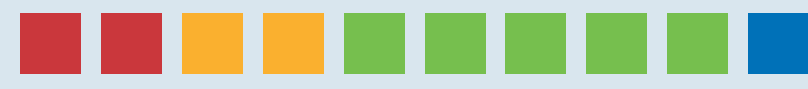 THE ECONOMICS OF ECOSYSTEMS AND BIODIVERSITY \\ TEEB $\quad$ FOR BUSINESS}

Chapter 1 Business, biodiversity and ecosystem services

Chapter 2 Business impacts and dependence on biodiversity and ecosystem services

Chapter 3 Measuring and reporting biodiversity and ecosystem impacts and dependence

Chapter 4 Scaling down biodiversity and ecosystem risks to business

Chapter 5 Increasing biodiversity business opportunities

Chapter 6 Business, biodiversity and sustainable development

Chapter 7 A recipe for biodiversity and business growth 


\section{Chapter 4: Scaling down biodiversity and ecosystem risks to business}

TEEB for Business Co-ordinator: Joshua Bishop (International Union for Conservation of Nature)

Editors: Nicolas Bertrand (UNEP), Mikkel Kallesoe (WBCSD)

Contributing authors: Conrad Savy (Cl), Bambi Semroc (Cl), Gérard Bos (Holcim), Giulia Carbone (IUCN), Eduardo Escobedo (UNCTAD), Naoya Furuta (IUCN), Marcus Gilleard (Earthwatch), Ivo Mulder (UNEP FI), Rashila Tong (Holcim)

Acknowledgements: David Bresch (Swiss Re), Jürg Busenhart (Swiss Re), Toby Croucher (Repsol/IPIECA), Andrea Debbane (Airbus), Andrew Deutsch (Philips), Anne-Marie Fleury (ICMM), Juan Gonzalez-Valero (Syngenta), Paul Hohnen, Mira Inbar (Dow), Sachin Kapila (Shell), Chris Perceval (WRI), David Richards, Oliver Schelske (Swiss $\mathrm{Re}$ ), James Spurgeon (ERM), Virpi Stucki (IUCN), Geanne van Arkel (InterfaceFlor), Mark Weick (Dow), Bernd Wilke (Swiss Re)

Disclaimer: The views expressed in this report are purely those of the authors and may not in any circumstances be regarded as stating an official position of the organisations involved.

The final edition of the TEEB for Business report will be published by Earthscan. If you have any additional information or comments you feel should be considered for inclusion in the final report then please email them by 6th September, 2010 to: teeb4biz@ufz.de

TEEB is hosted by the United Nations Environment Programme and supported by the European Commission; the German Federal Environment Ministry; the UK Government's Department for Environment, Food and Rural Affairs; the UK Department for International Development; Norway's Ministry for Foreign Affairs; The Netherlands' Interministerial Program Biodiversity; and the Swedish International Development Cooperation Agency. 


\section{THE ECONOMICS OF ECOSYSTEMS AND BIODIVERSITY}

\section{Chapter 4}

\section{Scaling down biodiversity and ecosystem risks to business}

\section{Contents}

Key messages $\quad 3$

4.1 Introduction 4

4.2 Integrating biodiversity and ecosystems into corporate risk management 5

4.3 Tools for managing biodiversity and ecosystem risks 13

$\begin{array}{ll}\text { 4.3.1 Standards, frameworks and methodologies } & 13\end{array}$

$\begin{array}{ll}\text { 4.3.2 Data collection tools } & 14\end{array}$

$\begin{array}{ll}\text { 4.3.3 Modelling and scenario building } & 17\end{array}$

4.3.4 Improving tools for biodiversity and ecosystems 18

$\begin{array}{ll}4.4 & \text { Strategies for scaling down biodiversity and ecosystem risk }\end{array}$

$\begin{array}{ll}\text { 4.4.1 Stakeholder engagement } & 20\end{array}$

$\begin{array}{ll}\text { 4.4.2 Partnerships } & 21\end{array}$

4.4.3 Adaptive management $\quad 24$

4.5 Conclusions and recommendations 26

$\begin{array}{ll}\text { References } & 28\end{array}$

\section{Boxes}

4.1 Holcim and IUCN: Implementing a biodiversity management system

4.2 Applying the mitigation hierarchy and biodiversity offsets in the financial sector

4.3 The Corporate Ecosystem Services Review

4.4 The Global Water Tool: helping companies make water-informed decisions

4.5 ARtificial Intelligence for Ecosystem Services (ARIES)

4.6 Investing in water knowledge versus the costs of bad decisions and restoration

4.7 Partnerships in the building materials sector

4.8 Business engagement initiatives under the CBD

4.9 Integrating biodiversity into business management and operations - the BAT Biodiversity Partnership

\section{Figures}

4.1 Financial consequences of climate policies and restricted access to petroleum reserves

4.2 The extractive project life cycle

4.3 Net Positive Impact and the mitigation hierarchy

4.4 Adaptive management framework

\section{Tables}

4.1 Biodiversity risks in different sectors

4.2 Benefits of corporate - NGO partnerships 


\section{Key messages}

Biodiversity and ecosystem risks to business are real, tangible and should be managed: Public acceptance of biodiversity loss is declining, leading to calls for low-impact production and increased compensation for adverse impacts on biodiversity and ecosystems.

Businesses are finding new ways to integrate biodiversity and ecosystems into risk assessment and management: Many companies are exploring how to manage the adverse impacts of their activities on BES. A few companies have made public commitments to 'No Net Loss', 'Ecological Neutrality' or even 'Net Positive Impact' on biodiversity, or on specific ecosystem services such as water resources.

A range of practical tools are available to help business reduce biodiversity and ecosystem risks: These tools include standards, frameworks and methodologies, data collection and analysis tools, as well as model and scenario building tools.

Economic valuation of biodiversity costs and benefits can inform risk management: In some cases, ecological restoration or offsets can deliver biodiversity and ecosystem benefits that exceed those of the original land use, and at modest cost. More work is needed to integrate economic valuation into environmental risk management.

Managing biodiversity risk involves looking beyond sites and products to the wider land and seascape: In many industries, corporate environmental risk management has focused on direct or primary impacts. However, increasing public scrutiny and more stringent regulations have led companies in a range of sectors to extend their risk horizon to include indirect or secondary impacts.

Effective biodiversity and ecosystem risk management may be facilitated by appropriate enabling frameworks and partnerships: These may include new markets for biodiversity-friendly products, investment screening processes that require attention to biodiversity impacts, and/or regulatory settings that pay close attention to biodiversity risks during the impact assessment process. Business risk management strategies also often involve public-private partnerships and stakeholder engagement. 
Business risks can stem from uncertainty in financial markets, project failures, legal liabilities, credit risk, accidents, natural causes and disasters as well as activist campaigns.

Business risk management is a process of identifying potential risks, assessing the level of risk presented based on the probability and severity of potential issues and prioritizing the risks based on available information and the financial materiality of the risk specifically to the company (as opposed to broader society).

The loss of biodiversity and the degradation of ecosystems can also lead to business risks. Failure to manage these risks adequately can leave companies vulnerable to a range of costly repercussions - including supply shortages, advocacy campaigns, fines and increasing regulations, declining customer demand for products and services and increasing difficulty in securing financing for projects.

Although current market practices do not adequately capture these risks, several elements suggest that this may be changing:

- Increasing requirements by voluntary and legislated codes on corporate governance as well as corporate social responsibility of companies to disclose material risks, as well as systems for the identification, evaluation and management of such risks ${ }^{1}$. Sometimes these will include risks from biodiversity and ecosystem services.

- New environmental legislation, such as the EU Environmental Liability Directive (ELD), increases potential liabilities of operators and therefore may create the need for risk transfers solutions such as insurance. As a consequence, insurers are challenged to find new ways of capturing and evaluating biodiversity and ecosystem services related risks (Busenhart et al. 2010).

- The inclusion of sustainability issues, including in some cases biodiversity and ecosystem services, into business school curricula².

In addition, biodiversity and ecosystem services tools and approaches already exist to help companies identify potential risks, assess the degree of risk and develop effective management strategies to mitigate risks. However, the full integration of biodiversity and ecosystem services within corporate environmental management systems is still in its early stage, partly reflecting the following:

- The lack of sound understanding of biodiversity and ecosystem services creates challenges in predicting the likelihood and severity of business impacts.

- Impacts on biodiversity and ecosystems often have global dimensions and consequences that may affect future investments and markets, for instance through the loss of vital inputs, increasing the cost of doing business, and reduced market demand.

Risks may also be seen as an opportunity for increased market share, new products and services, or the potential to better serve customers or society as a whole. Risk then becomes an asset rather than a liability (we examine more fully the opportunity component of risk management in chapter 5 of this report).

This chapter explores actions taken by companies to identify, manage and scale down biodiversity and ecosystem risks. It begins with an overview of corporate risk management systems and efforts made to integrate biodiversity and ecosystems within them (section 4.2), followed by a review of existing and emerging tools that can assist in identifying and managing these risks (4.3). The chapter continues with a discussion of best practices for risk management, including stakeholder engagement and adaptive management (4.4), followed by conclusions and recommendations for action (4.5). 


\section{INTEGRATING BIODIVERSITY AND ECOSYSTEMS INTO CORPORATE RISK MANAGEMENT}

Corporate risk management characterizes risk according to the degree of potential impact and the likelihood of the impact occurring. In some cases, a simple 2 dimensional matrix of probability (likelihood) and consequence (severity) can help evaluate risk. More often than not, though, the complexity of the issues involved is likely to call for a more elaborate representation, when $4 \times 4,4 \times 5$ or $5 \times 5$ risk matrices are used. The cells of such a matrix are assigned to one of several risk classes - e.g. critical, very high, high, moderate and low - to which specific management actions are attached, and thereby translating as priorities. A low probability/high consequence risk may, in this sense, be in the same risk class as a moderate probability/moderate likelihood risk.

In addition to determining an acceptable level of risk, the company develops a risk management strategy that identifies residual risks, develops a control strategy, assigns accountability and develops early warning mechanisms to manage these (Jones and Sutherland 1999). Table 4.1 provides a summary of the most likely biodiversity and ecosystem services related risks for different sectors.

For example, as traditional oil producing regions mature and yield progressively less oil, the petroleum industry is increasingly forced to explore and produce in ever more sensitive environments. In socially and environmentally sensitive areas, access to reserves can be denied, restricted, or unresolved. Where access is permitted, opposition from local communities can constrain production operations, making them more costly. Austin and Sauer (2002) assessed financial implications of possible restricted access of extractive companies to company reserves in ecologically important and protected areas. Under different scenarios, access pressures were reflected by different combinations of increased production costs, reduced production capacity and reserves being placed 'off-limits'.

\section{Figure 4.1 Financial consequences of climate policies and restricted access to petroleum reserves}

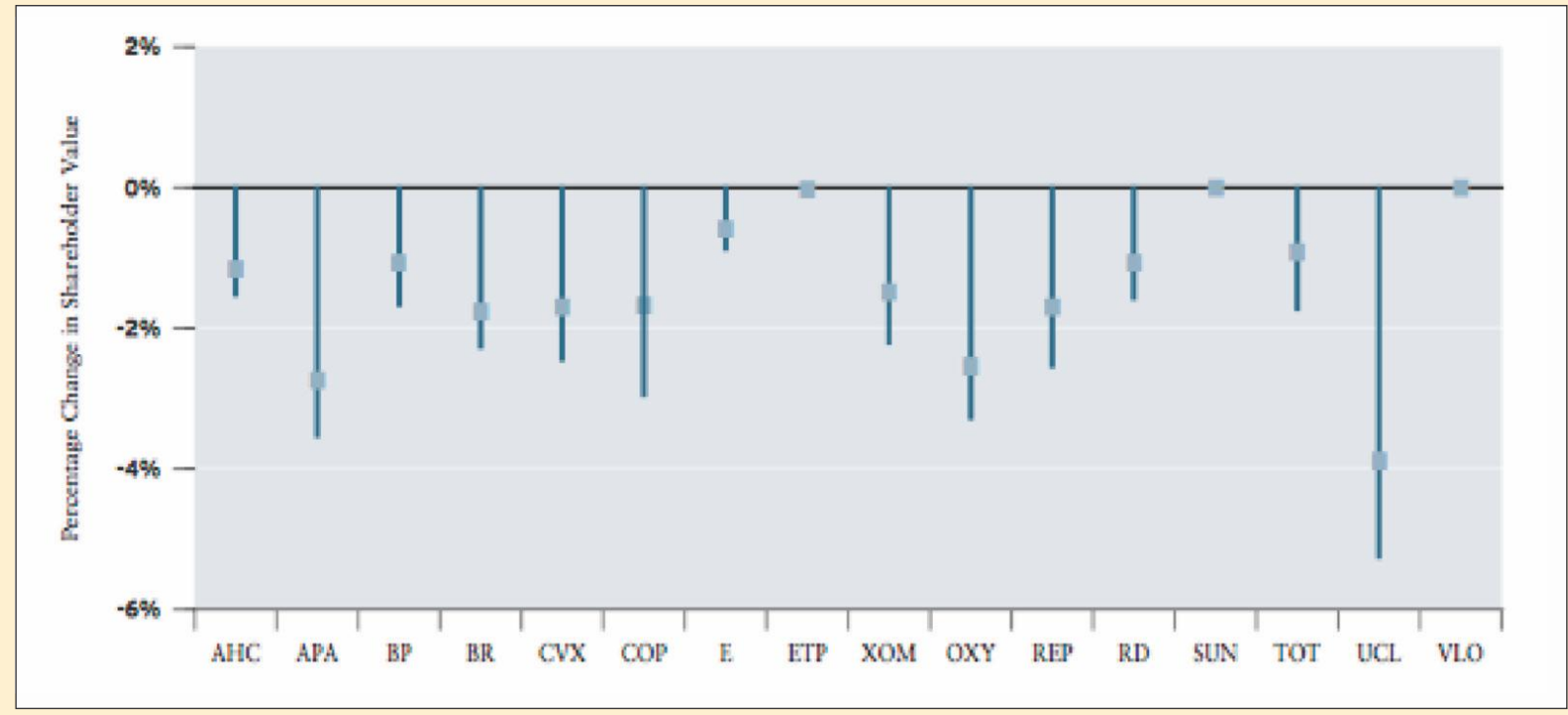

Range of possible outcomes and most likely impact for 16 companies:

Amerada Hess (AHC), Apache (APA), BP (BP), Burlington Resources (BR), ChevronTexaco (CVX), Conoco- Phillips (COP), Eni (E), Enterprise Oil (ETP), ExxonMobil (XOM), Occidental Petroleum (OXY), Repsol YPF (REP), Royal Dutch/Shell Group (RD),

Sunoco (SUN), TotalFinaElf (TOT), Unocal (UCL), and Valero Energy (VLO) 


\section{Table 4.1 Biodiversity risks in different sectors}

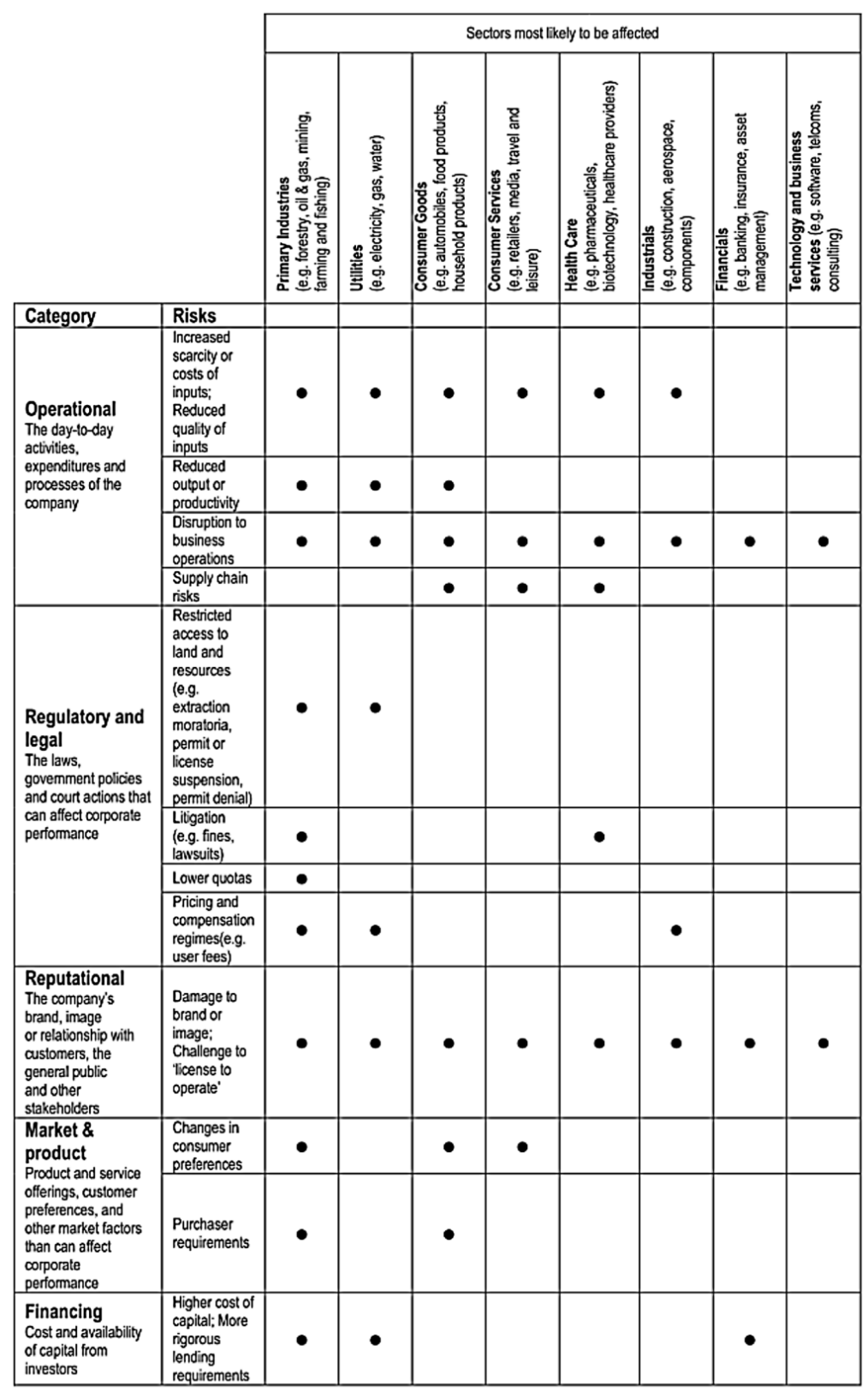

Source: Adapted from Evison and Knight (2010) and WRI et al. (2008)

The results, outlined in Figure 4.1, highlight that large direct footprint sectors, including oil and gas, can face material biodiversity-related risks that result in reduced shareholder value.

Utilities provide another example; the power sector may face a range of business risks as a result of global climate change and degrading ecosystems. $74 \mathrm{GW}$ - over half of existing and planned capacity for major power companies in Asia - is located in areas that are considered to be water scarce or stressed. Overuse of water and degraded ecosystems that are less able to capture or regulate water streams can lead to water-related disruptions for power companies, which can cause load losses or outrages, possibly reducing revenues and increasing costs (Sauer et al. 2010). 
Incorporation of biodiversity and ecosystem services risks into the corporate risk management framework presents some unique challenges.

One challenge is that companies base risk assessment on the potential for the issues to harm their business interests and account for them using financial terms. This results in a lack of accounting for those risks, such as impacts on biodiversity and ecosystems, that do not have a direct financial impact on the company and those that are more difficult to translate into economic losses and gains. The challenge lies in calculating the residual value of these broader societal risks within business accounting frameworks to better integrate them into corporate decision-making processes and weigh them alongside of the traditional factors of price and product quality.

A second challenge is the recourse to Net Present Value (NPV) in planning and managing investments. This means that minimizing early costs is favoured at the expense of incurring higher costs later. A cheaper but more damaging siting option, for instance, might be favoured even though there would be a longer and more damaging outcome, the latter costs discounted to very low values in the NPV calculation.

In most cases, the magnitude of the consequences to biodiversity and ecosystems and to businesses is uncertain due to a lack of scientific understanding of the state of species, habitats and ecosystem functions and their ability to affect resources on which businesses are dependent. This has given rise to the precautionary principle in which companies take actions to reduce the scientific uncertainty.

When assessing risk, businesses tend to focus on direct or primary impacts - those resulting from project activities which are usually limited to the project site and can be avoided or mitigated through management processes, mitigation procedures or the adoption of best practices (EBI 2003). Growing public perception, stricter regulation and more stringent voluntary standards have led to an increasing number of companies extending their risk management activities beyond direct impact considerations to include indirect, or secondary, impacts.

Indirect impacts are those that are not a direct result of project activities but may be triggered by the presence of the project in the broader landscape (EBI 2003). Given the potential for cascading biodiversity and ecosystem effects into the broader land- or sea-scape, there is an increasing interest in landscape level assessments, life cycle assessment processes and supply chain management strategies to mitigate these risks.

Understanding the potential financial implications of a particular risk is a vital input for prioritizing and managing risks. However, these risks are seldom quantified in financial terms (Houdet 2008). They may be perceived as less tangible and having only an indirect, and often unquantifiable, impact on the health of the company. In some instances, however, they may result in a very direct impact on a company's license to operate at a site and, in the worst cases, lead to shut downs of operations and direct economic losses. These losses, however, are seldom tracked and recorded as biodiversity and ecosystem-based losses and thus difficult to include within conventional risk management or cost-benefit analysis approaches.

Although studies are increasingly linking positive reputations, consumer confidence and trust to brand value, it is not possible to determine the percentage of value attributed to effective management of biodiversity and ecosystems (Earthwatch 2002, and F\&C 2004). Instead, companies tend to refer to 'doing the right thing' to account for their beyond-compliance investments in conservation.

Biodiversity and ecosystem risks are partly based on external factors not under the company's control, making them difficult to predict. Reputational risks, for instance, are created by the perception of external stakeholders on how 
business is conducted. This sense of trust and confidence, or lack thereof, in a company is mainly driven by the increased awareness of the direct or indirect impacts of company activities. Similarly, regulatory and legal frameworks often result from societal pressures to prevent real or perceived negative impacts. While there is value in anticipating these risks and, in some cases, having the opportunity to inform the development of new regulation, these benefits remain difficult to quantify.

Effective management of these risks therefore requires shared responsibility of governments and business decisionmakers and the use of an expanded framework that includes both direct and indirect impacts on biodiversity and relates these to the financial health of the company. In some cases, a company might calculate the potential loss of market share, impact on product or services prices, or effect on credit rating to determine the resources necessary for mitigation. It is likely that these approaches will expand to include indirect impacts and internalize the value of biodiversity and ecosystem services. This will most likely require broader stakeholder engagement to determine these values (see section 4.4.1).

Cement and construction company Holcim has adopted a specific biodiversity risk matrix, developed in joint collaboration with the Holcim - IUCN independent expert panel (see Box 4.1).

\section{Box 4.1 Holcim and IUCN: Implementing a biodiversity management system}

In 2007, Holcim made the strategic choice to engage proactively with IUCN on the theme of biodiversity to better understand the opportunities and risks linked to biodiversity and ecosystem conservation. The relationship has helped Holcim structure a corporate approach and prioritize biodiversity related activities at site level over the full life cycle of its operations. This engagement has resulted in an operational Biodiversity Management System (BMS) that enables better management of biodiversity in new projects and implements the appropriate corrective actions in sites of varying sensitivity.

An important first step in the BMS is the establishment of a biodiversity risk matrix followed by the introduction of measures appropriate for the risk level encountered at each site (see below). The risk level is determined first by the biodiversity importance (proximity to high biodiversity value areas) and second by the potential direct impact level. This methodology also takes into account the biodiversity value given by relevant local stakeholders.

Biodiversity risk matrix (@ 2010 Holcim)

\begin{tabular}{|c|c|c|c|c|}
\hline \multirow{2}{*}{$\begin{array}{c}\text { Biodiversity } \\
\text { Importance }\end{array}$} & \multicolumn{4}{|c|}{ Potential Impact } \\
\cline { 2 - 5 } Global & Critical & Significant & Medium & Low \\
\hline National & Critical & Significant & Medium & Low \\
\hline Local & Significant & Medium & Low & Low \\
\hline Low & Low & Low & Low & Low \\
\hline
\end{tabular}


The matrix is used as part of three implementation steps in the BMS:

- Step 1. Know the potential impact -- Annual environmental questionnaire collects (self reported) biodiversity information per site used for risk mapping. Where risk or impacts are unknown, there is a need to close knowledge gap.

- Step 2. Match the level of effort to risk -- Sensitive sites are required to implement full Biodiversity Action Plans and monitor progress. Collaboration with expert partners can assist sites to develop needed biodiversity inventories, set appropriate targets, and determine actions.

- Step 3. Monitor results to demonstrate progress towards targets -- At most sites, monitoring can be conducted by internal staff. For sensitive sites, external expert monitoring can provide additional credibility to the results. Biodiversity activities need to be integrated into existing operations management processes, such as rehabilitation planning and environmental management systems.

A full inventory of all $500+$ extraction sites owned by Holcim in over 70 countries has been conducted and all sites are categorized on the risk matrix. Top management has been informed of the sites which need attention first and a global biodiversity target has been set in order to monitor progress: by $2013,80 \%$ of sensitive sites will have a biodiversity action plan in place. Results and progress made and will be published in Holcim's sustainability report.

Holcim recognizes it lacks the capacity to adequately monitor and conduct the required biodiversity assessments. Therefore, Holcim will continue to work with external partners where appropriate whilst building capacity internally. There is also an opportunity to define smarter and more pragmatic performance indicators to measure the long term impact on biodiversity.

The outputs of Environmental and Social Impact Assessments, walkover surveys and more detailed biodiversity assessments have to serve as a basis for the operational environmental management of each site and as the point of departure for rehabilitation plans of the extraction sites. These tasks will remain the responsibility of the local operations.

Source: Carbone, Tong and Bos (2009) and Holcim - Bos and Tong (2010)

Much of the value of biodiversity and ecosystem services has been based traditionally on non-economic values defined by government regulation (e.g. Natura 2000), scientific consensus (e.g. IUCN Red List of Threatened Species) or consumer preferences (e.g. certified products). This value materializes via laws to protect biodiversity at particular sites, actions to prevent biodiversity loss by NGOs, and guidelines developed by certification schemes. Each of these mechanisms defines acceptable risks, yet often these values are not quantified in financial terms and in some cases there may be conflicting views regarding the value of a particular species, site or ecosystem.

Integration of biodiversity and ecosystems into existing risk management systems in the context of these non-economic values begins with an inherent presumption that biodiversity or ecosystems are valuable to business and/or society and thus constitute a risk requiring management. Assessment of the perceived value is usually defined in non-economic units such as species populations, ecosystem area or other appropriate bio-physical units. This is likely to be an imperfect proxy as the precise link between bio-physical units and economic value to a company will almost certainly not be linear, consistent or predictable.

The expansion of corporate risk assessment and management processes to include biodiversity and ecosystems has typically been built on existing processes, including risk registers, environmental impact assessments (EIAs) 
and environmental management systems. These often emphasize certain high-impact stages within the project life cycle (Figure 4.2), for instance early stages when costs may be lower and responses most flexible. Agribusiness companies, however, regularly manage risk throughout the project life cycle including once the project is operational. Some companies find their greatest risks to be associated with the sourcing of raw materials and thus develop supply chain management systems to mitigate these risks as well.

\section{Figure 4.2 The extractive project life cycle}

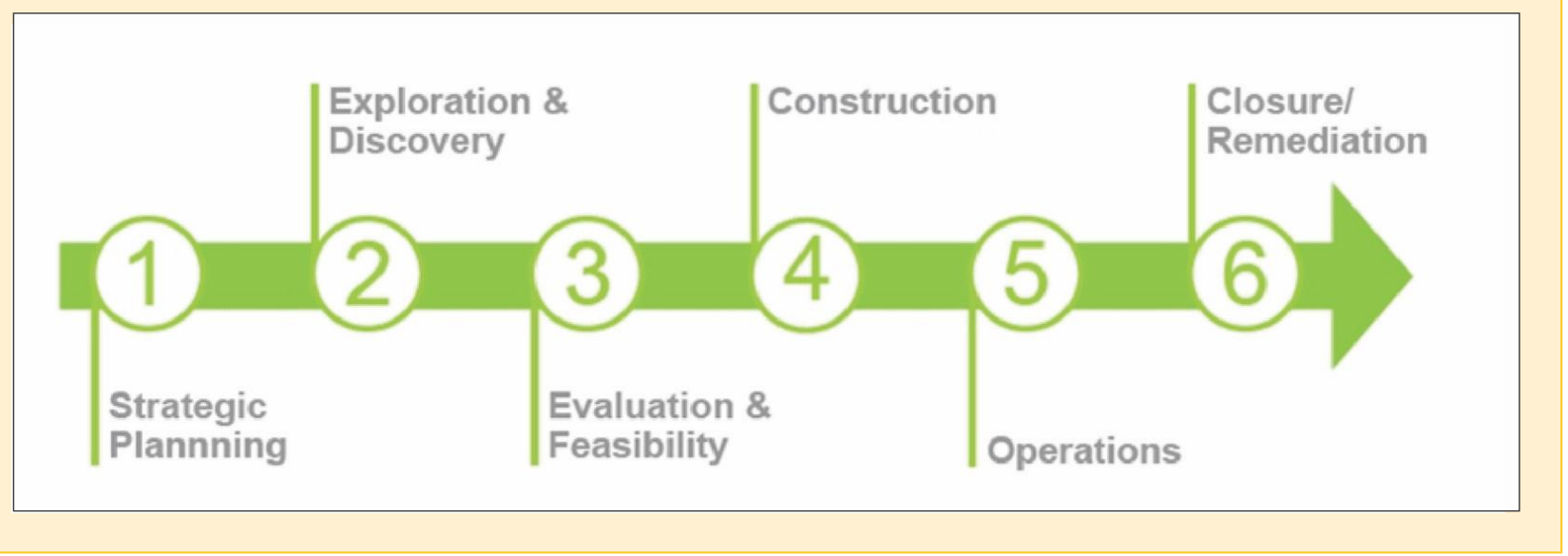

Source: Conservation International (2010

Implementation of formal valuation processes to assess short-term versus long-term biodiversity impacts and benefits to both the company and local communities is a relatively new concept. In most cases, existing risk management tools do not adequately integrate biodiversity and ecosystem risks, as they focus primarily on within the fence impacts and have difficulty capturing impacts that could affect the broader landscape. Several platforms in the oil and gas and mining sectors have developed additional guidance on integrating biodiversity within management systems (EBI 2003; IPIECA and OGP 2005; Johnson, 2006). Many certification standards, developed within the agriculture, fisheries, aquaculture and forestry sectors, include biodiversity principles, criteria and indicators.

Where biodiversity and ecosystem values have not been well accounted for in risk assessment and management (e.g. due to weak legislation, lack of public awareness or scientific knowledge) the advent of economic valuation can serve as an important tool for establishing value and raising awareness of the importance of identifying and managing related risk. A key gap for businesses is that many of the approaches to biodiversity and ecosystem services valuation have not been adequately standardized or tailored to business needs in the same way, for example, that biodiversity surveys and assessment science have been distilled into environmental impact assessment methods or standards.

Existing corporate risk management approaches tend to manage risks according to a hierarchy designed to avoid the highest-risk impacts to the extent possible and minimize and mitigate those that cannot be avoided (BBOP 2009). The mitigation hierarchy is inherently suited for managing biodiversity and ecosystem risks as it enables companies to consider options for managing risks associated with potential impacts and whether these can be avoided or should become part of a mitigation plan designed to minimize negative impacts. Companies are increasingly exploring ways to manage the residual impacts that are inherent in this approach, although this trend is still in its infancy (Box 4.2). 


\section{Box 4.2 Applying the mitigation hierarchy and biodiversity offsets in the financial sector}

The United Nations Environment Programme Finance Initiative (UNEP FI) and the Business and Biodiversity Offsets Programme (BBOP) commissioned PricewaterhouseCoopers Sustainability and Climate Change team to conduct a study exploring the following themes:

- Familiarity and awareness among the financial sector of the biodiversity mitigation hierarchy (see diagram to right) and biodiversity offsets;

- Corporate policy approaches of banks to understanding and addressing biodiversity issues;

- Roles and responsibilities within the banks on the management of biodiversity risks and opportunities; and,

- Tools,resources and training.

The analysis based on 26 in depth discussions with banks, environmental consultants, NGOs and bank clients found that:

- Biodiversity issues do affect financing decisions;

- Business drivers for banks are currently risk based and primarily reputational;

- Whilst the implementation of a biodiversity management framework is largely focused at the asset level, the application of the mitigation hierarchy and offsets is in its infancy; and,

- Bank policy frameworks and procedures are developing to incorporate a broader, strategic consideration of biodiversity risks.

Source: PricewaterhouseCoopers (2010)

Rio Tinto, for example, sets out in its biodiversity strategy the long-term goal of Net Positive Impact on biodiversity. This means ensuring, where possible, that the company's actions have positive effects on biodiversity features and their values that not only balance but are broadly accepted to outweigh the inevitable negative effects of the physical disturbances and impacts associated with mining and mineral processing. Rio Tinto aims to achieve this by reducing impacts and implementing positive conservation measures in the form of biodiversity offsets and other conservation measures (Rio Tinto 2008) (see Figure 4.3).

\section{Figure 4.3 Net Positive Impact and the mitigation hierarchy}


There is increasing interest in tying the level of compensation or investment in biodiversity conservation activities to the level of impact the project has based on the concept of biodiversity offsets. The Business and Biodiversity Offsets Programme (BBOP) has defined biodiversity offsets as:

"Measurable conservation outcomes resulting from actions designed to compensate for significant residual adverse biodiversity impacts arising from project development after appropriate prevention and mitigation measures have been taken. The goal of biodiversity offsets is to achieve no net loss and preferably a net gain of biodiversity on the ground with respect to species composition, habitat structure, ecosystem function and people's use and cultural values associated with biodiversity" (BBOP 2009b).

This requires a greater effort in avoiding and mitigating impacts, and measuring both the impacts and potential gains from investments in another site. The ability to assess biodiversity and ecosystem risks has been hampered by the costs of collecting data and an incomplete knowledge on BES. It is often difficult to define an acceptable impact in terms of ecosystem and species resilience, and to anticipate and avoid irreversible impacts from development projects. The measurement of potential losses and gains associated with socio-economic use values of biodiversity and ecosystem services economic valuation methods will play a key role in this. Offsets might thus play a role in facilitating the integration of economic valuation of biodiversity and ecosystem services into project development and management processes.

The mitigation hierarchy has been applied, to date, as a conceptual framework for thinking about risks and developing appropriate responses. In some cases, it has been used to determine relative proportions of risks that can be managed via the various strategies. Lacking is the ability to define the relative value of the biodiversity being affected or the degree to which the impact can be reduced through avoidance and mitigation strategies. Valuation of biodiversity and ecosystem services could significantly contribute to the mitigation hierarchy by facilitating such analyses. 


\section{TOOLS FOR MANAGING BIODIVERSITY AND ECOSYSTEM RISKS}

There have been many attempts to categorize the diversity of tools developed to assist businesses in identifying and managing biodiversity and ecosystems risks (OECD 2005 and Waage et al. 2008). Traditional typologies, based on how tools support various stages of risk assessment or the project lifecycle, have been extremely useful in fast-tracking the practical uptake of these tools. These may prove less useful, however, in three important aspects:

- Some tools, such as the ISO 14001 or Corporate Ecosystem Service Review (ESR) take a broad strategic look at risk assessment and can be applied at various stages in a project lifecycle.

- The project cycle itself is usually an iterative process involving adaptive management and feedbacks.

- The existence of a single 'tool' at a specific step in the risk assessment process may not be sufficient to support the full set of business needs at that specific stage.

The typology presented here looks at three broad types of tools: Standards, frameworks and method tools; data collection tools; and model or scenario-based tools.

\subsubsection{STANDARDS, FRAMEWORKS AND METHODOLOGIES}

Standards, frameworks and methodologies represent a continuum of tools. Standards establish "rules, guidelines or characteristics for products or related processes and production methods" (ISEAL 2010). Standards set the bar business can use to define whether they have achieved a certain level of best practice or not, in terms of good processes such as environmental management or good outputs such as avoiding critical habitats:

- Examples of multi-stakeholder voluntary efforts include the system standard ISO 14001 for environmental management (ISO 2004); the Programme for the Endorsement of Forest Certification (PEFC) and the Forest Stewardship Council (FSC) certification for sustainable forest management (www.pefc.org and www.fsc.org); and the WBCSD Green House Gas Protocol (www.ghgprotocol.org).

- Individual company standards include Starbucks' Coffee and Farmer Equity (C.A.F.E.) Practices, which sets criteria and indicators for environmentally and socially responsible coffee purchasing that are used to verify performance throughout their supply chain (www.starbucks.com/responsibility/sourcing/coffee).

Depending on the nature and the size of the company, internal standards can have significant impacts on their broader supply chains and sectors:

- The advent of the Wal-Mart commitment to sustainability has notably influenced previously impenetrable value chains such as gold and gemstones (www.loveearthinfo.com).

- The International Finance Corporation (IFC) Performance Standard 6 on Biodiversity Conservation and Sustainable Natural Resource Management identifies when projects or investments may occur in high risk areas and outlines a series of steps to be taken to minimize these risks. It has had a significant impact on project financing with the adoption of the Equator Bank Principles by 67 major financial institutions, committing projects that they finance to apply IFC's Performance Standards in non-High Income OECD countries, and local regulations elsewhere, in projects exceeding $\$ 10$ million (www.equator-principles.com).

Internal company standards are most often developed to enable a company to know that it is aware of risks measured on a consistent scale. Where regulations are absent, weak or unenforced, the normal evidence that performance is poor - e.g. prosecutions, licence violations - is not a good enough guide for the management and directors 
to know that they are managing risk adequately. Corporate standards backed by auditing and reporting provide assurance that this is happening.

Key components of all of these systems are the establishment of clear principles and criteria which present the performance level expected of a supplier or operation, indicators to monitor performance over time, and a verification process (preferably third-party) that ensures the data reported is truthful.

The process of transforming good practice into certification programmes is a lengthy and costly one which may not be warranted for all initiatives. For instance, many businesses have developed their own internal guidance on biodiversity and ecosystems best practice and manage these as standards or environmental management systems through internal verification processes.

There are also instances where additional tools may be required to fulfil the requirements of a standard or guideline. In such cases supplemental methods and frameworks might be developed to sketch out a suggested set of activities, provide checklists or other guidance recommendations designed to assist a business in assessing their performance against a specific standard or objective:

- The IFC, for example, has embarked on a process of developing explicit interpretation notes to support practical implementation of their standards. Similarly, BBOP is reviewing offset design approaches via a series of pilot studies with the intent of drawing out best practices that align with the stated principles.

- Sometimes, this supplemental guidance is explicitly tied to a standard, such as the High Conservation Value (HCV) framework, originally developed to support Forest Stewardship Council (FSC) certification. This framework, intended to stimulate the development of national toolkits with more detailed methods, defines biodiversity and ecosystems according to six broad areas of concern that include ecological, social, cultural and livelihood values.

- In other cases, the guidance may stand independently of other standards and support a general intent to understand biodiversity and ecosystem services related risks and value. This is the case for the Corporate Ecosystem Services Review, developed by the World Resource Institute (WRI), the World Business Council for Sustainable Development (WBCSD) and the Meridian Institute. This provides step by step guidance on how businesses can identify and manage potential risks around ecosystem services, including those they impact as well as those they depend on for their operations (see Box 4.3). In such cases, this guidance may support multiple standards or policies and perhaps even develop into standards of their own over time, either though greater integration with existing standards or in filling otherwise unfilled gaps.

\subsubsection{DATA COLLECTION TOOLS}

The existence of standards, frameworks and methodologies goes some way to helping businesses identify and manage environmental risks. Access to appropriate data as well as the interpretation of outputs are critical components to this:

- Businesses have, in most cases, relied on situation-specific data drawn from original studies which are guided by frameworks or methods for collection and analysis (e.g. via environmental impact assessment).

- Frameworks and standards are increasingly being explicitly designed, to draw on existing data collection processes and tools. This is often done in the interests of cost sharing as well as drawing on existing scientific expertise and credibility that is present with the broader scientific or NGO community. The Roundtable on Sustainable Palm Oil (RSPO) for instance references the High Conservation Value (HCV) framework in its description of sensitive habitats. HCV assessments are informed by national toolkits, where available, and have traditionally drawn on national data to map these areas. 


\section{Box 4.3 The Corporate Ecosystem Services Review}

The Corporate Ecosystem Services Review (ESR) is a structured methodology for corporate managers to proactively develop strategies for managing business risks and opportunities arising from their company's dependence and impact on ecosystems. It assists companies in identifying impacts and dependence on healthy ecosystems such as freshwater, timber, genetic resources, pollination, climate regulation, and natural hazard protection and connecting these to their bottom line. The ESR builds on existing environmental management systems and due diligence tools by:

- Looking beyond issues of pollution and natural resource consumption

- Addressing dependencies and impacts companies have on the natural environment

- Considering both business opportunities and risks

- Coupling economic and environmental issues

- Providing a framework for stakeholder engagement

- Enabling use of environmental risks and opportunities for more innovative corporate strategy

The ESR has been applied by over 100 companies and has resulted in a number of recognized benefits by:

1. Enabling companies to identify new business opportunities arising from the company's dependence and impact on ecosystems and the services they provide and to anticipate new markets as they are developing. In this way, the tool has also provided companies with information necessary to influence government policies on ecosystem conservation.

2. Strengthening existing approaches to environmental impact assessment by addressing ecosystem issues not usually considered during that process. For instance in the case of Mondi, Europe's largest producer of office paper, application of the ESR led to the development of initiatives to improve water efficiency through control of invasive species and selection of water efficient tree strains.

3. Providing a framework in which stakeholder engagement processes and relationships have improved. Syngenta, a large agribusiness company, applied the tool to identify opportunities to further engage a growing customer segment in India and identified multiple opportunities to provide additional services to these farmers.

4. Allowing companies to demonstrate leadership in this are by proactively addressing the degradation of ecosystem services.

Source: WRl et al. (2008)

Access to supporting data for such efforts has traditionally proved challenging due largely to the abundant, dispersed and often difficult to access nature of these national data:

- The Integrated Biodiversity Assessment Tool (IBAT) for business was developed as one solution to such needs, with the express intent of offering rapid and easy access to the most critical fine-scale national data sets which indicate critical habitats, protected and unprotected.

- The Global Water Tool (GWT) uses pre-loaded datasets to calculate water-related indicators necessary for the Global Reporting Initiative (see Box 4.4).

Such efforts depend on the underlying data to be maintained and updated in order to ensure that such tools continue to deliver appropriate and accurate information to users into the long term (EBM Network 2009). Unfortunately, this part of many tools often suffers from a 'Cinderella effect' in that while the tool interfaces which present data often gain a high profile, the underlying data from which they draw are expected to maintain themselves or left to decay after an initial flurry of activity. The World Database of Protected Areas, a joint initiative of IUCN and UNEP-WCMC, represents a critical data source and supporting processes for compiling information on legally protected areas from national sources. To ensure long- term maintenance and update of this globally important compilation of national data sets, the Proteus Partnership has been established. 


\section{Box 4.4 The Global Water Tool:}

helping companies make water-informed decisions

The Global Water Tool (GWT), developed by WBCSD member company CH2M HILL along with 22 companies with expertise from The Nature Conservancy and GRI, helps companies and organizations map their water use and assess levels of corporate risk across their global operations and supply chains. The Tool can be used to:

Compare a company's water uses (including staff presence, industrial use and supply chain) with key external water-related data

- Create key water Global Reporting Initiative (GRI) indicators, inventories, risk and performance metrics and geographic mapping. The GRI Indicators on total water withdrawals (EN8), water recycled/reused (EN10), and total water discharge (EN21) are calculated for each site, country, region and in total.

- Establish relative water risks in a company's portfolio to prioritize action

- Create graphs and maps

- View facilities spatially through Google Earth, which provides detailed geographic information, including surface water

- Enable effective communication with internal and external stakeholders on a company's water issues

- Allow calculation of water use and efficiency.

Despite careful selection, the most significant limitation of the Tool is the quality of the background water datasets that are available on a very local basis. For this reason, the tool does not aim to provide specific guidance on local situations, which require more in-depth, systematic analysis. Other tools, such as the Global Environmental Management Initiative Water Sustainability Planner Tool, may be more targeted towards this outcome.

An estimated 300 companies have used the GWT. Some companies use it as a first step to define the hot spots where more in-depth analysis needs to take place - for example, the Dow Chemical Company used it to map out its 157 manufacturing sites around the world, which drew attention to water supply risks for a number of sites. For Dow, the GWT is seen as an important piece of the puzzle driving their effective corporate water management strategy, and is also used to educate key stakeholders regarding business water-related risks. Other companies looking at measuring their water footprint have also used the GWT to define where this effort should take place. Borealis used the GWT to make projections of its sites' locations to 2025 , which - with the assistance of local water experts - will help plan for future sustainable water management actions.

Source: www.wbcsd.org/web/watertool.htm

Businesses themselves are a key collector and maintainer of data. ECOiSHARE is one attempt at creating a platform for businesses to compile and share appropriate data with peers and others. Sound science is critical for developing and maintaining data access tools. To date, these tools have focused primarily on sharing spatial information on priority sites based on species, habitats and ecosystems of global importance. Valuation of such sites in economic terms is still in its infancy and there is a clear need for consistent approaches to valuation to enable comparability across sites and ecosystems. Some initial on-line libraries and websites have been launched to facilitate user access to existing case-studies, for example ConsValMap, but the variation in scales, objectives and methods used renders comparison of values across regions or landscapes difficult. 


\subsubsection{MODELLING AND SCENARIO BUILDING}

There have been recent attempts to develop tools which allow the modeling of potential future scenarios to assess relative risk, with an emphasis on ecosystem valuation:

- While these may be seen as a specialized sub-set of data exposure tools, their increasing importance in more detailed risk assessment and mitigation planning may be seen as a secondary step in the risk assessment process that builds from traditional data access tools.

- In most cases, such tools rely heavily on human expertise, rather than simple automated processes, in understanding and interpreting results.

- The Integrated Valuation of Ecosystem Services and Tradeoffs (InVEST) tool, for example, is a scenario modeling tool aimed at a broad audience of stakeholders including private sector users, stemming from work conducted by partners within the Natural Capital Project. It draws on a combination of pre-loaded or user defined data sets to model the distribution of ecosystem services across areas of interest. The tool currently exists as an add-on to the popular ESRI Geographic Information Systems (GIS) software package.

- The ARtifical Intelligence for Ecosystem Services (ARIES), currently under development, is similarly aimed at a broad set of users that include the private sector (see Box 4.5).

\section{Box 4.5 ARtificial Intelligence for Ecosystem Services (ARIES)}

ARIES (ARtificial Intelligence for Ecosystem Services) is a web-based decision-support tool that can be used to assess ecosystem services and model potential future scenarios. ARIES calculates the extent to which an area provides or uses a service, and how the benefits of ecosystem services flow across the landscape to reach beneficiaries. ARIES offers various entry points for decision makers and planners, including spatial assessments and economic valuations of ecosystem services, optimization of payment schemes for ecosystem services, and spatial policy planning. Different ecosystem services can be assessed at once, identifying areas that provide multiple "bundled" services and tradeoffs between them. An optional biodiversity layer integrates assessments of biodiversity and ecosystems services, allowing users to assess the value of biodiversity-rich areas and policy options that will ensure provision of ecosystem services.

Specific ARIES case studies can be developed based on customization of existing Bayesian models. Current applications include designing payments for ecosystem services in biodiversity rich areas of Madagascar, assessing the benefits and beneficiaries of clean water in the cloud forest ecosystems of Mexico and of flood mitigation in Washington state, USA. Modeling the dynamic flow of benefits between terrestrial, coastal, and marine ecosystems is also another core activity in the ARIES project.

In ARIES, the economic value of ecosystem services is a function of the biophysical flow of a given benefit that is provided to beneficiaries. Such flow information is used to mediate known values expressing demand from the users and market or non-market values derived from established literature sources made available through an internal economic database. Economic values are therefore a direct function of provision and usage, honestly reflecting the ecological dynamics that determine supply on the one hand and the socio-economic drivers that determine demand on the other. In cases where ecosystem services are scarce or threatened, ARIES users can select non-linear functions to correctly address economic values in the vicinity of ecological thresholds. The value transfer engine in ARIES then uses the quantitative assessment of flows and estimates of critical thresholds to apply values from existing studies to an area under investigation. 


\subsubsection{IMPROVING TOOLS FOR BIODIVERSITY AND ECOSYSTEMS}

There are many tools available to identify and manage risk associated with biodiversity, ecosystems and ecosystem services but the emerging issue of valuing BES remains partly unresolved for the following reasons:

1. Most existing standards, guidelines and frameworks rely on the input of data, qualitative or quantitative, to arrive at useful outputs. There is however a distinct lack of underlying data exposure or interpretation tools to support these higher-level tools, resulting in a greater dependence on project-specific assessment by consultants or experts. In contrast, while non-economic values of biodiversity and ecosystem servies still require fine-scale project-specific assessments, there is a greater availability of tools which present reasonably scaled data at earlier stages in the project cycle that allow some degree of early risk assessment, for example IBAT. These tools also allow more focused assessment efforts targeted at filling information gaps or ground-truthing existing results. All information collection comes with at a cost. The issue is thus to understand the trade-offs between investment in better knowledge and information for investment and decision-making and the costs of making the wrong decisions and costs of restoration/rehabilitation (see Box 4.6).

\section{Box 4.6 Investing in water knowledge versus the costs of bad decisions and restoration}

The management costs for managing water resources and protecting environmental values are being passed on to water users through water charges as legitimate costs of protecting the long term sustainability of the resource and the security of access by water users. Key considerations in managing risk to river health and groundwater dependent ecosystems include:

- The risk of failing to realise the potential economic value of the water resources for consumptive use through overly conservative regulation of resource allocation, due to inadequate information about environmental requirements.

- The risk of over-allocation of the resource resulting in loss of ecosystem values and impairment of ecosystem functioning, due to inadequate information about environmental requirements.

- The cost of assessing ecosystem values and monitoring the status of the resource and compliance with water use regulations.

- The costs of rehabilitation of degraded aquatic ecosystems generally being greater than the costs of protection.

- Irreversibility of certain types of environmental impacts.

- Understanding the limits of ecosystem resilience.

- The role of water markets in allocating scarce resources to highest value uses, and creating a market value for water that promotes water use efficiency.

- Cost sharing principles for investment in programmes to restore ecosystems resulting from the legacy of history, including user pays and beneficiary pays.

- The importance of legally defined allocations of water for protection of ecosystem values.

- Achieving the right balance between environmental and socio-economic objectives, through good public policy informed by sound science.

- The role of community engagement in resource allocation planning 
2. The science of assessing economic values of biodiversity and ecosystem services has yet to be synthesized into best practice approaches for business needs. Environmental Impact Assessment (EIA) best practices were distilled, from the diversity of scientific approaches to surveying and researching biodiversity and ecosystems, to meet specific business needs. This allowed the development of a specialized sector of experts to meet business needs for environmental assessment, distinct from traditional ecological researchers. The same has yet to take off in the area of economic valuation but represent an area for active development by business in terms of defining their economic valuation needs and for scientists in distilling the minimum set of tools required to meet those needs.

3. Much of the discussion and development of tools has not been subject to significant or strategic review. The majority of information exists in grey literature or linked to NGO or business outputs that may have little or no review by other practitioners. As a result, an objective assessment of trends and needs around biodiversity risk assessment remains fairly undocumented or incomplete. Luckily however, as the field of tool development continues to mature, lessons learned - based on both successes and failures - will begin to emerge and benefit the broader community of users and developers. 


\section{STRATEGIES FOR SCALING DOWN BIODIVERSITY AND ECOSYSTEM RISK}

Best practices and tools constitute a vital component of risk management, but will never be able to address all biodiversity and ecosystems risks. Risk management systems are designed to identify issues presenting the highest risks and develop plans to avoid or mitigate these while monitoring other lower-risk issues. Effective monitoring of these risks may require additional strategies such as stakeholder engagement, partnerships and adaptive management systems to circumvent their becoming larger risks over time.

\subsubsection{STAKEHOLDER ENGAGEMENT}

Many companies have strong community outreach and stakeholder engagement programmes that are often managed independently from those for biodiversity and ecosystems. Stakeholder engagement, however, is also an important factor in managing biodiversity and ecosystems risks as the process can assist in the identification of potential risks, developing acceptable management strategies for mitigating risks, and monitoring changes over time. Stakeholders include anyone with the ability to affect the outcome of a particular project, whether positively or negatively, and can range from local communities and organizations to governments and shareholders (IFC 2007). Engaging stakeholders is a complex process that includes the following 8 components (IFC 2007):

1. Stakeholder Identification and Analysis

2. Information Disclosure

3. Stakeholder Consultation

4. Negotiation and Partnerships

5. Grievance Management

6. Stakeholder Involvement in Project Monitoring

7. Reporting to Stakeholders

8. Management Functions

While many companies have stakeholder engagement policies and strategies, there is a need to integrate certain biodiversity and ecosystems considerations within them as this can help mitigate risk. Topics specifically related to biodiversity and ecosystems that may be included in stakeholder engagement include (EBI 2003):

- Local knowledge and use of biodiversity, including the rights of indigenous peoples and customary use rights

- Local community dependence on natural resources for the provision of food, water, livelihood

- Other aesthetic values and to mitigate risks to human health.

Investing early on in these processes allows companies to better understand the local context and the value local communities and other stakeholders place on the biodiversity and the extent of their reliance on ecosystems to sustain their way of life. Continued engagement over the course of the project with a wide range of stakeholders can also play a valuable role in monitoring risks.

National and local government agencies constitute another key stakeholder for business engagement as they often regulate the biodiversity and ecosystems that provide valuable services to business. Engaging with relevant government agencies throughout the project life cycle can help identify changes in pending regulations and how they might affect the company and also provide an opportunity to provide input into processes designed to establish new regulations. 


\section{Table 4.2 Benefits of corporate - NGO partnerships}

\section{For the company}

Enhances corporate reputation

Increases access to land and license to operate

Helps to mitigate risk

Provides access to specialist expertise

Improves capacity to work with communities and access local information

Builds corporate values and capacity of staff

Increases credibility with key stakeholders and leverage with other NGOs

Presents new opportunities to engage with external stakeholders

\section{For the NGO}

Contributes to organization mission in new ways

Increases access to new locations and networks

Leads to involvement in integrated approach across a wider range of activities

Secures financial support for projects

Improves capacity for research, training and education

Builds capacity of individual staff and institutions Increases credibility and leverage with other corporations

Builds innovative approaches to priority issues

Source: Adapted from Hurrell and Tennyson (2006)

\subsubsection{PARTNERSHIPS}

Stakeholder engagement strategies can lead to the establishment of more formal collaborations and partnerships, either through bilateral or multi-stakeholder processes. These have proven effective strategies for companies in managing for biodiversity and ecosystems related risks and often result in other benefits as well (see Table 4.2). Establishing the most constructive engagements requires an understanding of the particular issue or objective to be addressed, to identify the type of expertise necessary, and the governance mechanisms required to undertake the work and achieve the desired level of credibility (see Box 4.7).

Many partnerships between conservation organizations and businesses have emerged in an effort to better manage impacts on biodiversity and ecosystems:

- Large conservation NGOs are increasingly spearheading multi-stakeholder initiatives to develop standards of good practice. Within the agricultural sector, WWF has joined with corporate and NGO partners to convene the Roundtables on Sustainable Palm Oil and Responsible Soy to develop standards of best practice for commodity production.

- Several companies have joined, on a more general level, a common effort to foster continued business engagement under the Convention on Biological Diversity (Box 4.8)

- Analyzing the benefits of these multi-stakeholder engagements to business and to conservation is challenging due to the lack of investment in establishing a baseline and developing a long-term monitoring framework to understand not only the growth of the market over time, but also the conservation, societal and business benefits imparted.

In some cases, industry associations have coordinated these efforts as the integration of biodiversity and ecosystems considerations becomes more of a norm within a particular sector:

- In the oil and gas and mining sectors, the Energy and Biodiversity Initiative, International Petroleum Industry Environmental Conservation Association (IPIECA) and the International Council on Mining and Metals (ICMM) have convened working groups and developed best practice guidance on these issues for their members. 


\section{Box 4.7 Partnerships in the building materials sector}

The 4-year (2007-2010) Holcim / IUCN partnership aims to develop robust ecosystem conservation standards for the company which could also contribute to sector-wide improvements in the cement and related sectors. The relationship is structured around three strategic objectives:

- Develop a more comprehensive corporate biodiversity policy and strategy.

- Support sustainable livelihoods and biodiversity conservation joint initiatives of mutual interests.

- Promote good practice by sharing the learning with wider industry and communities.

To support the implementation of the work, IUCN established an independent panel composed by 5 experts in different but related fields designed to provide input on biodiversity conservation policy for the Holcim Group; to review existing management tools used by Holcim; and to advise on how these might be strengthened to conserve biodiversity more effectively by bringing them together into a Biodiversity Management system that would address all stages of a life cycle of a quarry, from initial scoping to closure.

Members of the Panel have visited a number of quarry sites at different stages of development (from Greenfield to closure) in Spain, Indonesia, Belgium, Hungary, USA, UK and China. These visits allowed them to fine tune their recommendations to the realities faced by Holcim in their every day operations in different economic and cultural contexts.

The Panel's independence is one of the most strategic aspects of the IUCN-Holcim relationship. To preserve it, it was agreed that the Expert Panel would only act as an advisory body, and would not provide evaluations or assessments; and that it is only accountable to IUCN. All final products generated by the Expert Panel will be made publicly available by IUCN.

To complement the work conducted at the global level, and to strengthen the Holcim internal buy-in on biodiversity related matters, a number of local agreements have been established (in Sri Lanka, Vietnam, Costa Rica/Nicaragua and Spain) between both organizations.

Source: Carbone and Bos $(2009$

- Such voluntary initiatives have not included a certification or verification component that would enable reporting on uptake of the guidance.

Other examples of formal partnerships with stakeholders have involved bilateral arrangements between a company and one or more NGOs to develop policies and management standards that integrate biodiversity and ecosystems considerations or to better understand these issues around a particular site or suite of projects. Rio Tinto (Hurrell and Tennyson 2006) and BAT (see Box 4.9) have explored such models. Some bilateral partnerships have included staff secondments, in some cases such as with Shell and IUCN over a period of many years.

Many companies also seek to develop partnerships with local communities around development sites. These can develop out of stakeholder engagement processes and may involve partnerships with NGOs to facilitate the relationship. While these types of engagements often require a significant investment in stakeholder outreach and continued engagement, they can go a long way toward achieving and maintaining a license to operate in a particular region. These arrangements can take the form of payments for environmental services that designed to ensure the continued provision of the ecosystem services the company depends while also providing benefits, either financial or livelihood, to the local communities: 


\section{Box 4.8 Business engagement initiatives under the CBD}

The Convention on Biological Diversity (CBD) has recognized the importance of business engagement through, in particular, decisions VIII/17 and IX/26. At the 9th meeting of the Conference of the Parties (COP9), Germany launched a Business and Biodiversity Initiative to promote this process. To date, more than 40 companies have committed to a Leadership Declaration. This momentum was reiterated by the Jakarta Charter on Business and Biodiversity adopted in November 2009.

In order to scale-up and broaden business engagement towards COP-10, the Japanese business community -- including Nippon Keidanren Committee on Nature Conservation, the Japan Chamber of Commerce and Industry and Japan Association of Corporate Executives -- in cooperation with IUCN and various government agencies -- such as the Ministry of Agriculture, Forestry and Fisheries, Ministry of Economy, Trade and Industry and Ministry of Environment - announced, in May 2010, a multi-stakeholder initiative called Japan Business and Biodiversity Partnership. More than 300 blue-chip companies, through Nippon Keidanren, have expressed an interest to join this partnership through endorsing a Declaration on biodiversity and committed to promote actions to achieve the objectives of CBD through sharing experiences and cooperation with NGOs, research institutions and governmental organizations. This initiative, to be formally launched at COP-10, intends to cover all sectors and sizes of businesses.

Source: Furuta (2010)

\section{Box 4.9 Integrating biodiversity into business management and operations -} the BAT Biodiversity Partnership.

From an agricultural perspective, tobacco is similar to other crops in its ecological impacts, but most farmers also use fuelwood to cure their tobacco, so the industry is criticised for driving deforestation. BAT promotes tree planting wherever wood is used to cure tobacco. Nevertheless, a small proportion of wood is still harvested from natural forests. This is a practice that BAT aims to measure, minimise and halt. Fast growing plantations are part of the solution but do not support ecosystem services like native forests. The BAT Biodiversity Partnership was established in response to such issues and now comprises Fauna \& Flora International, the Tropical Biology Association and Earthwatch Institute.

In 2006, BAT published its Biodiversity Statement, recognising the company's impact and dependence on biodiversity, and the need to assess impacts, engage with stakeholders, develop action plans and share information with suppliers. Three indirect biodiversity measures were incorporated into BAT's Sustainability Report in 2008 and again in 2009:

- Reduce reliance on natural forest: Less than 3\% curing wood sourced from natural forest by 2015

- Further embed biodiversity management into BAT activities: Train responsible leaf managers, farmers and staff in biodiversity management in relation to business operations

- Manage impacts in high risk biodiversity locations through risk assessments and action plans: Identify high risk biodiversity locations by 2010 . Manage priority areas with appropriate actions.

Global Biodiversity Risk Mapping as well as Biodiversity Risk \& Opportunity Assessment and Corrective Action Planning (BROA/CAP) tools were developed. All BAT companies with agricultural operations will complete assessments and develop corrective action plans by 2010:

- Global risk mapping focuses attention on higher risk locations. At country level, it uses indicators of biodiversity richness and threat; rates of habitat loss; socio-economic development; scale, history and 
projected change of operations; and reliance on wood and forests. Operation maps are then overlaid on maps of sites of biodiversity significance and vegetation cover, to identify proximities and overlaps.

- The BROA process consists of desk exercises, stakeholder consultation and mapping to determine likelihood of biodiversity impact from operations and prioritise issues to be assessed in more detail. Field work and further consultation refine understanding of issues and opportunities, followed by corrective action planning. BROA encourages participants to look at situations over longer timeframes and wider landscapes than in day-to-day business, to see underlying trends. Collaboration with external stakeholders lies at the heart of BROA. Local 'ownership' of the findings and transparency with stakeholders drive corrective actions. BAT companies are now implementing action plans to address risks identified by BROA, such as reduced flows of irrigation water resulting from catchment deforestation or increased risk of unsustainably sourced fuelwood being drawn into the supply chain.

What started as corporate responsibility is becoming part of 'business as usual' for BAT, contributing to business sustainability through:

- Ecological security and sustainability of agricultural/forest supply chains

- Securing licence to operate and meeting tighter regulations

- Maintaining reputation and setting higher standards in the sector

- Building stakeholder and shareholder confidence

- Building employee confidence and strengthening the talent pipeline

- Better ways of working

- Collaborative local partnerships

Source: Gilleard (2010)

- Vittel paid farmers in a watershed to adopt more sustainable land use practices and restore ecosystems around water sources to address water contamination issues (Perrot-maitre 2006).

- Energía Global has supported a forest protection fund that pays landowners upstream of its dams to conserve or restore tree cover to reduce siltation (Porras and Neves 2006).

Not all ecosystem service related risks and opportunities can be successfully addressed through site level regulations. Government agencies can help establish voluntary initiatives that provide compelling incentives for corporate participation in establishing regulations, increased reporting and continuous improvement.

\subsubsection{ADAPTIVE MANAGEMENT}

As companies adopt environmental management systems and increasingly monitor performance on biodiversity and ecosystems, adaptive management approaches become increasingly important given the lack of information projects usually have at the beginning of a project:

- Adaptive management is a means of better integrating monitoring and evaluation within a management framework that values learning from experience and facilitates the integration of this learning into improved management practices.

- It takes a commitment to continuous improvement and establishes a management system designed to ensure that the project or management system does in fact improve over time.

- The framework consists of 5 steps that move from the conceptualization phase of a project through planning and implementing action and monitoring plans to analyzing this information to adapt as necessary and then sharing the findings more broadly (see Figure 4.4). 


\section{Figure 4.4 Adaptive management framework}

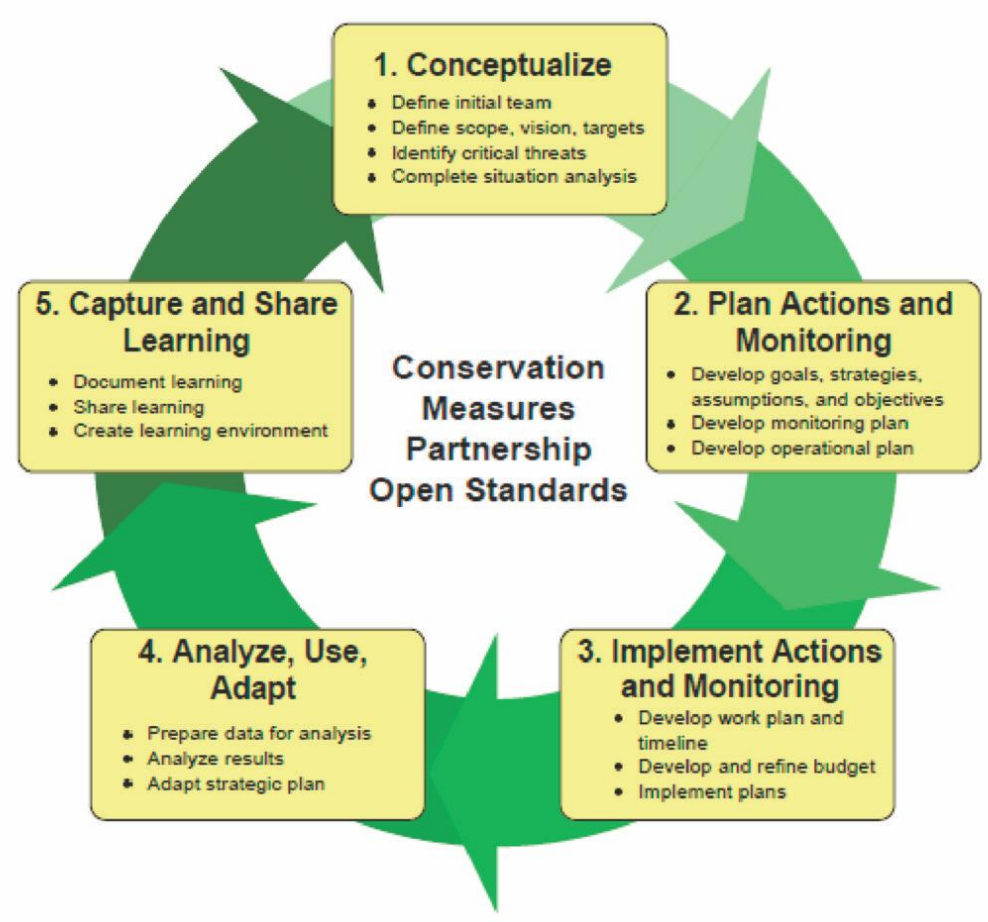

Source: The Conservation Measures Partnership (2007)

- It closely mirrors the ISO 14001 cycle, which follows a plan, do, check and act process. The key step of checking progress on a regular basis during the cycle to enable course corrections is a key component of the adaptive management process.

Within the adaptive management approach, monitoring and evaluation is built into each step of the process and not left as a final step that is only sometimes included in a site management plan or corporate strategy. The CBD has recognized the need for corporate adoption of adaptive management strategies for managing tourism development in vulnerable areas given the uncertainty surrounding current knowledge of these ecosystems and their biodiversity (SCBD 2004). Such advice could extend beyond the tourism sector to include all industries having the potential to impact biodiversity and ecosystems. This is especially important as companies consider climate change and develop adaptation strategies for managing for uncertainties associated with projected scenarios (Maclver and Wheaton 2003).

Corporate investments are managed over the long term and there is a high degree of variability that can take place over the life cycle of a project. In addition to the direct impacts that the project may have on the ecosystem, there may be additional pressures within the landscape or seascape that warrant further monitoring and consideration in mitigation planning. Adaptive management systems provide the framework in which such discoveries and discussions can take place within a company. Addressing some of these issues, however, may require collaboration with other stakeholders, especially in cases where outside pressures are adding to the vulnerability of a particular ecosystem. Adaptive management approaches that monitor beyond the fenceline of a project can identify these risks at an early stage and lead to lower-cost management interventions that prevent the materialization of the risk. 


\section{4 CONCLUSIONS AND RECOMMENDATIONS}

Biodiversity and ecosystem services decline constitutes material risks for business that need to be managed and an increasing array of tools, initiatives, best practice, standards and frameworks are available to assist companies in this process.

Most biodiversity assessment and management interventions follow steps that include an initial assessment of potential risks, the prioritization of risks, and the development and implementation of management plans and monitoring protocols within an adaptive management framework. Stakeholder engagement is crucial during each of these steps and in some cases formal partnerships may be established to better manage an issue. Another critical factor is the availability and access to data on priority species, sites and landscapes during initial project planning processes.

In summary, companies can adopt one or more of the following broad strategies to manage and scale down biodiversity, ecosystems and ecosystem services risks:

1. Avoidance - includes "no go" policies, where companies forgo operations in certain areas of high biodiversity and ecosystems value (e.g. World Heritage sites, IUCN protected areas category I-IV).

2. Good management practices - includes developing biodiversity action plans, monitoring, maintaining risk registries, adopting the mitigation hierarchy (of avoiding, minimizing, rehabilitating and offsetting), sourcing sustainably and greening supply chains, and having defined contingency plans.

3. Investment - includes purchasing eco-efficient technologies and allocating sufficient funds for maintaining natural capital.

4. Assurance - includes recognizing certification schemes, using third party verification and developing in-house quality and control systems.

5. Stakeholder engagement - includes building partnerships with research organizations, NGOs, industry associations and governments, as well as engaging with local communities and promoting transparency.

\section{Recommendations}

- Business should broaden their risk assessment and management practices to reflect the materiality of biodiversity and ecosystems

- Business should build internal capacity to understand and implement existing standards, frameworks and methodologies; data collection based tools; as well as modelling and scenario building tools

- biodiversity and ecosystem services valuation should be used to improve decisions around risk management

- Businesses should actively pursue engagements and partnerships with a range of stakeholders 


\section{Endnotes}

These include the ASX Corporate Governance Principles and Recommendations, the Combined Code on Corporate Gover- nance, the King Code of Governance for South Africa, the Sarba- nes-Oxley Act; and the Draft International Standard ISO 26000 (Guidance on social responsibility) respectively.

2 As evidenced, for example, in Beyond Grey Pinstripes, a survey and ranking of business schools focusing on the integration of social and environmental issues into curricula and research, published biennially by the Aspen Institute Center for Business Education (http://www.beyondgreypinstripes.org). In terms of course material, Harvard Business School has published a case on the CBD and business engagement (Bell and Shelman 2006). HEC Montréal is also finalising a case on CDC Biodiversité, a subsidiary of financial institution Caisse des Dépôts et de Consignation launched in Feb- ruary 2008 (Wilain de Leymarie 2009). 


\section{References}

Austin, D. and Sauer A., (2002) Changing Oil: Emerging environmental risks and shareholder value in the oil and gas industry. World Resources Institute, Washtington, D.C. http://www.wri.org/ publication/changing-oil

Bell, D. E. and Shelman M., (2006). "The Convention on Biological Diversity: Engaging the Private Sector”. Case N9-507-020. Harvard Business School, Boston.

Busenhart, J. Bresch, D. Wilke, B and Schelske, O., (2010). Case material prepared for TEEB. Swiss Re, Zurich.

Business and Biodiversity Offsets Programme (BBOP) (2009). Biodiversity Offset Design Handbook. BBOP, Washington, D.C. http://bbop.forest-trends.org/guidelines/odh.pdf

Business and Biodiversity Offsets Programme (BBOP) (2009b). Business, Biodiversity Offsets and BBOP: an overview. BBOP, Washington, D.C www.forest-trends.org/biodiversityoffset program/guidelines/overview.pdf

Carbone, G. and Bos, G., (2009). Case material prepared for TEEB. IUCN and Holcim.

Carbone, G. Tong, R. and Bos, G., (2009). Case material prepared for TEEB. IUCN and Holcim.

Conservation International (2010). Graph, as presented in the Integrated Biodiversity Assessment Tool for Business. URL www.ibatforbusiness.org.

The Conservation Measures Partnership (CMP) (2007). Open Standards for the Practice of Conservation (Version 2.0). URL: http://conservationmeasures.org/CMP/Site_Docs/CMP_Open_ Standards_Version_2.0.pdf.

Earthwatch (2002). Business and Biodiversity: A Guide to UKbased companies operating intenrationally. Earthwatch, Oxford. URL:http://www.businessandbiodiversity.org/pdf/BandBOseas.pdf.

The Energy and Biodiversity Initiative (EBI) (2003). Integrating Biodiversity Conservation into Oil and Gas Development. Conservation International, Washington, D.C. URL: http://www.theebi.org/pdfs/ ebi_report.pdf

Ecosystem-Based Management (EBM) Network (2009). "Using Ecosystem-Based Management Tools Effectively". EBM Network. URL: http://www.ebmtools.org/sites/natureserve/files/ Using\%20EBM\%20Tools\%20Effectively_0.pdf

Evison, W. and Knight, C., (2010). Biodiversity and business risk A Global Risks Network briefing. World Economic Forum (WEF), Geneva.

http://www.weforum.org/pdf/globalrisk/Biodiversityandbusinessrisk.pdf

F\&C Asset Management (2004). Is biodiversity a material risk for companies? An assessment of the exposure of FTSE sectors to biodiversity risk. F\&C Asset Management, London. URL: http://www.businessandbiodiversity.org/pdf/FC\%20Biodiversity\%20Report\%20FINAL.pdf.
Furuta, N., (2010). Case material for TEEB. IUCN, Tokyo.

Gilleard, M., (2010). Case material prepared for TEEB. Earthwatch, Oxford.

Holcim - Tong, R., and Bos, G., (2010). "Making biodiversity part of Business", Holcim.

Houdet, J., (2008). Integrating biodiversity into business strategies The Biodiversity Accountability Framework. Fondation pour la Recherche sur la Biodiversité (FRB) and Orée, Paris. URL: http://www.fondationbiodiversite.fr/images/stories/telechargement/Guide-oree-frb-en.pdf

Hurrell, S and Tennyson, R (2006). "Rio Tinto: Tackling the Crosssector Partnership Challenge". International Business Leaders Forum, London. URL: http://www.thepartneringinitiative.org/ docs/tpi/RioTinto.pdf

International Finance Corporation (IFC) (2007). Stakeholder Engagement: A Good Practice Handbook for Companies Doing Business in Emerging Markets. IFC, Washington, DC. URL: http://www.ifc.org/ifcext/enviro.nsf/AttachmentsByTitle/p_StakeholderEngagement_Full/\$FILE/IFC_StakeholderEngagement.pdf

International Petroleum Industry Environmental Conservation Association (IPIECA) and International Association of Oil and Gas Producers (OGP) (2005). A Guide to Developing Biodiversity Action Plans for the Oil and Gas Sector. IPIECA/OGP, London. URL: http://www.ipieca.org/activities/biodiversity/downloads/ publications/baps.pdf

International Organization for Standardization (ISO) (2004). Environmental management systems -- Requirements with guidance for use (2nd edition). ISO, Geneva. URL: http://www.iso.org/ iso/catalogue_detail?csnumber $=31807$

ISEAL Alliance (2010). Code of Good Practice for Setting Social and Environmental Standards (P005 - Version 5.01 - April, 2010). ISEAL Alliance, London. URL: http://www.isealalliance.org/ resources/p005-iseal-code-good-practice-setting-social-andenvironmental-standards-v50

Johnson, S., (2006). Good Practice Guidance for Mining and Biodiversity. International Council on Mining and Metals (ICMM), London. URL: http://www.icmm.com/page/1182/good-practiceguidance-for-mining-and-biodiversity

Jones, M. E., and Sutherland, G., (1999). "Implementing Turnbull: A Boardroom Briefing." Institute of Chartered Accountants in England and Wales. URL: http://www.icaew.com/index.cfm/ route/120612/icaew_ga/pdf

Maclver, D. C. and Wheaton E., (2003). "Forest Biodiversity: Adapting to a Changing Climate." Paper submitted to the XII World Forestry Congress 2003, Québec City, Canada. URL: http://www.fao.org/DOCREP/ARTICLE/WFC/XII/0508-B3.HTM. 
Organisation for Economic Co-operation and Development (OECD) (2005). Environment and the OECD Guidelines for Multinational Enterprises: Corporate Tools and Approaches. OECD, Paris. URL: http://www.oecd.org/document/36/0,3343,en_2649_34287_349 92996_1_1_1_1,00.html

Perrot-Maître, D., (2006). The Vittel Payments for Ecosystem Services: A "Perfect" PES Case? International Institute for Environment and Development, London. URL: http://www.iied.org/ pubs/pdfs/G00388.pdf

Porras, I. and Neves, N., (2006). "Costa Rica - Energía Global: Energía Global payments, Central Plateau - watershed protection contracts". International Institute for Environment and Development (IIED), London. URL: http://www.watershedmarkets.org/documents/Costa_Rica_Energia_Global.pdf

PricewaterhouseCoopers LLP (2010). Biodiversity offsets and the mitigation hierarchy: a review of current application in the banking sector. (Study completed on behalf of the Business and Biodiversity Offsets Programme and the UNEP Finance Initiative) URL: http://www.unepfi.org/fileadmin/documents/biodiversity_offsets.pdf

Rio Tinto (2008). Rio Tinto and biodiversity: Achieving results on the ground. URL: http://www.riotinto.com/documents/Reports Publications/RTBidoversitystrategyfinal.pdf

Sauer, A. Klop, P. and Agrawal, S., (2010). Over heating: Financial Risks from Water Constraints on Power Generation in Asia. World Resources Institute (WRI): Washington D.C URL: http://www.wri.org/publication/over-heating-asia

Secretariat of the Convention on Biological Diversity (SCBD) (2004). Guidelines on Biodiversity and Tourism Development: International guidelines for activities related to sustainable tourism development in vulnerable terrestrial, marine and coastal ecosystems and habitats of major importance for biological diversity and protected areas, including fragile ripari- an and mountain ecosystems. SCBD, Montreal. URL: http://cdn.www.cbd.int/doc/publications/tougdl-en.pdf

Sutherland, P., (2009). Case material prepared for TEEB.

Swiss Re (2004). Understanding reinsurance: How reinsurance create value and manage risk. Swiss Re, Zurich. URL: http://media.swissre.com/documents/understanding_ reinsurance_en.pdf

Villa, F. Ceroni, M. Bagstad, K. Johnson, G. and Krivov, S., (2009). "ARIES (ARtificial Intelligence for Ecosystem Services): A new too for ecosystem services assessment, planning, and valuation". In: Proceedings of the 11th Annual BIOECON Conference on Economic Instruments to Enhance the Conservation and Sustainable Use of Biodiversity (2009)

Waage, S. Stewart, E and Armstrong, K. (2008). Measuring Corporate Impact on Ecosystems: A Comprehensive Review of New Tools: Synthesis Report. Business for Social Responsibility (BSR). URL: http://www.bsr.org/reports/BSR_EMI_Tools_Application.pdf
Wilain de Leymarie, S., (2009) (draft). "CDC (Caisse des Dépôts et de Consignation) Biodiversité" sous la direction du Prof. Emmanuel Raufflet et de Nicolas Bertrand. HEC-Montréal.

WRI, WBCSD and Meridian Institute (2008) The Corporate Ecosystem Services Review: Guidelines for Identifying Business Risks and Opportunities Arising from Ecosystem Change, World Resources Institute, Washington DC. URL: http://pdf.wri.org/ corporate_ecosystem_services_review.pdf

www.equator-principles.com

www.fsc.org

www.ghgprotocol.org

www.loveearthinfo.com

www.pefc.org

www.starbucks.com/responsibility/sourcing/coffee 


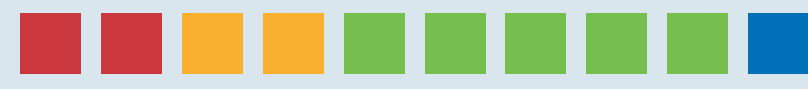 THE ECONOMICS OF ECOSYSTEMS AND BIODIVERSITY \\ TEEB $\quad$ FOR BUSINESS}

Chapter 1 Business, biodiversity and ecosystem services

Chapter 2 Business impacts and dependence on biodiversity and ecosystem services

Chapter 3 Measuring and reporting biodiversity and ecosystem impacts and dependence

Chapter 4 Scaling down biodiversity and ecosystem risks to business

\section{Chapter 5 Increasing biodiversity business opportunities}

Chapter 6 Business, biodiversity and sustainable development

Chapter 7 A recipe for biodiversity and business growth 


\section{Chapter 5: Increasing biodiversity business opportunities}

TEEB for Business Co-ordinator: Joshua Bishop (International Union for Conservation of Nature)

Editors: Nicolas Bertrand (UNEP) and Francis Vorhies (Earthmind)

Contributing authors: Robert Barrington (Transparency International UK), Joshua Bishop (IUCN), Ilana Cohen (Earthmind), William Evison (PricewaterhouseCoopers), Lorena Jaramillo (UNCTAD), Chris Knight (PricewaterhouseCoopers), Brooks Shaffer (Earthmind), Franziska Staubli (SIPPO), Jim Stephenson (PricewaterhouseCoopers), and Christopher Webb (PricewaterhouseCoopers)

Acknowledgements: Stuart Anstee (Rio Tinto), Andrea Athanas (IUCN), Bruce Aylward (Ecosystem Economics), Ricardo Bayon (EKO Asset Management Partners), Maria Ana Borges (IUCN), Roberto Bossi (ENI) David Brand (New Forests), Jim Cannon (Sustainable Fisheries Partnership), Nathaniel Carroll (Ecosystem Marketplace), Catherine Cassagne (IFC and Sustainability Advisory Services), Sagarika Chatterjee (F\&C Investments), lan Dickie (Eftec), Steinar Eldoy (StatoilHydro), Eduardo Escobedo (UNCTAD), Jan Fehse (EcoSecurities), Sean Gilbert (Global Reporting Initiative), Marcus Gilleard (Earthwatch Institute Europe), Annelisa Grigg (Global Balance), Frank Hicks (Biological Capital), Ard Hordijk (Nyenrode Business University), Joël Houdet (Orée), Mikkel Kallesoe (WBCSD), Sachin Kapila (Shell), Becca Madsen (Ecosystem Marketplace), Nadine McCormick (IUCN), Andrew Mitchell (Global Canopy Programme), Jennifer Morris (Conservation International), Carsten Neßöver (UFZ), Bart Nollen (Nollen Group), Ashim Paun (Cambridge University), Paola Pedroni (ENI), Danièle Perrot-Maître (UNEP), Wendy Proctor (CSIRO), Mohammad Rafiq (Rainforest Alliance), Conrad Savy (Conservation International), Paul Sheldon (Natural Capitalism Solutions), Daniel Skambracks (KfW Bankengruppe), Dale Squires (U.C. San Diego), Alexandra Vakrou (European Commission), and Jon Williams (PricewaterhouseCoopers)

Disclaimer: The views expressed in this report are purely those of the authors and may not in any circumstances be regarded as stating an official position of the organisations involved.

The final edition of the TEEB for Business report will be published by Earthscan. If you have any additional information or comments you feel should be considered for inclusion in the final report then please email them by 6 th September, 2010 to: teeb4biz@ufz.de

TEEB is hosted by the United Nations Environment Programme and supported by the European Commission; the German Federal Environment Ministry; the UK Government's Department for Environment, Food and Rural Affairs; the UK Department for International Development; Norway's Ministry for Foreign Affairs; The Netherlands' Interministerial Program Biodiversity; and the Swedish International Development Cooperation Agency. 


\section{THE ECONOMICS OF ECOSYSTEMS AND BIODIVERSITY}

\section{Chapter 5}

Increasing biodiversity business opportunities

\section{Contents}

Key messages $\quad 4$

$\begin{array}{lll}5.1 & \text { Introduction: Biodiversity as a business opportunity } & 5\end{array}$

$\begin{array}{ll}5.2 \text { Biodiversity and ecosystem services as a value proposition } & 7\end{array}$

5.2.1 Agriculture $\quad 7$

5.2.2 Biodiversity management services 8

$\begin{array}{ll}5.2 .3 \text { Cosmetics } & 9\end{array}$

5.2.4 Extractive industries $\quad 9$

5.2.5 Finance 9

$\begin{array}{ll}5.2 .6 \text { Fisheries } & 10\end{array}$

5.2.7 Forestry 11

5.2.8 Garments $\quad 12$

5.2.9 Handicrafts $\quad 12$

5.2.10 Pharmaceuticals $\quad 13$

5.2.11 Retail 13

5.2.12 Tourism $\quad 14$

5.2.13 Biodiversity: An opportunity for scaling up business $\quad 15$

$\begin{array}{lll}5.3 & \text { Emerging markets for biodiversity and ecosystem services } & 16\end{array}$

5.3.1 Regulatory markets for biodiversity and ecosystem services 16

5.3.2 Voluntary markets for biodiversity and ecosystem services 18

5.3.3 Opportunities for business in markets for biodiversity and ecosystem services 19

5.3.4 REDD+ and lessons for new ecosystem service markets 24

5.4 Tools to support markets for biodiversity and ecosystem services 28

5.4.1 Certification schemes for biodiversity and ecosystem service markets 28

5.4.2 Assessment and reporting for biodiversity and ecosystem service markets 29

5.4.3 Voluntary incentives for biodiversity business 30

$\begin{array}{ll}\text { 5.4.4 Further considerations for institutional investors } & 31\end{array}$

5.4.5 Public policy to support biodiversity business 31

5.5 What is to be done? 33

References $\quad 36$ 


\section{Boxes}

5.1 Chocolats Halba: Implementing agroforestry to ensure cocoa bean security and partner satisfaction

5.2 Conservation Grade nature-friendly farming

5.3 Yemen LNG: Investing in marine biodiversity

5.4 HSBC: Scaling up opportunities through learning and awareness

5.5 Biodiversity venture capital

5.6 Walmart - stocking sustainable products

5.7 Bayer Health Care and Glucobay

5.8 A model for biodiversity? The growth of the carbon market

5.9 Examples of ecosystem service markets driven by regulation

5.10 Examples of voluntary markets for ecosystem services

5.11 Landmarks and prospects in the development of REDD and REDD+

5.12 Marriott invests in REDD: The Juma Sustainable Development Reserve

5.13 The association for social and environmental standards

\section{Figures}

5.1 Key steps to developing an ecosystem services project

5.2 Three pillars to support the development of markets for ecosystem services

5.3 How REDD and forest carbon reduce the costs of climate change mitigation

\section{Tables}

5.1 Identifying biodiversity and ecosystem service opportunities

5.2 The business case for engaging in ecosystem service markets

5.3 Business activities supporting ecosystem service markets

5.4 Business opportunities in REDD and forest carbon

5.5 Biodiversity and ecosystem service market opportunities 


\section{Key messages}

- Biodiversity and ecosystem services offer opportunities for all business sectors: The integration of biodiversity and ecosystem services into business can create tangible and significant added value for companies primarily by increasing the cost-effectiveness of operations, ensuring the sustainability of supply chains, or enhancing revenues from penetrating new markets and attracting new customers.

- Biodiversity or ecosystem services can be the basis for new businesses: Conserving biodiversity and using biodiversity and ecosystem services sustainably and equitably can be the basis for unique business propositions, enabling entrepreneurs and investors to develop and scale up 'biodiversity businesses.'

- Biodiversity and ecosystem service markets are emerging, alongside markets for carbon: New markets for biodiversity and ecosystem goods and services are emerging - as have markets for greenhouse gas emission reductions and carbon - providing new biodiversity assets with local and international trading opportunities. A first major opportunity is likely to be Reducing Emissions from Deforestation and forest Degradation and related land-based carbon storage and sequestration methods (REDD+).

- Tools for building biodiversity business are in place or under development: Critical market-based tools for capturing biodiversity and ecosystem services opportunities, such as biodiversity performance standards for investors; biodiversity-related certification, assessment and reporting schemes; and voluntary incentive measures are already available or under development and could be promoted across all business sectors and markets.

- Appropriate public policies can create an enabling framework for new biodiversity and ecosystem service business opportunities: A range of public policy measures at national and international levels can create the enabling framework to scale up biodiversity and ecosystem services as viable business opportunities, such as payments for ecosystem services, REDD+, 'green development' finance, Access and Benefit Sharing, tax incentives, performance standards, and development cooperation. 


\section{INTRODUCTION: BIODIVERSITY AS A BUSINESS

Can businesses increase revenues and decrease costs by conserving biodiversity, restoring ecosystems or using biological resources sustainably? Does biodiversity offer new opportunities for business? This chapter examines these questions through the lens of three different approaches:

- By integrating biodiversity into business decision-making, companies can enhance their performance by reducing risk, increasing revenue streams, reducing costs or improving their products.

- Biodiversity itself presents potentially huge untapped opportunities in the form of new products and services - i.e. 'biodiversity business' opportunities.

- New markets for biodiversity and ecosystem services are emerging - inspired in part by the development of carbon markets; if scaled up, these markets could represent major business opportunities and a significant part of the solution to the biodiversity finance challenge.

Through a series of case studies and other examples, this chapter illustrates the diversity of realized or promising opportunities within these three categories. The chapter also considers the enabling conditions required to see these opportunities expand to their full potential, defines a set of questions to help business identify such opportunities, and identifies some of the potential challenges.

Table 5.1 provides a framework for identifying potential biodiversity and ecosystem service opportunities for various sectors. It is similar to the table used in previous chapters to identify biodiversity and ecosystem service risks and opportunities. Importantly, biodiversity and ecosystem service risks and opportunities are likely to be different in scope and significance for different sectors. With respect to opportunities, the following section in this chapter highlights a range of potential opportunities for a number of major business sectors. These are also indicated by a black circle in Table 5.1 . 
CHAPTER 5 PAGE 5 
Table 5.1 Identifying biodiversity and ecosystem service opportunities

Indicative market sectors with BES opportunities

\begin{tabular}{|c|c|c|c|c|c|c|c|}
\hline Categories & $\begin{array}{l}\text { Indicative BES } \\
\text { opportunities }\end{array}$ & $\begin{array}{l}\text { Biological } \\
\text { resource- } \\
\text { based in- } \\
\text { dustries } \\
\text { (e.g. forestry, } \\
\text { farming, } \\
\text { fishing) }\end{array}$ & $\begin{array}{l}\text { Extractive } \\
\text { industries } \\
\text { (e.g. mining, } \\
\text { oil and gas) }\end{array}$ & $\begin{array}{l}\text { Consu- } \\
\text { mer } \\
\text { goods } \\
\text { (e.g. } \\
\text { clothing, } \\
\text { cosmetics, } \\
\text { furniture) }\end{array}$ & $\begin{array}{l}\text { Consu- } \\
\text { mer ser- } \\
\text { vices } \\
\text { (e.g. } \\
\text { retailers, } \\
\text { tourism) }\end{array}$ & $\begin{array}{l}\text { Health } \\
\text { care } \\
\text { (e.g. } \\
\text { pharmaceu- } \\
\text { ticals, } \\
\text { bio-therapy) }\end{array}$ & $\begin{array}{l}\text { Financials } \\
\text { (e.g. } \\
\text { banking, } \\
\text { biodiversity } \\
\text { services, } \\
\text { green invest- } \\
\text { ment funds) }\end{array}$ \\
\hline \multirow{4}{*}{$\begin{array}{l}\text { Operational } \\
\text { day-to-day } \\
\text { activities, } \\
\text { expenditures and } \\
\text { processes of the } \\
\text { company }\end{array}$} & $\begin{array}{l}\text { Increased quality, } \\
\text { decreased cost of } \\
\text { inputs }\end{array}$ & 0 & & $\mathrm{C}$ & 0 & 0 & \\
\hline & $\begin{array}{l}\text { Increased output } \\
\text { or productivity }\end{array}$ & 0 & & & & & 0 \\
\hline & $\begin{array}{l}\text { Sustainability } \\
\text { of business } \\
\text { operations }\end{array}$ & 0 & 0 & & & & \\
\hline & $\begin{array}{l}\text { Supply chain } \\
\text { opportunities }\end{array}$ & & & & & & \\
\hline \multirow{2}{*}{$\begin{array}{l}\text { Regulatory } \\
\text { and legal } \\
\text { Laws, policies, } \\
\text { court actions } \\
\text { that can affect } \\
\text { performance }\end{array}$} & $\begin{array}{l}\text { Lower transition } \\
\text { costs in anticipa- } \\
\text { ting new policies }\end{array}$ & & 0 & & & & 0 \\
\hline & $\begin{array}{l}\text { Mitigation of risk } \\
\text { due to environ- } \\
\text { mental disaster }\end{array}$ & & 0 & & & & 0 \\
\hline \multirow{3}{*}{$\begin{array}{l}\text { Reputational: } \\
\text { brand, image, } \\
\text { relationship with } \\
\text { stakeholders }\end{array}$} & $\begin{array}{l}\text { Improvement to } \\
\text { brand or image }\end{array}$ & & & 0 & 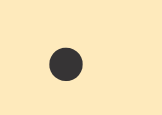 & & \\
\hline & $\begin{array}{l}\text { Attract new } \\
\text { customers }\end{array}$ & & & & 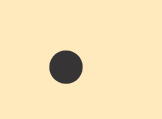 & 0 & \\
\hline & $\begin{array}{l}\text { Reach new niche } \\
\text { markets }\end{array}$ & & & 0 & 0 & 0 & \\
\hline \multirow{2}{*}{$\begin{array}{l}\text { Markets \& } \\
\text { products: } \\
\text { Factors that can } \\
\text { affect corporate } \\
\text { market perfor- } \\
\text { mance }\end{array}$} & $\begin{array}{l}\text { Changes in consu- } \\
\text { mer preferences }\end{array}$ & & & & ) & 0 & \\
\hline & $\begin{array}{l}\text { Purchaser } \\
\text { requirements }\end{array}$ & 0 & & 0 & & & \\
\hline $\begin{array}{l}\text { Financing: } \\
\text { Cost and availabi- } \\
\text { lity of capital }\end{array}$ & $\begin{array}{l}\text { Attract growing } \\
\text { SRI investment }\end{array}$ & 0 & 0 & 0 & 0 & 0 & \\
\hline
\end{tabular}




\section{BIODIVERSITY AND ECOSYSTEM SERVICES AS A VALUE}

'Biodiversity businesses' -- defined as "commercial enterprises that generate profits via activities which conserve biodiversity, use biological resources sustainably, and share the benefits arising from this use equitably" (Bishop et al. 2008) -- may focus on biodiversity-friendly production of commodities (food, timber, fabrics) or the sustainable use of ecosystems (tourism, extractives, cosmetics, pharmaceuticals). Their reliance on biodiversity and ecosystem services makes sustaining their supply chains and raw materials of vital importance.

The number of businesses profiting directly or indirectly from biodiversity and ecosystem services has risen sharply in recent years. Business leaders realise that biodiversity and ecosystem services pose new opportunities for improving their companies' profit margins and performance levels. Integrating biodiversity conservation and ecosystem services into supply chain management or utilising biodiversity and ecosystem services responsibly in current products and practices can result in significant savings and revenues for businesses, as well as heightened efficiency and success. Good risk management pertaining to biodiversity and ecosystem services often leads to tangible savings, and biodiversity and ecosystem services can frequently unleash hidden value in existing production and marketing practices. The benefits from integrating biodiversity and ecosystem services are especially advantageous in that they also generate corporate social responsibility opportunities at a time when the public is increasingly aware of the importance of environmental conservation.

The growing interest to conserve the environment, combined with consumers' focus on health, wellness and humane sourcing, is changing the marketplace. For example, Lifestyles of Health and Sustainability - or LOHAS - consumers are focused on health and fitness, the environment, personal development, sustainable living, and social justice (www.lohas.com). This global movement includes over 80 million consumers, representing a potential market of US $\$ 500$ billion for food products, sustainable tourism, green building suppliers, and low-energy consumption equipment, among other products and services.

In this context, biodiversity and ecosystem conservation and sustainable use represent an array of business opportunities. The following pages highlight various industries and businesses that are profiting from biodiversity and ecosystem services, both directly from conservation and sustainable use, and indirectly through the incorporation of biodiversity and ecosystem services in existing products and services.

\subsubsection{AGRICULTURE}

Many consumers increasingly prefer organic foods. In addition to healthier products, these consumers are seeking traceability, ethical sourcing, sustainability, and corporate social responsibility (Organic Monitor 2009a). In response to these trends, major brands are shifting toward natural, fair trade and organic products (Kline \& Company 2009) ${ }^{1}$.

Organic Monitor estimated global sales of organic food and drink in 2007 at US $\$ 46$ billion, a threefold increase since 1999. US organic food sales alone (3.5\% of the total US food market) grew by $15.8 \%$ in 2008 , reaching US $\$ 22.9$ billion and almost tripling the growth rate of the food sector for the same year, as stated by the Organic Trade Association (OTA 2009; Organic Monitor 2009b). 
Fair trade has also gained importance as a means to source sustainable agricultural products. In 2008 , fair trade certified sales amounted to approximately US $\$ 4.08$ billion worldwide, a $22 \%$ increase on the previous year. Although this still represents a small fraction of world trade, fair trade products in some categories can account for $20-50 \% \%$ of sales. In June 2008 , it was estimated that over 1 million farmers and their families were benefiting from fair trade-funded infrastructure, technical assistance, and community development projects (FLO 2010).

Other sustainable agricultural practices include those promoted by Rainforest Alliance, which account for 205,000 hectares certified for the production of agricultural products such as bananas, cocoa, coffee, tea, citrus, flowers, and pineapples. These hectares directly benefit more than one million people in 14 countries and ensure a net positive impact on biodiversity and ecosystem services (Willie 2009).

\section{Box 5.1 Chocolats Halba: Implementing agroforestry to ensure cocoa bean security and partner satisfaction}

Chocolate and confectionery company Chocolats Halba, a subsidiary of Swiss retailer COOP, has integrated sustainable cocoa sourcing into its supply chain. Like the rest of the chocolate industry, the company faces chronic supply shortages. Because of price instability, cocoa production is more risky for small-scale farmers, who produce most of the world's cocoa; many are searching for alternative employment opportunities. Chocolats Halba discovered that the best way to support farmers was to establish diversified agroforestry systems that include cocoa as one of many crops. In such systems, biodiversity is generally higher because they establish a more diverse landscape. With agroforestry systems, farmers also have a higher and more diverse income, which means that cocoa farming is not only good for biodiversity and ecosystem services - it is also good for making cocoa growing attractive again. According to Christoph Inauen, Head of Chocolats Halba Sustainability and Projects:

"Farmers that work with us realise that we are not only interested in cocoa but also in their livelihood, their income, biodiversity (we help them reforest deforested areas), and other issues. This makes our relationship very strong: farmers give their best to improve the quality of the cocoa in order to give us something back. So we have reliable sourcing partners and very strong relationships with our farmers. In the case of a supply shortage, this would surely help us."

The benefits of biodiversity-based corporate social responsibility lie with the quality of its products, the security of its supply chain, the long-term contentment of its cocoa-growing partners, and the positive environmental impacts being generated in tropical countries-which are among the most important regions for conserving biodiversity and ecosystem services.

Source: Inauen (2010a and 2010b)

\subsubsection{BIODIVERSITY MANAGEMENT SERVICES}

Biodiversity management and advisory services range from advising companies on possible biodiversity and ecosystem service risks during an environmental impact assessment, to developing corporate biodiversity strategies and action plans, to independent auditing or reviewing of a company's biodiversity performance.

Although most biodiversity management services focus on mitigating biodiversity risk, there are also services exploring how to capture biodiversity opportunities - for example, by exploring how biodiversity-friendly supply chains can improve a company's marketability among investors or consumers. One example is the collaboration 


\section{Box 5.2 Conservation grade nature-friendly farming}

The UK-based Conservation Grade certification system of 'nature-friendly farming' provides food brands, producers and consumers with efficient food production while enhancing biodiversity and ecosystem services and preventing wildlife declines on farmland. It does so by requiring Conservation Grade farmers to take $10 \%$ of their land out of production for conversion to wildlife habitats. In return, these farmers are able to use the Conservation Grade logo on all of their products and have access to a supply contract for their produce for which there is a guaranteed premium over the market price.

The Conservation Grade farming scheme exemplifies innovative new solutions to feeding the growing world population without destroying biodiversity and ecosystem services. Independent scientific trials have demonstrated that the Conservation Grade system leads to significant increases in biodiversity, as compared to conventional agriculture, without foregoing output for the land under conservation.

Source: http://www.conservationgrade.org/

between a large German energy company, E.On, and IUCN on greening so-called 'blue energy.' IUCN is helping the company to better understand both the biodiversity risks and opportunities of supplying electricity from offshore renewable technologies, such as wind farms, and thus is enabling the company to better manage its biodiversity impacts (Wilhelmsson et al. 2010).

\subsubsection{COSMETICS}

Natural and organic cosmetic companies were the early adopters of organic and fair trade products, sourcing these ingredients and launching certified products well before other industries. Some of these companies have set up fair trade and organic projects to protect endangered plant species and encourage sustainability. Others are using fair trade to guarantee long-term supply of organic ingredients. Major companies in the organic cosmetic sector reported positive growth for 2008, including Weleda, with a sales increase of $9.5 \%$ to $€ 238.3$ million; Wala, with 'Dr. Hauschka' brand sales increasing by $7.3 \%$ to $€ 103$ million; and Lavera, with an increase of $16 \%$ to $€ 35$ million (BioFach 2009a and 2009b) ${ }^{2}$.

\subsubsection{EXTRACTIVE INDUSTRIES}

Oil, gas and mining companies, by their very nature, can have significant impacts on the natural environment; these impacts often lead to negative consumer perceptions of these industries. Businesses in this sector are therefore well placed to take advantage of the numerous opportunities created by biodiversity and ecosystem services (Box 5.3).

\subsubsection{FINANCE}

The finance sector stands to benefit from biodiversity and ecosystem services in many ways, including improved stakeholder perception, streamlined operations, enhanced ability to attract talent, and increased profit through investments in biodiversity and ecosystem services (Box 5.4).

Several bio-enterprise investment funds have emerged to invest in businesses that demonstrate potential to deliver both financial returns and biodiversity and ecosystem benefits. A few funds, or proposed funds, have also faced difficulties, generating useful lessons about the particular constraints of investing in biodiversity businesses. Some investment funds couple financial assistance with business development assistance and the development of 


\section{Box 5.3 Yemen LNG: Investing in marine biodiversity}

Yemen LNG Company Ltd is involved in a large-scale energy project that includes the construction and operation of a liquefied natural gas plant in the area of Balhaf, Republic of Yemen - a remote spot on the country's south coast. The company has implemented a marine biodiversity action plan in order to improve its environmental performance and in turn its attractiveness to investors and the public. One major challenge for such a largescale project is to ensure the credibility of the company's environmental strategies and their implementation.

In early 2009, Yemen LNG finalized a partnership with IUCN to design and manage an independent review process for the company's marine biodiversity action plan. Specifically, the agreement is to obtain independent third-party assessment of the company's strategy for marine biodiversity protection and implementation of its biodiversity action plan. Through such an independent environmental auditing process, the company hopes not only to improve its performance with respect to both the environmental and social aspects of its marine biodiversity strategy, but also to be able to demonstrate to its Board, investors and other stakeholders that it is doing so.

Source: http://yemenling.com/ws/en/go.aspx?c=soc_Environment

management expertise, so as to improve biodiversity and ecosystem services business management, build capacity and help ensure better returns. Examples include Verde Ventures, an arm of Conservation International (Cl), the EcoEnterprises Fund, an arm of The Nature Conservancy (TNC), and Root Capital, formerly EcoLogic Finance (Box 5.5).

\subsubsection{FISHERIES}

In response to the crisis in this sector, fishing fleets and companies must care increasingly about the sustainability of supply. The sector also has the opportunity to cater to the growing number of LOHAS consumers eager to consume fish without negatively impacting the environment. Several certification and eco-labelling schemes for sustainably managed fisheries have emerged, providing assurance to these buyers and consumers. Perhaps the most recognized organisation certifying sustainable seafood is the Marine Stewardship Council (MSC) (www.msc.org).

\section{Box 5.4 HSBC: Scaling up opportunities through learning and awareness}

In 2002, HSBC launched Investing in Nature, a \$50-million, five-year partnership with several conservation organisations. As part of this initiative, HSBC sent 2,000 of its employees on Earthwatch Institute field research projects around the world and supported the training of 230 developing-country scientists. Participating HSBC employees also had a responsibility to undertake an environmental project in their workplace or local community, supported by a small grant from the company. This initiative not only supported conservation on the ground but did so in a way that strengthened biodiversity and ecosystem services awareness and commitment across the HSBC workforce.

Employees who participated in Investing in Nature, as well as those who take part in the more recent HSBC Climate Partnership, bring their new knowledge of biodiversity and ecosystems back to the company, acting as 'environmental champions' within the business and developing projects that further HSBC's commitment to sustainability. Such projects can help increase the company's ability to attract young talent (Connor 2010).

A recent independent evaluation undertaken by the Ashridge Business School concluded that $80 \%$ of senior HSBC managers agreed that the programme contributes to embedding sustainability into the 'DNA' of the business, while $83 \%$ agreed it is worth the investment because the programme gives HSBC a competitive advantage. 


\section{Box 5.5 Biodiversity venture capital}

Verde Ventures provides support to small and medium-sized businesses that contribute to healthy ecosystems and human well-being. It applies a pre-investment biodiversity review process as well as a postinvestment biodiversity monitoring. Since its creation, in 2003, it has helped partners restore and conserve more than 300,000 hectares of important lands and generate sales of nearly US $\$ 32$ million. As of 31 March 2010 , it had invested US $\$ 14.8$ million in agroforestry, alternative energy, ecotourism, sustainable harvest of wild products and marine initiatives.

For over a decade, the EcoEnterprises Fund has invested in sustainable businesses, particularly small and growing businesses in Latin America and the Caribbean (www.ecoenterprisesfund.com). The Fund also complements targeted financing with technical assistance to foster success. The first Fund, launched jointly by The Nature Conservancy and the InterAmerican Development Bank's Multilateral Investment Fund in 2000 , deployed US $\$ 6.3$ million to 23 sustainable companies, with products ranging from organic shrimp to organic spices, from FSC-certified furniture to pesticide-free biodynamic flowers and acai palm berry smoothies. The businesses created over 3,500 jobs, generated US $\$ 281$ million in sales, leveraged US $\$ 138$ million in additional capital and conserved 860,773 hectares of land. A new investment fund, EcoE II, is to be launched by the end of 2010 and will target companies at the next stage of business growth, providing expansion capital and advisory support to help develop operations and bring results to scale.

Root Capital, a non-profit social investment fund, focuses on sustainable grassroots businesses in the rural areas of developing countries, specifically targeting those businesses that are caught in the "missing middle', too small and risky to access capital from mainstream banks and too large for microfinance. It complements its provision of capital with financial education and training and provides connections to emerging ethical supply chains. Since its launch in 2000 , it has provided over US $\$ 175$ million in credit to 265 small and growing businesses in 30 countries, maintaining a 99\% repayment rate from borrowers. For many of its loans, the fund uses future sales contracts from companies like Green Mountain Coffee Roasters, Marks \& Spencer, Starbucks, and Whole Foods as collateral.

Most companies in the sector, from suppliers to sushi restaurants, claim that carrying the MSC label has provided several business opportunities. These include access to new markets-both geographically and in terms of new niche markets from sustainable product categories-and retention of existing markets. Small-scale fishermen report price premiums for their certified fish. For the US-based fish restaurant Bamboo Sushi, selling only sustainable seafood is a lucrative business model-the restaurant's sustainable menu has made it more successful than ever (www.bamboosushipdx.com). Big retailers, including discounters Aldi and Lidl, request MSC-certified frozen products from their suppliers. With consumers and seafood buyers increasingly aware of the importance of healthy oceans, today the growing market for MSC-certified seafood is estimated to be worth over US $\$ 2.5$ billion (MSC 2009).

\subsubsection{FORESTRY}

Consumer preference for products derived from sustainably managed forests has strongly driven this industry's development and marketing techniques. Forest management certification is becoming an important requirement to access the EU market, which is considered the largest consumer and importer of timber and timber-derived products worldwide. Certified timber is now increasingly available in international markets. 
Certification schemes for the forestry sector include the Forest Stewardship Council (FSC), the Programme for the Endorsement of Forest Certification Scheme (PEFC), and the Rainforest Alliance (RA). By May 2009, the global area of certified forest endorsed by FSC and PEFC amounted to 325.2 million hectares, approximately $8 \%$ of global forest area. Certified wood products are now common in many large retailers like B\&Q in the UK, Home Depot in the US and Ikea worldwide.

\subsubsection{GARMENTS}

According to Environmental Leader, consumers' preference for ethically sourced, organic and fair trade fabrics will continue to grow for the garment industry as well (Willan 2009). Eco-fabrics are thought to bring 'something extra' to the product (Prescott 2009) and natural fibres - mainly cotton and blends - are fashionable and often preferred over man-made fibres (CBI 2008).

In the garment and textile sector, organic cotton has become a marketing tool for many companies. Today, organic cotton cultivation covers about 32 million hectares of land (FiBL and IFOAM 2009). Global retail sales of organic cotton clothing and home textiles accounted for more than US $\$ 3$ billion in 2008 (www.naturalfibres2009.org).

Especially in Europe, there is a widespread demand for natural fibres other than organic cotton; this varies slightly depending on yearly trends and inputs. On the other hand, textured silks are in constant demand and are rapidly increasing in popularity.

Natural fibres such as pima cotton, alpaca wool, or mohair wool have also recently become popular. They are mainly used in high-end products due to their relatively high production and raw-material costs and therefore remain a niche market. Developing country companies such as The Star Knitwear Group of Mauritius, during Texworld 2009, presented fabrics elaborated not only from Africa's cotton but also from bamboo, corn, Tencel, and Modal (Prescott 2009; www.eartheasy.com).

Sustainable leather is used in the garment and accessories industries in such items as jackets, belts, purses, luggage and wallets. This might come from the skins of animals such as crocodiles, lizards and snakes that are sustainably managed and legally traded. There are many opportunities for this sector to engage in profitable biodiversity and ecosystem services conservation, as consumers are demanding eco-friendly small leather goods, whether they are made from recycled materials or using environmentally friendly production processes, e.g. tanning ( $\mathrm{CB}$ I 2009b; Mazzanti et al. 2009).

\subsubsection{HANDICRAFTS}

The biodiversity-based handicrafts sector is another area that provides opportunities for job creation in developing countries. In Vietnam, for example, handicrafts directly involve almost two thousand craft villages and are expected to generate US $\$ 1.5$ billion in turnover by 2010 (VIETRADE 2006 and 2008). The products are made from biological resources (bamboo, rattan, rush, leaf, wood, etc.) and other materials such as metal and stone.

Handicrafts are strongly influenced by fashion trends, consumer purchasing patterns and economic conditions (Barber et al. 2006). Social and environmental values are gaining importance within this sector and a fair trade movement is appearing in the handicrafts and decoration sector. An international 'label' for this sector is now available from the World Fair Trade Organisation (WFTO) (www.wfto.com). 


\section{Box 5.6 Walmart - stocking sustainable products}

In 2005, Walmart announced a new environmental strategy involving, among other objectives, a commitment to sell sustainable products. The company is implementing a sustainable product index to assess the environmental impacts of the products it stocks and relaying this information to its customers by way of a labelling system. The sustainable product index measures such facets of production as energy usage, material efficiency and human conditions; products with higher scores have lower environmental footprints and promote biodiversity and ecosystem services conservation in numerous ways. Walmart has stated that its customers want:

"products that are more efficient, last longer and perform better. They want to know the product's entire lifecycle. They want to know the materials in the product are safe, that it is made well and is produced in a responsible way."

Therefore, Walmart's sustainable product initiative increases customer numbers and business revenues, while at the same time reducing the company's expenses-for example, through decreased dumpster costs from the elimination of excess product packaging.

\subsubsection{PHARMACEUTICALS}

Sources: Plambeck et al. (2008); http://walmartstores.com/Sustainability/; http://walmartstores.com/Sustainability/9292.aspx; Bernick et al. (2010)

Many businesses use wild genetic resources as inputs to production. Over 400,000 tons of medicinal and aromatic plants are traded worldwide every year; $80 \%$ are wild harvested, mostly without consideration of where they come from or the sustainability of collection practices (Traffic International 2006). Demand continues to grow for these plants.

The pharmaceutical industry is an important user of wild genetic resources, along with biotechnology, seed producers, animal breeders, crop protection services, horticulture, cosmetics, fragrance, botanicals, and the food and beverage industries. Each sector is part of a unique market, with distinct research and development processes and different demands for access to genetic resources (Laird and Wynberg 2005).

Consistent data on the use and value of genetic resources do not exist for most sectors and only rough estimates are available. For example, ten Kate and Laird (1999) suggest that between 25 and 50 percent of the value of global pharmaceutical sales is based on the use of genetic resources. Based on the total market value of the pharmaceutical sector - currently around US $\$ 825$ billion according to IMS (2009) - these ratios imply that the value of genetic resources used in medicine may be between US\$206 and 412 billion. By comparison, the commercial global seed market, which also relies on wild genetic material, is expected to reach a total value of US $\$ 42$ billion in 2010 (Global Industry Analysts 2008). An example is provided in Box 5.7.

Wild ingredients and other raw materials used in the medical sector may be certified organic but are often not labelled as such, as the final product typically does not allow for this. More generally, producers can refer to the Good Agricultural and Collection Practices (GACP) for medicinal plants (WHO 2003), and ensure that documentation is complete and traceable in order to guarantee the origin and consistent quality of wild products. Adherence to such practices can help ensure a stable source of raw materials and thus a more secure supply chain, as well as reducing the risk of charges of 'bio-piracy' or inadequate benefit sharing (for further discussion see chapter 6).

\subsubsection{RETAIL}

Large retailers can have significant impacts on biodiversity and ecosystem services, through such measures as sustainable sourcing, discernment in choosing which items to stock, improved packaging and distribution techniques. In return, these companies can benefit from decreased operating costs, heightened customer loyalty and increased supply chain security. 


\section{Box 5.7 Bayer Health Care and Glucobay}

Glucobay is an oral antidiabetic manufactured by Bayer Health Care, sold since 1990 and currently approved in over 95 countries. The active ingredient of Glucobay is the natural sugar Acarbose, which inhibits the absorption of glucose into the bloodstream in the small intestine and thereby prevents potentially dangerous spikes of glucose ('blood sugar'). Based on data provided in Bayer's annual reports, since at least 2001 Glucobay has been one of the company's ten best-selling pharmaceutical products, accounting for about Euro 300 million in annual sales or between 5 and 8 percent of sales by Bayer's primary health care division.

In US Patent No. 3951745 of 1974 , Bayer scientists wrote that they had isolated a number of strains of the Actinoplanes sp. bacteria with a high efficiency of inhibiting the enzyme glucosidase. They further disclosed that they obtained the strains from public and private micro-organism collections in several countries, including twelve strains obtained in Kenya (Frein and Meyer 2008). In 1995, Bayer filed for a patent on a new way to manufacture the product. The patent application (US 5753501), which was subsequently issued in Europe, the USA and Australia, reveals that an Actinoplanes sp. bacteria strain called SE 50 had unique genes that enable the biosynthesis of acarbose in fermentors. This strain originates from Kenya's Lake Ruiru. In 2001, in an article in the Journal of Bacteriology, a group of Bayer scientists and German academics confirmed that SE 50 was being used to manufacture acarbose (McGown 2006). Since 1990, it may be estimated that Bayer has generated sales of Glucobay, produced with soil bacteria originating from Kenya, worth at least Euro 4 billion.

Source: al-Janabi, S., and Drews, A. (2010) for TEEB

\subsubsection{TOURISM}

New consumer trends toward more environmentally sustainable activities have positively affected the tourism sector. One survey indicates that 'sustainable travellers' are willing to spend an average of $10 \%$ more on travel services and products provided by environmentally responsible tourism suppliers (CBI 2009a).

Many travel agents have realised that sustainable tourism provides an excellent market opportunity, in which economic profit and respect for the environment go hand in hand. By 2009, in South Africa - where the first label for FairTrade Tourism was developed - about 45 tourism products had been certified, including hotels, safari lodges, guest houses, backpacker lodges, eco-adventure activities, and township tours. Both local and international tour operators use the certification, according to the standards of FairTrade Tourism South Africa, including operators from Germany, Switzerland and the UK (CBI 2004 and 2009c; FTTSA 2009).

The International Ecotourism Society (TIES) has developed a worldwide network in support of "responsible travel to natural areas that conserves the environment and improves the well-being of local people" (www.ecotourism.org). With members in over 90 countries including more than 50 local, national and regional ecotourism associations, TIES engages in awareness raising and educational projects to build the market for ecotourism.

Further evidence of the growth of this sector is the announcement in late 2009 that the Partnership for Global Sustainable Tourism Criteria (GSTC) and the Sustainable Tourism Stewardship Council (STSC) will merge to become the Tourism Sustainability Council (TSC 2009). In 2010 this new global membership council will be launched to offer a common understanding of sustainable tourism and the adoption of universal sustainable tourism principles and criteria.

There are many hundreds of examples of successful ecotourism companies, and there is a growing number of organisations promoting these companies. For instance, the Athens-based EcoClub promotes "ecologically and socially just tourism" (www.ecoclub.com), and Planeta.com offers a World Travel Directory "for those seeking meaningful eco-friendly, people-friendly, and place-friendly travel" (www.planeta.com). 


\section{Box 5.8 A model for biodiversity? The growth of the carbon market}

Size and growth of carbon markets - The overall carbon market grew in 2008 to a total value transacted of about US $\$ 126$ billion ( $€ 86$ billion), double its 2007 value. This includes both project-based transactions, such as CDM projects and the voluntary market, and the allowances market, such as the EU Emissions Trading System.

\section{Size and growth of businesses that have commercialised climate change opportunities - Global reve-} nues for companies involved in the wind, solar and biofuels markets reached $\$ 116$ billion in 2008 - an almost tenfold rise over five years. Despite the set back in 2009 , due to the global recession, the long-term prognosis is still for a rapid rise, to over $\$ 300$ billion annually by 2020 . For the first time, one sector alone - wind - had revenues exceeding $\$ 50$ billion. One estimate based on a broader definition of climate change-related sectors, including energy efficiency, waste and water, suggests that global revenues already exceed $\$ 530$ billion and could grow to $\$ 2$ trillion by 2020 - which would make the sector comparable in size to today's global oil and gas industry.

Size and growth of investments in climate change opportunities - According to a recent UNEP report, new global investments in sustainable energy technologies - including venture capital, project finance, public markets, and research and development - reached $\$ 155.4$ billion in 2008 , an increase of 4.7 percent from $\$ 148.4$ billion in 2007 , despite the economic downturn.

Sources: World Bank (2009); http://ec.europa.eu/environment/climat/emission/index_en.htm; Clean Edge (2009), HSBC (2009); UNEP et al. (2009)

\subsubsection{BIODIVERSITY: AN OPPORTUNITY FOR SCALING UP BUSINESS}

Even businesses lacking an apparent direct interaction with the natural world can find opportunities and incentives in changing societal and consumer preferences to 'go green'. Consumers increasingly value products and services that have a positive and meaningful association with the environment. Corporate action on biodiversity and ecosystem services can therefore help businesses distinguish themselves from their competitors while also improving relations with investors, employees and communities. This shift can enhance investments-whether from socially conscious investors or the growing number that increasingly see adept environmental management as a proxy for good overall management-help attract top young talent, who are increasingly aware of the natural world and their impact on it, and build good will both locally and internationally.

In addition, there is a vast array of biodiversity and ecosystem services business opportunities already being captured in the marketplace. By incorporating biodiversity and ecosystem services into entrepreneurial thinking and business planning, opportunities to scale up existing BES businesses as well as to develop new areas for pro-biodiversity businesses are sure to emerge in the short term. 


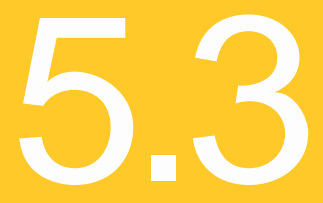

\section{EMERGING MARKETS FOR BIODIVERSITY AND ECOSYSTEM SERVICES}

Ecosystem service markets may be defined as "the bringing together of a buyer and seller so that they can trade ecosystem service credits" (Ecosystem Services Project 2008). Within this definition, ecosystem service credits can be considered marketable units representing the protection and/or enhancement of ecosystem services.

The presence of market-traded credits is a distinguishing factor from other forms of payment schemes such as private payments for ecosystem services (e.g. Australian water permitting schemes), public payment programmes (e.g. New York payments to land owners in Catskill/Delaware and Croton watersheds), and certification schemes (e.g. Marine Stewardship Council), which could fall under the general heading of payments for ecosystem services (PES) (TEEB 2009).

The main reason for establishing ecosystem service markets is to 'internalize' the external ecological costs of doing business (as opposed to using ecosystems 'for free', which as we have seen tends to lead to over-use). Who ends up paying the cost of using ecosystem services will depend on market structure, the availability of substitutes and other factors. In general, we can expect that part of the cost will be absorbed by business and part may be passed on to the final consumer. Other reasons for business to engage in ecosystem service markets are outlined below (Table 5.2).

\section{Table 5.2 The business case for engaging in ecosystem service markets}

1. Market differentiation Businesses that take a lead in ecosystem service markets can differentiate themselves from competitors and may be more likely to stay ahead of regulatory, investor, or consumer expectations. Benefits include regulatory goodwill, reputational benefits, and potential improvements in staff recruitment and retention (Mulder et al. 2006), as well as helping to ensure the long-term sustainability of business operations.

2. Revenue generation: selling credits

3. Revenue generation: supporting services
Growth and diversification of ecosystem service markets is increasing the opportunity to invest in or develop projects that generate revenue through the sale of BES credits. Indications suggest that this growth will continue, although ambiguities around the pace and nature of regulatory reform are leading to uncertainty about the pattern of growth.

The market for supporting and advisory services for ecosystem markets is likely to grow in conjunction with market expansion and diversification. As competition increases, markets will benefit from higher service standards, with early movers defining these standards to a great extent. It is these early movers who are likely to establish themselves in ecosystem service markets and may receive the bulk of the financial rewards.

\subsubsection{REGULATORY BIODIVERSITY AND ECOSYSTEM SERVICES MARKETS}

Markets for ecosystem services can be divided into regulatory or 'compliance' markets and voluntary markets. This section examines ecosystem service markets enabled by government regulations, while voluntary markets are considered in the following sub-section. 
Regulatory markets are driven by government or regulatory bodies that set a limit or 'cap' on the degree of ecosystem use or damage permitted in a certain area, or create tradable quotas for 'sustainable' activities (e.g. wind power generation). Regulation then allows firms or individuals to trade ecosystem service credits in order to meet their obligations or profit from surplus credits (Fischer 2003). This kind of market is possible because the cost of reducing environmental damages or meeting the quota is not equal for all, for example because of technological requirements or scale issues. Firms or individuals for whom the cost is relatively high will tend to purchase credits from firms or individuals who can meet the quota at lower cost or have more credits than they need. Examples are provided in Box 5.9.

\section{Box 5.9 Examples of ecosystem service markets driven by regulation}

Australia - BushBroker: The clearing of native vegetation in the State of Victoria is regulated under the Victorian Planning and Environment Act of 1987. In 2006, the Victorian Government introduced the BushBroker scheme, which requires that clearing of native vegetation be compensated by an appropriate offset. Permit applicants can source these offsets through the BushBroker register. Offsets are gains in native vegetation extent and/or condition that are permanently protected and linked to a particular clearing site. Applicants can either generate offsets on their own property or purchase these offsets as native vegetation credits from thirdparty providers. To date, over $\$ 4$ million worth of trades have been facilitated by the programme.

The system also allows the 'banking' of credits for future use. For instance, a construction company could donate land for the conservation reserve system and register the resulting credits for future offset use. The major revenue generation opportunity for business is through the generation of native vegetation credits through improved land management, re-vegetation of previously cleared areas, and protection of existing stands of trees. This relatively low-cost process can generate significant additional income from land that might otherwise have low commercial value. Average prices for credits under the BushBroker scheme have ranged from AUD $\$ 42,000$ to $\$ 157,000$ per hectare.

U.S. - Biodiversity banking: The US Federal Endangered Species Act prohibits development that leads to declines in populations of endangered species. Land owners obliged to mitigate their impacts on endangered species habitat can buy credits from approved biodiversity banks. One example is the Mariner Vernal Pool Conservation Bank, a 160-acre bank that has plans to generate USD $\$ 50$ million in revenue and, by March 2007 , had sold $\$ 4.4$ million worth of credits. Another is the Sutter Basin Conservation Bank, a 424-acre bank that has announced plans to generate $\$ 15$ million in revenue by selling Giant Garter Snake habitat credits. These credits, equivalent to one acre of snake habitat each, are required by developers to meet permit obligations imposed by the U.S. Fish and Wildlife Service and the California Department of Fish and Game for protecting Giant Garter Snake habitat.

U.S. - Wetland banking: The US Federal Clean Water Act obliges developers to compensate for the destruction of wetlands. Developers can provide their own compensation or purchase credits, in the form of wetland acres, within the same watershed as their development to offset the ecological damage they cause. Between 20 and 30 percent of the 450-plus approved wetland banks in the U.S. have been developed by large corporations, predominantly energy or pipeline companies such as Chevron, Tenneco, and Florida Power and Light. These companies have surplus land, are looking for ways to diversify their income streams, and are attracted by relatively low costs $^{3}$. The US market in wetland credits is currently worth about USD $\$ 1.1-1.8$ billion annually. 


\subsubsection{VOLUNTARY BIODIVERSITY AND ECOSYSTEM SERVICES MARKETS}

These markets occur where motivated counterparties voluntarily enter into a buying and selling agreement for ecosystem service credits, without reference to regulatory requirements. Companies take this action voluntarily in order to manage ecosystem-related risk, improve corporate social and environmental performance, and in some cases, prepare for anticipated regulatory markets. This last factor means that the governance systems and standards used in regulatory markets have a significant influence over those used in voluntary markets (and vice versa). Examples of voluntary markets for ecosystem services are provided in Box 5.10.

\subsection{Examples of voluntary markets for ecosystem services}

Green development mechanism $(\mathbf{g d m})$ is the working name of a proposed innovative financial mechanism under the Convention on Biological Diversity (CBD) intended to engage business in its implementation (UNEP/CBD/WG$\mathrm{RI} / 3 / \mathrm{NF} / 13$ 2010). A gdm could mobilise private sector finance to mitigate biodiversity loss through a market mechanism, much as the better-known CDM has done to mitigate climate change. By establishing a standard and accrediting process to certify the supply of biodiversity-protected areas and by facilitating market exchanges, a gdm would enable the sale of gdm-certified biodiversity conservation to willing buyers, including businesses and consumers.

Current thinking is that a voluntary market could deliver significant biodiversity supply for which there would be adequate voluntary demand from business, consumers and others. For example, if the top 500 companies globally were to voluntarily commit just $1 / 100$ th of $1 \%$ of their annual revenues for gdm-certified biodiversity supply, this would generate $\$ 2.5$ billion of potential demand. At some point, policy makers may decide that businesses and consumers should be obliged to pay for the biodiversity impacts of their production and consumption patterns and therefore a regulatory framework could be established to ensure adequate and appropriate levels of biodiversity demand. However, a pilot phase of a gdm could be voluntary and focus on developing the standards and certification scheme for certified supply, and in so doing, provide insights on the level and nature of demand (www.gdm.earthmind.net).

Mission Markets Inc. is an example of a new company anticipating the emergence and growing importance of biodiversity and ecosystem services markets, as societal and market norms shift towards sustainability and social responsibility. As such, it has created an electronic transactions and communications platform for voluntary environmental and social capital markets. It allows the increasing number of investors focusing on Socially Responsible Investing (SRI) and sustainability to access a network through which to find, compare and assess new investments, organizations and assets. The platform not only consolidates social and environmental markets, but provides transparency and liquidity, unifying selected metrics so that visitors can compare organization and assets in creative ways, confirming the quality and credibility of transactions and the accountability of the organizations themselves (www.missionmarkets.com).

Voluntary Agriculture, Forestry \& Land Use (AFOLU) Carbon Market: Voluntary carbon offset transactions reached USD $\$ 705$ million in 2008, doubling in size from the previous year and with credit prices increasing by an average of $20 \%$. Of this traded volume, $11 \%$ was accounted for by AFOLU projects, with potential biodiversity and poverty-reduction co-benefits, including: Afforestation/ Reforestation; Avoided Deforestation (REDD); Improved Forest Management; and Agriculture Soil Management. Interest in land-use/project based carbon credits has been driven by both actual and anticipated changes in the regulatory environment and the creation of market standards such as the Voluntary Carbon Standard (VCS) and the Climate, Community and Biodiversity Standard (CCBS). These provide assurance for both buyers and sellers, use credible carbon accounting methods, and have stream- lined registration processes. The methodologies of the disparate standards do vary, however, taking different ap- proaches to quantifying baselines, leakage, and additionality across AFOLU project types ${ }^{4}$. Current buyers include: 
- Companies that have voluntarily committed to being carbon neutral;

- Companies purchasing credits to meet corporate social and environmental responsibility objectives;

- Corporate entities anticipating compliance with future regulation;

- Traders and brokers wishing to take advantage of possible future price increases; and

- Individuals offsetting their personal carbon footprints.

As quality projects are brought to market, technical expertise develops, and adequate financing is sourced, indications are that the AFOLU market will continue to grow and should remain a significant opportunity for business. With offset credits from forestry projects specifically allowed in the proposed U.S. climate legislation, it is anticipated that demand for AFOLU projects will increase over the next two to five years.

Malaysia - Malua BioBank is a collaborative effort of the Eco Products Fund LP, a private equity firm jointly managed by New Forests Inc and Equator Environmental LLC, and the state government of Sabah, which has given conservation rights to the Malua BioBank for a period of 50 years. The aim is to raise US $\$ 10$ million for the rehabilitation of 34,000 hectares of formerly logged forest adjacent to the Danum Valley Conservation Area. The Malua BioBank sells Biodiversity Conservation Certificates, which are each equivalent to 100 square meters of protected and restored rainforest. Certificates are currently sold at $\$ 10$ per unit (equivalent to $\$ 1,000$ per hectare), and 21,500 credits have been purchased so far by Malaysian companies. The certificates are registered in the Markit ${ }^{5}$ environmental registry and can be traded or retired. Revenue generated from certificate sales is used to fund the running costs of the project and is invested in a trust fund for the conservation management of the 50-year license. Any profit beyond this will be shared between the forest management license holder (Yayasan Sabah, a foundation established by the Sabah government to improve local livelihoods) and the Malua BioBank investors (www.maluabank.com/).

Note that purchases of Certificates from the Malua BioBank cannot be used by companies to offset their impacts on rainforests in other locations. When purchasing certificates, the buyer contractually agrees that the certificates do not represent offsets against clearing or degrading other forests. In this respect, the Malua BioBank provides an example of a non-offsetting market and highlights developers' reputational risks and sense of environmental responsibilities as the main drivers for business to engage with ecosystem service markets.

Sources: The Katoomba Group and New Carbon Finance (2008), Hamilton et al. (2009), Cullen and Durschinger (2008), Gripne (2008)

\subsubsection{ECOSYSTEM SERVICES MARKET OPPORTUNITIES FOR BUSINESS}

Ecosystem service markets represent an opportunity for businesses to reduce adverse impacts on ecosystems and biodiversity (and potentially to have a net positive impact), with the associated benefits of meeting existing or anticipated regulatory requirements, managing environmental risks, and improving corporate environmental and social performance. Greater rewards may be gained by those companies that exceed standard expectations and offer innovation in their approaches to ecosystem service markets.

Taking a lead in ecosystem service markets may help companies improve their relationships with environmental regulators, by showing forward thinking (BSR 2006). Some of the more innovative projects in this area go beyond providing ecosystem benefits and incorporate local communities in projects, helping to reduce poverty as well. Regulators may take lessons from the experience of innovative projects, helping to close the gap between regulator expectations and business practices. This can give businesses early indications of regulator action, leading to competitive advantage. 
Ecosystem service markets present an opportunity to diversify and increase revenue for companies either directly, through project development and the sale of credits in the market, or indirectly, by providing support services to facilitate market development and implementation. Although market prospects are difficult to predict and heavily dependent on future regulatory decisions, markets for ecosystem services are expected to grow rapidly in the coming decades (Mulder et al. 2006). For example, Forest Trends and The Katoomba Group predict that markets for water quality trading under regulatory schemes will exceed US $\$ 500$ million by 2010 . Markets for biodiversity offsets are conservatively estimated to be worth \$1.8-2.9 billion today (Madsen et al. 2010) and could grow to US $\$ 10$ billion by 2020 (Carroll 2008).

At each stage in the operation of ecosystem service markets, there are cost-saving and revenue-generating opportunities for business. Table 5.3 illustrates where these opportunities may lie and the sectors to which they are most relevant. 


\section{Table 5.3 Business activities supporting ecosystem service markets}

\begin{tabular}{|c|c|c|}
\hline Activity & Role & Relevant business sectors \\
\hline \multicolumn{3}{|l|}{ Finance } \\
\hline $\begin{array}{l}\text { Project finance } \\
\text { and banking }\end{array}$ & $\begin{array}{l}\text { Providing investment capital for commercial } \\
\text { ecosystem service projects }\end{array}$ & $\begin{array}{l}\text { Investment and commercial banks, } \\
\text { venture capital, companies seeking to } \\
\text { offset adverse ecosystem impacts }\end{array}$ \\
\hline $\begin{array}{l}\text { Fund creation and } \\
\text { management }\end{array}$ & $\begin{array}{l}\text { Establishing and managing ecosystem service } \\
\text { funds and managing fund investment profiles }\end{array}$ & $\begin{array}{l}\text { Investment fund managers, fund } \\
\text { management consultancies }\end{array}$ \\
\hline Brokerage & $\begin{array}{l}\text { Linking sellers and buyers and facilitating } \\
\text { trade in ecosystem service credits }\end{array}$ & Brokers and consultancies \\
\hline \multicolumn{3}{|l|}{ Governance } \\
\hline Monitoring & $\begin{array}{l}\text { Collecting and analysing ecosystem service } \\
\text { data for accountability and to facilitate price } \\
\text { transparency }\end{array}$ & $\begin{array}{l}\text { Environmental consultancies, NGOs, } \\
\text { research departments }\end{array}$ \\
\hline Registry services & $\begin{array}{l}\text { Collating and organising data on ecosystem } \\
\text { service assets and transactions }\end{array}$ & Financial information service companies \\
\hline Certification & $\begin{array}{l}\text { Third-party assurance of project perfor- } \\
\text { mance against certification standards }\end{array}$ & $\begin{array}{l}\text { Environmental consultancies, NGOs, } \\
\text { approved certification bodies }\end{array}$ \\
\hline $\begin{array}{l}\text { Validation and } \\
\text { verification }\end{array}$ & $\begin{array}{l}\text { Verifying project/business plans and } \\
\text { performance against market standards }\end{array}$ & Assurance providers (accredited verifiers) \\
\hline \multicolumn{3}{|c|}{ Project development } \\
\hline $\begin{array}{l}\text { Project } \\
\text { developers }\end{array}$ & $\begin{array}{l}\text { Planning, securing finance for, and } \\
\text { managing the development of ecosystem } \\
\text { service projects }\end{array}$ & $\begin{array}{l}\text { Land-owners, land-management companies, } \\
\text { construction and infrastructure developers, } \\
\text { forestry and agricultural companies, environ- } \\
\text { mental consultancies, private companies }\end{array}$ \\
\hline $\begin{array}{l}\text { Project } \\
\text { technical support }\end{array}$ & $\begin{array}{l}\text { Technical expertise and support for the } \\
\text { design of ecosystem service projects and } \\
\text { services }\end{array}$ & $\begin{array}{l}\text { Environmental consultancies, NGOs, } \\
\text { research departments }\end{array}$ \\
\hline $\begin{array}{l}\text { Market } \\
\text { intelligence } \\
\text { services }\end{array}$ & $\begin{array}{l}\text { Provision of data on status and trends in } \\
\text { ecosystem service markets }\end{array}$ & $\begin{array}{l}\text { Specialised ecosystem market informa- } \\
\text { tion providers, news and intelligence } \\
\text { agencies, market exchanges, banks }\end{array}$ \\
\hline $\begin{array}{l}\text { Market strategy } \\
\text { support }\end{array}$ & $\begin{array}{l}\text { Interpretation of market information and } \\
\text { advice on market strategy }\end{array}$ & Strategy consultancies, brokerages \\
\hline Insurance services & $\begin{array}{l}\text { Provision of financial compensation for insu- } \\
\text { rable loss and reduction of project risk }\end{array}$ & Insurance companies \\
\hline Legal services & $\begin{array}{l}\text { Advice on project legal issues, e.g. land } \\
\text { tenure, legal protection status, legal status } \\
\text { of traded rights }\end{array}$ & Legal firms \\
\hline
\end{tabular}


One of the main commercial opportunities in ecosystem service markets is the design, establishment, and management of ecosystem service projects or of investments in such projects. Some of the key steps in developing an ecosystem service project are outlined in Figure 5.1.

\section{Figure 5.1 Key steps in developing an ecosystem services project}

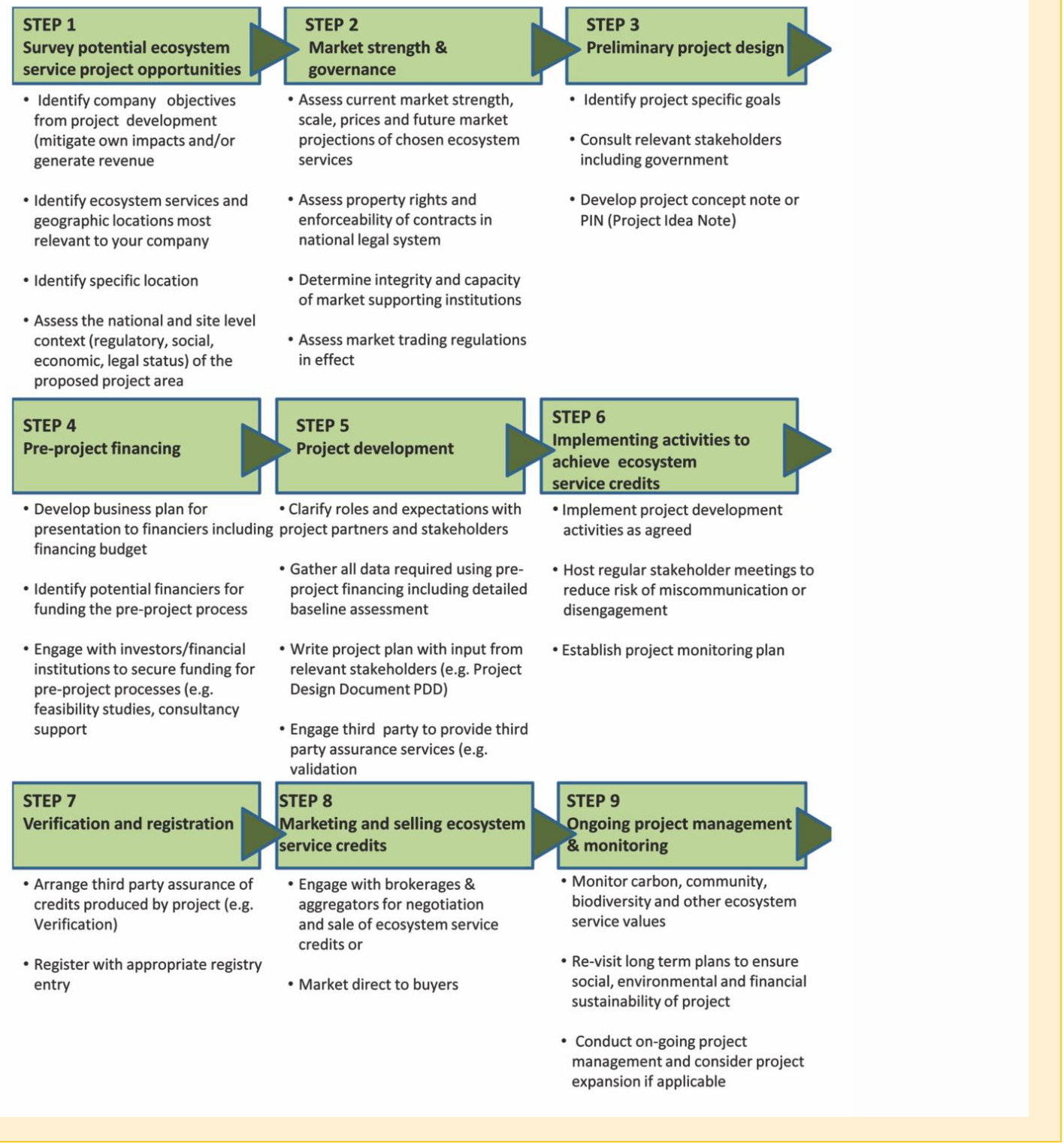

Source: PricewaterhouseCoopers for TEEB, building on Carter Ingram et al. (2009)

Addressing each of these steps systematically and building flexibility into ecosystem service projects during the early planning stages will help to ensure project profitability over the long term. It may be difficult to predict the timescales for some of these steps, and this should be taken into consideration during the planning process.

Ecosystem service markets differ significantly in the levels of financial investment, government regulation, and the maturity of supporting institutions. At one end of the spectrum, the U.S. wetland mitigation scheme (initiated in 1983) benefits from clear legal requirements and detailed guidance for wetland offsets in state and federal government regulations, supported by well-defined liability and enforceable property rights. Market demand for 
wetland offsets comes from residential, commercial and industrial projects that impinge on wetlands. This in turn has stimulated private investment in the supply of wetland offsets and related market services. At the other end of the spectrum, the potential market for REDD credits is still awaiting development of standardised methodologies, market access agreements, support services, and well-defined and enforceable property rights in certain areas of implementation, without which there is likely to be little interest from mainstream investors.

Within the current range of ecosystem service markets, there is already a significant number of commercial opportunities. As ecosystem service markets grow, the scale and range of business opportunities is expected to increase substantially. Figure 5.2 identifies some of the key areas that can be expected to contribute to the expansion and strengthening of ecosystem service markets, once established.

\section{Figure 5.2 Three pillars to support the development of markets for ecosystem services}

\section{Financial}

- Clearly defined BES credits and debits

- Insurability of BES assets

- Investor awareness and support for commercial ventures

- Competitive risk/reward profile

- Combined ecosystem, business development and financial expertise

\section{Regulatory}

- Secure use and/or property rights over ecosystem assets and services

- Clear baselines in order to assess the 'additionality' of BES investments

- Approved standards and methods for assessing debits and credits

- Fiscal incentives (e.g., tax credits for conservation)

- Legal authority to trade ecosystem credits/debits (including internationally)

- Adequate regulatory capacity to enforce

\section{Market}

- Clearly defined asset classes

- Efficient project approval processes

- Modest transaction costs

- Widely accepted monitoring, verification and enforcement systems

- Linked registries to record transactions (especially for intangibles, e.g., offsets)

- Competitive intermediary services (e.g., brokers, validators)

Source: PricewaterhouseCoopers for TEEB

One of the key requirements for developing ecosystem markets is the presence of well-defined and enforceable property rights ${ }^{6}$. For a project buyer, developer, or seller, there are a number of rights-related factors to consider, including the following ${ }^{7}$ :

- Clear definition of the nature and extent of the property right;

- Ability to measure and verify the property right at reasonable cost;

- Ability to enforce ownership of the property right at reasonable cost;

- The value of the right and the willingness to purchase the right by other parties;

- Ability to transfer ownership of the property right at reasonable cost;

- Reliable information on the ecosystem services provided by the property; and

- Low sovereign risk, meaning that future government decisions are unlikely to significantly reduce the value of the property right. 


\subsubsection{REDD+ AND LESSONS FOR NEW ECOSYSTEM SERVICE MARKETS}

Deforestation is thought to account for roughly $17 \%$ of annual global greenhouse gas emissions (IPCC 2007). Curbing deforestation appears to offer the largest, most cost-effective, and fastest means of mitigating emissions from now until 2030 (Addams et al. 2009; IAP 2009; Copenhagen Accord). Actions to do this are known as Reducing Emissions from Deforestation and Degradation (REDD), and REDD has risen quickly in priority over recent years throughout the international climate change talks (Box 5.11).

REDD projects seek to create or strengthen incentives for the protection of existing forests through actions that prevent deforestation and/or forest degradation. This may be achieved through a range of measures, with funding from the carbon market or as direct payments from governments for forest protection and management.

The proposed REDD mechanism has been expanded to REDD+, which includes not only emissions reductions from curbing deforestation, but also the conservation of carbon stocks in standing forests, enhancement of forest carbon stocks, afforestation, reforestation, and sustainable management of forests. All are potentially allowable as REDD+ projects, depending on the final agreement, which may be approved at COP16 in Mexico in December 2010 (Parker et al. 2009; Forum for the Future 2009).

\section{Box 5.11 Landmarks and prospects in the development of REDD and REDD+}

- 2005 - Proposal by governments of Costa Rica, Papua New Guinea and others for the inclusion of avoided deforestation in a post-Kyoto climate change agreement receives support from several countries at COP11 in Montreal

- 2007 - UNFCCC Parties at COP13 include reference to REDD in the Bali Action Plan and Bali Road Map for a post-Kyoto climate change framework

- 2009 - US $\$ 4.6$ billion committed to REDD projects across six international funds

- 2009 - Recognition of the role and need for a REDD finance mechanism in the COP15 Copenhagen Accord

- 2010 - REDD+ mechanism may be approved at COP 16 in Mexico

- 2011 - REDD+ mechanism may go live following ratification of the Kyoto II Agreement

- 2013 - REDD + credits may be accepted as allowable compliance units under Phase III of the European Emissions Trading System (EU ETS)

Primary forest is, in general terms, carbon dense and biologically diverse, with tropical, temperate, and boreal forests containing about two-thirds of the world's terrestrial species. It follows that for intact forest landscapes, one of the most effective ways to conserve biodiversity is by avoiding deforestation. In the case of degraded lands, restoration by the establishment of mixed native species along with avoidance of future deforestation can yield multiple biodiversity benefits (UNEP 2008) ${ }^{8}$.

REDD+ is likely to be the first internationally coordinated, biodiversity-related market of significant size and is likely to offer many valuable lessons, including how to develop economically efficient, environmentally effective and politically acceptable markets, standards, and regulations. These lessons will be important for the establishment and growth of other ecosystem markets as well.

The Eliasch Review (2008) estimated that the funds required to halve emissions from the forest sector by 2030 could be about US $\$ 17$ - 33 billion per year, based on various estimates from the literature and from work 


\section{Figure 5.3 How REDD and forest carbon reduce the costs of climate change mitigation}

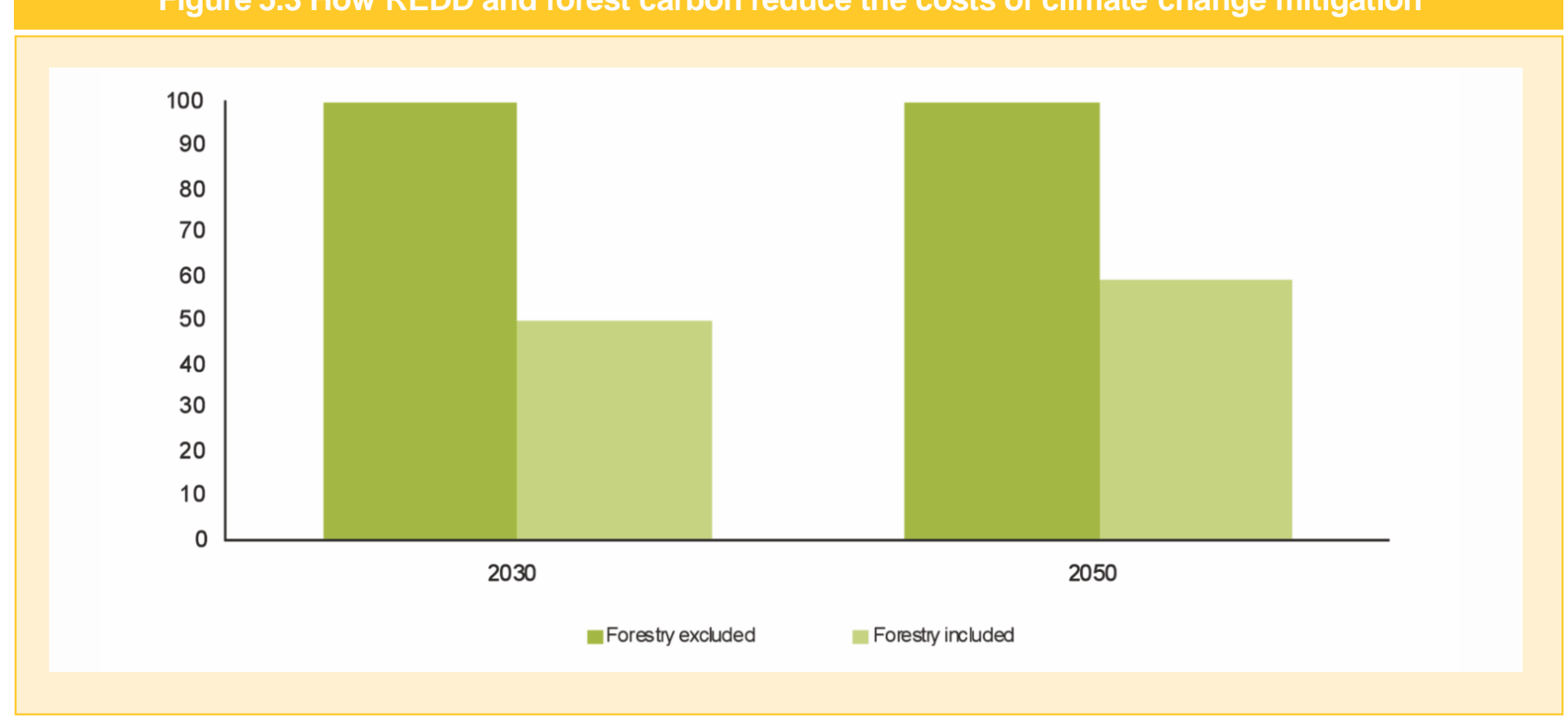

Source: Eliasch (2008)

commissioned by the Review. However, the Eliasch Review also highlighted that the global economic costs of climate change caused by deforestation could reach US $\$ 1$ trillion a year by 2100 . In other words, the cost of action is considerably lower than the cost of inaction.

Additionally, the Eliasch Review indicated that REDD+ (along with other forestry mechanisms) should be included in the activities undertaken to reduce greenhouse gas emissions, as this would significantly lower the overall cost of meeting the emission reduction targets currently under negotiation at the UNFCCC (Figure 5.3).

Reducing deforestation will require substantial financing. Notwithstanding early funding commitments, it is difficult to imagine the private sector funding major REDD+ projects without greater clarity on the long term policy framework and regulatory regimes, and without strengthening institutional arrangements in many of the countries where such projects are planned or required. Furthermore, issues such as 'leakage' mean that REDD+ is unlikely to be widely accepted, unless a coordinated, international effort is established.

Despite the slow pace of international climate change negotiations, many Parties to the UNFCCC are keen to demonstrate that REDD+ projects can be successfully designed and implemented. Several pilot projects have been financed either through voluntary bilateral or multi-lateral funding, or through the sale of carbon emission reduction credits in the voluntary carbon market. Analysis for TEEB by PricewaterhouseCoopers shows that, as of mid-2010, 22 operational REDD projects were publically reported, despite the lack of an international agreement on REDD. These early projects are expected to deliver around $37.5 \mathrm{Mt}$ of $\mathrm{CO}_{2} \mathrm{e}$ in emission reductions over their lifetimes (typically 20 to 30 years), generating useful lessons which are likely to influence the future development of a potential $6 \mathrm{GtCO}_{2} \mathrm{e}$ market (Forum for the Future 2009).

National governments also continue to move ahead with the design and establishment of carbon markets. Examples of evolving policy frameworks include Australia, Japan, and the USA. These, like the EU Emissions Trading Scheme (EU ETS), are part of the policy response that pass sovereign-level obligations to the private and public sectors. They are also likely to allow carbon credits generated from sub-national REDD projects for compliance purposes: REDD+ within a carbon market is therefore expected to offer a significant opportunity to the private sector. 


\section{Table 5.4 Business opportunities in REDD and forest carbon}

\begin{tabular}{|c|c|c|c|c|}
\hline Finance & Governance & $\begin{array}{l}\text { Project } \\
\text { development }\end{array}$ & $\begin{array}{l}\text { REDD+ related } \\
\text { opportunities }\end{array}$ & Market activity \\
\hline $\begin{array}{l}\text { Equity investment } \\
\text { and project finance - } \\
\text { Providing upfront } \\
\text { financing for estab- } \\
\text { lishment of REDD } \\
\text { projects, underpin- } \\
\text { ned by carbon } \\
\text { revenue streams } \\
\text { and grants as well } \\
\text { as forest product } \\
\text { revenues. } \\
\text { Fund creation and } \\
\text { management - } \\
\text { Creating REDD } \\
\text { funds and attracting } \\
\text { investment into the } \\
\text { fund on a for-profit } \\
\text { or not-for-profit } \\
\text { basis. Managing the } \\
\text { applications, invest- } \\
\text { ments, and monito- } \\
\text { ring of recipient } \\
\text { REDD projects. }\end{array}$ & $\begin{array}{l}\text { - Registry services - } \\
\text { Systems to trade } \\
\text { and trace carbon } \\
\text { credits generated } \\
\text { by projects. } \\
\text { - Capacity building } \\
\text { for REDD market } \\
\text { participants - } \\
\text { Provision of training } \\
\text { and management } \\
\text { support for govern- } \\
\text { ment, civil society } \\
\text { organisations and } \\
\text { the private sector } \\
\text { actors involved in } \\
\text { the REDD market. } \\
\text { - Validation and } \\
\text { verification services - } \\
\text { Validation and } \\
\text { verification of a } \\
\text { project's carbon, } \\
\text { biodiversity, ecosys- } \\
\text { tem service, } \\
\text { community and if } \\
\text { relevant, REDD+ } \\
\text { performance } \\
\text { according to } \\
\text { selected standards. }\end{array}$ & $\begin{array}{l}\text { - Project development } \\
\text { - Planning, securing } \\
\text { finance for and } \\
\text { managing the } \\
\text { development of } \\
\text { REDD projects. } \\
\text { - Project technical } \\
\text { support - Technical } \\
\text { expertise and } \\
\text { support for the } \\
\text { design of REDD } \\
\text { activities. Creation } \\
\text { of technological } \\
\text { products to support } \\
\text { project design and } \\
\text { monitoring e.g. } \\
\text { GlS hardware. } \\
\text { - Monitoring - } \\
\text { Collecting and } \\
\text { assessing carbon, } \\
\text { biodiversity, } \\
\text { Providing advice on } \\
\text { project structuring, } \\
\text { tax structuring, } \\
\text { finance raising and } \\
\text { carbon transactions. } \\
\text { community and other } \\
\text { relevant performance } \\
\text { data for accountabi- } \\
\text { lity purposes. } \\
\text { - Legal services - } \\
\text { Advice on contracts } \\
\text { (e.g. land ownership). } \\
\text { Providing insurance } \\
\text { products against } \\
\text { risks to reduce risks } \\
\text { for REDD activities. } \\
\text { - }\end{array}$ & 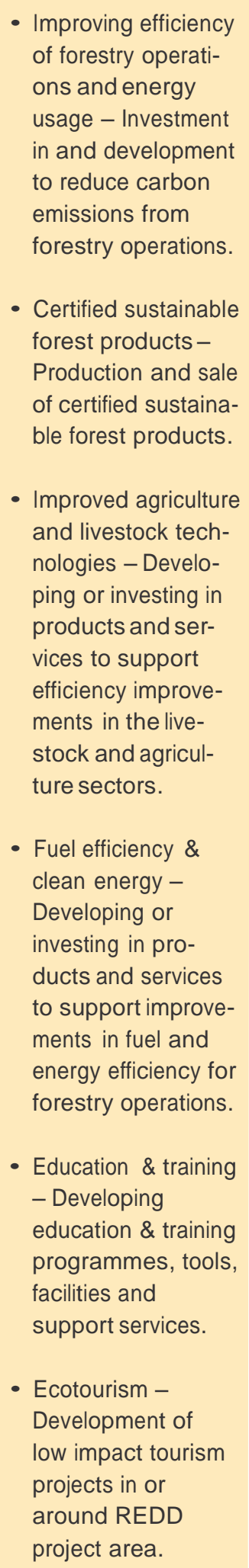 & $\begin{array}{l}\text { - Secondary trading } \\
\text { of REDD credits - } \\
\text { Purchase and sale } \\
\text { of REDD credits } \\
\text { on the carbon } \\
\text { market for profit. } \\
\text { Providing } \\
\text { liquidity to a market. } \\
\text { - Brokerage - Linking } \\
\text { sellers and buyers } \\
\text { and facilitating } \\
\text { REDD credit } \\
\text { transactions. } \\
\text { - Project aggregation } \\
\text { - Generating portfo- } \\
\text { lios of multiple } \\
\text { REDD projects } \\
\text { through purchasing } \\
\text { in the primary } \\
\text { market. } \\
\text { - Market intelligence } \\
\text { services - Provision } \\
\text { of data on of } \\
\text { REDD market. } \\
\text { surket technical } \\
\text { tion of market infor- } \\
\text { mation and giving } \\
\text { advice on marke- } \\
\text { ting/sales strategy. }\end{array}$ \\
\hline
\end{tabular}


The current immaturity and potential future scale of the REDD+ market presents major opportunities for a variety of businesses, particularly if and when sub-national REDD+ projects are allowed to sell credits in regulated carbon markets (as opposed to REDD + activities that are directly funded by governments and linked to performance at national level). As in other markets, it seems likely that early movers willing to take the risks will reap the greatest rewards. Table 5.4 illustrates the areas in which a range of business opportunities may arise within the different components of a REDD+ market.

While REDD+ could deliver significant climate and biodiversity benefits, it is clear that some industrial sectors may be negatively affected if deforestation is significantly reduced. This will be particularly acute for those businesses that rely on access to rural land, such as agriculture or Forest, Paper \& Packaging (FPP). These industries could see increased competition for natural forest and other lands from carbon developers seeking to establish REDD+ projects. This could result in higher land prices, limit the land area available for timber harvesting and increase operational costs. Such impacts may be offset to some extent by companies through active participation in the REDD+ market. For example, FPP companies may afforest or reforest land and implement sustainable forest management systems for the purposes of forest carbon stock enhancement and generate revenue through the sale of carbon offset credits, alongside pulp and paper products ${ }^{9}$.

Regulatory uncertainties aside, the potential benefits of REDD+ in both the short and long-term have led some businesses to take the plunge. Box 5.12 describes how a large international hotel chain is seeking to offset its greenhouse gas emissions by funding a REDD scheme in the Brazilian Amazon.

\section{Box 5.12 Marriott invests in REDD: The Juma Sustainable Development Reserve}

In Brazil, the Marriott international hotel group has dedicated US $\$ 2$ million towards a fund administered by the Amazonas Sustainable Foundation which protects 590,000 hectares of threatened rainforest in the Juma Sustainable Development Reserve. The hotel group is investing in this project to offset its own estimated carbon footprint of 3 million metric tons of $\mathrm{CO}_{2}$ per year.

The Juma project provides incentives for local communities to protect the forest by distributing payments through the 'Bolsa Floresta' programmes, including 'Bolsa Floresta Family', 'Bolsa Floresta Social', 'Bolsa Floresta Association' and 'Bolsa Floresta Sustainable Income Generation'. For example, the Bolsa Floresta Family programme provides a value card for each local family which can be credited with up to 50 Reais (around US\$25) each month, depending on forest protection performance. Investments in the project are also used to fund research and conservation work in the reserve as well as supporting various local economic initiatives. According to the project's own calculations, it will avoid deforestation of 330,000 ha of natural rainforest by 2050 , generating a carbon credit of approximately 189 million tons. The reputational boost from the group's investment in the Juma project is significant; for example, the initiative has helped Marriott win numerous sustainability awards including the World Travel and Tourism Council's 2009 'Tourism for Tomorrow Award for Sustainability'. It is hoped that the initiative may increase the group's position in the sustainable tourism market.

Sources: http://www.forestcarbonportal.com; http://www.marriott.co.uk; Forum For The Future (2009), and PricewaterhouseCoopers for TEEB 


\section{TOOLS TO SUPPORT MARKETS FOR BIO- DIVERSITY AND ECOSYSTEM} SERVICES

Biodiversity business opportunities are supported by an increasingly robust collection of market-based tools which enable companies to adopt biodiversity-responsible practices and indeed to develop and market biodiversity-based goods and services. Such market-based tools compliment the policy instruments for biodiversity which are extensively reviewed in the TEEB report for policy makers (TEEB 2009). This section highlights a selection of market-based tools for biodiversity business, including those related to responsible investment, responsible production, and responsible reporting.

For the investment community, one key mechanism for integrating biodiversity into decision-making is Performance Standard 6 on Biodiversity Conservation and Sustainable Natural Resource Management, developed by the International Finance Corporation (IFC). This standard, together with all of the IFC's environmental and social standards, not only guides the investments of the IFC - the private sector arm of the World Bank - but it also influences the investment practices of more than 60 multi-national banks that have adopted the Equator Principles (TEEB 2009). These Principles call for adherence to IFC Performance Standards with respect to project financing in excess of $\$ 10$ million in emerging markets. The IFC's Performance Standards are currently under revision and the next iteration of Performance Standard 6, in particular, will provide an even more robust approach to addressing biodiversity issues in investment decisions ${ }^{10}$.

\subsubsection{CERTIFICATION SCHEMES FOR BIODIVERSITY AND ECOSYSTEM SERVICE MARKETS}

Growing consumer environmental concerns have stimulated markets for products and production practices that conserve biodiversity, as noted in Chapter 1 . These markets are supported by a range of certification schemes that verify the environmental claims of companies with respect to their products and practices. Although few of the existing social and environmental certification schemes focus on biodiversity, most address some aspects of the biodiversity challenge.

For example, in the coffee sector, one can find schemes that emphasize landscape or ecosystem protection, such as Rainforest Alliance certification, others that promote environment-friendly farming practices (e.g., organic agriculture), and still others that emphasize social equity in the use of biological resources (e.g., FairTrade certification). Taken as a whole, these certification schemes contribute to biodiversity-responsible business practices. A few of them, however, are particularly noteworthy in terms of their contributions to biodiversity conservation at the landscape and ecosystem level; these are highlighted below:

Rainforest Alliance certification is a comprehensive process that promotes and guarantees improvements in agriculture and forestry. Their independent seal of approval, one of the most widely-recognized and ubiquitous in the growing 'sustainable marketplace', ensures that the goods and services it approves were produced "in compliance with strict guidelines for protecting the environment, wildlife, workers and local communities" (www.rainforest-alliance.org $)^{11}$.

The Marine Aquarium Council (MAC) brings together fisheries and organizations that collect, produce and handle marine aquarium organisms around the world, committing its members to work towards compliance with a shared set of standards. The MAC vision is to certify the entire supply chain, starting with sustainable and responsible management of the marine site, from which fish and marine organisms are harvested. 
Its core Ecosystem Fishery Management Standard includes the commitment: "To verify that the collection area is managed according to principles of ecosystem management in order to ensure ecosystem integrity and the sustainable use of the marine aquarium fishery" .

In addition, there are attempts to assess or certify the biodiversity performance of individual companies. One of the more promising initiatives, coming out of Brazil and gaining international prominence, is the LIFE Institute. They have created and are responsible for managing LIFE Certification, which qualifies and recognizes public and private organizations that promote biodiversity conservation and sustainable development initiatives, thus ensuring the protection of ecosystem integrity .

Each of these certification schemes provides structures, standards and certification processes that can help companies verify their biodiversity responsibility to the market. Such certifications can help companies penetrate new, more discerning markets and also make them more attractive to the growing number of responsible consumers and investors.

\subsubsection{ASSESSMENT AND REPORTING FOR BIODIVERSITY AND ECOSYSTEM SERVICE MARKETS}

As companies begin to address biodiversity more strategically in their planning and decision-making, new tools for assessing and reporting on biodiversity are needed, as discussed in Chapter 3 . Below we highlight three examples that show how such tools can help companies realize new biodiversity business opportunities:

The Corporate Ecosystem Services Review (ESR) includes a wealth of supporting tools and training materials to assist companies in coming to grips with the biodiversity aspects of their operations. For example, Mondi "used the ESR to develop several new strategies for dealing with the ecosystem service challenges to their FSC certified South African plantations" while Syngenta used the ESR to "identify a number of possible opportunities to help farmers either reduce their impacts on ecosystems or adapt to ecosystem change".

The Global Reporting Initiative (GRI) Biodiversity Reporting Resource was released in 2007 to assist companies in reporting their biodiversity performance. As the tool explains: "Reporting offers organizations an

\section{Box 5.13 The association for social and environmental standards}

ISEAL is the global association for social and environmental standards and has become an umbrella organization for a growing number of sustainability standards and certification schemes. ISEAL members include Fairtrade Labelling Organizations International (FLO), Forest Stewardship Council (FSC), International Federation of Organic Agriculture Movements (IFOAM), International Organic Accreditation Service (IOAS), Marine Aquarium Council (MAC), Marine Stewardship Council (MSC), Rainforest Alliance, and Social Accountability International (SAI). One of the key roles of ISEAL is to harmonize the ways that different sustainability standards are administered, verified and assessed.

To this end, in 2010 ISEAL is launching a new "Verification Code of Good Practice for Assessing the Impacts of Standards Systems". This aims to define good operating practices in terms of accreditation, certification and auditing of entities to social and environmental standards, and also to create a requirement for all credible standards systems to measure and demonstrate their contributions to social and environmental impacts using consistent methodologies. A focus of the Code will be to achieve a balance between ensuring that certification is rigorous, in terms of meeting the needs of consumers, but also accessible, by ensuring that smaller enterprises can afford to enter certification programmes and see them as market enablers rather than barriers. 
opportunity to explain their relationship with biodiversity. In what way does the organization respond to negative impacts on biodiversity deriving from its activities? What are positive impacts?"

The Natural Value Initiative (NVI) is a recent development that helps the finance sector evaluate and assess how companies - particularly in the food, beverage and tobacco (FBT) sectors - are managing their biodiversity opportunities and risks (www.naturalvalueinitiative.org). It includes the Ecosystem Services Benchmark (ESB), which is somewhat akin to the ESR noted above. The ESB has been tested on over 30 FBT companies that are particularly dependent on biodiversity and can therefore have significant impacts on mitigating biodiversity loss.

\subsubsection{VOLUNTARY INCENTIVES FOR BIODIVERSITY BUSINESS}

As discussed in the TEEB report for national and international policy makers, incentive measures for biodiversity and ecosystem services can be greatly strengthened through appropriate government policies and regulatory frameworks. However, in addition to these policy tools, there are several types of voluntary incentives which can encourage and enable biodiversity business. These include the following:

- Awareness raising initiatives, which can change perceptions of investors, managers, employees or consumers about biodiversity

- Voluntary biodiversity offsets, which are conservation measures that can compensate for the residual, unavoidable harm to biodiversity caused by development projects

- Biotrade arrangements, which have promoted the collection, production, transformation, and commercialisation of goods and services derived from native biodiversity under criteria of environmental, social and economic sustainability

- Bioprospecting arrangements and Access and Benefit Sharing agreements, which have funded biological research and discovery partnerships between pharmaceutical companies and countries with high levels of biodiversity

- Stewardship payments, which pay landscape managers to deliver biodiversity conservation and provide environmental services that benefit the public

- Conservation auctions, which can be used to deliver stewardship payments

- Conservation covenants as part of voluntary land transactions, to embed biodiversity conservation in the title deed

- Payments for watershed protection, which range from payments by private water users to environmental agencies and NGOs, to direct payments by central governments to private landowners, and can be a cost-effective means of providing reliable supplies of fresh water

- Public-private partnerships, which explore business opportunities for safeguarding biodiversity, and can link commercial debt finance with public subsidies to produce social, commercial and biodiversity benefits

In this respect, biodiversity leaders within the private sector as well as the non-profit sector are developing new means to stimulate business engagement in the conservation and sustainable use of biodiversity and ecosystem services. 


\subsubsection{FURTHER CONSIDERATIONS FOR INSTITUTIONAL INVESTORS}

At present, institutional investors generally have little understanding of, and see little value in, biodiversity and ecosystem services. This could change, however, into a situation in which biodiversity and ecosystem services are valued by markets, causing capital inflows to companies that will benefit from new opportunities as well as capital outflows from companies that are seen to use biodiversity and ecosystem services unsustainably.

F\&C, an asset manager, identified the following policy characteristics as relevant to the development of biodiversity and ecosystem services trading and markets (F\&C 2010):

- In order to reduce investment risk, investors need a level of certainty about the fundamental nature of a new market - this is likely to require government intervention and regulation.

- Investors are wary of subsidies that may be subject to swift changes due to political pressure - such as the EU subsidies for biofuels.

- Landowners and those who grant permits for development could create rapid changes in the effectiveness of biodiversity management by linking development permit awards to good environmental management.

- All ecosystems services cannot be traded with ease and so it will be necessary to focus on a restricted number that can familiarise investors and markets with the concepts and allow an understanding of the risks and opportunities. The importance of building knowledge and trust amongst investors cannot be overstated; excessively complex or rushed schemes are likely to fail.

- Changes should not unfairly disadvantage companies based in particular countries - for example, increasing the costs of access to land for a mining company should apply equally to all such companies, whatever their domicile.

- Data provision is crucial to good investment decisions, and also to good public policy decisions.

- Cost-effective metrics and valuation methodologies are needed for example to value the ecosystem services delivered by forests in monetary terms, or to assess ecosystem service debits and credits in bio-physical terms.

If public policies intended to encourage biodiversity business are to attract significant support from institutional investors, concerns such as these will need to be addressed comprehensively.

\subsubsection{PUBLIC POLICY TO SUPPORT BIODIVERSITY BUSINESS}

The TEEB report for policy makers includes a detailed review of various policies that could be implemented at the national and international levels to reduce the loss of biodiversity. Some of these would clearly create an enabling framework to scale up new biodiversity and ecosystem services business opportunities, notably those recommended in Chapter 5 of the report, entitled 'Rewarding benefits through payments and markets' (TEEB 2009). These include the following:

- "Promote PES demonstration activities and capacity building to develop the knowledge base, reduce transaction costs and scale up successful initiatives. Further efforts are needed to confirm where, in what form and under what conditions PES work best for biodiversity, and to improve their targeting, monitoring and 
governance... Spatial analyses - including data on economic costs and benefits - can help to map areas that are most important for providing ecosystem services, as well as the distribution of providers and beneficiaries, in order to identify synergies and priorities for both policymakers and private investors."

- "Support an international agreement on a REDD+ mechanism as part of the global climate regime, while ensuring that other ecosystem services besides climate mitigation are taken into account. Depending on how REDD+ is designed and implemented, it could not only provide incentives for reducing emissions from deforestation and degradation but also secure biodiversity and other benefits at international, national and local levels."

- "Contribute to emerging international initiatives to support direct investment in biodiversity public goods and natural capital across a wider array of ecosystems, such as the proposed Green Development Mechanism (GDM)."

- "Successfully conclude negotiations under the CBD on the international regime for more efficient and equitable sharing of the benefits arising out of the utilisation of genetic resources. A premium is needed for traditional local knowledge that leads to successful commercialisation based on genetic resources, together with better screening and contractual and dispute resolution procedures to minimise transaction costs."

- "Make more systematic use of opportunities to provide tax exemptions for activities that integrate ecological concerns and promote conservation. Tax breaks can provide powerful incentives for private actors to donate land or to engage in long-term stewardship agreements."

- "Help producers prepare for new market opportunities as consumers and public procurement policies stimulate demand for biodiversity and ecosystem services-friendly products and services. Policymakers can support the development of robust process and performance standards and verification systems that explicitly include biodiversity and ecosystem services biodiversity and ecosystem services conservation... Public business advisory and support programmes should be geared to help companies meet the needs of new markets for green products and services."

- "Cooperative measures should be put in place to support developing countries' production and export sectors, to enable them to participate effectively in the development and implementation of new market standards. Targeted support of this kind can be an important part of international development aid, offering synergies between biodiversity and ecosystem services, development and poverty reduction."

Such policy developments would reinforce the voluntary tools and incentives outlined above. In order to ensure synergies between private initiatives and public policies, however, it is essential to engage business in the development of biodiversity policies at both the national and international levels. 


\section{WHAT IS TO BE DONE?}

New approaches to integrating biodiversity into existing 'mainstream' businesses, the emergence of new biodiversity businesses, the development of new and innovative markets for biodiversity and ecosystem services this chapter has sought to show that biodiversity and ecosystem services are much more than a business risk but can and are increasingly the basis for profitable business opportunities.

A business approach to biodiversity and ecosystem services can deliver net positive biodiversity impacts, as well as net positive financial returns. As suggested by the following table, adapted from the Ecosystem Marketplace, biodiversity and ecosystem services are likely to provide lucrative business opportunities in the years ahead.

\section{Table 5.5 Biodiversity and ecosystem service market opportunities}

\begin{tabular}{|c|c|c|c|}
\hline \multirow{2}{*}{$\begin{array}{l}\text { Biodiversity and ecosystem } \\
\text { service market opportunities }\end{array}$} & \multicolumn{3}{|c|}{ Market size (US\$ per annum) } \\
\hline & 2008 (actual) & 2020 (est.) & 2050 (est.) \\
\hline $\begin{array}{l}\text { Certified agricultural products } \\
\text { (e.g., organic, fair-trade) }\end{array}$ & $\begin{array}{c}\text { \$40billion } \\
(2.5 \% \text { of global } \\
\text { food and beverage market })\end{array}$ & $\$ 210$ billion & $\$ 900$ billion \\
\hline Certified forest products & $\begin{array}{c}\$ 5 \text { billion } \\
\text { of FSC-certified products }\end{array}$ & $\$ 15$ billion & $\$ 50$ billion \\
\hline $\begin{array}{l}\text { Forest-based carbon offsets } \\
\text { in regulated markets } \\
\text { (e.g. CDM, REDD+) }\end{array}$ & $\begin{array}{l}\text { Various pilots } \\
\text { (e.g. New South Wales GHG Abatement } \\
\text { Scheme): } \$ 0.5 \text { million }\end{array}$ & $\$ 5$ billion & $\$ 5$ billion \\
\hline $\begin{array}{l}\text { Forest-based carbon offsets } \\
\text { in voluntary markets } \\
\text { (e.g. VCS) }\end{array}$ & $\$ 21$ million in 2006 & $\$ 5$ billion & $\$ 5$ billion \\
\hline $\begin{array}{l}\text { Payments for ecosystem services } \\
\text { mediated by government }\end{array}$ & $\$ 3$ billion & $\$ 7$ billion & $\$ 15$ billion \\
\hline $\begin{array}{l}\text { Government payments } \\
\text { for water-related } \\
\text { ecosystem services }\end{array}$ & $\$ 5.2$ billion & $\$ 6$ billion & $\$ 20$ billion \\
\hline $\begin{array}{l}\text { Voluntary payments for } \\
\text { watershed management }\end{array}$ & $\begin{array}{l}\text { Various pilots such as in Costa Rica, } \\
\text { Ecuador, etc: } \$ 5 \text { million }\end{array}$ & $\$ 2$ billion & $\$ 10$ billion \\
\hline $\begin{array}{l}\text { Biodiversity offsets in regulated } \\
\text { markets (e.g. US wetland banking) }\end{array}$ & \$3.4 billion & $\$ 10$ billion & $\$ 20$ billion \\
\hline $\begin{array}{c}\text { Voluntary } \\
\text { biodiversity offsets }\end{array}$ & $\$ 17$ million & $\$ 100$ million & $\$ 400$ million \\
\hline Bio-prospecting agreements & $\$ 30$ million & $\$ 100$ million & $\$ 500$ million \\
\hline $\begin{array}{l}\text { Land trusts, easements and other } \\
\text { fiscal incentives for conservation } \\
\text { (e.g. TNC programmes in } \\
\text { North America and Australia) }\end{array}$ & $\begin{array}{l}\$ 8 \text { billion } \\
\text { in U.S. alone }\end{array}$ & $\$ 20$ billion & Difficult to predict \\
\hline
\end{tabular}

Adapted from: http://moderncms.ecosystemmarketplace.com/repository/moderncms_documents/PES_MATRIX_06-16-08_oritented.1.pdf 
From a business perspective, the reasons and opportunities to invest in biodiversity and ecosystems are increasingly compelling. These opportunities are most evident in cases where business profitability depends directly on the quality and quantity of ecosystem services - in ecotourism ventures, for instance - but also for businesses that rely on natural resources like wood, water, fibre, fish and wild genetic material. Biodiversity business opportunities can be found in a surprisingly wide range of sectors, including mining, energy, agriculture, fisheries, construction, forestry, tourism, pharmaceuticals, cosmetics, banking and even fashion.

So what is to be done? Why do we not see more significant investment by the private sector in biodiversity conservation? Why do we not see a surge in the growth of new biodiversity businesses across a range of sectors from agriculture to banking to tourism? If ecosystem services are as important to life on this planet as scientists tell us they are, why do we not see a rapid expansion in both domestic and international markets for ecosystem services?

Perhaps we need more market-based tools, but more importantly, perhaps we need more faith in the potential of business to conserve biodiversity and restore ecosystems. In practice, this means assigning greater responsibility but also increased access and influence for business in how biodiversity assets are managed. In almost every country in the world today, major biodiversity assets are either directly owned or controlled by governments - including mountains, forests, grasslands, wetlands, lakes and rivers, coastal areas, and, exclusive economic zones in the seas. In short, if we really want to harness to power of business to help stop the loss of biodiversity and to restore degraded landscapes and ecosystems, we will need to rethink the way that society manages natural capital and biodiversity assets.

Importantly, increased private sector access to biodiversity assets will only deliver sustainable results if it is bundled with an appropriate set of rights and responsibilities. Where access to natural assets remains wide open - notably in the high seas and their fisheries - it is clear from experience that business on its own is not able to deliver biodiversity conservation and sustainable resource management. Of course, government subsidies to the fishing industry, as highlighted in the TEEB report for policy makers, do not help this situation.

If we are serious about upscaling biodiversity opportunities for business, what needs to be done is to empower businesses to responsibly manage key biodiversity assets so that they are conserved, used sustainably and equitably, and when necessary, restored. This requires a serious commitment to rethinking the way we manage nature in order to make capitalism work for conservation. 


\section{Endnotes}

1 IFOAM (The International Federation of Organic Agricultural Movements) explains: "Organic agriculture is a production system that sustains the health of soils, ecosystems and people. It relies on ecological processes, biodiversity and cycles adapted to local conditions, rather than the use of inputs with adverse effects. Organic agriculture combines tradition, innovation and science to benefit the shared environment and promote fair relationships and a good quality of life for all involved." See: http://www.ifoam.org/ press/press/2 $008 / 20080522_{\text {_Press_Release_Organic }}$ Agriculture_for_Biodiversity.php

2 A recent survey by UEBT (Union for Ethical BioTrade) indicated a significant level of consumer interest in biodiversity and ecosystem services responsibility in this sector. See: http://uebt.ch/conferences/dl/UEBT _BIODIVERSITY_BAROMETER_web280410.pdf

3 One company claims that the development of land in Louisiana into a wetland bank means that it will be able to sell acre/credits for $\$ 20,000$ - $\$ 25,000$ each. On this basis, the company may generate $\$ 150$ million from its 7100 acre wetland bank selling credits to developers (WRI, 2008).

$4 \quad$ Leakage occurs when reducing deforestation in one area simply results in higher deforestation elsewhere. Projects provide

'additionality' only where they have additional forest protection, afforestation or reforestation benefits above and beyond what would happen in their absence (the baseline scenario).

$5 \quad$ Markit is an environmental commodities markets infrastructure provider.

6 Property rights can be defined as a "claim to a benefit (or income) stream that the State will agree to protect through the assignment of duty to others who may covet, or somehow interfere with, the benefit stream' (Bromley 1991). For business, the protection of this claim to environmental service benefit (or income) streams is fundamental to engaging in ecosystem service markets (Adger and Luttrell, 2000; Bayon 2004).

$7 \quad$ It is important to understand that these factors will differ according to the ecosystem service and the country in which the investment is being made and should be considered as part of a standard risk assessment process.

8 If REDD activities are concentrated in areas of both high carbon stocks and high biodiversity values then it will simultaneously help to meet the carbon reduction objectives of the UNFCCC and also the biodiversity conservation objectives of the Convention on Biological Diversity (UNEP, 2008).

9 Fiscal incentives to restore this land by shifting perverse incentives supporting biodiversity destruction are needed. In some countries, this could offer a major opportunity for business and REDD financing. Safeguards are needed for poor communities who own or use these lands.
10 The 14 April 2010 draft states the following: "Performance Standard 6 recognizes that protecting and conserving biodiversity, the maintenance of ecosystem services, and the sustainable management of natural resources are fundamental to sustainable development...This Performance Standard reflects the objectives of the Convention on Biological Diversity to conserve biological diversity and promote the use of renewable natural resources in a sustainable manner. This Performance Standard addresses how clients can avoid, reduce, restore, and offset impacts on biodiversity arising from their operations as well as sustainably manage renewable natural resources and ecosystem services." See: http://www.ifc.org/ifcext/policyreview.nst/Content/PerformanceStandard6.

11 For example, the two critical criteria with respect to ecosystems conservation in their standard for sustainable agriculture are as follows (See http://www.rainforest-alliance.org/agriculture/documents/sust_ag_standard.pdf):

'2.1 Critical Criterion. All existing natural ecosystems, both aquatic and terrestrial, must be identified, protected and restored through a conservation program. The program must include the restoration of natural ecosystems or the reforestation of areas within the farm that are unsuitable for agriculture.'

'2.2 Critical Criterion. The farm must maintain the integrity of aquatic or terrestrial ecosystems inside and outside of the farm, and must not permit their destruction or alteration' 


\section{References}

Addams, L. Boccaletti, G. Kerlin, M. and Stuchtey, M. (2009) Charting Our Water Future: Economic frameworks to inform decision-making. 2030 Water Resources Group, McKinsey \& Company. URL http://www.mckinsey.com/clientservice/water/ charting_our_water_future.aspx

Adger, W.N. and Luttrell C., (2000) 'Property rights and the utilisation of wetlands'. Ecological Economics, 35 (1), pp. 75-89.

Barber, T. and Krivoshlykova M., (2006) Global Market Assessment for Handicrafts, USAID, Volume 1 (final draft).

Bayon, R. (2004) 'Making Environmental Markets Work: Lessons from Early Experience with Sulfur, Carbon, Wetlands and Other Related Markets', presented at Katoomba Group meeting, Lucarno, Switzerland.

Bayon, R. Carroll, N. Hawn, A. Kenny, A. Walker, C. Bruggeman, D. Campbell, E. Ferguson, A. and Fleischer, D., (2006) Banking on Conservation: Species and Wetland Mitigation Banking. The Katoomba Group's Ecosystem Marketplace. URL: http://

moderncms.ecosystemmarketplace.com/repository/moderncms documents/market_insights_banking_on_mitigation.1.pdf

Bernick, L. and Guth, J (2010) "Retail: Stocking the Shelves with Green". GreenBiz Reports, Five Winds International (March).

BioFach (2009a) "Weleda on the road to success", BioFach Vivaness Newsletter № 203 (7 August 2009).

BioFach (2009b) "Natural cosmetic growing against the trend", BioFach - Vivaness Newsletter № 204 (21 September).

Bishop, J., Kapila, S., Hicks, F., Mitchell, P. and Vorhies, F. (2008) Building Biodiversity Business. Shell International Limited and the International Union for Conservation of Nature: London, UK, and Gland, Switzerland. 164 pp. (March) URL: http://data.iucn.org/dbtw-wpd/edocs/2008-002.pdf

Bromley, D. W. (1991) Environment and Economy: Property Rights and Public Policy, Oxford: Basil Blackwell.

Business for Social Responsibility (BSR) (2006) Environmental Markets: Opportunities and Risks for Business. (Online) URL: www.bsr.org/reports/BSR_Environmental-Markets.pdf

Campbell K. T. Crosbie, L. Howard, R. Mitchell, A. and Ripley, S., (2010) The Forest Footrpint Disclosure Annual Review 2009, The Global Canopy Programme, Oxford. URL: http://www.forestdisclosure.com/docs/FFD_Annual_Review_WEB.pdf

Carbon Disclosure Project (CDP) (2010) Becoming a Signatory or Founding Signatory Member. URL: https://www.cdproject.net/

SiteCollectionDocuments/CDP_WD_Signatory_Brochure_2010.pdf

Carroll, N. (2008) 'Compliant Biodiversity Offsets' in Payments for Ecosystems Services: Market Profiles. Forest Trends and The Ecosystem Marketplace.
Carter, I. J, Stevens, T. Clements, T. Hatchwell, M. Krueger, L. Victurine, R. Holmes, C. and Wilkie, D., (2009) WCS REDD Project Development Guide, USAID. URL: http://www.translinks.org/ Docustore/tabid/409/language/en-GB/Default.aspx? Command=Core_Download\&Entryld $=3646$

$\mathrm{CBI}$ (Centre for the Promotion of Imports from developing countries) (2004) European buyers' requirements: Benchmarking the tourism industry (September).

CBI (2008) The Outerwear market in the EU. Prepared by Fashion Research \& Trends (September).

CBI (2009a) Long Haul Tourism: The EU market for adventure travel (March).

CBI (2009b) Luggage and (leather) accessories - CBI Market Survey: The EU Market for wallets and purses (April).

CBI (2009c) European buyer requirements: Tourism (June).

Clean Edge (2009) Clean Energy Trends 2009. (March) URL: http://www.cleanedge.com/reports/pdf/Trends2009.pdf

Connor, M., (2010) "Survey: U.S. Consumers Willing to Pay for Corporate Responsibility", Business Ethics, the Magazine of Corporate Responsibility (29 March) URL: http://businessethics.com/2010/03/29/1146-survey-u-s-consumers-willingto-pay-for-corporate-responsibility/

Cullen, M.A and Durschinger , L.L. (2008) Emerging market for land-use carbon credits. ITTO Tropical Forest Update 18/3. URL: http://www.itto.int/direct/topics/topics_pdf_download/topics_id=1 $881 \&$ no $=0$

Ecosystem Services Project (2008) The Markets For Ecosystem Services Project: Factsheet. URL: www.ecosystemservicesproject.org/html/publications/docs/facts/Markets_Flyer2_web.pdf

Eliasch, J., (2008) Climate Change: financing global forests: the Eliasch review. London; Sterling, Earthscan.

Evison, W. and Knight.C., (2010) Biodiversity and business risk: A Global Risks Network briefing. World Economic Forum (WEF), Geneva. URL: http://www.weforum.org/pdf/globalrisk/Biodiversityandbusinessrisk.pdf

Fair Trade in Tourism South Africa (FTTSA) (2009) pers. comm.

FiBL and IFOAM (2009) The World of Organic Agriculture. Statistics and Emerging Trends 2009. Bonn, Frick, Geneva.

Fischer, C. (2003) Combining Rate-Based and Cap-and-Trade Emissions Policies. Discussion Paper Resources for the Future. URL: www.rff.org/Documents/RFF-DP-03-32.pdf

FLO (FairTrade Labelling Organisation) (2010) Facts and figures web page. URL: http://www.fairtrade.net/facts_and_figures.html 
Forest Trends \& The Katoomba Group, 2008. Payments for Ecosystem Services: Market Profiles.

Forum For The Future, 2009. Forest Investment Review. URL: http://www.forumforthefuture.org/projects/forest-investmentreview

GRI (Global Reporting Initiative) (2007) Biodiversity: a GRI Reporting Resource. URL: http://www.globalreporting.org/NR/rdonlyres/07301B96-DCF0-48D3-8F85-8B638C045D6B/0/ BiodiversityResourceDocument.pdf (last access 289 June 2010).

Gripne, S., (2008) 'Markets for Biodiversity: Delivering returns from emerging environmental markets.' PERC Reports: Volume 26, No.4, December 2008.

Hamilton, K. Sjardin, M. Shapiro, A. and Marcello T., (2009) Fortifying the Foundation: State of the Voluntary Carbon Markets 2009. The Katoomba Group and New Carbon Finance.

HSBC (2009) Climate Change Index annual review, (September). Inauen, C., (2010a) Presentation: 'Promoting biodiversity through sustainable cocoa sourcing - Experiences from a pilot project in Honduras.'

IAP (Interacademy Panel on International Issues) (2009) 'IAP Statement on tropical forests and climate change'. URL: http://www.interacademies.net/Object.File/Master/10/070/Statement_DES1748 _IAP\%20forests_11.09_P-2-1.pdf

Inauen, C., (2010b) Pers. Comm.

Instituto LIFE, 2009. Regulations for LIFE certification (preliminary version, July). URL: http://institutolife.org/interface/public/ images/en/downloads/LIFE_Regulations_7-17-2009.pdf (last access 9 July 2010).

IPCC (Intergovernmental Panel on Climate Change) Fourth Assessment Report: Climate Change 2007. URL: http://www.ipcc.ch/ publications_and_data/publications_and_data_reports.htm

Kline \& Company (2009) Natural personal care products: will the growth continue? Presentation made at the 2009 edition of the In-Cosmetics trade fair (April).

Madsen, B. Carroll, N and K.M., (2010) State of Biodiversity Markets. URL: http://www.ecosystemmarketplace.com/documents/ acrobat/sbdmr.pdf

MAC (Marine Aquarium Council) (2001) Core Ecosystem and Fishery Management International Performance Standard for the Marine Aquarium Trade (Issue 1 - July) URL: http://aquariumcouncil.org/materials/mac_efm_standard.pdf (last access 9 July 2010).

Mazzanti, R and Zavettieri, S., (2009) Summer 2010 Trends: Mysty, mimetic hues and weatherproof materials. Fiera de Milano Press Office, Milan (16 September). URL: www.mipel.com/files/coms- tampa96mipel_eng.pdf (last access 13 October 2009).
MSC (Marine Stewardhip Council) (2009) Net Benefits: The first ten years of MSC certified sustainable fisheries. URL: http://www.msc.org/documents/fisheries-factsheets/netbenefits-report/net-benefits-introduction-web.pdf

Mulder, I. ten Kate, K. and Scherr S.,(2006) Private sector demand in markets for ecosystem services: preliminary findings. Forest Trends. URL: www.fsd.nl/downloadattachment/72341/60533/private_sector_demand.pdf

Organic Monitor Gives (2009a) "Organic Monitor Gives 2009 Predictions" (30 January). URL: http://www.organicmonitor.com/ r3001.htm

Organic Monitor (2009b) "Global Organic Market: Time for Organic Plus Strategies” (29 May). URL: http://www.organicmonitor.com/ r2905.htm

Organic Trade Association (OTA) (2009) "Organic Trade Association Releases Its 2009 Organic Industry Survey" press release (4 May). URL: http://www.organicnewsroom.com/2009/05/organic_ trade_association_rele_1.html

Parker, C. Mitchell, A. Trivedi, M. and Mardas, N., (2009) The Little REDD+ Book. Global Canopy Programme (GCP). URL: http://www.globalcanopy.org/themedia/file/PDFs/LRB_lowres/ Irb_en.pdf

Plambeck, E. L. and Denend, L., (2008) The Greening of Wal-Mart. Stanford Social Innovation Review (Spring). URL: http://csi.gsb.stanford.edu/greening-wal-mart (last access 29 June 2010).

Prescott, J., (2009) "Buyers pre-empt demand for sustainability". Ecotextile News, (25 September). URL: www.ecotextile.com/ news_details.php?id=10016

State of Victoria Department of Sustainability and Environment (2006) Bushbroker: Native vegetation credit registration and trading.

TEEB - The Economics of Ecosystems and Biodiversity (2009) TEEB for National and International Policy Makers (2009) URL: http://teebweb.org/ForPolicymakers/tabid/1019/language/ en-US/Default.aspx (last access 9 July 2010).

Tourism Sustainability Council (TSC) 2009. "Partnership for Global Sustainable Tourism Criteria and Sustainable Tourism Stewardship Council Announce Merger to Form Tourism Sustainability Council". URL: http://www.sustainabletourismcriteria.org/index.php? option=com_content\&task=view\&id=266\&ltemid $=483$

Traffic International (2006) Traffic Bulletin, Vol. 21 No. 1 (July).

UNEP (2008) Forest Biodiversity. COP 9 MOP 4 Bonn, Germany.

UNEP and New Energy Finance (2009) Global Trends in Sustainable Energy Investment 2009. URL: http://sefi.unep.org/fileadmin/ media/sefi/docs/publications/Executive_Summary_2009_EN.pdf 
UNEP/CBD/WG-RI/3/INF/13 (2010) Innovative Financial Mechanisms - Initiating Work on a Green Development Mechanism. URL: http://www.cbd.int/wgri3/meeting/Documents.shtml

VIETRADE (Vietnam Trade Promotion Agency) (2006) Vietnamese handicrafts and traditional craft villages (November).

VIETRADE (2008) Vietnamese handicrafts and traditional craft villages (November).

Willan, Becky (2009) "Twenty Trends for Sustainability in 2009-10", Environmental Leader (24 September). URL: http://www.environmentalleader.com/2009/09/24/twenty-trends-for-sustainabilityin-2009-10./

Wilhelmsson, D. Malm, T. Thompson, R. Tchou, J. Sarantakos, G. McCormick, N. Luitjens, S. Gullström, M. Patterson Edwards, J.K. Amir, O. and Dubi, A., (eds.) (2010) Greening Blue Energy: Identifying and managing the biodiversity risks and opportunities of off shore renewable energy. URL:

http://data.iucn.org/dbtw-wpd/edocs/2010-014.pdf

Willle, C., (2009) Rainforest Alliance - Sustainable Agriculture Network. Presentation at the Sustainability Conference Nuremberg, (February).

World Bank (2009) State and Trends of the Carbon Market 2009. URL: http://wbcarbonfinance.org/docs/State_Trends_of_the Carbon_Market_2009-FINAL_26_May09.pdf

WHO (World Health Organization) (2003) WHO guidelines on good agricultural and collection practices (GACP) for medicinal plants. Geneva.

WRI (World Resources Institute) (2008) Examples of Ecosystem Service-related Business Risks and Opportunities. URL: www.wri.org/project/ecosystem-services-review

WRI, WBCSD and Meridian Institute (2008) The Corporate Eco- system Services Review: Guidelines for Identifying Business Risks and Opportunities Arising from Ecosystem Change. World Resour- ces Institute, Washington DC. URL: http://pdf.wri.org/corporate_ecosystem_services_review.pdf

www.bamboosushipdx.com (last access 9 July 2010)

www.eartheasy.com (last access 9 July 2010)

www.ecoclub.com (last access 9 July 2010)

www.ecoenterprisesfund.com (last access 9 July 2010)

www.ecotourism.org (last access 9 July 2010)

www.gdm.earthmind.net (last access 9 July 2010)

www.lohas.com (last access 9 July 2010)

www.msc.org (last access 9 July 2010)

www.missionmarkets.com (last access 9 July 2010) www.naturalfibres2009.org (last access 9 July 2010)

www.naturalvalueinitiative.org (last access 9 July 2010)

www.planeta.com (last access 9 July 2010)

www.rainforest-alliance.org (last access 9 July 2010)

www.wfto.com (last access 9 July 2010)

www.wri.org (last access 9 July 2010) 


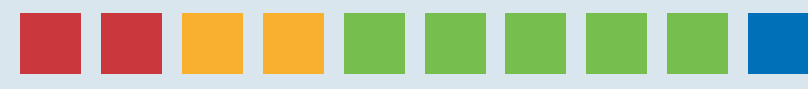 THE ECONOMICS OF ECOSYSTEMS AND BIODIVERSITY \\ TEEB $\quad$ FOR BUSINESS}

Chapter 1 Business, biodiversity and ecosystem services

Chapter 2 Business impacts and dependence on biodiversity and ecosystem services

Chapter 3 Measuring and reporting biodiversity and ecosystem impacts and dependence

Chapter 4 Scaling down biodiversity and ecosystem risks to business

Chapter 5 Increasing biodiversity business opportunities

Chapter 6 Business, biodiversity and sustainable development

Chapter 7 A recipe for biodiversity and business growth 


\section{Chapter 6: Business, biodiversity and sustainable development}

TEEB for Business Co-ordinator: Joshua Bishop (International Union for Conservation of Nature)

Editor: Linda Hwang (BSR)

Contributing authors: Suhel al-Janabi (GTZ), Andreas Drews (GTZ), Joshua Bishop (IUCN)

Acknowledgements: Kit Armstrong (Plexus Energy), Tim Buchanan (BSR), Toby Croucher (Repsol), Juan Gonzalez-Valero (Syngenta), Michael Oxman (BSR)

Disclaimer: The views expressed in this report are purely those of the authors and may not in any circumstances be regarded as stating an official position of the organisations involved.

The final edition of the TEEB for Business report will be published by Earthscan. If you have any additional information or comments you feel should be considered for inclusion in the final report then please email them by 6 th September, 2010 to: teeb4biz@ufz.de

TEEB is hosted by the United Nations Environment Programme and supported by the European Commission; the German Federal Environment Ministry; the UK Government's Department for Environment, Food and Rural Affairs; the UK Department for International Development; Norway's Ministry for Foreign Affairs; The Netherlands' Interministerial Program Biodiversity; and the Swedish International Development Cooperation Agency. 


\title{
THE ECONOMICS OF ECOSYSTEMS AND BIODIVERSITY
}

\author{
Chapter 6 \\ Business, biodiversity and \\ sustainable development
}

\section{Contents}

Key messages 3

6.1 Impacts of integrating biodiversity and ecosystem services in business 4

6.2 Conflicting aspects of sustainable development and biodiversity conservation 5

6.3 Challenges for companies in integrating BES with social development 6

6.3.1 Poor understanding of the links between ecosystem services and poverty 6

$\begin{array}{ll}\text { 6.3.2 Risks of business engagement in sustainable development } & 7\end{array}$

6.3.3 Project-induced in-migration $\quad 8$

6.3.4 Integrating ecosystem services into corporate poverty reduction programmes 9

6.3.5 Difficulties in measuring success 9

6.3.6 Lack of agreement on access and benefit sharing arrangements 11

6.4 Conclusion and recommendations 13

6.4.1 Linking economic development and poverty alleviation $\quad 13$

6.4.2 BES play a critical role in sustainable development $\quad 14$

$\begin{array}{ll}\text { 6.4.3 Recommendations } & 14\end{array}$

$\begin{array}{ll}\text { References } & 17\end{array}$

\section{Boxes}

6.1 Poverty and ecosystem degradation

6.2 Poverty reduction and biodiversity conservation: A trade-off?

6.3 The social impacts of biodiversity offsets: Rio Tinto in Madagscar

6.4 Freeport Indonesia and the impacts of in-migration

6.5 Mapping ecosystem services with livelihood strategies in China

6.6 Assessing the impact of livelihood strategies in Nicaragua

6.7 Novartis Coartem Anti-Malaria Treatment: A win-win for biodiversity, health and poverty reduction?

6.8 Comsur: Linking biodiversity management with community social drivers 


\section{Key messages}

Economic and social development generally involves more consumption and open markets, both highly correlated with business development but also often associated with biodiversity loss and ecosystem decline. The challenge is to reinforce economic development strategies that are ecologically sustainable, socially equitable and good for business.

Good governance and clear property rights are essential for business development, environmental protection and poverty reduction. Better understanding of how governance arrangements and especially property rights contribute to biodiversity loss and ecosystems degradation is essential in order to design responses that are not only ecologically sustainable but also socially acceptable. Reform of resource tenure, access rights and benefit-sharing arrangements can be a complement to successful corporate community engagement.

There are potential synergies between business, conservation and poverty reduction, but these are not realized automatically. Biodiversity and ecosystem services are not routinely considered in corporate decision making related to social investment programmes. Many companies have programmes that support biodiversity conservation and separate programmes that support local economic development. In many cases, these programmes are in conflict, although a few companies have found ways to combine biodiversity and ecosystems with their social programmes.

Good business for the company must also be good business for the local community. Gaining the social license as well as government goodwill has become a standard requirement in the modern business world; this includes making a visible contribution to local environmental quality. Business can help meet both sustainable development and biodiversity conservation objectives through measures such as engaging with other sectors operating in the region and/or country to enhance the creativity of development initiatives and help scale pilot initiatives, as well as undertaking direct conservation actions. 


\section{IMPACTS OF INTEGRATING BIODIVERSITY AND ECOSYSTEM SERVICES IN BUSINESS}

Sustainable development, according to one of the most widely-accepted definitions, is development that meets the needs of the present without compromising the ability of future generations to meet their own needs (Brundtland 1987). Poverty eradication, the reduction of unsustainable patterns of production and consumption, and the protection and management of natural resources are frequently cited as both overarching objectives and essential requirements for sustainable development.

Achieving sustainable development is made more difficult as biodiversity and the ecosystem services that underpin all life on earth are degraded. As noted in Chapter 2, people have made unprecedented changes to ecosystems in recent decades to meet growing demand for food, fresh water, fiber and energy. The quality of life for billions of people has improved, but these changes have weakened nature's ability to deliver key services such as the purification of air and water, protection from natural disasters, and the provision of medicines. The Millennium Ecosystem Assessment, among many other analyses, has emphasized that the loss of ecosystem services is a significant barrier to reducing poverty, hunger and disease (Millennium Ecosystem Assessment 2005).

The challenge for business is to ensure that their social and economic development activities do not lead to further loss of biodiversity and degradation of ecosystem services. There is a great opportunity to align such programmes with the capacity of ecosystems to supply services for local populations. However, more coordination is necessary to ensure that corporate social and economic development programmes can conserve biodiversity and support local livelihoods through more rational utilization of land and other natural resources. This chapter explores the potential synergies and conflicts between business, biodiversity and sustainable development, highlighting examples of attempts by companies and others to align social and environmental responsibility. 


\section{CONFLICTING ASPECTS OF SUSTAINABLE DEVELOPMENT AND BIODIVERSITY CONSERVATION}

In some cases, the objectives of corporate programmes focused on human and economic development on the one hand, and environmental sustainability on the other, are in conflict (see for example Boxes 6.1 and 6.2). This is one of the more challenging aspects of integrating biodiversity, ecosystems and ecosystem services in business. In short, many corporate interventions designed to address biodiversity conservation and social development may find that they are unable to achieve both simultaneously.

\section{Box 6.1 Poverty and ecosystem degradation}

"Despite the seemingly obvious links between ecosystem services and poverty, the reliance of the poor on ecosystem services is rarely measured and is thus typically overlooked in national statistics, poverty assessments and land-use and natural resource management decisions. In particular, the patterns of winners and losers associated with ecosystem change, and their impact on the chronically poor and women in particular, has been given little consideration. Such inattention can lead to inappropriate strategies that ignore the role of environment in poverty reduction, possibly leading to further marginalisation of the poorest sectors of society and increased pressure on ecosystems."

Source: Shackleton et al. (2008)

Three quarters of the world's poorest people - about 1.2 billion individuals who live on less than one US dollar a day - live in rural areas and their survival depends in large part on agriculture (Cervantes-Godoy and Dewbre 2010). The limited purchasing power of poor people leaves them less able to obtain substitutes for local resources from sources outside their immediate surroundings. As a result, they are highly dependent on the integrity of the local environment for the supply of food, water, energy, shelter and other basic needs.

Healthy, functioning natural environments provide a range of ecosystem services to rural communities. Poor rural households in particular, rely on cash income and subsistence from the use of natural resources, such as small-scale farming, fishing, hunting and the collection of firewood or other natural products (WRI 2005). When considered from the perspective of local communities, it is this local level of biodiversity that is important: the distribution and abundance of wild species, the range of crop plants and livestock and the diversity of ecosystems that are directly accessible to them (Ash and Jenkins 2007).

\section{Box 6.2 Poverty reduction and biodiversity conservation: A trade-off?}

The Rwanda periphery of the Volcano National Park is famous for its mountain gorilla population. Much of the area also has excellent soils, the value of which is likely to increase as the use of fertilizer and improved potato varieties double and even triple potential crop yields. Concurrently, export markets throughout the region are becoming more accessible with better operating markets, improved roads, and more extensive communications networks. However, economic growth and poverty-reduction programmes may increase the risk of agricultural encroachment on protected areas around the volcano, due to higher land values and potential profits from cultivation. 


\section{CHALLENGES FOR COMPANIES IN \\ INTEGRATING BES WITH \\ SOCIAL DEVELOPMENT}

Given the high dependence of rural communities and poor households on their physical environment, there may be an opportunity for companies to implement programmes that address both biodiversity conservation and sustainable development at the same time. However, companies face various challenges in integrating such programmes, as discussed below.

\subsubsection{POOR UNDERSTANDING OF THE LINKS BETWEEN ECOSYSTEM SERVICES AND POVERTY}

Biodiversity and ecosystem services are not routinely considered in corporate social development programmes for at least three reasons:

- Poor understanding of the ecological processes that produce ecosystem services. Understanding biophysical processes helps to predict the ecological effects of human actions and other natural phenomena, both beneficial and detrimental, on the production of ecosystem services and is essential to assess management alternatives.

- Spatial and temporal dimensions of ecosystem service production, use, and value are not well understood. Decisions made locally have the potential to affect natural resources and ecosystem services elsewhere. Decision makers may not be aware of the regional or global impacts of local decisions.

- Lack of information on the monetary and non-monetary values (including social or cultural values) of ecosystem services.

Decisions relating to natural resource conservation and restoration, as well as economic development, require an understanding of the services provided by natural systems and the response of these systems to natural and human-induced change. Some strategies for achieving poverty reduction can increase pressures on ecosystems, compromising their capacity to produce and maintain benefits over the long run. Conversely, business support for conservation activities can have unexpected social consequences that must be taken into account (Box 6.3).

In general, investments to enhance the supply of certain commodities (for example, food production) can degrade biodiversity and reduce the supply of other natural resources (e.g., water, fish, or wildlife), and ultimately remove income sources for local populations. In addition, the over-exploitation of provisioning ecosystem services often degrades services in another location (Rodriguez et al. 2006). For example, Eucalyptus plantations in southern India provide pulp and tannin, but affect downstream hydropower projects due to reduced water yield from forested catchments. Similarly, natural forest areas that are logged for timber or used for mining may decrease the value of carbon sequestration, flood control and biodiversity conservation. This can decrease future provisioning services and increase the vulnerability of local populations to environmental variability. 


\section{Box 6.3 Aligning social and environmental impacts: Rio Tinto in Madagscar}

Rio Tinto has a policy goal of Net Positive Impact (NPI) on biodiversity in its operations. The company aims to achieve NPI by combining state-of-the-art avoidance, mitigation and ecosystem restoration with biodiversity offsets and other conservation actions. In Madagascar, the company is considering, as part of its offset strategy, supporting the conservation of approximately 60,000 hectares of lowland rainforest, to compensate in part for the unavoidable residual impacts of its mining operations in the region.

In this case, the area to be conserved and the resulting biodiversity benefits are thought to meet and possibly exceed the conservation gains required to compensate for the residual impacts of the company's mining operations. A study was commissioned to estimate the monetary value of these biodiversity benefits. The study examined the costs of conservation, including both up-front investment as well as the management costs of protected areas, together with the opportunity costs that local people bear when they lose access to land that had historically provided food and cash income in lean periods as well as a resource for agricultural expansion.

The ecosystem benefits considered included wildlife habitat (valued at US\$2.7 million in net present value terms), hydrological regulation (US\$760,000) and carbon storage (US\$26.7 million), as well as potential eco-tourism benefits (US\$2.5 million). The study concluded that there are significant net economic benefits associated with conservation (about US $\$ 20$ million net of all costs). However, while many of these benefits accrue globally (e.g. wildlife habitat, carbon storage), the costs of conservation are mainly borne by local communities whose access to forest resources is restricted.

The study underscored the need for, and the potential scale of, compensation for the opportunity costs incurred by local populations, for example through Payments for Ecosystem Services. While the value of carbon storage is significant in this case, local communities would need to receive roughly one-third of the potential revenues from Reducing Emissions from Deforestation and Forest Degradation (REDD) in order not to be disadvantaged by conservation, and roughly half of potential REDD revenues in order to be better off than without conservation.

Source: Olsen and Anstee (2010)

\subsubsection{RISKS OF BUSINESS ENGAGEMENT IN SUSTAINABLE DEVELOPMENT}

Companies often engage in cross-sectoral collaboration to facilitate their sustainable development programmes. Companies may wish to bear in mind however that such collaboration can strengthen or supplement but should not replace the role of government.

The roles and responsibilities of governments and companies are sometimes blurred, as both often work toward similar objectives. Many corporate investment programmes, whether focused on biodiversity, economic development or both, aim to help local communities expand their use of available resources in order to meet their needs.

Companies can make positive contributions to protecting and respecting human rights, but they also face legal and practical limitations as a non-government actor. While businesses can promote respect for human rights by assessing and addressing their own human rights impacts, their efforts cannot replace the role of governments in implementing and protecting human rights (for discussion see Ruggie 2010). 
In addition, and notwithstanding the potential for companies to assist local partners in project development and implementation, businesses are sometimes held responsible for delivering outcomes that lie beyond their competence or expertise (IPIECA 2006). In Peru, for example, Peru LNG addressed this risk by working closely with the National Council for the Environment to build partnerships with local NGOs and other initiatives that aligned with their goals for biodiversity conservation (IPIECA 2006). By engaging local stakeholders with both biodiversity conservation expertise and long-standing relationships with communities, Peru LNG was able to help build trust and establish goodwill with local communities.

\subsubsection{PROJECT-INDUCED IN-MIGRATION}

Large scale land use projects can dramatically change the social landscape around project sites. Early project documents typically outline the potential benefits that local people in the project area might expect. These benefits generally include measures to mitigate project impacts, compensation for loss of resources or environmental damage, promises of participation in the project through wage labor, and project-related community development programmes. These promises often raise local community expectations of the potential for the project to transform lives and livelihoods, particularly in remote and neglected regions that have difficulty accessing national development programmes (USAID 2010; Banks 2009).

In many parts of the world, the economic opportunities associated with such large scale projects can generate significant in-migration of individuals and groups from elsewhere, potentially fundamentally reconfiguring existing local social structures and relationships (Banks 2009; IFC 2009). An example is provided in Box 6.4

\section{Box 6.4 Freeport Indonesia and the impacts of in-migration}

PT Freeport Indonesia's Grasberg gold and copper mine, located in West Papua, Indonesia, was constructed between 1967 and 1972 and has been operational ever since. The original mine concession included the customary lands of two indigenous tribal groups, the Amungme and the Kamoro. Over time, as both the mine and the region have developed, employment opportunities and better living conditions have attracted other indigenous tribes (including the Dani, Ekari, Moni, Nduga, and Damal) to the area. As their numbers increased, the migrant tribes became established as numerically strong, politically powerful stakeholder groups, pressing their claims to be recognized as indigenous groups entitled to compensation by Freeport.

Source: IFC, 2009

Several challenges arise from in-migration:

- Rapid population growth and large increases in the numbers of people living within the project area can strain public infrastructure, services, and utilities.

- Due to increased numbers of people, project managers may be unexpectedly requested to contribute to the construction, renovation, and/or maintenance of new infrastructure, services, and utilities.

- Migrants may undermine the well-being of some members of the original resident population by threatening their way of life and the basis of existing livelihoods.

Project-induced in-migration may substantially change the context in which a project operates. An influx of migrants may affect host communities by changing how they secure their livelihoods or by introducing other (potentially disruptive and undesirable) socio-economic changes. Whatever the nature of the impacts, they can increase project costs and risks and ultimately may affect the business license to operate. 


\subsubsection{INTEGRATING ECOSYSTEM SERVICES INTO CORPORATE POVERTY REDUCTION PROGRAMMES}

Economic growth has been a major factor in reducing poverty in rural areas, but the relationship at a local scale between ecosystem services and poverty reduction needs to be better understood. For example, the loss of genetic diversity may be associated with reduced food security, increased economic uncertainty, increased vulnerability to pests and diseases, reduction in the possibilities for adaptation and loss of local knowledge (Shackleton et al. 2008; WRI 2005). In Mozambique, communities rely on local resources such as firewood, honey, reeds, bamboo, clay, and palm to meet their every day needs. The use of these 'free' products is often undervalued due to limited information (Shackleton et al. 2008). At a minimum, a stronger understanding of how ecosystems become degraded and how to improve the capacity of ecosystems to deliver ecosystem services that are important for local communities can go a long way toward ensuring the success of corporate sustainable development programmes in rural areas (see Box 6.5).

\section{Box 6.5 Mapping ecosystem services with livelihood strategies in China}

The potential for poverty reduction through ecosystem management varies greatly across China due to the intrinsic properties of different ecosystems. An analysis of ecological zones found that the risk of poverty is high in grasslands characterized by variable seasonal rainfall. Their sustainable management requires an understanding of the ecosystem processes of each grassland type and the livelihood practices which have developed with them. The nomadic lifestyles of many of the indigenous peoples of these regions, centered on livestock management, have also evolved to respond to the high year-to-year variability of rainfall that largely determines local ecosystem productivity.

Source: Adapted from Chinese Academy of Agricultural Sciences (2008)

Most companies are still in the early stages of understanding their own impacts and dependencies on ecosystem services. As such, most do not have the internal resources and trained staff needed to conduct thorough research into ecosystem processes for the regions where they operate, and map that against livelihood strategies at the local level.

\subsubsection{DIFFICULTIES IN MEASURING SUCCESS}

While there are potential business benefits from supporting local economic and social development (ODI and EAP 2007; IFC and BSR 2008), including reduced risk and increased social license to operate, the benefits for local communities are often more difficult to assess. Organizations like the International Petroleum Industry Environment Conservation Association, the International Finance Corporation, and the Centre for Good Governance provide guidance and tools on how to conduct social impact assessments that can help to identify the positive and negative impacts of business activities and programs. However, even these organizations recognize the complexity of assessing the many social and environmental dimensions of their activities (IPIECA and OGP 2002). Corporate social development programs may introduce alternative livelihood strategies as a strategy to reduce pressure on natural resources, for example, but evidence suggests that this does not always occur even if successful alternatives are provided (Sievanen et al. 2005). In addition, the difficulties of implementation do not always result in the adoption of alternative strategies by beneficiaries (Wells et al. 2007). 


\section{Box 6.6 Assessing the impact of livelihood strategies in Nicaragua}

The USAID-University of Rhode Island SUCCESS Program in Nicaragua, an integrated coastal management and marine conservation program, demonstrates the difficulty of measuring the impacts of social and economic development programs. The program focuses on creating and supporting livelihood development strategies that will have beneficial impacts on the sustainable management and conservation of Nicaragua's coastal and marine resources. Local communities depend on coastal resources for food and income, yet an array of physical, social, and economic factors threaten the health and sustainability of these resources. The SUCCESS Program and these communities are monitoring the ecosystems, developing alternative livelihoods, and managing aquaculture and natural resources using approaches to restore them to their former richness and improve community quality of life. Specific questions regarding project livelihood impacts were addressed, including:

- Whether the project increased household incomes or diversified sources of income, compared to nonproject beneficiaries

- Whether households involved in livelihood activities have reduced dependence on fishing, or have different attitudes towards resource management and conservation, compared to non-project beneficiaries

Impact variables included household income, net revenues generated from enterprise activities assisted, number of household productive activities (diversification variable), material style of life indicators and dependence on fishing as a household activity. The study concluded that household income and net revenues are poor measures for assessing impacts and that material style of life, livelihood diversification and perception of change indicators may be better measures, especially for extremely poor, rural, and natural resource dependent households such as those in the communities around the Padre Ramos estuary. 


\subsubsection{LACK OF AGREEMENT ON ACCESS AND BENEFIT SHARING ARRANGEMENTS}

The value of wild genetic resources as inputs to the pharmaceutical industry has been noted in preceding chapters (and also in TEEB 2009). Other sectors that rely on genetic resources and/or naturally-occurring biochemical compounds include biotechnology, seed production, animal breeding, crop protection, horticulture, cosmetics, fragrance, botanicals, and the food and beverage industries.

In many cases, the genetic material used by industry is derived from biodiversity-rich, tropical countries. Moreover, the industrial potential of particular species is often based on the indigenous knowledge of local communities that have used these resources for centuries. However, while the profits gained from exploiting wild genetic resources can be significant, as described in chapter 5 , the benefits arising from such uses, are hardly ever shared with the countries and communities of origin.

Until recently, developing countries had no means to ensure that the utilization of their resources, traditional knowledge and cultural practices would be recompensed. Hence one of the three objectives of the Convention on Biological Diversity (CBD) is to regulate "access to genetic resources and ensure the fair and equitable sharing of benefits arising out of their utilization" (http://www.cbd.int/abs/regime.shtml). The principles laid down in Article 15 of the CBD on access and benefit-sharing (ABS) provide significant opportunities for poverty alleviation and sustainable development.

Recently, considerable efforts have been devoted to articulating and establishing principles for ABS in international and national law and in voluntary guidelines. In general, these ABS frameworks seek to:

- Support poverty alleviation and nature conservation

- Support capacity development by transferring technologies, knowledge and skills

- Enhance social development especially in countries of origin

- Ensure accountability and good governance at all levels

An important milestone in the development of an international ABS framework was an agreement on the voluntary 'Bonn Guidelines on Access and Benefit-Sharing', which addressed issues such as 'mutually agreed terms' and 'prior informed consent' for the use of genetic resources (SCBD 2000). Despite this agreement, in 2002, at the World Summit on Sustainable Development (WSSD), the world's governments concluded that voluntary guidelines were not able to address on-going problems of 'mis-appropriation' of genetic resources. The WSSD called on the $\mathrm{CBD}$ to develop "an international regime to promote and safeguard the fair and equitable sharing of benefits arising out of the utilization of genetic resources" (see Chapter IV, subsection (0) of the WSSD Plan of Implementation). Subsequent Decisions at CBD COP7 and COP8 took up this request and laid the basis for a legally-binding ABS regime (or "Anti - Biopiracy Protocol") with compliance mechanisms at its heart and a deadline of late 2010 (i.e. COP 10).

Negotiating positions on the proposed new ABS regime are subtle but may be broadly summarized as follows: most developing country governments (as providers of genetic resources) prefer an inclusive and comprehensive protocol to ensure 'fair shares' of the benefits arising from the use of genetic resources. Many industrialized or 'user' country governments, on the other hand, favor more flexible and voluntary approaches. The latter argue that imposing strict benefit-sharing obligations on users of genetic resources (or their derivatives), as well as on the use of associated traditional knowledge about wild plants and animals, would make use of these resources less attractive, impede research and development efforts and hamper business operations. 
Reaching a compromise on ABS will not be easy. However, encouraging lessons may be learned from several recent voluntary agreements, which demonstrate how access to genetic resource can be combined with biodiversity conservation and equitable benefit-sharing (Box 6.7).

\section{Box 6.7 Novartis Coartem Anti-Malaria Treatment:} A win-win for biodiversity, healith and poverty reduction?

In 1994 the Swiss based Novartis healthcare multinational, together with Chinese partners, started developing the combination drug Coartem, which is today the world's leading artemisinin-based combination therapy for the treatment of malaria. The product is based on extracts of the Artemisia annua plant, which originates in China and other South East Asian countries. Access to the resource was granted by the Chinese Government and is now secured by several suppliers, mainly in China. Artemisia is currently mainly cultivated, using improved seed material, rather than collected from the wild, in order to meet high demand and reduce the pressure on the species' natural habitat.

The active components Artemether and Lumefantrine ${ }^{1}$ were known to Chinese Traditional Medicine and further developed and refined by Novartis research laboratories. Coartem patents have been granted in roughly 50 countries (international application number PCT/EP1999/004355) and are co-owned by Novartis and the Institute of Microbiology and Epidemiology and the Academy of Military Medical Sciences of the Government of China.

Benefit-sharing by Novartis includes scientific training, technology transfer (e.g. laboratory equipment), about US\$150 - 160 million for raw material from Artemisia producers, plus additional royalties and other payments to the Chinese scientific partners.

In 2001 Novartis entered into a Memorandum of Understanding with the World Health Organisation to provide Coartem to public agencies in malaria-endemic developing countries at not-for-profit prices. On the basis of this agreement, the number of treatments provided increased from 4 million in 12 countries (in 2004) to 84 million in over 60 countries (in 2009). It is estimated that about 800,000 lives have been saved as a result of the delivery of 320 million Coartem treatments. The average sale price of Coartem to authorized public buyers in 2010 is less than one US dollar (i.e. 76 US cents for one adult treatment or 36 cents for a child). Novartis estimates the full economic value of these treatments at about US\$1 billion, if Coartem had been supplied on normal 'forprofit' basis ${ }^{2}$.

Source: al-Janabi, S., and Drews, A. (2010) for TEEB, based on material available at URL: www.novartis.com/newsroom/corporatepublications/index.shtml; and URL: www.corporatecitizenship.novartis.com/downloads/business-conduct/Biodiversity.pdf 


\section{CONCLUSION AND RECOMMENDATIONS}

For the poor, livelihood choices are constrained by a range of linked obstacles, ranging from geographic isolation to market failures, weak institutions, and social and political exclusion (Jenkins 2007). Business activity can create jobs and stimulate entrepreneurial activities, enable technology transfer, build human capital and physical infrastructure, and offer a variety of products and services for a range of consumers and other businesses, including those operating at the 'base of the pyramid'. ${ }^{3}$ The challenge for companies is to determine what role they can play in creating economic opportunities so that individuals can create their own solutions to generate income and other opportunities to improve their quality of life.

\subsubsection{LINKING ECONOMIC DEVELOPMENT AND POVERTY ALLEVIATION}

To create and expand economic opportunity along their value chains, global companies often support local initiatives focused on economic development and sometimes create their own programmes to support local populations. These include training programmes, institutional capacity building for NGOs, local governments, and local business associations, and linking core business competencies with national and local needs.

Some extractive sector companies have started to think more strategically about community or social investment as a way of not only 'doing good' but also creating the type of operating environment conducive to business (Box 6.8). Many international oil and gas companies are challenged by increasingly stringent 'local content' requirements, which refer to a government preference for providing employment, training and supplier opportunities to nationals. Companies often find it difficult to meet such local content requirements because local firms may be uncompetitive due to lack of relevant experience, poor production quality and reliability, low health, safety and environmental standards, and inappropriate technical capabilities (ODI and EAP 2007).

By investing strategically in local communities, companies can not only help to create a skilled workforce and a more competitive local enterprise sector, but also secure a competitive advantage over rivals, help them break into other sectors like construction and manufacturing, while also meeting the terms of their contracts (EAP and ODI 2007). Such strategic community investment, as it is often called, is focused on sustainable community development. It is more complex and more difficult to implement than corporate philanthropy, but, if done well, its effects can be considerably longer lasting and more in line with both company and community needs (IFC and BSR 2008).

\section{Box 6.8 Comsur in Bolivia: Linking biodiversity with community social drivers}

In 2004, Comsur operated the Don Mario gold mine in Bolivia, located in a rare dry forest ecosystem of global significance, home to many endemic species and nearly 100 threatened or endangered species. Comsur's biodiversity programme included fencing of operation areas to prevent access by animals, closing roads to prevent illegal logging, and a 12,000 tree reforestation programme. At the same time, Comsur provided surrounding communities with employment opportunities and financial assistance for educational, sanitation and infrastructure projects. The mine also purchased agricultural products from the communities. Through surveys and public meetings in the different communities and in partnership with the local authorities of San Juan, COMSUR analyzed the particular needs of each community and developed programs to respond to these needs, in consultation with community leaders. 


\subsubsection{BES PLAY A CRITICAL ROLE IN SUSTAINABLE DEVELOPMENT}

In terms of business influence on community development, it should be noted that growth in economic activity does not necessarily equate with reduced poverty, a better environment, greater equality, or a higher quality of life for local populations. In other words, we need to understand better the economic impacts of business and their relationship to biodiversity and sustainable development. Even less clear is the relationship between specific corporate activities-such as social investment programmes, local sourcing and procurement initiatives-and their impacts on the economy, the local quality of life, and the environment.

Business has a major role to play in poverty reduction, working alongside governments and NGOs. Business can also make a significant contribution to biodiversity conservation, as this report has attempted to show. The question is how to align business success with poverty reduction, business with ecosystems, and biodiversity conservation with human development. Experience shows that there are potential synergies between business, conservation and poverty reduction, e.g. private sector participation in water supply and sanitation (Johnstone and Wood 2001), agribusiness development (McNeely and Scherr 2002), forest product markets (Macqueen 2008), and payments for ecosystem services (Pagiola 2005). However, these synergies are not realized automatically.

Development assistance strategies have long relied on the private sector as an engine of economic growth. Business can contribute to poverty reduction in many ways, through job and wealth creation, transfer of technology and skills, and the efficient supply of affordable goods and services (UNDP 2004). Experience has also shown that certain conditions must be met in order to encourage private investment and enterprise development, including:

- Good governance (the 'rule of law')

- Affordable labour and capital costs

- Management talent (sourced locally or internationally)

- Light taxes and regulatory burden

- Access to resources, technology and markets (e.g. communications and transport infrastructure, secure property rights, competitive trade and investment policy)

The links between business development, economic growth and poverty reduction are not straight-forward. To begin with, the poor may not share equally in market-led growth. In some situations, they may end up worse off either absolutely or relatively, due to changes in the distribution of income and wealth associated with market-led growth or globalization. To what extent such adverse social outcomes are an inevitable result of market-led growth or the result of imperfect competition and the persistence of market barriers is a matter of continuing debate (Rajan and Zingales 2006; Milanovic 2006).

\subsubsection{RECOMMENDATIONS}

Business can address the challenge of meeting both sustainable development and biodiversity conservation objectives through various measures, including:

i) Advocate for alignment between government programmes: stronger linkages and better alignment between government policies and programmes that address ecosystem management and sustainable development would make it easier for business to align its own efforts. 
ii) Engage with other sectors operating in the region and/or country: business can engage with government, donor agencies, and other industries in the areas where it operates. Partnerships enable companies to contribute to sustainable development with a reduced risk of being responsible for outcomes outside of their expertise, enhance the creativity of development initiatives, and help scale pilot initiatives, distributing benefits to a wider audience.

iii) Conduct thorough 'upfront' work during social impact assessment in order to build more inclusive business models: meaningful social investment and CSR programmes should begin with a thorough socio-economic baseline. Where possible, engage with community members in their homes, talk to people about how they earn their income, whether their children are in school, the type of health problems they have, and how many additional people they support. This type of analysis is not typically part of a social impact assessment (SIA)—while the SIA does focus on a range of issues that provides an overview of a community, the main focus is on developing mitigation plans in areas where the company might have an impact.

iv) Direct interventions in biodiversity and ecosystem services: conservation actions are generally more effective if directed at the better management of ecosystem services that local communities depend on, and at the direct and indirect drivers that are undermining these services. This includes better accounting for ecosystem services and the services which are most relevant for poverty reduction. 


\section{Endnotes}

1 The anti-malarial activities of Artemether and Lumefantrine target the food vacuole of the malaria parasite. When the parasites infect human red blood cells (erythrocytes) they ingest and degrade hemoglobin and concentrate the iron in the form of 'haem' in a food vacuole. Artemether and Lumefantrine are thought to interfere with the process of detoxification of haem to haemozoin and thus disrupt the feeding process of the parasite.

2 Novartis Annual Reports from 2004 to 2009 give a sum value of USD 981 million (see the Novartis Access-to-Medicine tables to which the years 2001 and 2002 as well as quarter 1 of 2010 have been added). The estimated value of USD 1 billion represents the financial value if the program had been a for-profit enterprise and is calculated using the total number of treatments shipped times the ex-factory price of Coartem to private-sector purchasers in malaria-endemic developing countries, less payments to Novartis to cover costs under the terms of its partnership with the WHO.

3 Bottom or Base of the Pyramid is a phrase used to describe individuals in the largest and poorest socio-economic group (see Prahalad, 2006). 


\section{References}

al-Janabi, S., and Drews, A. (2010) Genetic Resources as 'Biodiversity value added' for their providers, their users and mankind. ABS Capacity Development Initiative for Africa (GTZ), contribution to TEEB.

Ash, N. and Jenkins, M. (2007) 'Biodiversity and Poverty Reduction: The importance of biodiversity for ecosystem services' UNEP-WCMC, Cambridge, UK.

Banks, G. (2009) 'Activities of TNCs in Extractive Industries in Asia and the Pacific: Implications for Development', Transnational Corporations 18 (1): 43-60.

British American Tobacco. 'Social Responsibility in Tobacco Production', http://www.bat.com/group/sites/uk_3mnfen.nsf/vwPagesWebLive/DO6ZXK5Q? opendocument $\& S K N=1 \& T M P=$ 1, accessed 21 April 2010

Bruntland, G. (ed.), (1987), 'Our common future: The World Commission on Environment and Development', Oxford, Oxford University Press.

Cervantes-Godoy, D. and Dewbre, J., (2010), 'Economic Importance of Agriculture for Poverty Reduction', OECD Food, Agriculture and Fisheries Working Papers, No. 23, OECD Publishing. doi: 10.1787/5kmmv9s20944-en.

Chinese Academy of Agricultural Sciences (CAAS), CAB International, UNEP World Conservation Monitoring Centre, Stanford University - The Natural Capital Project, Walker Institute for Climate System Research, University of Reading, Ningxia Centre for Environment and Poverty Alleviation, Ningxia Development and Reform Commission (2008). 'China Ecosystem Services and Poverty Alleviation Situation Analysis and Research Strategy', a report commissioned by NERC/ESR/DfID. URL: www.nerc.ac.uk/research/ programmes/espa/documents/Final\%

20Report\%20China\%20-\%20annex.pdf, accessed 21 April 2010.

Conservation International (2008) 'New Loans for Coffee Farmers, Nature Reserves'. URL: http://www.conservation.org/FMG/ Articles/Pages/loans_for_coffee.aspx, accessed 21 April 2010

Cotula, L., (2010) Investment contracts and sustainable development: How to make contracts for fairer and more sustainable natural resource investments, Natural Resource Issues No. 20. IIED, London

Crawford et al. (2008) 'Impact Assessment of the SUCCESS Program Livelihood Activities in the Padre Ramos Estuary Nature Reserve of Nicaragua', Coastal Resources Center, University of Rhode Island and Centro de Investigación de Ecosistemas Acuaticos, Universidad Centroamericana.

Engineers Against Poverty (EAP) \& Overseas Development Insti- tute. (2007) 'Learning From AMEC's Oil and Gas Asset Support Operations in the Asia Pacific Region with case study of the Bayu-Undan Gas Recycle Proejct, Timor-Leste', Overseas Development Institute and Engineers Against Poverty, London.
IFC. (2009) 'Projects and People: A Handbook for Addressing Project-Induced In-Migration'. International Finance Corporation, Washington DC.

IFC and BSR (2008) 'Local Content in Supply Chain". URL: http://www.commdev.org/section/_commdev_practice/local_ content_in_supply_chain, accessed 17 May 2010

IFC. (2004) 'A Guide to Biodiversity for the Private Sector, Comsur: A Junior Mining Company's Efforts to Conserve Biodiversity in Bolivia', http://www.ifc.org/ifcext/enviro.nsf/AttachmentsByTitle/ BiodivGuide_CaseStudy_Comsur/\$FILE/Comsur.pdf, accessed 11 June 2010.

IPIECA. (2006) 'Partnerships in the Oil and Gas Industry', http://www.ipieca.org, accessed 5 July, 2010.

Jenkins, B., (2007) 'Expanding Economic Opportunity: The Role of Large Firms. Corporate Social Responsibility Initiative Report No. 17', Cambridge, MA Kennedy School of Government, Harvard University.

Johnstone, N. and Wood, L., (eds.) (2001) 'Private firms and public water: realising social and environmental objectives in developing countries', Edward Elgar: Cheltenham.

Kenney, A., (2006) 'Chevron Opens Mitigation Bank in Paradis(e)', http://www.ecosystemmarketplace.com/pages/dynamic/article.pa ge.php?page_id=4255\&section=home\&eod=1\#close, accessed 17 May 2010

Macqueen, D., (2008) 'Supporting small forest enterprises A cross-sectoral review of best practice', IIED Small and Medium Forestry Enterprise Series No. 23. IIED, London, UK.

McNeely, J. and Scherr, S., (2002) 'Ecoagriculture: Strategies to Feed the World and Save Wild Biodiversity', Island Press: Washington, D.C..

Mellor, J., (2002) Poverty Reduction and Biodiversity Conservation: The Complex Role for Intensifying Agriculture, WWF Macroeconomics for Sustainable Development Program Office, Washington, DC.

Millennium Ecosystem Assessment (2005). 'Ecosystems and human well-being: Opportunities and challenges for business and industry'. Island Press, Washington, D.C.

ODI and EAP. (2007) 'Learning from AMEC's Oil and Gas Asset Support Operations in the Asia Pacific Region', Overseas Development Institute and Engineers Against Poverty, London.

Olsen, N., and Anstee, S., (2010) Estimating the costs and benefits of conserving the Tsitongambarika Forest in Madagascar. IUCN and Rio Tinto, Gland.

Pagiola, S. Arcenas, A. and Platais, G., (2005) 'Can Payments for Environmental Services Help Reduce Poverty? An Exploration of the Issues and the Evidence to Date from Latin America', World Development Vol. 33, No. 2, pp. 237-253. 
Perrot-Maitre, D., (2006) The Vittel payments for ecosystem services: a "perfect" PES case? International Institute for Environment and Development, London, UK

Prahalad, C.K., (2006) The Fortune at the Bottom of the Pyramid: Eradicating Poverty Through Profits, Wharton School Publishing, Upper Saddle River, NJ.

Rajan, R.G., and Luigi Zingales, L. (2006) 'Making Capitalism Work for Everyone', World Economics Vol. 7, No. 1 (January-March): 1-10; Milanovic, B. (2006) 'Global Income Inequality: A review', World Economics Vol. 7, No. 1 (January-March): 131-157.

Rodriguez, J. P. et al. (2006) 'Trade-offs Across Space, Time, and Ecosystem Services,' Ecology and Society 11 (1): 28.

Ruggie, J., (2010) 'Report of the Special Representative of the Secretary-General on the issue of human rights and transnational corporations and other business enterprises, John Ruggie', Advance edited report, April 9, 2010.

Scherr, S. White, A. and Khare, A., (2004) 'For Services Rendered: The Current Status and Future Potential of Markets for the Environmental Services Provided by Tropical Forests', International Tropical Timber Organizations, Yokohama, Japan.

Secretariat of the Convention on Biological Diversity (2002) Bonn Guidelines on Access to Genetic Resources and Fair and Equitable Sharing of the Benefits Arising out of their Utilization, Montreal.

Shackleton, C. et al. (2008) 'Links Between Ecosystem Services and Poverty Alleviation: Situation analysis for arid and semi-arid lands in southern Africa', Consortium on Ecosystems and Poverty in Sub-Saharan Africa,

Sievanen, L. Crawford, B. Pollnac, R. and Lowe, C., (2005)

'Weeding Through Assumptions of Livelihood Approaches in ICM: Seaweed Farming in the Philippines and Indonesia', Ocean \& Coastal Management 48 (3-6): 297-313.

Syngenta Foundation. 'Projects modules and activities', http://www.syngentafoundation.org/index.cfm?pagelD=576, accessed 21 April 2010.

TEEB - The Economics of Ecosystems and Biodiversity (2009) TEEB for National and International Policy Makers. Summary: Responding to the Value of Nature. (2009) URL: http://www.teebweb.org/ LinkClick.asp ? fileticket $=14$ Y 2 nqqliCg $\% 3 d \&$ tabid=1019\&language $=$ en-US

UNDP. (2004) 'Unleashing Entrepreneurship: Making Business Work for the Poor', United Nations Development Program: New York; UNDP (2008) Creating Value For All: Strategies For Doing Business With The Poor, United Nations Development Program: New York.

USAID. (2010) 'Alliance Industry Guide: Extractives Sector', U.S. Agency for International Development, Washington, DC.
Wells, S. Makoloweka, S. and Samoilys, M., (2007) ‘Putting Adaptive Management into Practice: Collaborative Coastal Management in Tanga, Northern Tanzania', The World Conservation Union and Irish Aid. Nairobi Kenya. p.197

World Economic Forum. (2010) 'Biodiversity and Business Risk', A briefing paper for participants engaged in biodiversity related discussions at the World Economic Forum Davos-Klosters Annual Meeting

WRI. (2005) 'The wealth of the poor: Managing ecosystems to fight poverty.' WRI, Washington, DC. 


\section{Chapter 1 Business, biodiversity and ecosystem services}

Chapter 2 Business impacts and dependence on biodiversity and ecosystem services

Chapter 3 Measuring and reporting biodiversity and ecosystem impacts and dependence

Chapter 4 Scaling down biodiversity and ecosystem risks to business

Chapter 5 Increasing biodiversity business opportunities

Chapter 6 Business, biodiversity and sustainable development 
芒

$\frac{0}{2}$

ह

衣

$\pi$

के

¿

중

음

is

s.

兵

อ

更

胥

0.

ळ

¿

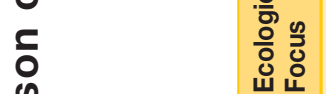

:

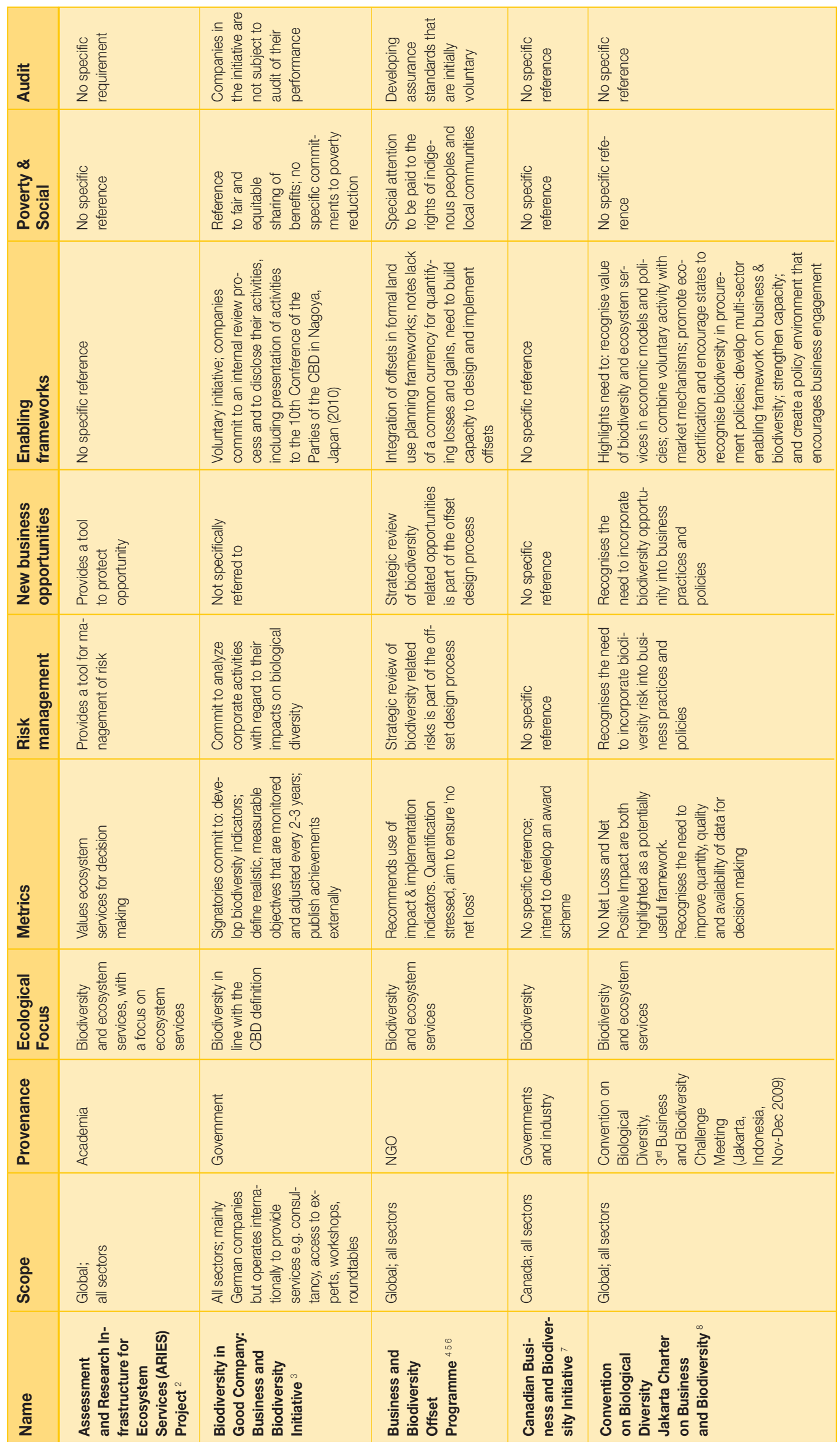




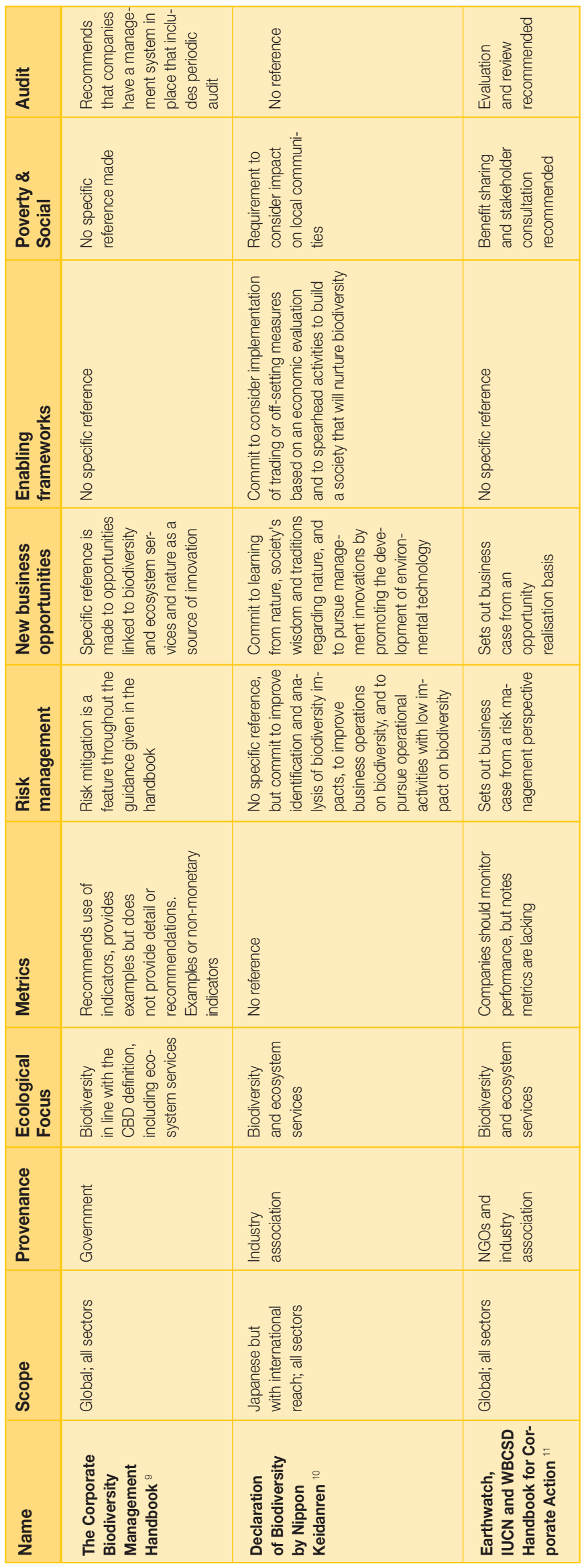




\begin{tabular}{|c|c|c|c|c|}
\hline$\frac{\text { 䓂 }}{\frac{\partial}{4}}$ & 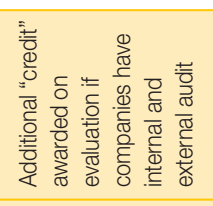 & 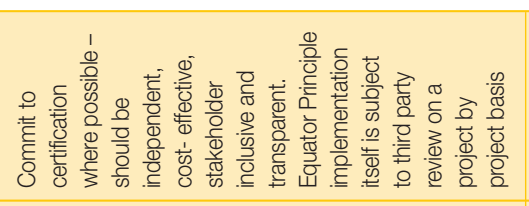 & 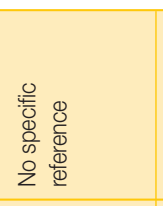 & 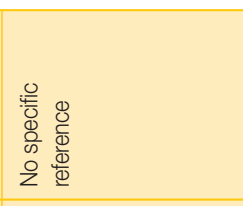 \\
\hline 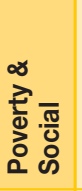 & 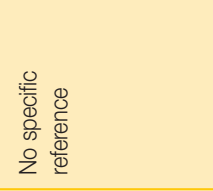 & 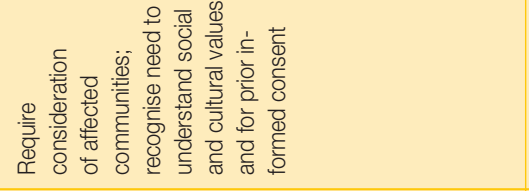 & 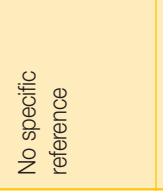 & 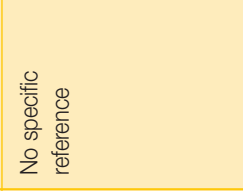 \\
\hline 密 & 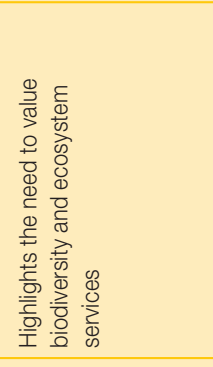 & 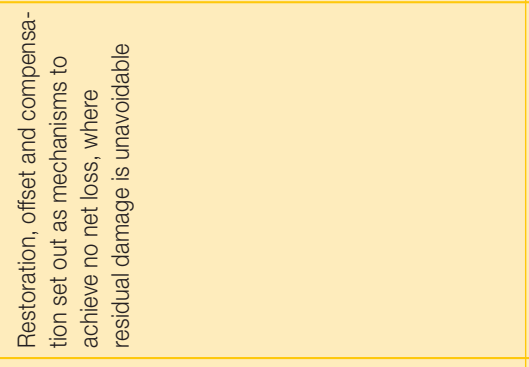 & 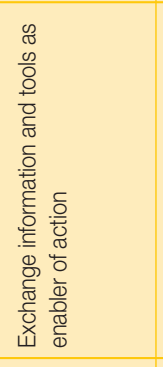 & 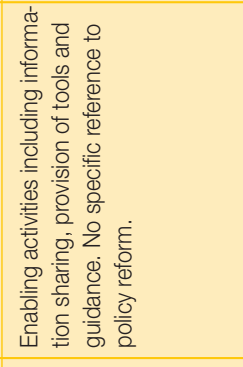 \\
\hline 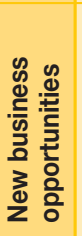 & 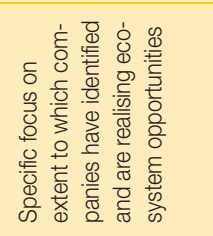 & 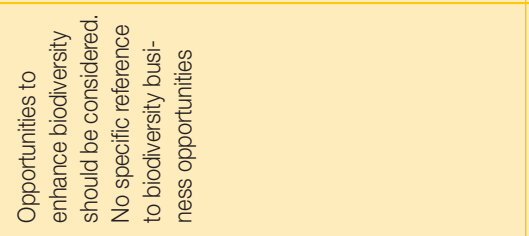 & 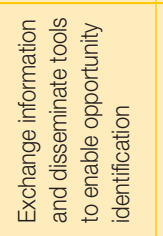 & 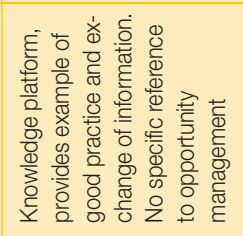 \\
\hline 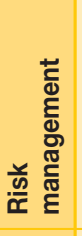 & 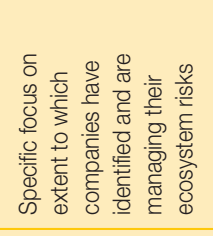 & 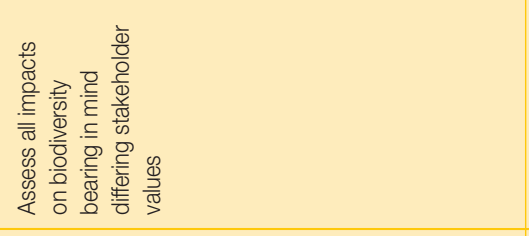 & 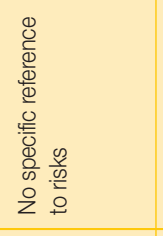 & 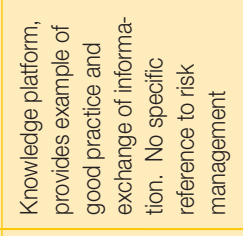 \\
\hline 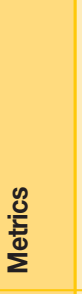 & 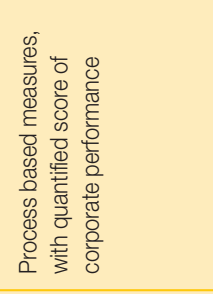 & 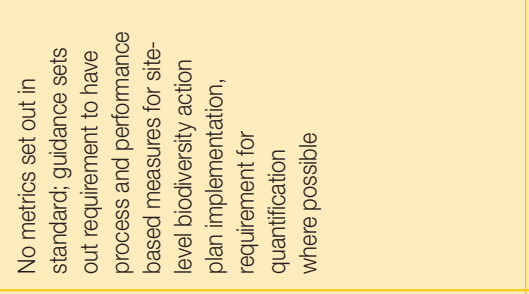 & 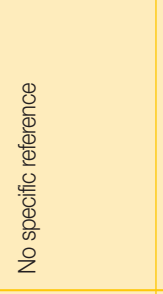 & 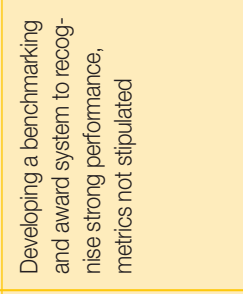 \\
\hline 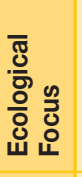 & 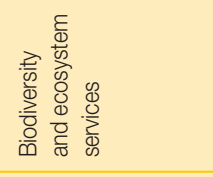 & 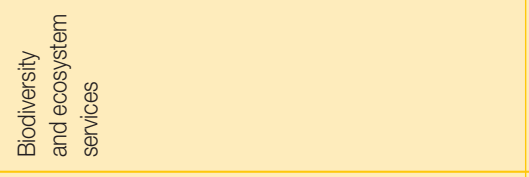 & 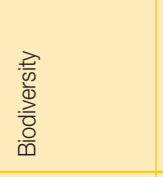 & 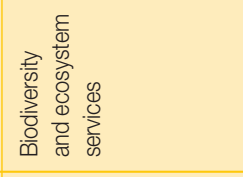 \\
\hline 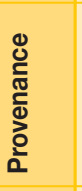 & 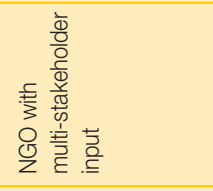 & 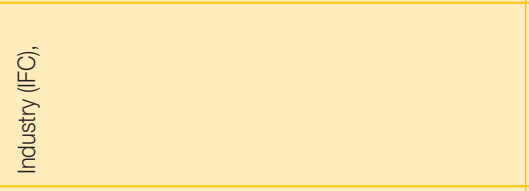 & 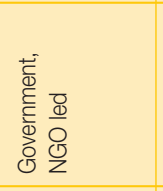 & 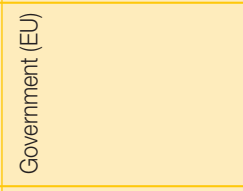 \\
\hline : & 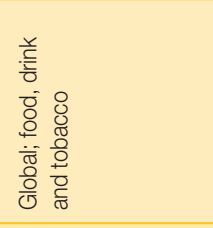 & 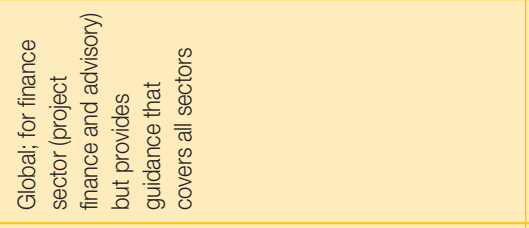 & 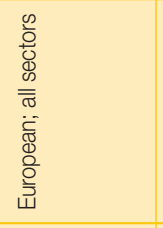 & 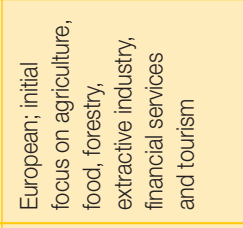 \\
\hline 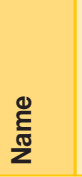 & 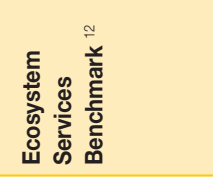 & 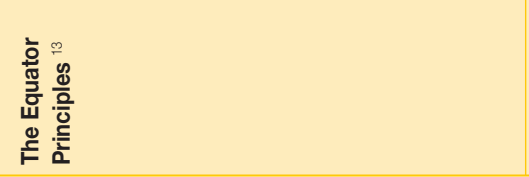 & 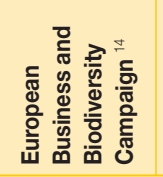 & 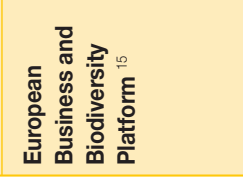 \\
\hline
\end{tabular}




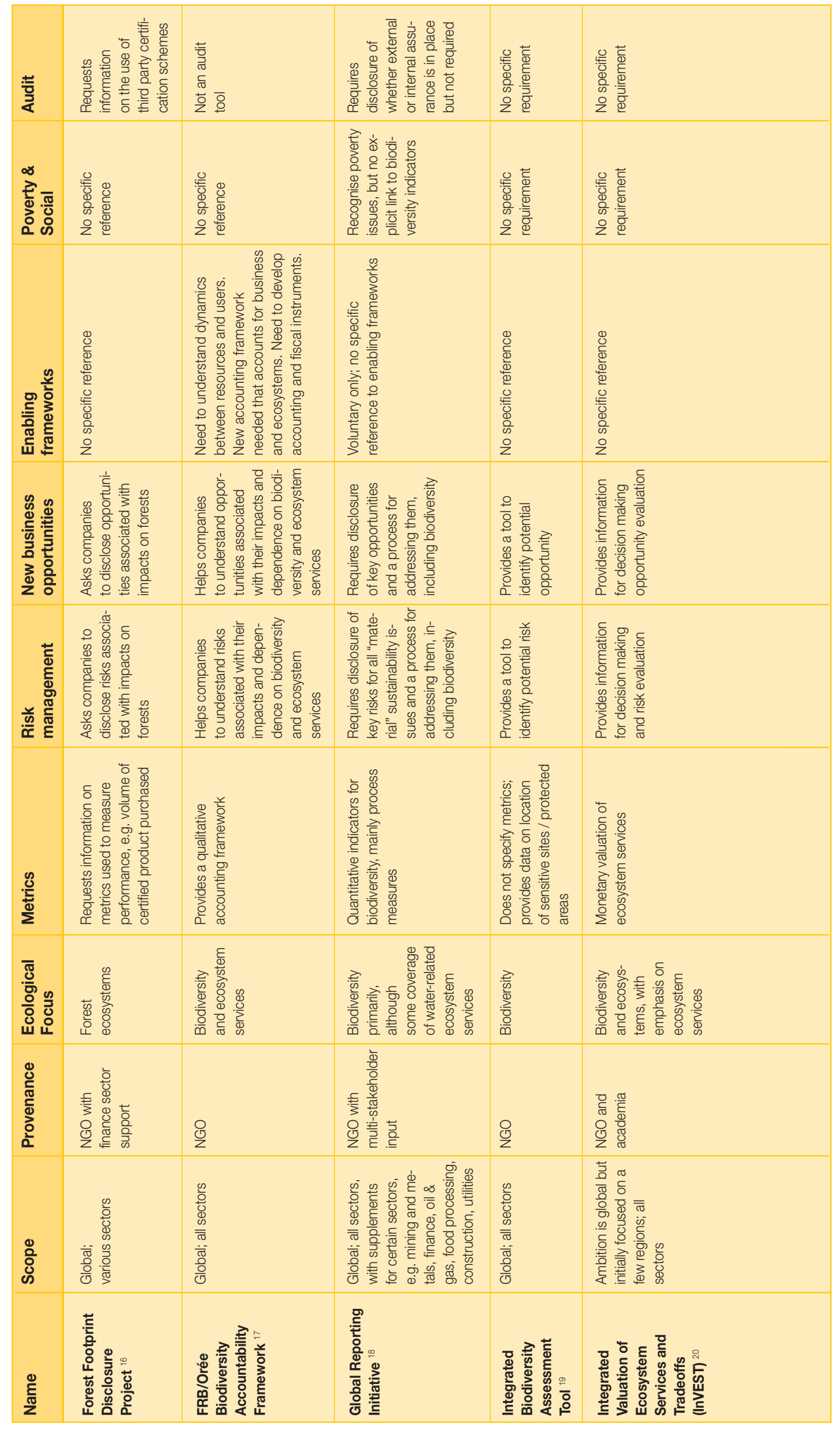




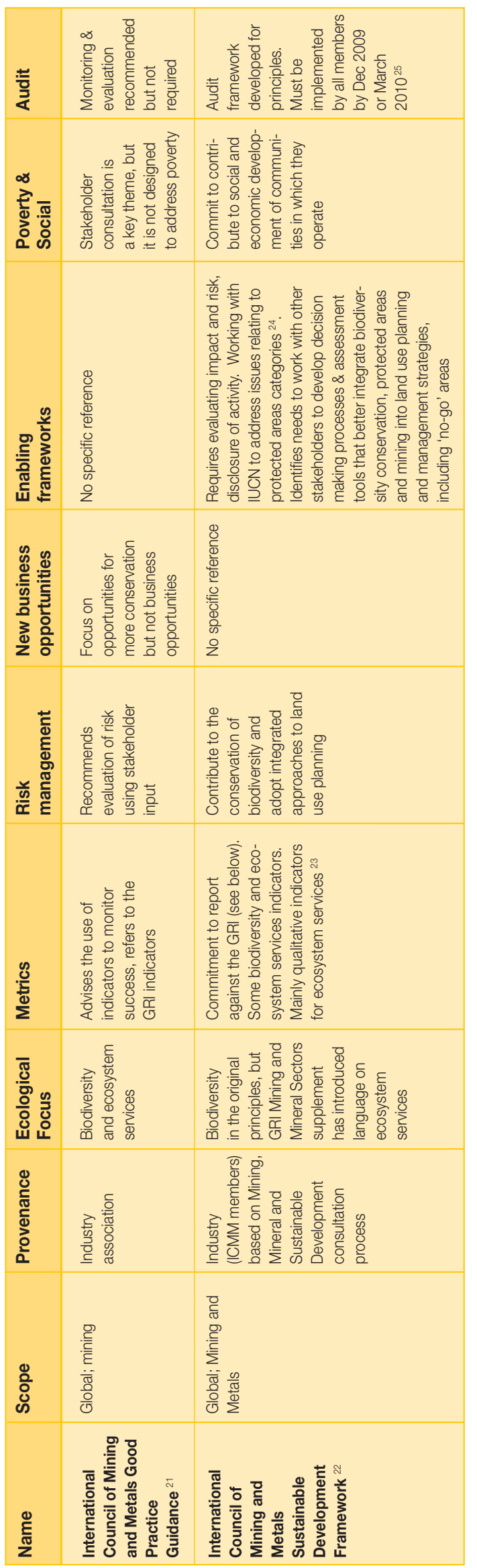




\begin{tabular}{|c|c|c|c|c|}
\hline 蒙 & 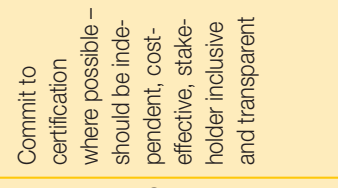 & 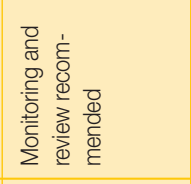 & 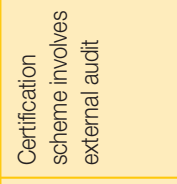 & 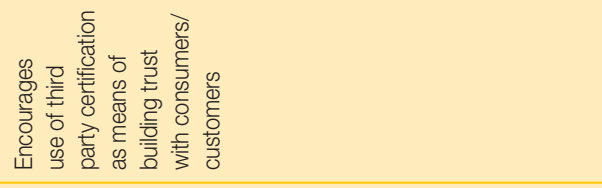 \\
\hline 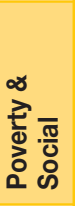 & 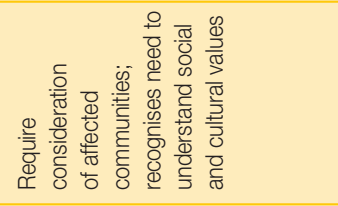 & 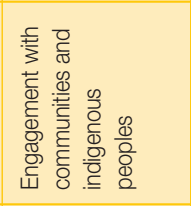 & 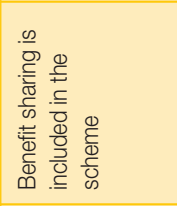 & 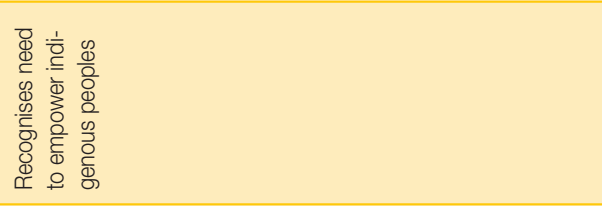 \\
\hline 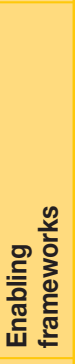 & 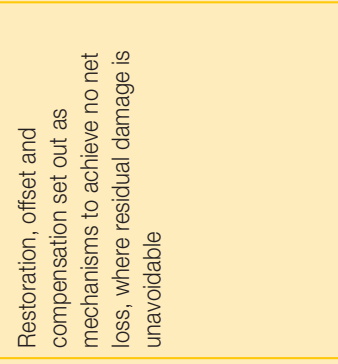 & 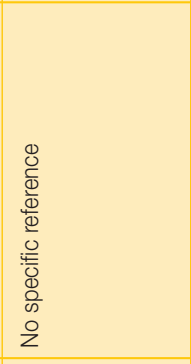 & 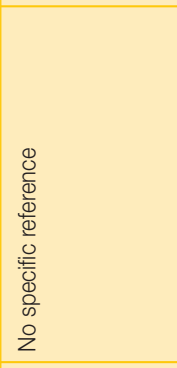 & 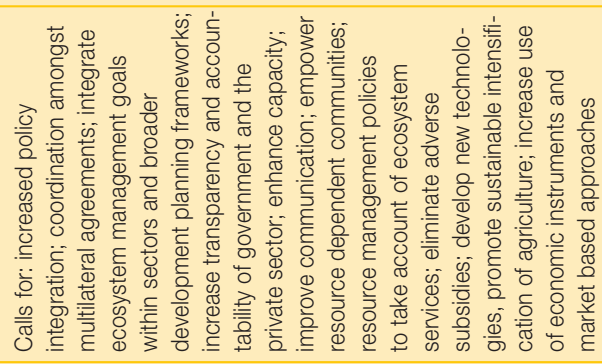 \\
\hline 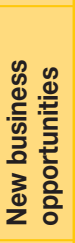 & 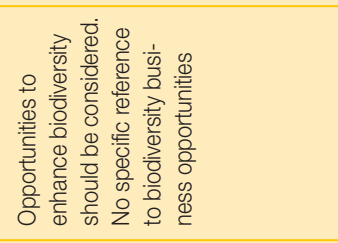 & 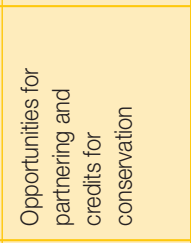 & 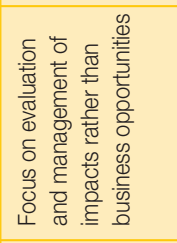 & 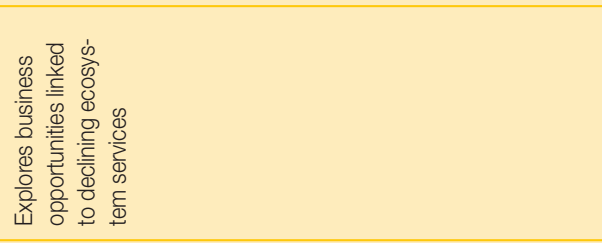 \\
\hline 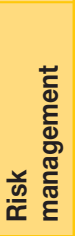 & 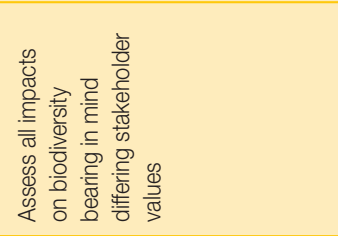 & 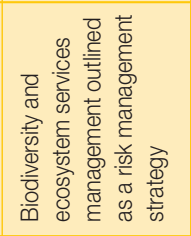 & 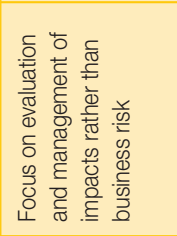 & 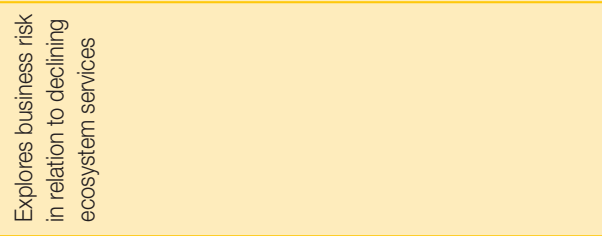 \\
\hline : & 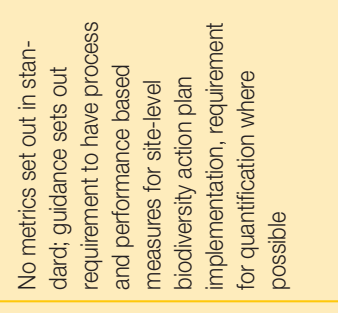 & 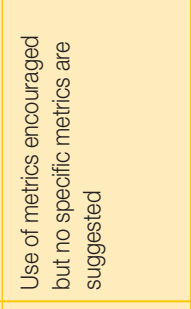 & 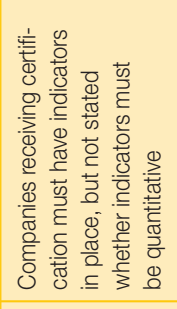 & 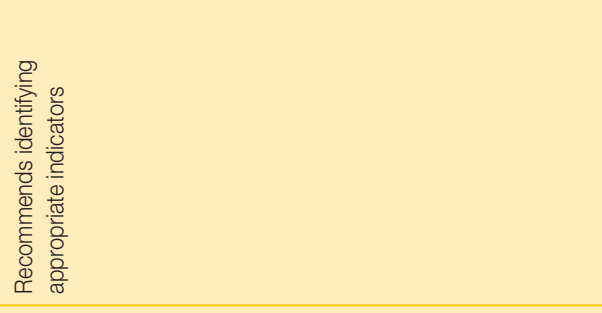 \\
\hline 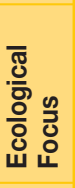 & 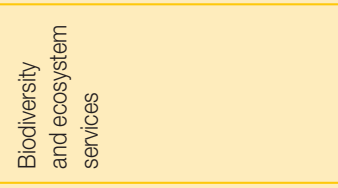 & 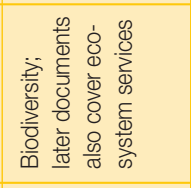 & 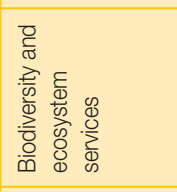 & 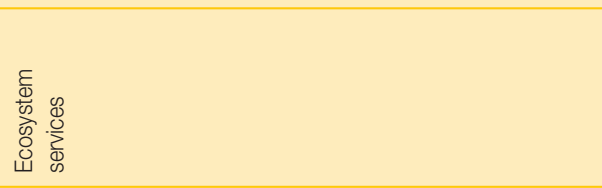 \\
\hline 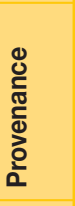 & 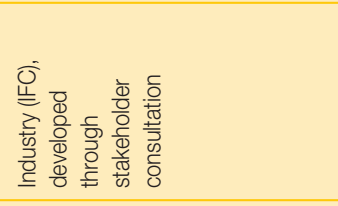 & 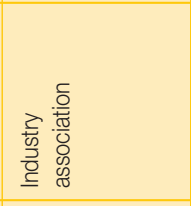 & 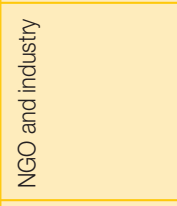 & 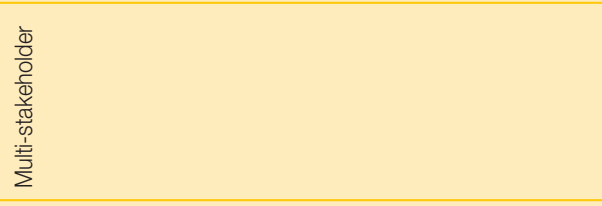 \\
\hline 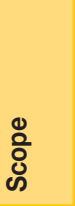 & 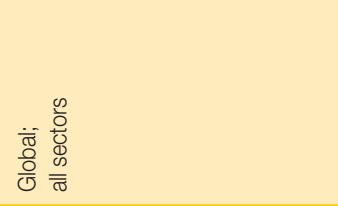 & 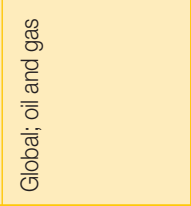 & 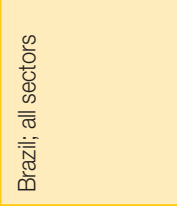 & $\begin{array}{l}\frac{\infty}{0} \\
\frac{0}{0} \\
\frac{\infty}{\pi} \\
\frac{\pi}{\pi} \\
\frac{\bar{\pi}}{\pi} \\
\frac{0}{0}\end{array}$ \\
\hline 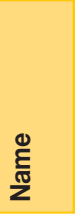 & 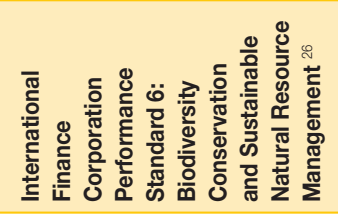 & 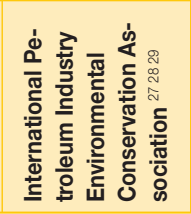 & 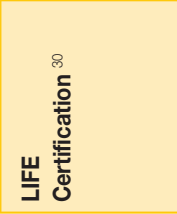 & 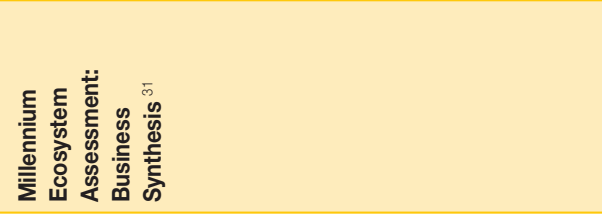 \\
\hline
\end{tabular}




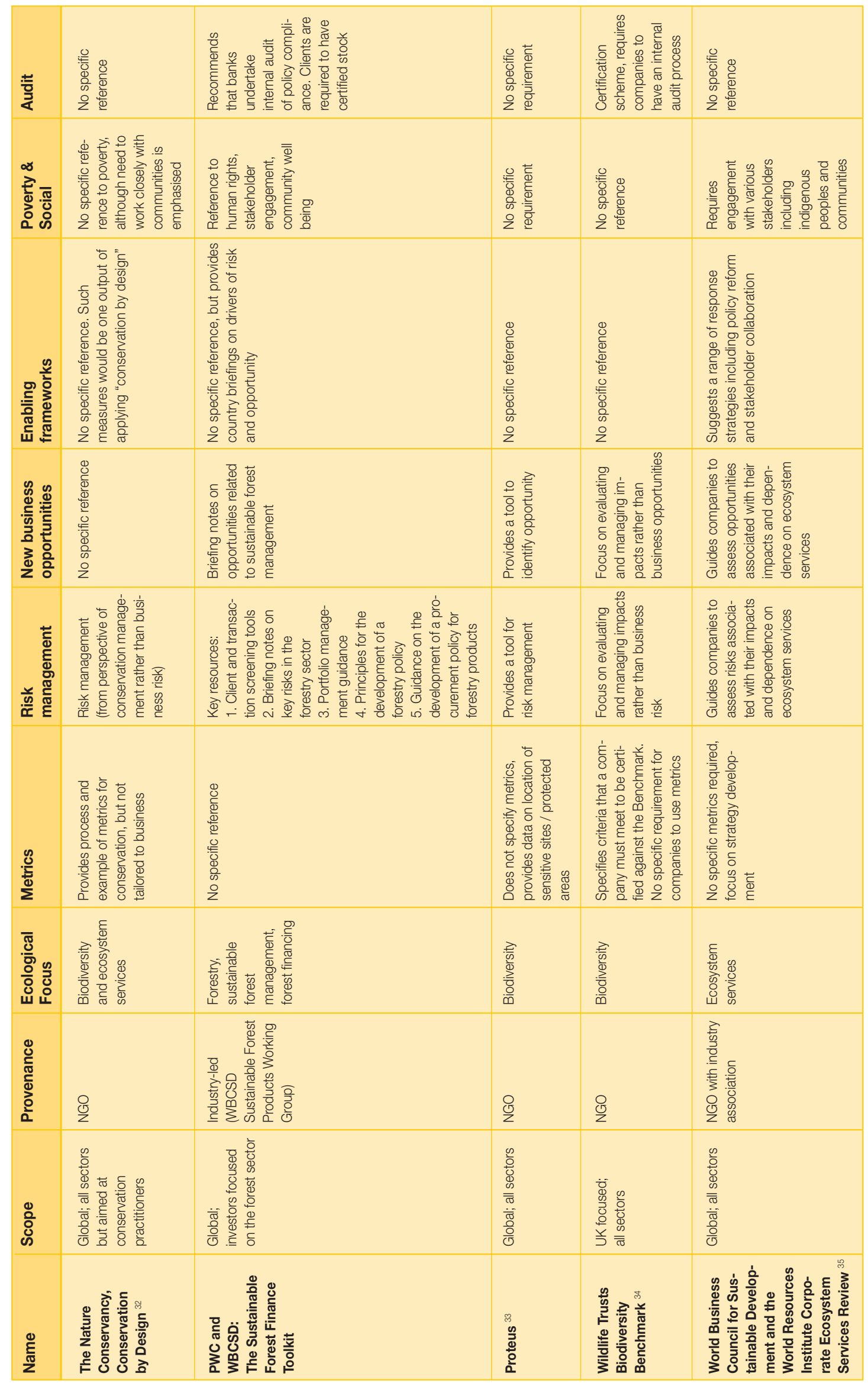




\begin{tabular}{|c|c|c|c|}
\hline 蒙 & 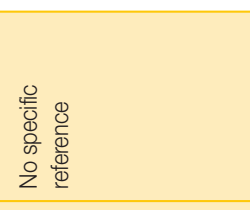 & 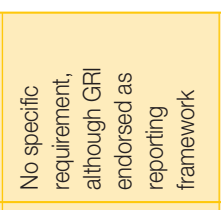 & 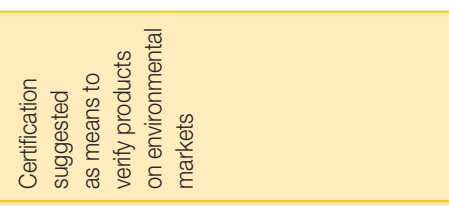 \\
\hline 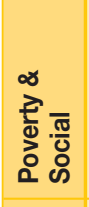 & 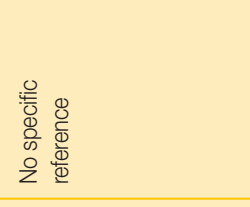 & 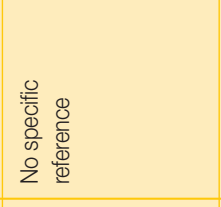 & 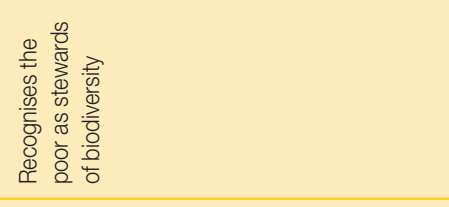 \\
\hline 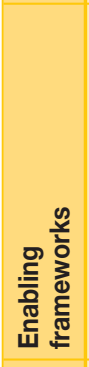 & 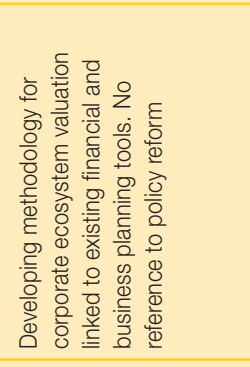 & 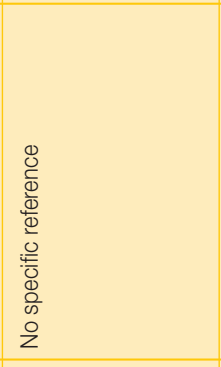 & 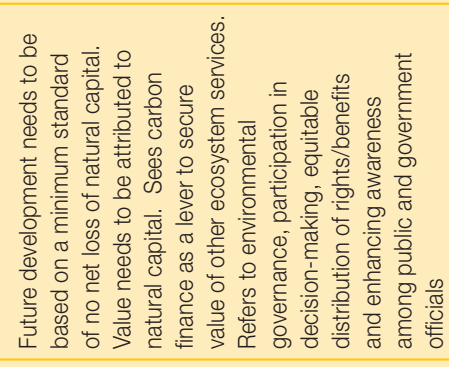 \\
\hline 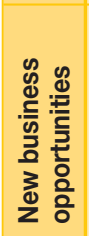 & 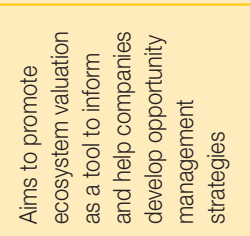 & 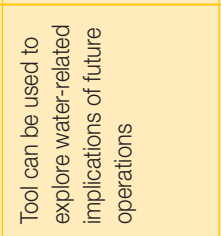 & 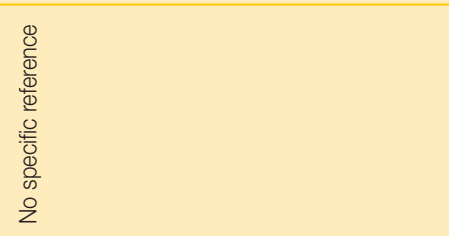 \\
\hline 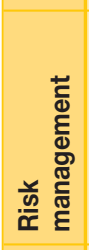 & 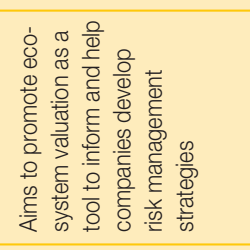 & 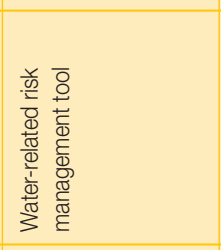 & 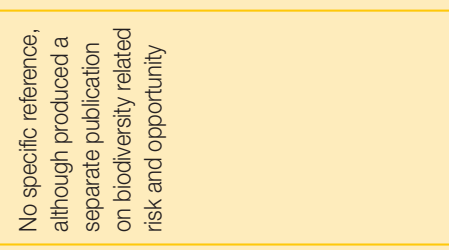 \\
\hline 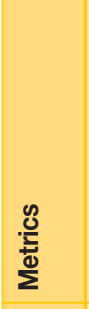 & 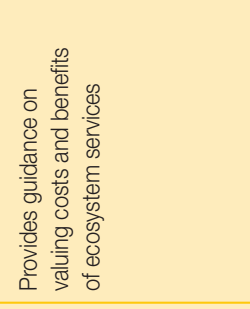 & 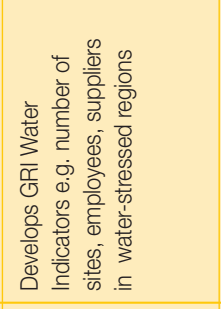 & 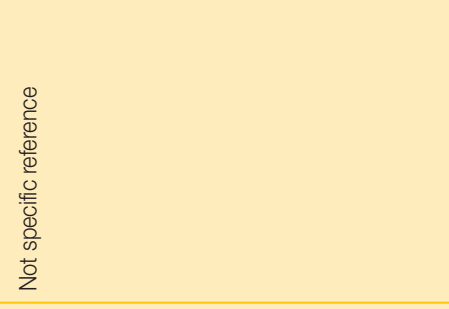 \\
\hline 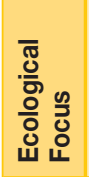 & 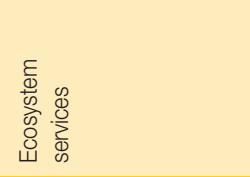 & 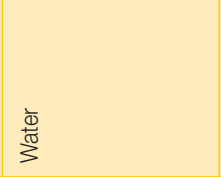 & 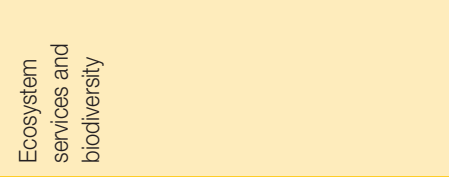 \\
\hline 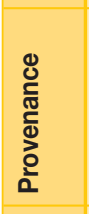 & 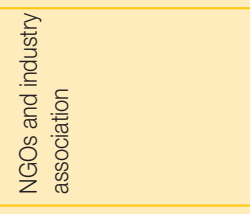 & 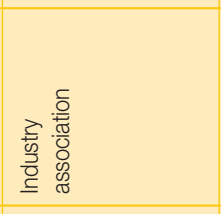 & $\frac{0}{2}$ \\
\hline $\begin{array}{l}\text { ¿ू } \\
\text { ¿ू }\end{array}$ & 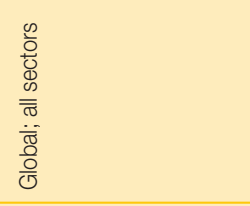 & 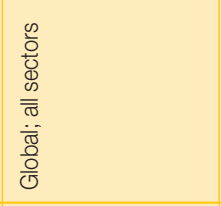 & 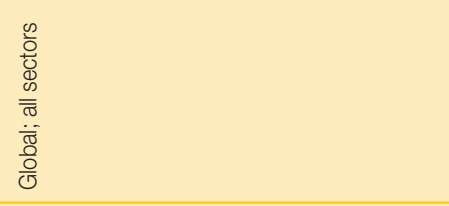 \\
\hline 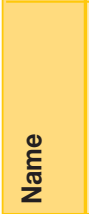 & 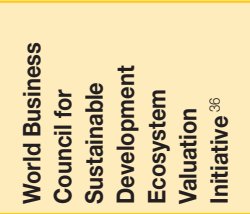 & 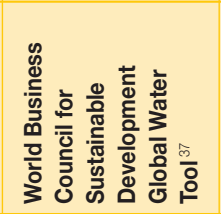 & 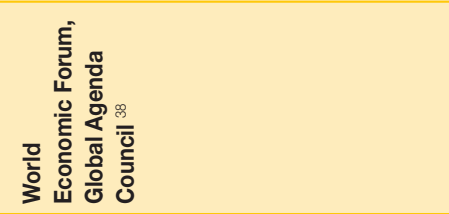 \\
\hline
\end{tabular}




\section{Endnotes}

1 The table is not exhaustive; a more comprehensive list of relevant initiatives is given in UNEP (2010) Are you a green leader?

2 Assessment and Research Infrastructure for Ecosystem Services (ARIES) Project (ecoinformatics.uvm.edu/aries)

3 BMU and GTZ (2008) Leadership Declaration for the Implementation of the UN Convention on Biological Diversity, An Initiative of the Federal Ministry for Environment, Nature Conservation and Nuclear Safety and Leading Companies (www.business-andbiodiversity.de/en/homepage.html)

4 Business and Biodiversity Offsets Programme (2009) Business, Biodiversity Offsets and BBOP: An Overview. BBOP, Washington, D.C.

5 Business and Biodiversity Offsets Programme (2009) Biodiversity Offset Implementation Handbook. BBOP, Washington, D.C.

6 Business and Biodiversity Offsets Programme (2009) Biodiversity Offset Design Handbook. BBOP, Washington, D.C.

7 Canadian Business and Biodiversity Program (www.businessbiodiversity.ca/index.cfm)

8 CBD (2009) The Jakarta Charter on Business and Biodiversity (www.cbd.int/doc/business/jakarta-charter-busissness-en.pdf)

9 Prof. Dr. Stefan Schaltegger (Leuphana University Lüneburg) and Uwe Beständig (Leuphana University Lüneburg) (2010) Corporate Biodiversity Management Handbook. A guide for practical implementation.

10 Nippon Keidanren (Japan Business Federation) (2009) Declaration of Biodiversity by Nippon Keidanren (www.keidanren.or.jp/ english/policy/2009/026.html)

${ }^{11}$ Earthwatch, IUCN and WBCSD (2002) Business and Biodiversity: Handbook for Corporate Action

12 Grigg, A., Cullen, Z., Foxall, J., Crosbie, L., Jamison, L., and Brito, R. (2009) The Ecosystem Services Benchmark. Fauna \& Flora International, United Nations Environment Programme Finance Initiative and Fundação Getulio Vargas - FGV (http://www.naturalvalueinitiative.org)

13 The Equator Principles (http://www.equator-principles.com/)

${ }^{14}$ European Business and Biodiversity Campaign (www.globalnature.org/30707/campaigns/eu-business-biodiversitycampaign/02_vorlage.asp)

${ }^{15}$ European Business and Biodiversity Initiative (ec.europa.eu/ environment/biodiversity/business/index_en.html)

${ }^{16}$ Forest Footprint Disclosure Project (2009) Forest Footprint Disclosure Request (www.forestdisclosure.com)
17 Houdet, J. (Ed.), 2008 (re-edition 2010) Integrating biodiversity into business strategies. The Biodiversity Accountability Framework.

${ }^{18}$ GRI (2006) G3 Guidelines

19 Integrated Biodiversity Assessment Tool (mww.ibatforbusiness.org)

20 Integrated Valuation of Ecosystem Services and Tradeoffs (InVEST) (www.naturalcapitalproject.org/InVEST.html)

${ }^{21}$ ICMM (2006) Good Practice Guidance for Mining and Biodiversity

22 International Council of Mining and Metals (2008) Sustainable Development Framework (www.icmm.com/our-work/sustainabledevelopment-framework)

${ }^{23}$ Global Reporting Initiative (2000-2010) Sustainability Reporting Guidelines; Mining and Metals Sector Supplement

${ }^{24}$ ICMM (2003) Position Paper: Mining and Protected Areas

25 ICMM (2008) Sustainable Development Framework: Assurance Procedure

${ }^{26}$ International Finance Corporation (2006) Performance standard 6: Biodiversity conservation and sustainable natural resource management (www.ifc.org/ifcext/sustainability.nsf/AttachmentsByTitle/pol_PerformanceStandards2006_PS6/\$FILE/PS_6_BiodivCo nservation.pdf)

27 IPIECA (2007) An Ecosystem Approach to Oil and Gas Industry Biodiversity Conservation

${ }^{28}$ IPIECA (2006) Key Biodiversity Questions in the Oil and Gas Lifecycle

29 IPIECA (2005) A Guide to Developing Biodiversity Action Plans for the Oil and Gas Sector

${ }^{30}$ LIFE Certification (2009) Regulations for LIFE Certification: Preliminary Version.

${ }^{31}$ Millennium Ecosystem Assessment (2005) Ecosystems and Human Well-being: Opportunities and Challenges for Business and Industry. World Resources Institute, Washington, DC

32 http://www.nature.org/aboutus/howwework/cbd/

${ }^{33}$ Proteus (proteus.unep-wcmc.org)

34 The Wildlife Trusts (2006) The Wildlife Trusts Biodiversity Benchmark (www.wildlifetrusts.org)

${ }^{35}$ Hanson, C, Finisdore, J, Ranganthan, J and Iceland, C (2008) The Corporate Ecosystem Services Review (pdf.wri.org/corporate_ecosystem_services_review.pdf) 
${ }^{36}$ WBCSD (2009) Business and Ecosystems. Issues Brief 1: Corporate Ecosystem Valuation

37 WBCSD Global Water Tool (www.wbcsd.org/web/ watertool.htm)

38 World Economic Forum, Global Agenda Council (www. weforum.org/pdf/GAC09/council/ecosystems_biodiversity/ proposal.htm) 


\section{Annex 2.1: Case studies - cotton and the Aral Sea and timber in China}

Contributors: Mark Trevitt (Trucost plc), Alistair McVittie (Scottish Agricultural College), Luke Brander (Institute for Environmental Studies), Joshua Bishop (IUCN)

\section{Objectives and methodology}

This annex examines in more detail the economic impacts and dependence of business on ecosystems and biodiversity, through case studies of the agriculture and textile industry in Central Asia and the construction and materials sector in China. The case studies show how unsustainable use of ecosystem services and failure to account for the non-market values of ecosystems can lead to environmental crises, with profound economic consequences and impacts on the business bottom line.

Both case studies examine the costs resulting from ecosystem degradation that may be embedded in a company's supply chain, due to the impact and dependence of the raw materials they use on particular ecosystem services. In both instances, the economic consequences resulting from ecosystem degradation are highlighted alongside the value of the ecosystems services lost as a result of failing to use natural resources sustainably. Due to the lack of primary data, benefits transfer techniques are employed to assess the value of ecosystem services lost, and to illustrate how economic valuation of the benefits provided by ecosystems can help safeguard important business values for the future.

\section{Case Study 1: Cotton production and the destruction of the Aral Sea}

A striking example of how the unsustainable use of scarce water resources can destroy an entire ecosystem is provided by the desiccation of the Aral Sea. Situated between the nations of Kazakhstan and Uzbekistan in Central Asia (formerly part of the Soviet Union), the Aral Sea was the world's fourth largest inland sea in 1960, providing a wealth of ecosystem services to surrounding communities. By 2007, the Aral Sea had shrunk to 10 percent of its original size, mainly due to water abstraction from its two major tributaries, the Amu Darya River and the Syr Darya River. The diversion of water from these rivers was in turn a direct result of the development of irrigated cotton production in the surrounding region ${ }^{1}$.

The crisis had its roots in the early decades of the twentieth century, when the government of the Soviet Union initiated a plan to expand irrigation in the region, to cultivate cotton for export, and thereby to increase the standard of living of the region's growing population². The government recognized that the expansion of irrigation for the cultivation of cotton would reduce water inflow to the Aral Sea but the trade-off was considered worthwhile, as it was believed that "a cubic meter of river water used for irrigation would be more economically beneficial than the same volume delivered to the Aral Sea"3.

In 1956, the Kara Kum Canal was opened, resulting in the diversion of large amounts of water from the Amu Darya River. The subsequent reduction in river water volume ultimately resulted in the separation of the Aral Sea into two water bodies in 1987, a small Aral Sea in the North and a large Aral Sea in the South, as well as significant increases in salinity.

The expansion of irrigated area and consumption of water resources was driven largely by growth in cotton production. The greatest consumer of fresh water in the Aral Sea basin is Uzbekistan, which on average uses about $54 \%$ of the region's total water resources ${ }^{4}$. By 1991, cotton accounted for over $65 \%$ of Uzbekistan's gross domestic output, consumed $60 \%$ of its resources, and employed $40 \%$ of the country's labour force, while more than $70 \%$ of the total arable land in the Republic was devoted to cotton production ${ }^{6}$. 
Over the period 1960-90, the development of irrigation around the Aral Sea increased from approximately 4.5 million hectares (ha) to just over 7 million ha, while the surface area of the Aral Sea declined from almost 70 square kilometers (km2) to under $40 \mathrm{~km} 2$ (see Figure 1). While some economic progress was achieved in the short run, it was realized

at the expense of the environment and the long-term economic sustainability of the region.

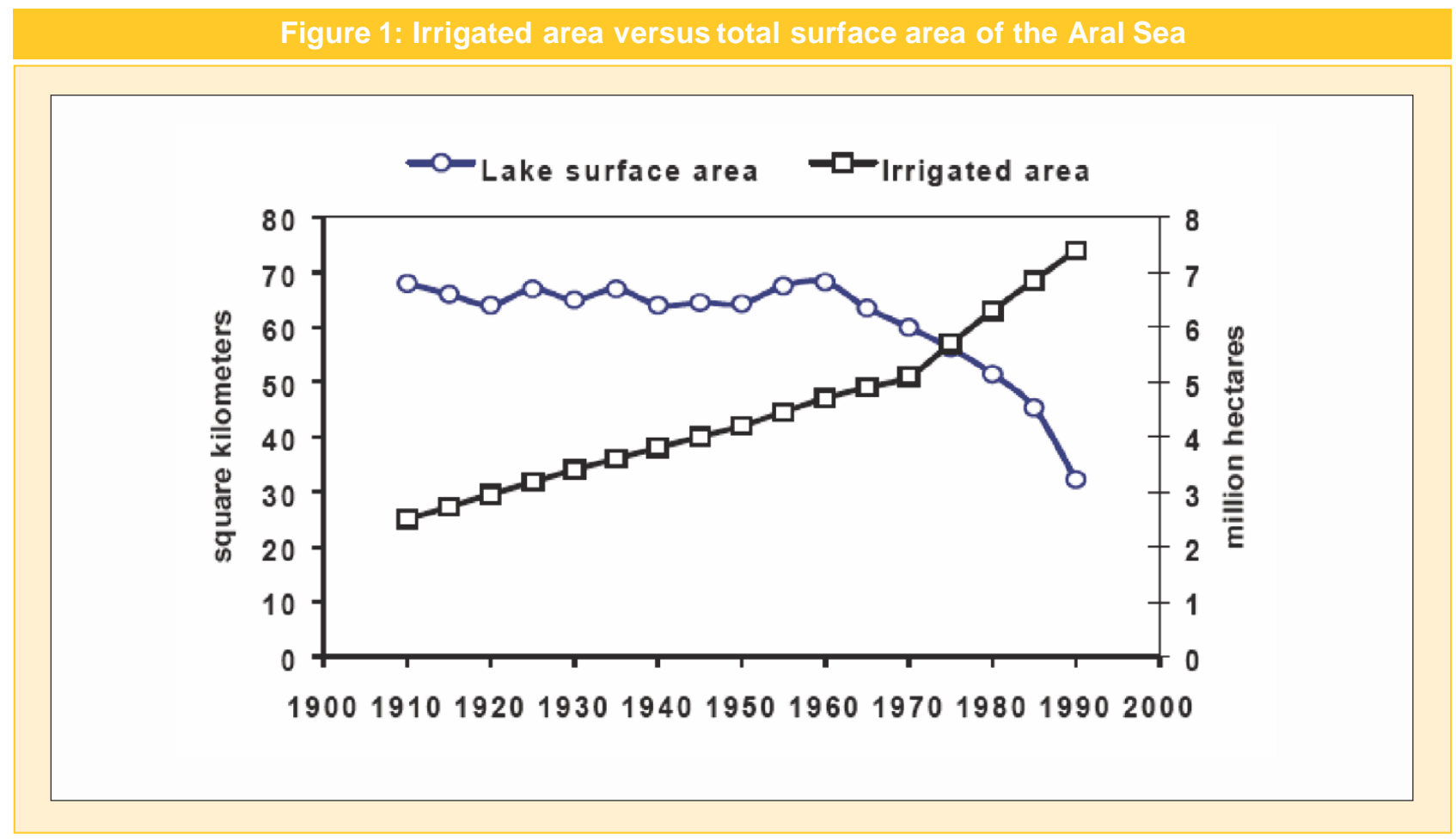

Source: Micklin (1993)

\section{Impacts on ecosystems and people}

Increased use and runoff of pesticides and fertilizer resulted in the pollution of surface and groundwater, while declining downstream water availability and increased salinity deprived the regions' lakes and wetlands of their life source. As a result, the ecosystems of the Amu Darya delta in Uzbekistan and the Syr Darya delta in Kazakhstan have suffered substantial damages. In the Amu Darya delta, wetlands that had covered some

550,000 ha in 1960 were reduced by $95 \%$ or to about 27,500 ha in 1990 , replaced by sandy deserts, while more than 50 delta lakes, covering some 60,000 ha, simply dried up ${ }^{5}$. Similarly, the lakes of the Syr Darya delta shrank from about $500 \mathrm{~km} 2$ in 1960 to $40 \mathrm{~km}^{2}$ in $1980^{6}$. So-called Tugai forests, which covered about 100,000 hectares in the Amu Darya delta in 1950, were reduced to just $20-30,000$ hectares by $1999^{7}$. Other impacts resulting from water diversion and pollution are summarized below:

- Prior to 1960 , over 70 species of mammals and 319 species of birds lived in the river delta, while by 2007 only 32 species of the former and 160 of the latter remained ${ }^{7}$.

- The number of fish species occurring in the lakes dropped from 32 to 6 due to increased salinity and loss of spawning and feeding grounds ${ }^{8}$.

- Commercial fisheries that produced some 40,000 metric tons of fish in 1960 were wiped out by the mid-1980s, with the loss of over 60,000 jobs $^{1,2}$.

- Poor water management and derelict infrastructure have led to declining soil fertility, including soil erosion, which threatens $19 \%$ of irrigated land ${ }^{9}$. 
ANNEX 2.1: CASE STUDIES - PAGE 
- With the shrinking of the Aral Sea, the climate of the surrounding region has become more continental, with shorter, hotter, drier summers and longer, colder, snowless winters. The growing season has been reduced to an average of 170 days per year, while dust storms occur on average on more than 90 days per year 9 .

- In the last 15 years there has been a 3,000\% increase in reported chronic bronchitis and in kidney and liver diseases, including cancer, while arthritic diseases have increased by $6,000 \%$. The infant mortality rate is among the world's highest ${ }^{9}$.

- Average life expectancy has decreased from 65 to 61 years ${ }^{1,2}$.

\section{Focus on the agriculture and textile industry}

The case of the Aral Sea can be understood as a creeping environmental problem, where changes accumulate over time, degradation is generally imperceptible and the full scale of the impact is not recognized until a crisis occurs. One early indicator of environmental deterioration in the basin was the decline in cotton yields, due to water quality and soil problems linked to irrigation (see Figure 2).

\section{Figure 2: Cotton yield trend in three Central Asian countries near the Aral Sea}

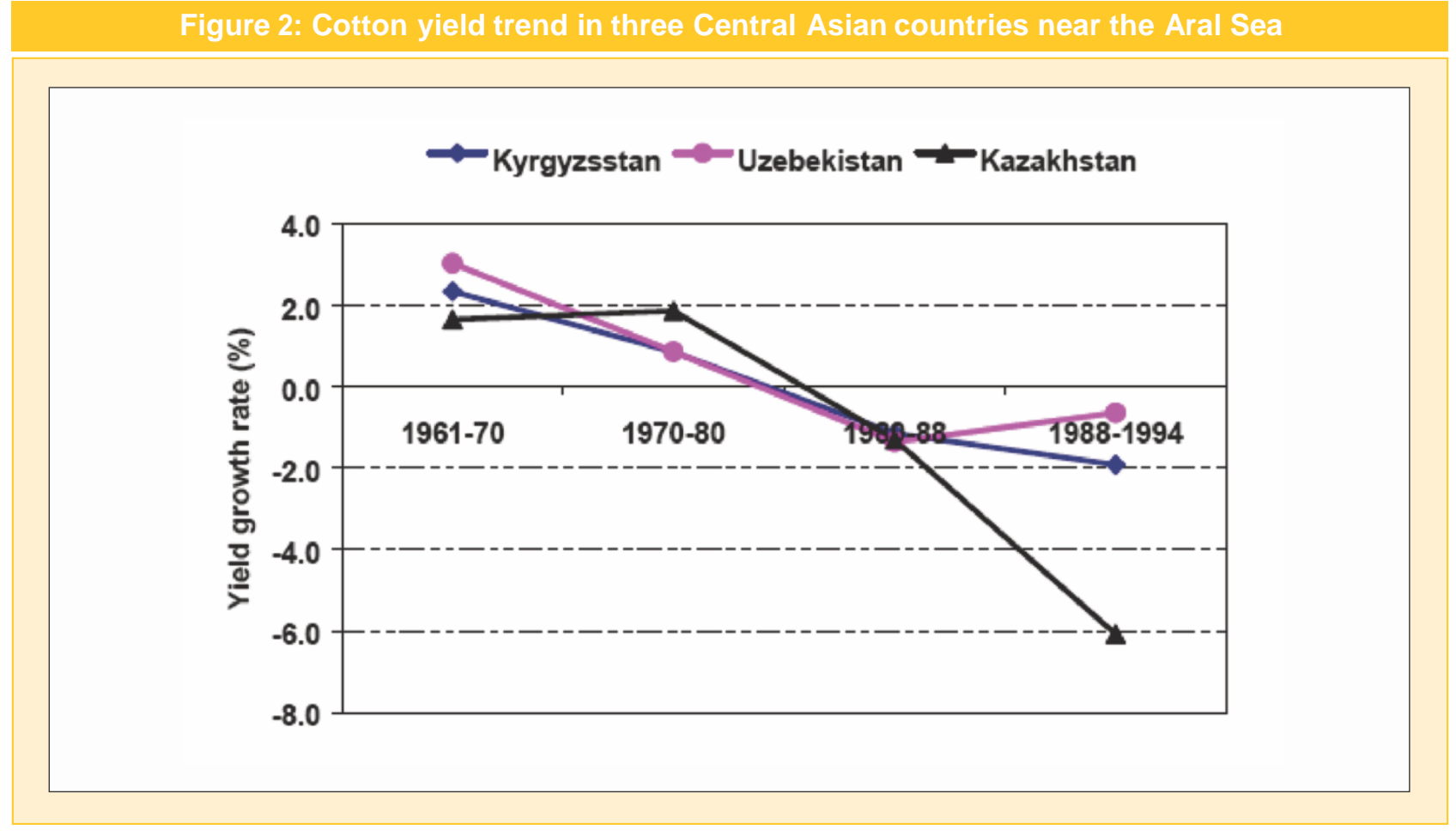

Sources: Cai, McKinney \& Rosegrant (2001), FAOSTAT

In response to soil degradation, Uzbek farmers actually increased the volumes of water they consumed, by 'flushing' their fields with irrigation water in order to wash away excess salt. This practice now threatens the very survival of Uzbek agricultural production, especially cotton, as rising salt levels kill or retard the growth of natural vegetation and crops $^{10}$.

No comprehensive estimates were found of the economic damages resulting from the desiccation of the Aral Sea. One study, published in 1990, examined the cost of measures to redress some negative environmental consequences, suggesting that the minimum damage to the environment as result of unsustainable agricultural and irrigation practices in the Aral Sea was at least US\$1.4 billion, taking into account measures to prevent polluted drainage water from entering rivers, reconstruction of the irrigation system, introduction of new plants and irrigation techniques, and stabilization of the sea floor ${ }^{11}$. In addition, the cost to improve sanitary, hygienic and medical 
services, to create new jobs, and reform the economy was estimated at over US $\$ 3.49$ billion $^{12}$. Other estimates examine the cost of constructing two canals to redirect water from the Volga, Ob and Irtysh rivers in order to restore the Aral Sea to its former size over a 20-30 year period, estimated at over US $\$ 30$ billion ${ }^{13}$.

None of the studies cited above explicitly considers the loss of ecosystem services within the Aral Sea basin. For this case study, a meta-analytic value function for wetlands was applied, based on previously estimated parameters for spatial variables, size, type, abundance, GDP per capita, and population density ${ }^{14}$. This function was used to value the loss of ecosystem services resulting from the disappearance of 522,500 ha of wetlands over the period 1960-1990, suggesting annual economic losses of around US $\$ 100$ million $^{15}$. A summary of the estimation procedure and results are provided in Table 1.

Note that this analysis covers only a portion of the overall ecosystem service losses, and may under-estimate the true scale of losses, given that the transfer of monetary values from other wetland ecosystems may not reflect the specific conditions of the Aral Sea basin. Nevertheless, from this analysis it appears that the externalities associated with increased cotton production in the Aral Sea basin are significant. While the agricultural industry has not borne all of these costs, it has been severely affected. Unsustainable irrigation practices, resulting in water-logging, increased soil salinity and lower yields, have reduced the value of crop production by about US $\$ 1.4$ billion per year or approximately one-third of the value of potential output ${ }^{16}$.

\section{Implications for business}

The manufacture of cotton garments by the retail clothing industry is connected to a chain of environmental dependence and impacts on water resources in the countries where cotton is grown and processed - mainly involving water abstraction and pollution during cultivation and processing. Almost two thirds of all cotton produced worldwide is used by the textiles industry for clothing manufacture ${ }^{17}$. Global demand for cotton has increased steadily, and in 2008 annual world cotton production reached over 26 million tonnes ${ }^{18}$.

Cotton accounts for about $2.6 \%$ of global fresh water consumption, or over 250 billion cubic meters $(\mathrm{m} 3)$ of water per year ${ }^{18}$. Cotton is a water-intensive crop, requiring about 11,000 litres of water per kilogramme of final cotton textile, on average, worldwide ${ }^{18}$. In Uzbekistan, cotton production is generally even more water-intensive, with almost 20,000 litres of water used for every kilogramme of cotton harvested, due to inefficient irrigation practices, implying total consumption for cotton production at over 8.5 billion cubic metres of water per year ${ }^{18,20}$.

Due to limited domestic capacity for textile production in Uzbekistan, over 70\% of Uzbek cotton - around 800,000 tonnes - is sold on the world market every year, making it the world's second largest exporter ${ }^{19}$. According to the UN, the single largest consumer of Uzbek cotton is the European Union, which absorbs $29 \%$ of Uzbek cotton exports, valued at around US\$350 million per year ${ }^{20}$. 


\section{TABLE 1. ESTIMATION OF ARAL SEA WETLAND VALUES}

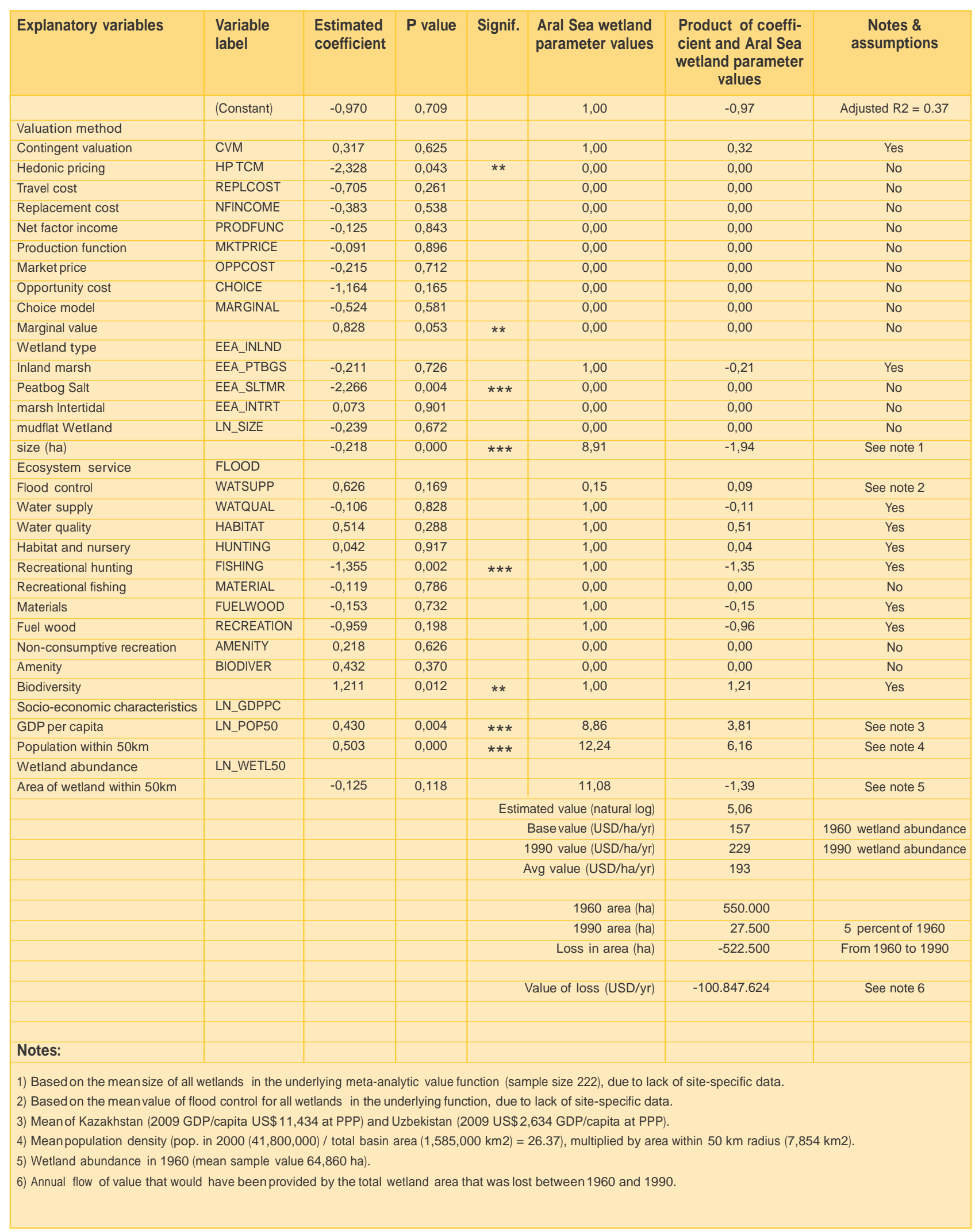




\section{Case Study 2: Deforestation and the construction industry in China}

Forests provide a range of goods and services on which human societies and businesses depend ${ }^{20}$. As the largest country by population and third-largest country by area, China's use of forest ecosystems not only affects the country itself but the global environment as well. When the People's Republic of China was founded in 1949, the country was very poor, damaged by years of warfare, and in need of major economic reconstruction. Demand for timber for construction and other uses was and remains high.

At mid-century, China still had large tracts of natural forests in the Northeast (including Heilongjiang, Jilin and eastern Inner Mongolia), the Southwest (covering Yunnan, western Sichuan, and eastern Tibet) and parts of Xinjiang in the Northwest and Hainan in the South ${ }^{21}$. During the 1950s and 1960s, however, nearly 1 million workers moved into forested areas to produce timber to meet the growing demand for construction materials ${ }^{22}$. From the $1950 \mathrm{~s}$, timber harvests in China increased from about 20 million cubic meters $\left(\mathrm{m}^{3}\right)$ per year to some $67.7 \mathrm{~m}^{3}$ by $1995{ }^{23,24}$. Demand for timber was largely driven by the construction boom; average wood consumption between 1983 and 1997 was broken down as follows: construction (64 percent), furniture (13\%), fuel (8\%), pulp (7\%) and other uses $(8 \%)^{25}$.

\section{Impacts on forest ecosystems}

Over the period 1949 to 1981 , China's use of forest resources almost completely depleted its natural forest stocks. The cumulative area harvested was 75 million hectares (ha), of which $92 \%$ were natural forests ${ }^{26}$. Rapid deforestation led to adverse structural changes, such as: (1) reduced stocking volume $\left(\mathrm{m}^{3} / \mathrm{ha}\right)$, (2) timber age structure tilted towards younger stands, (3) changes in species composition, (4) reduced natural regeneration, and (5) low growth and yields of forest plantations ${ }^{27}$. The ecological functions of forest ecosystems, particularly watershed protection and soil conservation, were also comprised. The decline of forest area likewise contributed to biodiversity loss, due to the disturbance, conversion and fragmentation of habitats ${ }^{28}$.

The prolonged deforestation and degradation of natural forest ecosystems in China reached a tipping point in the late 1990s, leading to a series of ecological disasters. In 1997, severe droughts caused the lower reaches of the Yellow River to dry up for 267 days, putting industrial, agricultural, and residential water uses throughout the northern plains in jeopardy ${ }^{29}$. The next year, in 1998, major flash flooding occurred in China in almost all major river basins, devastating large areas and resulting in the loss of 4,150 lives, displacement of millions of people, and significant damages to property and infrastructure, estimated at about 248 billion Yuan (approximately

$\$ 30$ billion USD in 1998)30. Total precipitation in the Yangtze River basin in 1998 was lower and lasted longer, compared to flooding that occurred in 1954, and yet the Yangtze River experienced record flooding, with 8 peaks over a period of two months, indicating a severe reduction in water holding capacity within the basin ${ }^{23}$.

\section{Impacts and dependence of the construction and materials sector on forests}

Following these ecological disasters, it became apparent to both central and regional government bodies that ecological conditions in the upper reaches of the Yangtze and Yellow River basins were affecting the economic welfare and ecological security of millions of people living in the middle and lower reaches of these basins ${ }^{23}$. At the time, the Chinese government determined that the removal of $85 \%$ of the upper river basin's original tree cover and farming on steep slopes were the primary causes of the drought that affected the Yellow River in 1997, as well as the widespread flooding in the Yangtze River Basin in $1998^{23,31}$. Intensive logging in areas around the major river systems had led to increased runoff of soil into the rivers, raised river levels as silt was deposited downstream, and thus increased the severity of flooding ${ }^{32}$. In response, in 1998, the Chinese government banned logging in 17 provinces as part of a new Natural Forest Conservation Program (NFCP), intended to run from 1998 to 2010 . The main aims of the NFCP were to ${ }^{24}$ : 


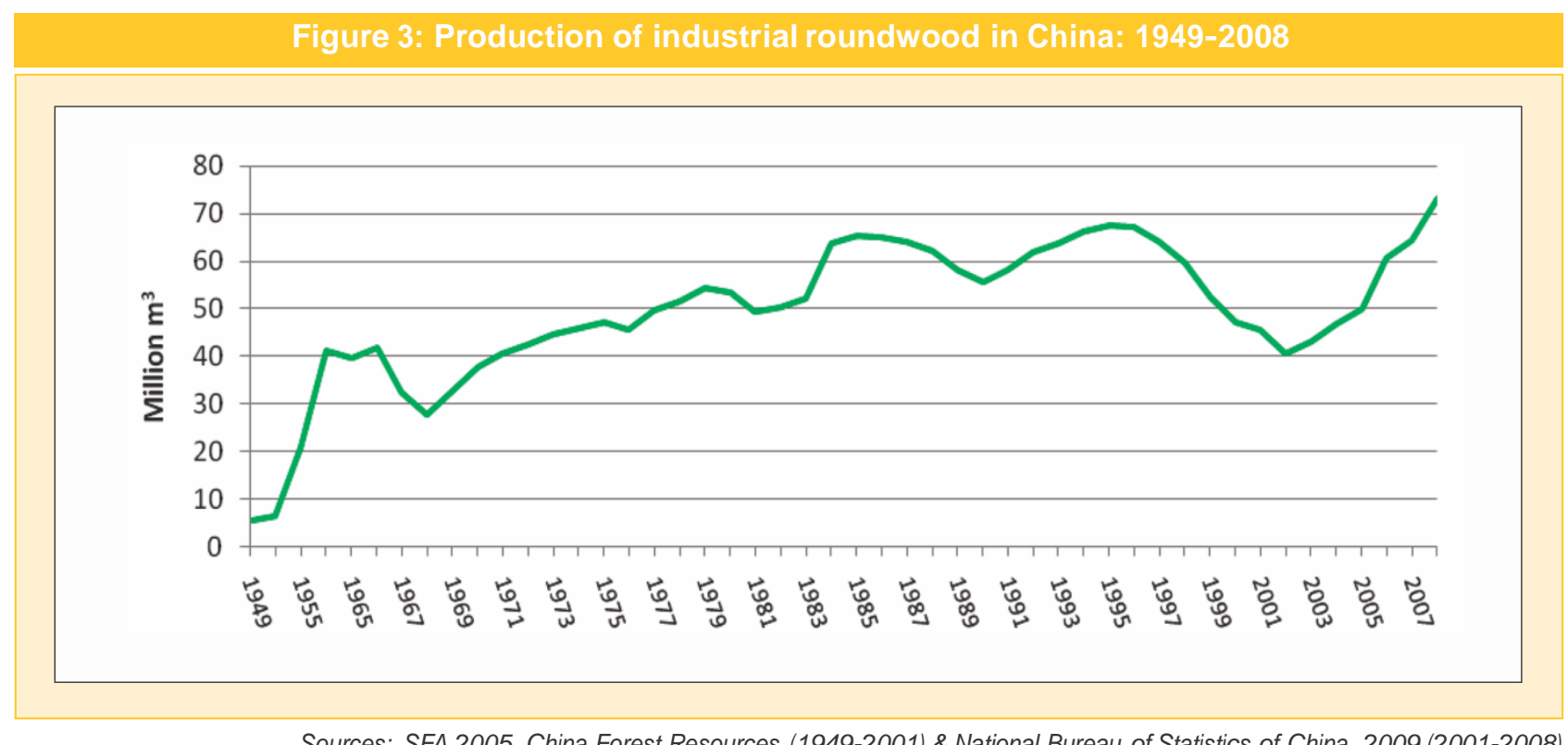

Sources: SFA 2005, China Forest Resources (1949-2001) \& National Bureau of Statistics of China, 2009 (2001-2008)

- restore natural forests in ecologically sensitive areas,

- plant forests for soil and water protection,

- increase timber production in forest plantations,

- protect existing natural forests from excessive cutting, and

- maintain multiple-use management of forests.

The initial investment by the central government in the NFCP from 1998 to 2000 totaled 22.26 billion Yuan (\$2.69 billion) ${ }^{36}$. From $2000-2010$, the State Council allocated a further 96.2 billion Yuan ( $\$ 11.63$ billion) for forest protection, regeneration, management and relocation of forest workers, and related activities ${ }^{36}$. Under the NFCP, timber harvests from natural forests in China were reduced from 32 million $\mathrm{m}^{3}$ in 1997 to 12 million $^{3}$ by $2003^{33}$. The logging restrictions imposed under the NFCP resulted in a significant decline in roundwood production between 1998 and 2003, as illustrated in Figure 3.

The logging bans and harvest reductions also displaced a large number of loggers and other forest sector employees, and led state-owned forest enterprises to abandon about a half of their logging, hauling, and processing assets (worth an estimated 30 billion Yuan) ${ }^{34,35}$. Moreover, interest payments on loans to these forest enterprises had to be written off by the government, at a further cost of one billion Yuan annually ${ }^{35}$. Restrictions on lumber supply also caused timber prices to increase by 20-30 percent at the Beijing wood market in $1998^{29}$.

\section{Valuing ecosystem losses in timber markets}

Over the period 1950-1998, many ecosystem values were not adequately taken into account in decisions regarding the use China's forest resources, resulting in excessive deforestation and the loss of ecosystem services. In a study by Wang Hongchang (1997), the impact of deforestation in China since pre-historical times was estimated by separately examining the various ecosystems services affected, such as climate regulation, provision of timber, food supply, regulation of water resources, erosion and flood prevention, and nutrient cycling ${ }^{36}$. Based on this study, we can estimate the value of forest ecosystem services lost due to timber production over the period 19501998 (assuming a linear relationship in value). The study by Wang Hongchang was used here for two reasons: first, because it is focused on China and second, because the estimated value of lost ecosystem services is specifically related to deforestation. A summary of the data used and our analysis is provided in Table 2 . 


\section{TABLE 2. ESTIMATION OF FOREST ECOSYSTEM SERVICE VALUES IN CHINA}

\begin{tabular}{|c|c|c|c|c|c|c|}
\hline $\begin{array}{l}\text { Ecosystem } \\
\text { service (ES) } \\
\text { losses due to } \\
\text { deforestation }\end{array}$ & $\begin{array}{l}\text { Valuation method and } \\
\text { assumptions }\end{array}$ & $\begin{array}{l}\text { Value of ES lost due } \\
\text { to total deforestation } \\
\text { from pre-history } \\
\text { to } 1988: 289.33 \text { Mha } \\
\text { (in } 1992 \text { billion yuan) }\end{array}$ & $\begin{array}{l}\text { Value per } \\
\text { hectare } \\
\text { (yuan/ha) }\end{array}$ & $\begin{array}{l}\text { Value of ES } \\
\text { lost due to } \\
\text { deforestation } \\
\text { from } 1950-98 \text { : } \\
83.04 \text { Mha } \\
\text { (1992 billion } \\
\text { yuan) }\end{array}$ & $\begin{array}{c}\text { Value of ES lost } \\
\text { due to logging: } \\
59.5 \% \text { of } \\
\text { deforestation } \\
\text { (1992 billion yuan) }\end{array}$ & $\begin{array}{l}\text { Value of ES lost due } \\
\text { to use of timber in } \\
\text { construction \& } \\
\text { materials: } 64 \% \text { of } \\
\text { lumber output (1998 } \\
\text { US\$/m } 3 \text { ) }\end{array}$ \\
\hline $\begin{array}{l}\text { Reduced } \\
\text { precipitation }\end{array}$ & $\begin{array}{l}\text { Replacement cost: } \\
\text { Estimated cost } \\
\text { of water diversion project } \\
\text { (from South to North) }\end{array}$ & 81,00 & 279,96 & 23,25 & 13,83 & 29,88 \\
\hline $\begin{array}{l}\text { Reduced lumber } \\
\text { output }\end{array}$ & $\begin{array}{l}\text { Market price: Average } \\
\text { timber price increase due } \\
\text { to scarcity (Fujian) and } \\
\text { fuelwood tax (Guizhou) }\end{array}$ & 19,40 & 67,05 & 5,57 & 3,31 & 7,16 \\
\hline Desertification & $\begin{array}{l}\text { Value of production: } \\
50 \% \text { of crop losses due } \\
\text { to desertification are } \\
\text { attributed to deforestation }\end{array}$ & 18,80 & 64,98 & 5,40 & 3,21 & 6,94 \\
\hline Lost water runoff & $\begin{array}{l}\text { Replacement cost: } \\
\text { Additional water 'lost' } \\
\text { as runoff due to defore- } \\
\text { station valued as per } \\
\text { water diversion project }\end{array}$ & 66,70 & 230,53 & 19,14 & 11,39 & 24,61 \\
\hline $\begin{array}{l}\text { Loss of plant } \\
\text { nutrients }\end{array}$ & $\begin{array}{l}\text { Replacement cost: } \\
\text { Value of lost nutrients d } \\
\text { ue to erosion based on } \\
\text { the retail price of chemical } \\
\text { fertilisers }\end{array}$ & 41,00 & 141,71 & 11,77 & 7,00 & 15,13 \\
\hline $\begin{array}{l}\text { Reservoir and } \\
\text { lake } \\
\text { sedimentation }\end{array}$ & $\begin{array}{l}\text { Replacement cost: } \\
\text { Cost of constructing } \\
\text { new reservoir capacity } \\
\text { to replace sedimentation } \\
\text { losses }\end{array}$ & 0,80 & 2,77 & 0,23 & 0,14 & 0,30 \\
\hline $\begin{array}{l}\text { Loss of river } \\
\text { transport } \\
\text { capacity }\end{array}$ & $\begin{array}{l}\text { Wages: Lost income of } \\
1.1 \text { million workers due to } \\
50 \% \text { reduction in the } \\
\text { length of navigable rivers }\end{array}$ & 4,10 & 14,17 & 1,18 & 0,70 & 1,51 \\
\hline $\begin{array}{l}\text { Property } \\
\text { loss from } \\
\text { flooding }\end{array}$ & $\begin{array}{l}\text { Damage cost: } 50 \% \text { of an- } \\
\text { nual flooding losses are } \\
\text { attributed to deforestation }\end{array}$ & 13,40 & 46,31 & 3,85 & 2,29 & 4,94 \\
\hline $\begin{array}{l}\text { One-off } \\
\text { flooding } \\
\text { damages } \\
(1998)\end{array}$ & $\begin{array}{l}\text { US } \$ 30 \text { billion (Yin, 1998) } \\
\text { divided by cumulative } \\
\text { roundwood production } \\
\text { over 1950-1998 (SFA } \\
2005 \text { ) }\end{array}$ & NA & NA & NA & NA & 10,37 \\
\hline Total & & 245,20 & 847,48 & 70,37 & 41,87 & 100,82 \\
\hline
\end{tabular}

Using data from Wang Hongchang and other sources, the value of forest ecosystem services lost is estimated at US $\$ 12.2$ billion annually. This estimate is then linked to the production of roundwood over the period 19501998 , in order to compare the costs of ecosystem service losses to the market price of timber ${ }^{37}$. Specifically, the external costs of deforestation are apportioned according to the share of timber production in the overall use of forest 


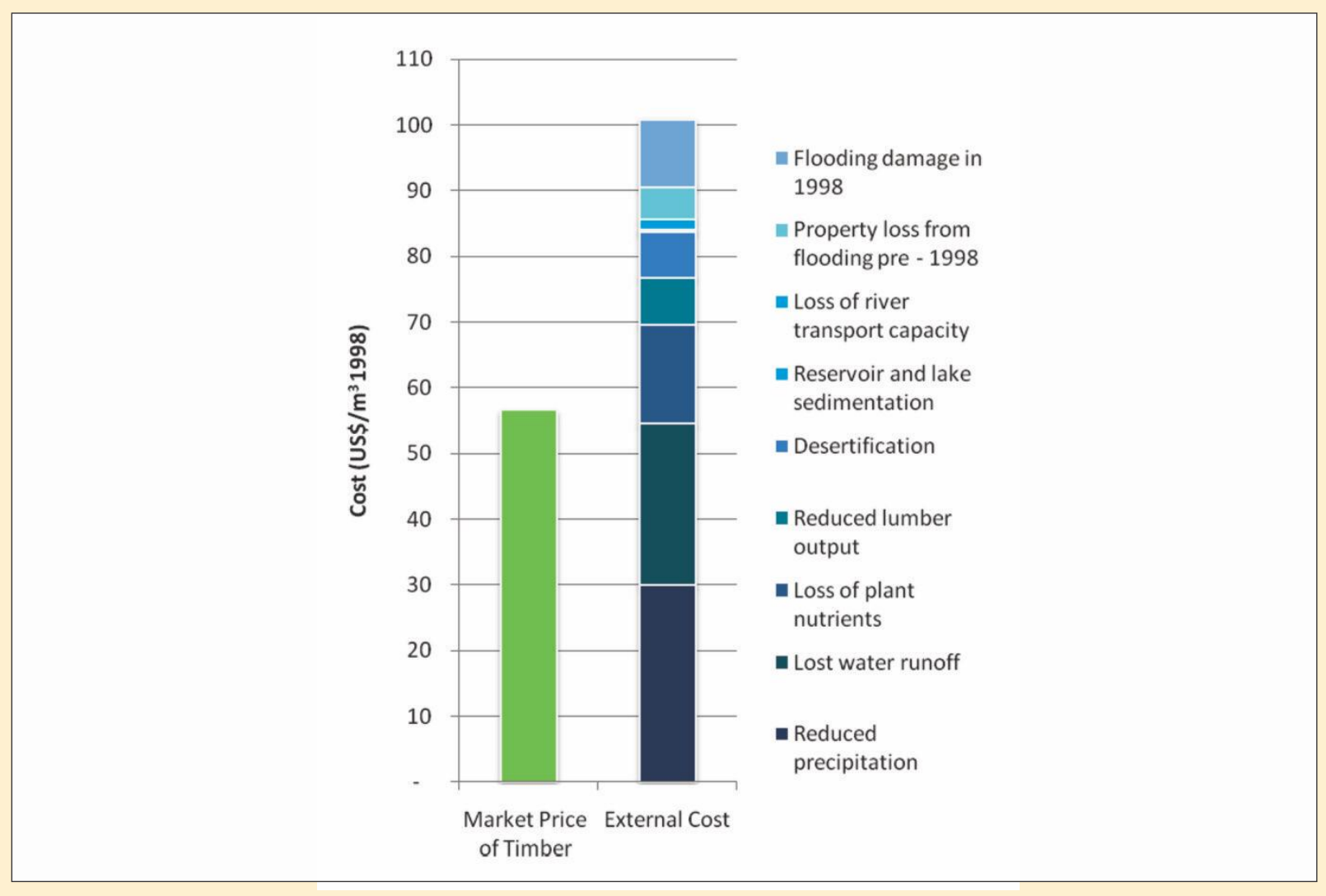

resources $(59.5 \%)^{33}$ and the share of the construction sector in total consumption of timber $(64 \%)^{23}$. Figure 4 shows the results, including the value of ecosystem services lost due to deforestation over the period 1950-1998, as well as flooding damages due to reduced watershed protection and soil conservation services.

Conventional financial analysis would consider only those products and services that have a market price, and thus exclude many forest ecosystems services because they are generally not priced. The observed 20-30 percent increase in lumber prices, following the imposition of a logging ban in 1998, reflects a small part of the true cost of timber consumption in China. According to full cost recovery principles, if the full external cost of ecosystem degradation resulting from the use of timber by the construction and materials sectors were reflected in market prices, the cost of this important economic input would increase by up to $178 \%$.

\section{China's impact on the global environment}

China and the rest of the world are closely connected through trade and investment, hence changes in forest policy and forest use in China can have significant impacts elsewhere. As a result of the decline in domestic forest resources and the 1998 logging ban, China's own production has not been able to keep pace with demand for timber. Imports have made up the difference, putting increased pressure on forests in other countries.

In effect, the external costs of deforestation have been shifted abroad, leading to growing concerns about deforestation in timber-exporting countries, such as Burma, Indonesia and Russia. Over the past 10 years, unprecedented economic growth, coupled with a shortage of domestic forest resources as a result of deforestation and the resulting logging ban, has led China to become the world's largest importer of unprocessed logs and 
tropical timber and the world's second largest importer of wood products. Since 1995, China's imports of wood products have increased by 450 percent ${ }^{38}$. Of every ten tropical trees traded in the world in 2004, five were destined for China ${ }^{38}$.

\section{Overall conclusion}

The two case studies presented above illustrate the importance for businesses to assess the impacts and dependencies of their products and services on ecosystems and biodiversity, throughout their value chains.

In the case of the Aral Sea, the diversion of water to support cotton production and exports pushed the region's hydrologic system beyond the point of sustainability. The agriculture industry effectively reduced its costs by ignoring (externalising) the value of environmental damage. If these externalities were included in the costs of cotton production, both overall output and the scale of irrigation would probably have been much lower ${ }^{6}$. The lesson to be learned from the destruction of the Aral Sea is that water resources can and do disappear when used unsustainably, and that changes in ecosystems can have far-reaching impacts on those that depend on the services they provide. The loss of ecosystem services and the costs of protecting and rehabilitating ecosystems need to be valued and considered explicitly in decisions on how to use water resources more efficiently ${ }^{39}$.

In the case of China, unsustainable harvesting of timber led to increased scarcity of raw materials, as well as the loss of valuable forest ecosystems services. Ultimately, the logging industry lost its license to operate in many forest areas, when the Chinese government imposed a logging ban in 1998. The resulting shortage of timber supplies led to an increase in the cost of timber to the construction sector, which would have had knock-on effects throughout the supply chain, narrowing operating margins, disrupting production and increasing market volatility. More importantly, it is evident that the deforestation which occurred in China over many decades undermined many important ecosystems services, contributing to ecological disasters with significant human and economic consequences.

Each case serves as cautionary tale of how the under-valuation of ecosystem services leads to ecosystem degradation and economic consequence for society and businesses that are often only recognized after the fact. 


\section{Endnotes}

${ }^{1}$ URL: http://www.scientificamerican.com/article.cfm?id= reclaiming-the-aral-sea (last access 1 April 2010).

2 Nalwalk, Krilsin (2000) The Aral Sea Crisis: The Intersection of Economic Loss and Environmental Degradation, University of Pittsburgh, Graduate School of Public and International Affairs (April 25).

3 Micklin, Philip (1988) "Desiccation of the Aral Sea: A Water

Management Disaster in the Soviet Union" Science, Vol.

241:1170-1175 (2 September).

$4 \quad$ UNEP (2006) Challenges to International Waters, Global Inter- national Water Assessment, Regional Assessment 24 Aral Sea (February).

5 FAO (1998) Time to save the Aral Sea? Agriculture and Consumer Protection Department. UN Food and Agriculture Organization: Rome.

$6 \quad$ Micklin, P.P. (1992) "The Aral crisis: Introduction to the Special

Issue" Post-Sov. Geogr. Vol. 33(5):269-83.

7 Severskiy, I., Chervanyov, I., Ponamorenko, Y., Novikova, N.M., Miagkov, S.V., et al. (2005) Global International Waters Assess- ment (GIWA) 24, Aral Sea. University Kalmar, Sweden.

$8 \quad$ Micklin, Philip, and Aladin, Nikolay V. (2008) "Reclaiming the

Aral Sea" Scientific American, (April).

9 World Bank (2003) Irrigation in Central Asia: Social, Economic and Environmental Considerations. The World Bank: Washington, D.C.

10 Spoor, Max, and Krutov, Anatoly (2004) "The 'Power of Water' in a Divided Central Asia" in Mehdi parvizi Amineh \& Henk Houweling (eds.) Central Eurasia in Global Politics: Conflict, Security and Development Brill Academic Publishers: Leiden, Boston, 595.

11 Glazovskiy, N.F. (1991) "Ideas on an Escape from the 'Aral

Crsis"' Soviet Geography, Vol. 22, No. 2: 73-89 (February).

12 Glavosky, N.F. (1995) Regions at Risk: Comparison of Threa- tened Environments, The Aral Sea Basin, United Nations Univer- sity Press.

13 Temirov, Rustam (2003). "Lobbying Grows in Moscow for

Siberia-Uzbekistan Water Scheme" Eurasianet, (February 19).

14 See: Brander, Luke M., Florax, Raymond J. G. M., and Vermaat, Jan E. (2006) 'The Empirics of Wetland Valuation: A Comprehensive Summary and a Meta-Analysis of the Literature' Environmental \& Resource Economics (2006) 33: 223-250 (DOI

10.1007/s10640-005-3104-4); and: Ghermandi, Andrea, van den Bergh, Jeroen C.J.M., Brander, Luke M., de Groot, Henri L.F., and Nunes, Paulo A.L.D. (2009) The Values of Natural and Constructed Wetlands: A Meta-analysis, Tinbergen
Institute Discussion Paper TI 2009-080/3 (available at: http://ssrn.com/ abstract=1474751). 
15 Brander, Luke (2010) Personal Communication, Institute for Environmental Studies, VU University Amsterdam.

16 Kijne, J.W. (2005) Aral Sea Basin Initiative: Towards a strategy for sustainable irrigated agriculture with feasible investment in drainage. Synthesis report, FAO: Rome (June).

17 Chapagain, A.K., Hoekstra, A.Y., Savenije, H.H.G. and Gautam, R. (2006) "The water footprint of cotton consumption: An assessment of the impact of worldwide consumption of cotton products on the water resources in the cotton producing countries" Ecological Economics 60(1): 186203 (http://www waterfootprint.org/Reports/Chapagain_et_al_2006_cotton.pdf).

18 USDA (2008) Cotton: Production, Supply and Distribution, Foreign Agricultural Service, United States Department of Agriculture: Washington, D.C.

19 Environmental Justice Foundation (2005) White Gold: the true cost of cotton.

20 Salim, E., and Ullsten, O. (1999) Our Forests Our Future. Cambridge University Press, Cambridge, UK.

21 CNFCM 2000. Center for Natural Forest Conservation Management, Unpublished report to The World Bank.

22 Xhao, Guang and Shao, Guofan (2002) “Logging Restrictions in China: A Turning Point for Forest Sustainability" Journal of Forestry, (June).
23

21st Century" Science, 288(5474): 2135-2136.

24 Cohen, David H. and Vertinsky, Ilan (2002) China's Natural Forest Protection Program (NFPP): Impact on Trade Policies Regarding Wood. Prepared for CIDA with the Research Center for Ecological and Environmental Economics, Chinese Academy of Social Sciences, 63 pages.

\section{CNFCM (2000) op}

cit.

26 Song, Conghe and Zhang, Yuxing (2010) "Forest Cover in China from 1949 to 2006" Chapter 15 in H. Nagendra and J. Southworth (eds.), Reforesting Landscapes: Linking Pattern and Process, Landscape Series 10, Springer.

27 Yin, R.S. (1998) "Forestry and the environment in China: The current situation and strategic choice," World Development

26(12): 2153-2167.

28 Studley, J. (1999) "Forests and environmental degradation in

Southwest China," International Forestry Review 1(4):260-65.

29 Xu, J.T. and Cao Y.Y. (2002) "Converting steep cropland to forest and grassland: Efficiency and prospects of sustainability," International Economic Review (Chinese), no. 2, pp. 56-60. 
30 Sun, J., Zhao, C. and Wang, L. (2002) "The Long March of Green: The chronicle of returning agricultural land to forests in China," China Modern Economics Press, Beijing, P. R. China.

31 http://www.earth-policy.org/index.php?/plan_b_updates/ 2002/update11 (last access 5 February 2010).

32 Lang, Graeme (2002) "Deforestation, Floods, and State Reactions in China and Thailand," Working Paper Series, No. 21, City University of Hong Kong.

33 FAO (2001) Forests out of bounds: impacts and effectiveness of logging bans in natural forests in AsiaPacific, Asia-Pacific Forestry Commission.

$34 \mathrm{Li}$, Z. (2001) Conserving natural forests in China: Historical perspective and strategic measures, Chinese Academy of Social Sciences (working report).

35 Yin, Runsheng, Jintao Xu, Zhou Li, and Can Liu (2005) "China's Ecological Rehabilitation: Unprecedented Efforts, Dramatic Impacts, and Requisite Policies," China Environment Series 6:17-

32.

$36 \quad$ Wang Hongchang (1997) "Deforestation and Desiccation in China: A Preliminary Study," in Mao Yu-shi, Ning Datong, Xia Guang, Wang Hongchang, Vaclav Smil, An assessment of the Economic Losses Resulting from Various Forms of Environmental Degradation in China, Occasional Paper of the Project on Environmental Scarcities, State Capacity, and Civil Violence (Cambridge: American Academy of Arts and Sciences and the University of Toronto, 1997)

37 McVittie, Alistair (2010) Personal Communication, Land Economy \& Environment Research Group, Scottish Agricultural College.

38 Greenpeace (2006) Sharing the Blame: Global Consumption and China's Role in Ancient Forest Destruction.

39 Khristoforov, A.V. (2001) "Hydroecological security of the river basins. The methods of assessment and ways its availability," in Tuzova,T.V. (ed.) Water and Sustainable Development of Central Asia, published as part of the projects "Regional cooperation on the usage of water and power resources in Central Asia (1998)" and "Hydroecological problems and sustainable development of Central Asia". Bishkek, p 85-87 (in Russian). 
